\title{
Internal labor markets : theory and evidence at the firm level
}

Citation for published version (APA):

Dohmen, T. J. (2003). Internal labor markets : theory and evidence at the firm level. [Doctoral Thesis, Maastricht University]. Datawyse / Universitaire Pers Maastricht. https://doi.org/10.26481/dis.20030523td

Document status and date:

Published: 01/01/2003

DOI:

10.26481/dis.20030523td

Document Version:

Publisher's PDF, also known as Version of record

\section{Please check the document version of this publication:}

- A submitted manuscript is the version of the article upon submission and before peer-review. There can be important differences between the submitted version and the official published version of record.

People interested in the research are advised to contact the author for the final version of the publication, or visit the DOI to the publisher's website.

- The final author version and the galley proof are versions of the publication after peer review.

- The final published version features the final layout of the paper including the volume, issue and page numbers.

Link to publication

\footnotetext{
General rights rights.

- You may freely distribute the URL identifying the publication in the public portal. please follow below link for the End User Agreement:

www.umlib.nl/taverne-license

Take down policy

If you believe that this document breaches copyright please contact us at:

repository@maastrichtuniversity.nl

providing details and we will investigate your claim.
}

Copyright and moral rights for the publications made accessible in the public portal are retained by the authors and/or other copyright owners and it is a condition of accessing publications that users recognise and abide by the legal requirements associated with these

- Users may download and print one copy of any publication from the public portal for the purpose of private study or research.

- You may not further distribute the material or use it for any profit-making activity or commercial gain

If the publication is distributed under the terms of Article $25 \mathrm{fa}$ of the Dutch Copyright Act, indicated by the "Taverne" license above, 
INTERNAL LABOR MARKETS 
C2003 T.J. Dohmen, Maastricht

All rights reserved. No part of this publication may be reproduced, stored in a retrieval system, or transmitted, in any form, or by any means, electronic, mechanical, photocopying, recording or otherwise, without the prior permission in writing, from the author.

Published by Universitaire Pers Maastricht ISBN 9052783756

Printed in the Netherlands by Datawyse Maastricht 


\title{
INTERNAL LABOR MARKETS Theory And Evidence AT THE Firm Level
}

\author{
PROEFSCHRIFT
}

ter verkrijging van de graad van doctor aan

de Universiteit Maastricht,

op gezag van de Rector Magnificus,

Prof. dr. A.C. Nieuwenhuijzen Krusemann, volgens het besluit van het College van Decanen, in het openbaar te verdedigen op

vrijdag 23 mei 2003 om 14.00 uur

$$
\text { door }
$$

Thomas Johamnes Dohmen

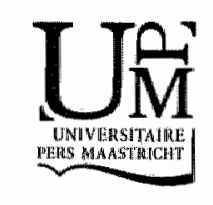




\section{Promotores:}

Prof. dr. Franz C. Palm

Prof. dr. Gerard A. Pfann

\section{Beoordelingscommissie:}

Prof. dr. Joan Muysken (voorzitter)

Dr. Sybrand Schim van der Loeff

Prof. dr. Coen N. Teulings (Erasmus Universiteit Rotterdam)

Dit onderzoek is gefinancierd door de Nederlandse Organisatie voor Wetenschappelijk Onderzoek (NWO), project 510-10-024-P.

This research has been financed by the Netherlands Organization for Scientific Research (NWO), grant 510-10-024-P. 


\section{Acknowledgments}

It is a good feeling to end an episode of life with something tangible in hands, especially because the invisibility of intellectual work creates, at times, dissatisfaction. Although this book captures only an excerpt of my effort throughout the past four years, it embodies a proper portrait of my academic work. It also reflects the support and contributions of many friends and colleagues without whom it would not have been possible to write this thesis.

I am grateful to my advisors Gerard Pfann and Franz Palm for offering me the possibility to conduct my research, for their advice and encouragement throughout, for their thorough reviews of all chapters, for their constructive comments and suggestions that improved my work, for things they made possible beyond all this, and for everything else that I learned from them about economics, academics, and life. Having had Franz Palm as an advisor has been a stroke of luck. For he has been very helpful and, most of all, always gave his prudent advice when I needed it. I should have consulted him more often to benefit even more from his profound knowledge and thoughtful comments. Fortunately, I soon will be able to do exactily that when Franz, Gerard and I will continue with a research project that grew out of one of the dissertation chapters.

Gerard has guided my first steps in this research, which has roots in my work as a student assistant at the Business Investment Research Center (BIRC), where I started to explore and prepare the data from the personnel files of Fokker, that he had obtained from the bankruptcy trustees. Fortunately, Gerard suggested to exploit these data further during my doctoral studies and encouraged me to prepare a first draft of a paper - based on some of my earlier work on the data - for a conference in Maastricht shortly after I had commenced my Ph.D. research. The results of our co-operation on this paper are manifest in chapter 4 . We have had long and stimulating discussions on many topics ever since. Although either one of us had been away from Maastricht for most of the last two years, he remained the valuable counsellor in the daily research routine. We debated and argued about economics exploiting diverse communication technologies, or we accommodated by meeting in various places around the globe (once we made arrangements to exchange ideas up in the sky above the Great Plains). Gerard also established a pleasant and very stimulating research environment at BIRC, from which I profited throughout.

The enjoyable atmosphere at BIRC was surely fostered by amiable people. I thank everybody who has at one time or the other been associated with BIRC and shared his thoughts during the short Monday morning briefings, which nicely launched the week ahead. The q-seminars on Wednesdays, 
where we discussed research in progress with o broader group of interested researchers, proved to be extremely inspiring. For their stimulating ideas and proposals, I am indebted to all participants, especially to Rene Belderbos, Boris Blumberg, Martin Caree, Wilko Letterie, and Ben Kriechel. Boris and Wilko have been very helpful in many other respects. I am also grateful to Ellen Nelissen and Ingrid Wesselingh for their excellent office support that facilitated my research a lot.

My very special thank goes to Ben, who has since long been a continual companion and true friend. That we became colleagues at BIRC did not happen by accident. Ben knew that I was longing for a challenging wellequipped research position just like the one he had accepted when I was still at Warwick. So he brought me into contact with Gerard and everything took its known course. Sharing an office for four years, Ben had to endure my temper and my quirks. Countless times, I interrupted his work by throwing another question at him. Thereby I learned a lot, especially about using computers and certain software packages efficiently. I remember being very happy when I could once tell him about a useful feature which I discovered by accident. We exchanged many ideas and discussed our work. Apart from this, we collaborated on the time consuming project of inferring Fokker's hierarchical job structure from individual job transitions, which inter alia resulted in the joint paper with Gerard that is included in chapter 5. Along the way we had some heated discussions, but we always maintained a most pleasing work atmosphere. We have had good times during joint visits of various workshops and conferences. But most of all, our friendship has grown outside the realm of academia.

I would also like to thank Fokker's bankruptcy trustees, especially $\mathrm{Mr}$. Ben Knüppe, for making the personnel data available, Jacob Haanstra and Peter Somers for sharing their profound knowledge and insights on personnel policies and providing additional information that was especially useful for the work in chapters 5 and 6.

Many of my thoughts expressed in this book have matured during my visit to the Economics Department at the University of Chicago. The invitation by Robert Lucas and Boyan Jovanovic and the hospitality of the University of Chicago are gratefully acknowledged. I was fascinated by the atmosphere in the department and have benefitted a lot from attending seminars and the classes by Gary Becker, James Heckman, Steve Levitt, Derek. Neal, and Susanne Schennach, and especially by interacting with the other Ph.D students.

My research has profitted from comments and suggestions on earlier drafts of different chapters by James Brown, Mike Gibbs, Joop Hartog, Guido Imbens, Boyan Jovanovic, Derek Neal, Niels Westergård-Nielsen, Gerard van 
den Berg, and Jan van Ours. Discussing some of my ideas with Joe Altonji, Gary Becker, Richard Blundell, James Heckman, Boyan Jovanovic, Edward Lazear, Robert Lucas, Dale Mortensen, Kevin M. Murphy, Canice Prendergast, Aloysius Siow, Lars Stole, and Robert Topel has been very inspiring. I am grateful to all of them.

Furthermore, I would like to thank participants at the following conferences and seminars for their contributions: the Meteor Conference 1999 at Maastricht University, two Meetings of BIRC's Scientific Council (in St. Gerlach and Chicago), the 3rd IZA European Summer School in Labor, the NAKE Research Day at the Dutch Central Bank in Amsterdam, the 6th Spring Meeting of Young Economists in Copenhagen, the Amual Meetings of the Society of Labor Economists in Austin, a departmental seminar at the University of Aarhus, the 2001 Annual Meeting of the European Economic Association in Lausanne, the 2002 CEPR conference "Incentives and Beyond" in Stockholm, and the European Winter Meetings of the Econometric Society in Budapest.

I would like to express my gratitude to Joan Muysken, Sybrand Schim van der Loeff and Coen Teulings for their effort as members of the assessment committee and their comments on the manuscript. I very much appreciate the help of Rianne Kriechel-Mans in preparing the summary in Dutch. My thanks also go to Andie and Jonathan Tatkon-Coker for polishing up the English of the first two chapters, and especially to Lukas Roegler for proof reading the entire manuscript. Financial support from NWO is gratefully acknowledged.

Mein größter Dank gilt aber meinen Eltern und Verena, ohne deren Unterstützung und Geduld so vieles nicht möglich gewesen wäre. 



\section{Contents}

List of Tables

List of Figures vii

Preface viii

1 Introduction $\quad 1$

1.1 Introduction . . . . . . . . . . . . . . 2

1.2 Contributions and Relevance of this Study . . . . . . . . 3

1.3 Research Questions .................... 4

1.4 Outline of the Study .................. 5

2 Literature Review 9

2.1 Introduction . . . . . . . . . . . . 10

2.2 The Organization of Specialized Labor . . . . . . . . . . 12

2.3 The Employment Relationship . . . . . . . . . . . . . . . 14

2.3.1 Human Capital and Specific Investments . . . . . . 15

2.3 .2 Separations .................. 18

2.3.3 Motivation Mechanisms and Incentives . . . . . . . . 19

2.4 Internal Organization . . . . . . . . . . . . 25

2.4.1 Hierarchies and Firm Size . . . . . . . . . . 25

2.4.2 Knowledge, Information, and Coordination . . . . . . 26

2.5 The Firm as an Institutional Labor Market . . . . . . . . . . . 27

2.6 Job Ladders and Assignment . . . . . . . . . . . . . . . . 29

2.7 Compensation and the Employment Relationship . . . . . . 32

2.8 Empirical Studies of Internal Labor Markets . . . . . . . . . 38

2.9 Careers in Internal Labor Markets . . . . . . . . . . . . . . . . 42

2.10 Conclusion . . . . . . . . . . . . . . . . 45

3 The Firm and Its Personnel Data 47

3.1 Introduction . . . . . . . . . . . . . 48 
3.2 History of the Firm . . . . . . . . . . . . . . 48

3.3 Economic Conditions from 1987 until $1996 \ldots . . . .550$

3.4 The Development of the Workforce . . . . . . . . . . . 55

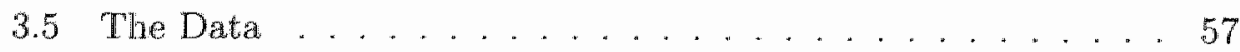

4 Worker Separations $\quad 59$

4.1 Introduction . . . . . . . . . . . . . . . 60

4.2 The Data . . . . . . . . . . . . . . . . . . . . . 61

4.3 Testable Implications from Turnover Models . . . . . . . . . 63

4.4 The Econometric Model . . . . . . . . . . . . . . . . 66

4.5 Worker Characteristics . . . . . . . . . . . . . . 68

4.6 Estimation Results . . . . . . . . . . . . . . . . . . 74

4.7 Conclusion . . . . . . . . . . . . . . . . . . . . 93

5 The Internal Workings of a Firm 95

5.1 Introduction . . . . . . . . . . . . . . . . 96

5.2 The Firm and its Personnel Data ... . . . . . . . . . . . . 98

5.2 .1 The Firm . . . . . . . . . . . . . . . . . . . . . . . . . . . . . . . . .

5.2 .2 The Data . . . . . . . . . . . . . . . . . . . . . . . . 989

5.2 .3 Development of the Workforce . . . . . . . . . . . . . 999

5.3 The Corporate Hierarchy . . . . . . . . . . . . . . . . . 100

5.3 .1 Identification of Levels . . . . . . . . . . . . . . . 100

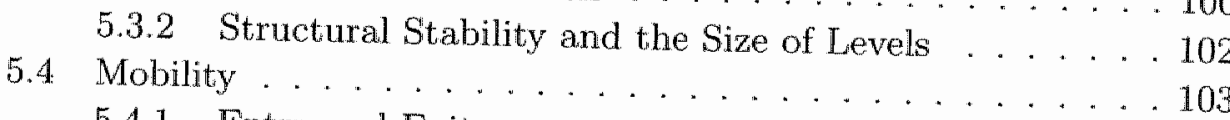

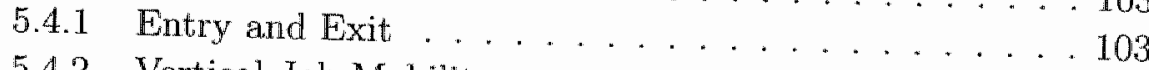

5.4 .2 Vertical Job Mobility . . . . . . . . . . . . . . . . . . . . 105

5.4 .3 Lateral Job Mobility . . . . . . . . . . . . . . . . . . . . . . . . . . . . . . . . . . . . . 111

5.5 Wages and the Hierarchy . . . . . . . . . . . . . . . . . . . 112

5.5.1 Administrative Rules in Wage Setting. . . . . . . . . 113

5.5 .2 Job Levels and Wages . . . . . . . . . . . . . . . . . 114

5.6 Wage Growth and Job Transitions . . . . . . . . . . . . . . . . . 120

5.6.1 How are Promotions and Demotions Defined? . . . . . 120

5.6 .2 Wages and Promotions . . . . . . . . . . . . . . . 120

5.7 Careers . . . . . . . . . . . . 125

5.7 .1 New Hires versus Ineumbents . . . . . . . . . . 126

5.7 .2 Job Ladders Across Hierarchical . . . . . . . . . . 126

5.7.3 Monkey Bars Within Hierarchical Levels . . . . . . . 129

5.8 Conclusion . . . . . . 131 
6 Wage Policy and Earnings Profiles 133

6.1 Introduction . . . . . . . . . . . . . 134

6.2 The Data . . . . . . . . . . . . . . . . . . . 135

6.3 The Wage Policy of the Firm . . . . . . . . . 137

6.3.1 The Salary System for Blue-Collar Workers . . . . . 138

6.3.2 The Salary System for Juvenile Blue-Collar Workers . . 140

6.3.3 The Salary System for White-Collar Workers . . . . . 142

6.3.4 The Stability of the Salary System and Nominal Wage Rigidity . . . . . . . . . . . . . . . 144

6.4 Institutional Arrangements and Wage Profiles . . . . . . 147

6.4.1 Serial Correlation in Wage Growth and Green Card Effects . . . . . . . . . . . . . . . 147

6.4 .2 Cohort Effects . . . . . . . . . . . . . 148

6.5 Wage Mobility . . . . . . . . . . . . . . . . . 150

6.5.1 Wage Mobility in Good and Bad Times . . . . . . . 150

6.5.2 Wage Mobility and Performance ... . . . . . . 151

6.5.3 Wage Growth and Promotion to Higher Job Levels . . 154

6.5.4 Downward Wage Mobility . . . . . . . . . . 155

6.6 Nominal Rigidity and Motivation . . . . . . . . . 156

6.7 Performance and Earnings Profiles _. . . . . . . . . 158

6.8 Conclusion . . . . . . . . . . . . . . . . 163

7 Careers in Internal Labor Markets 165

7.1 Introduction . . . . . . . . . . . . 166

7.2 Stylized Facts . . . . . . . . . . . . . . . . . . . 169

7.3 The Internal Organization of Workers . . . . . . . . . 172

7.4 A Model without Human Capital Accumulation . . . . . . . 181

7.4.1 Corporate Expansion and Career Dynamics ... . . 184

7.4 .2 Contraction . . . . . . . . . . . . . . 185

7.5 On-the-Job Firm-Specific Capital Accumulation . . . . . . 186

7.6 Firm-Specific Training . . . . . . . . . . . . . . . . 192

7.6.1 Training in the First Period . . . . . . . . . . . 192

7.6 .2 The Timing of Training . . . . . . . . . . 193

7.7 Extensions of the Model . . . . . . . . . . . . . 195

7.8 Conclusion . . . . . . . . . . . . . . . . 197

8 Conclusion 199

A Definition of Variables 209

A.1 Plant Locations . . . . . . . . . . . . . . . . . 210

A.2 Schooling Degrees . . . . . . . . . . . . . . . 211 
A.3 Performance Evaluations . . . . . . . . . . . . . . . 212

$\begin{array}{ll}\text { Bibliography } & 213\end{array}$

$\begin{array}{ll}\text { Summary in Dutch } & 228\end{array}$

$\begin{array}{ll}\text { Curriculum Vitae } & 237\end{array}$ 


\section{List of Tables}

4.1 Distribution of the Highest Completed Schooling Degree . . . 71

4.2 Training Courses . . . . . . . . . . . . . . . 72

4.3 Distribution of Performance Evaluation Scores . . . . . . . . 74

4.4 Firm-Specific Tenure . . . . . . . . . . . . . . 78

4.5 Parameter Estimates for Age . . . . . . . . . . . . . . 85

4.6 Education and Training ... . . . . . . . . . . . . 89

4.7 Wage Grades and Career Effects . . . . . . . . . . . . . . 91

4.8 Performance Evaluation and Other Variables . . . . . . . . 92

5.1 Hierarchical Composition, 1987-1996 . . . . . . . . . . . 102

5.2 Entry into Hierarchical Levels, 1987-1996 . . . . . . . . . . . . 103

5.3 Exit from Hierarchical Levels, 1987-1996 . . . . . . . . . . 105

5.4 Transition Matrix $1987-1991 \ldots \ldots$. . . . . . . . . 107

5.5 Transition Matrix $1991-1996 \ldots . . \ldots 108$

5.6 Lateral Job Transitions to a Different Field of Activity . . . 111

5.7 Distribution of Pay for New Hires in Wage Deciles . . . . . . 116

5.8 Distribution of Pay for Separating Workers in Wage Deciles . . 117

5.9 Salary Premium of Promotion . . . . . . . . . . . . . 121

5.10 Distribution of Pay for Promotees in Salary Deciles Before and

After Promotions . . . . . . . . . . . . . . 122

5.11 Serial Correlation in Wage Growth . . . . . . . . . . . . 124

5.12 Promotion and Wage Growth . . . . . . . . . . . . 125

5.13 Age and Tenure: New Hires versus Promoted Incumbents . . . 127

5.14 Education Level: New Hires versus Promoted Incumbents . . . 128

6.1 Contractual Wages in a Wage Scale for Blue-Collar Workers . 139

6.2 Yearly Contractual Wage Increase for Blue-Collar Workers . . 140

6.3 Wage Differences between Adjacent Blue-Collar Scales . . . . 140

6.4 Wage Profile of Juvenile Blue-Collar Workers . . . . . . . . . . 141

6.5 Wage Differences between Adjacent White-Collar Scales . . . . 143

6.6 Nominal Wage Changes in the Salary System . . . . . . . . 145

6.7 Upward Wage Scale Transitions . . . . . . . . . . . . . 150 
6.8 Upward Wage Scale Mobility and Performance . . . . . . . 152

6.9 Promotion Prospects and Wage Growth . . . . . . . . . 155

6.10 Earnings Function Estimates - White-Collar Workers . . . . . 160

6.11 Earnings Function Estimates - Blue-Collar Workers . . . . . . 161

A.1 Fokker Subsidiaries and Plant Locations . . . . . . . . . 210

A.2 Schooling Degrees . . . . . . . . . . . . . . . . . 211

A.3 Distribution of Performance Evaluation Scores . . . . . . . . 212 


\section{List of Figures}

3.1 World Aircraft Market, Orders and Fokker Deliveries . . . . 52

3.2 Remaining Orders and Size of the Workforce . . . . . . . 56

4.1 Development of the Workforce . . . . . . . . . . . . 62

4.2 Tenure Distribution . . . . . . . . . . . . . . . . . 69

4.3 Age Distribution . . . . . . . . . . . . . 70

4.4 Distribution over Wage Scales . . . . . . . . . . . 73

4.5 Baseline Hazards at Different Subsidiaries . . . . . . . . . . 77

4.6 Duration Dependence of Job Tenure . . . . . . . . . . . . 80

4.7 Age Effects . . . . . . . . . . . . . . . . 83

5.1 Development and Composition of the Workforce by Activities 100

5.2 Inflow-Outflow and Employment Growth Rates . . . . . . . 104

5.3 Monthly Mobility . . . . . . . . . . . . . . . . . . . 110

5.4 Mean Wage . . . . . . . . . . . . . . . . 115

5.5 Job Level Wage Distributions in 1991 . . . . . . . . . . . . 119

6.1 Performance Ratings over Time . . . . . . . . . . . . . 136

6.2 Mean Wages and Cohort Wages 1987-1996 . . . . . . . . . 149

7.1 Aircraft Demand and Employment Dynamics . . . . . . 171 


\section{Preface}

When I started to work with the personnel records of the Dutch national aircraft manufacturer Fokker four years ago, I could not foresee how much these data would shape my thinking about the functioning of labor markets. I began with great enthusiasm and the sensation of adventure, feeling that the analysis of the data would easily help pushing the frontier of research on internal labor markets. But I soon experienced that empirical research is cumbersome, and that dead-ends often impede pioneering advances. Cleaning the personnel records and transforming the data into a suitable format to work with determined much of a mechanical and at times tiresome early work routine. Consequently, my initial enthusiasm somewhat faded.

Nevertheless, the struggle remained inspiring. Casual observations in the data and results of numerous empirical investigations - some of which made their way into this dissertation - stirred up ideas about the workings of internal labor markets, which guided my reading of the labor market literature and influenced my interpretation of it. I gained an inkling that motivated me to build a new model on careers in organizations that should reflect my notion of the internal economics of firms. Thinking about the model and discussing my ideas with many colleagues refreshed my sense of adventure, but I unfortunately discovered quite often that 'my ideas' had been sensed before and had been already documented in the literature. Pushing the frontier is extremely difficult.

I learned during these four years that academic research is a process of small steps. Clearly, it is neither feasible nor useful to document all the thoughts that have emanated in the course of producing this book. But, I hold it important that a dissertation documents the route of scholarly development. Therefore, I present the chapters, which reflect various stages of my academic exploration, in their chronological sequence of completion. As a consequence of scientific progress, some issues tackled in earlier chapters might be approached from a different angle or studied in greater detail in later
chapters. 
Chapter 1

\section{Introduction}


"The greatest improvement in the productive powers of labor, and the greater part of the skill, dexterity, and judgment with which it is anywhere directed or applied, seem to have been the effects of the division of labor." (Smith, 1976: Book 1, Chapter 1)

\subsection{Introduction}

The opening sentence of the first book of the Wealth of Nations cited in the epigraph and the fact that Adam Smith devotes the first three chapters of his account to the division of labor underscores the fact that the study of labor mexits a central part in economic analysis. Further and further division of labor has undoubtedly characterized productivity growth of today's advanced economies during the past centuries. Increased degrees of specialization are not only evident by the array of different occupations, but even more so by the variety of specialized disciplines within most occupations. Workers have become more knowledgeable on ever narrower domains as the accumulated stock of knowledge in society has grown. The more that is known, i.e. the greater the stock of human capital, the higher are the benefits to a greater division of labor. However, the coordination of specialized individuals becomes a challenge for economic organization (cf. Hayek, 1945, p. 520).

The costs of coordinating specialists, who have to complete complementary tasks to produce a good, are a major factor limiting specialization and further division of labor (see Becker and Murphy, 1992). ${ }^{1}$ This vital insight draws attention to the organization of labor and eventually offers scope for an explanation of the emergence and prevalence of large enterprises. Firms might be better suited to cope with coordination costs that manifest themselves as communication costs, motivation costs, or other transaction costs. ${ }^{2}$

The internal organization of labor in firms differs from that in decentralized markets. Devising a decentralized pricing system inside firms in order to avoid free riding and to achieve the efficient allocation is unworkable because an exceedingly complicated system of contracts, which usually require sidepayments among joint input owners, is required under joint production and

\footnotetext{
Most economists after Adam Smith argued that the division of labor was largely restricted by the extent of the market.

${ }^{2}$ Armen Alchian and Harold Demsetz were among the first to explain under what conditions a team productive process is optimally organized as the contractual form of a firm (see Aichim and Demsetz, 1972). Before them, other economists had offered theories of the firm. Coase (1937), for example, relied on the clever thought that firms exist where they cas establish contracts at lower costs than the market. Oliver Williamson (1985) argues explicitly that firms exist to reduce coordination or transaction costs that arise in the presence of firm-specific human and nonliuman capital.
} 
shared ownership (see Rosen, 1988). A superior, because less complicated and less costly, organization structure than a decentralized pricing system entails that one person has residual control. This person (principal) hires the team of workers, assigns them to positions in the firm in which they are most productive, and monitors and rewards their performance. Formal rules set standards concerning the quantity and quality of work and define work conditions. Contractual difficulties arise because employment contracts are necessarily incomplete due to bounded rationality (Simon, 1951) and the impossibility to specify the course of action in all possible contingencies in a written contract. Relational contracts have to be self-enforcing because contractual terms relating, for example, to performance or specific investments are typically not verifiable in court. Implicit agreements, informal rules and customary law often shape such relational contracts.

The internal workings of a firm are complex and have not been widely studied from an economic perspective in the context of a coherent framework. ${ }^{3}$ Still, knowing what happens inside firms is important to better understand the functioning of labor markets, because an internal organization of jobs might generate labor market outcomes that are at odds with the prediction of the conventional competitive labor market model. This is especially relevant because large organizations often foster long-term employment relations, which characterize a substantial fraction of current jobs (see Farber, 1999).

\subsection{Contributions and Relevance of this Study}

This dissertation explores the internal economics of a firm, both empirically and theoretically. Some empirical evidence suggests that an array of different forces - including learning about talents, human capital acquisition, and job assignment - impact on individual careers in internal labor markets. However, this evidence is still temuous and only based on a few case studies, which are necessarily specific in nature. In order to advance science, it is crucial to determine which findings are idiosyncratic and which outcomes apply to a broad range of internal labor market careers in different countries, industries, and periods, so that a widely valid portrayal of the internal economics of firms crystallizes. To contribute to this endeavor, I analyze the personnel data of the Dutch national aircraft manufacturer N.V. Koninklijke Vliegtuigenfabriek Fokker, compare the results with those of related studies,

\footnotetext{
${ }^{3}$ Particular aspects of employment relationships and the organization of work have been studied in different strands of a vast literature (see chapter 2 for a review).
} 
and exploit particularities and virtues of the data to shed light on issues that could not be explored by previous studies.

I then build a model that is consistent with the collection of empirical facts that derive from this study as well as from other studies. The model integrates different theoretical concepts. Such a modeling approach has thriven in the recent theoretical literature of careers in organizations (e.g. Bernhardt, 1995; Demougin and Siow, 1994; and Gibbons and Waldman, 1999a). Yet, these modern models on careers in organizations have limitations, either because the model setup does not permit a comprehensive analysis of job mobility dynamics - Demougin and Siow (1994), for example, cannot study careers that involve more than one career step - or because the model pays only little attention to the internal organization of labor in firms. In this dissertation, I develop a theoretical framework that fixes these problems. The model assumes a command production technology that induces a pyramidal hierarchical structure. Such an internal organization is an efficient design in many settings as it minimizes costs of processing specialized knowledge (Bolton and Dewatripont, 1994; Garicano, 2000). Managerial output is transferred through chains of command. The most capable managers have to be assigned to the highest ranked positions because their decisions have multiplicative effects on productivity in lower levels with such command production technologies (Rosen, 1982). The optimal allocation of workers to job positions changes during a worker's career because institutional knowledge is transferred from older generations to younger generations and skills are acquired when workers learn on the job. At the same time, the firm learns about the capabilities and talents of its workers, so that the sorting of workers to jobs becomes a dynamic process that determines job mobility and career earnings in internal labor markets.

\subsection{Research Questions}

In order to better understand the determinants of observed patterns of wage growth and mobility during a worker's career in an organization, the empirical part of this dissertation scrutinizes individual job and wage mobility in a large firm. A first subset of research questions relates to the determinants of the length of an employment relationship.

- What impact do individual characteristics have on worker turnover at
the firm level? - Do these determinants of individual separation probabilities change
between periods of growth and decline? 
A second set of questions focuses on job mobility and earnings profiles:

- What does the pattern of internal job mobility look like?

- What is the relationship between job levels and wages?

- What does the wage policy of the firm look like and how does it affect individual earnings profiles?

- How are career wages determined and how important is job change for wage growth?

A model is then built in the theoretical part of the dissertation in order to explain the forces that generate the observed patterns of job mobility and earnings dynamics. Questions that are addressed in this context include the following:

- What is the effect of learning on career dynamics?

- How are internal job mobility rates affected by an expansion or contraction of the workforce when job positions on different hierarchical levels are limited?

- How does the interaction between learning and human capital acquisition affect job assignment?

\subsection{Outline of the Study}

To illuminate the scientific context in which the research questions are embedded, chapter 2 surveys the economics literature that is relevant for the issues dealt with in later chapters. This literature is comprised of a wide range of topics in labor economics that relate to the organization of labor, the nature of the firm, and attributes of the employment relationship. Progress towards a better understanding of distinct aspects of careers, job mobility, and compensation has been made in different specialized areas of the economics literature. Contract theory, agency theory, human capital theory, or the literature on learning and job assignment are some examples of such specialized disciplines. After reviewing building block models from different strands of the literature and introducing contending views concerning the internal organization of labor, I summarize the empirical evidence about the internal workings of firms and discuss the modern economic literature that deals with careers in organizations. 
Chapter 3 provides some background information about the Dutch national aircraft manufacturer Fokker and the special conditions that characterize the industry during the period for which the company's personnel records are available. The unique data set, which is analyzed in the empirical part of this dissertation, contains information on 17610 workers and spans a period of almost ten years from January 1987 until March 1996. During this period, the firm went through an expansion phase and a period of severe downsizing, which eventually led to the firm's bankruptcy on March 15, 1996. More than any data that has been analyzed so far and that I am aware of, Fokker's personnel records allow to study the impact of changes in economic conditions on labor market outcomes. Because of their event history structure, the data are particularly suited to study the timing of important events that mark careers like job change, wage change and turnover.

The empirical part of the dissertation starts in chapter 4 with an econometric investigation of the predictive power of various turnover theories, which stress different aspects and mechanisms that lead to job separations. The chapter explores the determinants of separation rates and examines how these differ between episodes of corporate expansion and corporate decline. The econometric technique to estimate hazard rates for job separation is chosen to accommodate the data, which come from a single firm and span a time period marked by enormous changes in economic conditions. To control for the nonstationary environment, the role of calendar time and tenure duration is reversed in a Cox proportional hazard model. Worker turnover characteristics are found to differ significantly between episodes of workforce expansion and contraction, an aspect that has not received adequate attention in theoretical work. In addition, institutional arrangements like early retirement plans cause strong discontinuities of separation hazards for eligible and anticipating workers, an insight that should receive attention in the form of a careful designing of such personnel policies. Further empirical results show that the effects of firm-tenure, human capital, and careers inside the firm are largely in accordance with the implications from existing theoretical models, but that no single model generates all observed patterns.

Chapter 5 assesses empirically the internal workings of the firm to compare results from analyzing Fokker's personnel data with outcomes reported in the existing literature. Repetition and comparison of results is key to finding out what holds true in general and what marks idiosyncrasy. But the data also allow to distinguish between production workers and managers, and between jobs in different fields of activity within the firm. I found multiple ports of entry that are concentrated in low blue-collar and white-collar levels. Promotions from within prevail and firm-specific hurnan capital seems important. New entrants are younger and hold higher educational creden- 
tials than incumbent workers who are promoted to similar jobs. Upward job transitions are crucial to ensure persistent wage growth because wages are strongly related to job levels. Horizontal job-mobility is important as well, because job-rotation improves promotion chances, stimulates wage growth, and reduces the lay-off risk.

Furthermore, the chapter sheds light on differences in the functioning of internal labor markets during periods of workforce growth and decline. Thereby, it draws attention to issues that have not been addressed in the empirical internal labor market literature so far. Relative sizes of hierarchical levels vary little during the episode of corporate expansion in spite of the unbalanced entry pattern. Promotion rates fall and demotion rates rise when the firm enters the stage of demise. Changes in job transition rates are stronger among jobs that are cut more severely during downsizing. These are important new empirical facts that stimulate the development of a theoretical model, which is in chapter 7 of this dissertation. The chapter also finds that downward mobility almost never results in nominal wage cuts; yet it frequently coincides with degradation in wage scales, and hence leads to a reduced expectation of future wage growth. Real wage decreases, on the other hand, are common, especially during downsizing when nominal wages are not changed for most workers for more than three years.

Chapter 6 continues to study the wage policy and its effects on individual earnings profiles in more depth. It examines how a formal salary system affects the relation between experience, performance and earnings. The reward system defines the level of wages and annual contractual wage growth for wage scales, wage grades, and performance ratings. The amount of wage variation in a given scale and grade that can be attributed to differences in performance ratings is small relative to the variation caused by contractual experience-wage profiles. Typically, a handful of wage scales are attached to jobs so that wage growth without job change is limited. Better performance raises the probability of being assigned to a higher job level. The resulting relation between performance measures and earnings profiles observed in cross-sections, therefore, merits a different interpretation than is suggested in the economics literature.

Chapter 7 develops a model that explains a broad pattern of evidence about careers in multilevel organizations. It considers the role of the interaction between learning about workers' capabilities and the acquisition of human capital, both on the job and through formal training experiences, for career dynamics. The model analyzes how these forces affect job mobility and wage dynamics when workers are assigned to limited slots of jolos in a corporate hierarchy. The model derives a dependence relation between changes in the size of the workforce and internal job mobility rates. The model's 
predictions about the impact of economic conditions on the careers of individual workers are consistent with the empirical evidence found in chapter 5 that promotion rates rise (fall) during a corporate expansion (contraction). The model shows how promotion and wage dymamics are affected by learning about workers' capabilities and the process of human capital acquisition on-the-job as well as formal training experiences of employees.

In summary, the plan of the book is as follows: Chapter 2 gives an overview of the economies literature into which this dissertation is embedded. Chapter 3 provides background information about the firm and its personnel data that are the basis for the empirical analysis in the following chapters. Chapter 4 evaluates the determinants of worker separations at the firm level during times with changing economic conditions. Chapter 5 analyzes patterns of internal job mobility and the relation of wages to jobs. Chapter 6 takes a closer look at the wage policy of the firm and studies how it affects individual career earnings. Chapter 7 develops a theoretical model that captures a broad pattern of empirical evidence about careers in internal labor markets. Finally, chapter 8 concludes. 
Chapter 2

Literature Review 


\subsection{Introduction}

There is no generally accepted definition of the term internal labor market", but the concept is widely associated with Doeringer and Piore's (1971) account that defines - rephrasing Dunlop (1966) - the internal labor markets as "an administrative unit, such as a manufacturing plan, within which the pricing and allocation of labor is governed by a set of administrative rules and procedures" (Doeringer and Piore, 1971, pp. 1-2). Rules and procedures characterize work practices that secure job rights, restrict hiring to particular jobs, classify job ladders and promotion paths, and affect the wage structure. In this view, interual labor markets are institutional labor markets. This characterization can be traced to Kerr (1954) who distinguished between the "free choice" labor market and the institutional labor market. The free choice labor market has no distinct geographic or occupational limits, so that employers can freely choose to enter and workers can freely decide if, when, and where to offer their services. Institutional labor markets, on the other hand, have limited dimensions and are structured by formal and informal rules that set sharper boundaries between the "internal' and 'external' markets and define more precisely the points of entrance. Such rules are, for example, established by the personnel policies of companies, by collective agreements, or by actions of government. Kerr identified two general types of institutional labor markets: Communal ownership or craft markets, in which unions often regulate movements (across firms) of workers belonging to carefully defined occupational groups, and private property or industrial enterprise markets, in which the firm constitutes its own rule. This dissertation is concerned with the latter type, to which I will refer from now on as the "internal labor market" (ILM).

Large private firms permeate the labor markets of advanced economies. A substantial fraction of labor market participants spend their working lives in such organizations, which constitute an alternative form of contracting to institution-free labor markets with simultaneous transaction of work for pay. Employment relations between employees and firms are often long (see Hall, 1982; Farber, 1997) and cannot be described as a series of spot markets. Instead, the pricing and allocation of labor in firms is often determined by a set of formal and informal rules. Such organizational structures affect a wide range of career outcomes - including human capital accumulation, specialization, occupational choice, job mobility, and pay - that are frequently in conflict with the predictions of the conventional competitive labor market
model.

While a large sociology literature, which I will not review further, has long recognized the role of organizations for career advancement, skill devel- 
opment, occupational choice, and mobility (see e.g. Whyte, 1956; Simon, 1957; Kanter, 1977; Spilerman, 1977; Rosenbaum, 1979), labor economists have only recently devoted effort on a larger scale to developing integrative models of careers inside firms that explain a broad pattern of evidence (see Gibbons and Waldman, 1999b for a survey). Nonetheless, economists, traditionally being preoccupied with the study of optimal resource allocation, have analyzed hitherto many distinct aspects of employment relationships and the organization of labor. This literature and the more recent economic literature on careers in organizations is reviewed in this chapter to illuminate the research context in which the following chapters are embedded.

The plan of the chapter is as follows. Section 2.2 deals with the fundamental problem of allocating and coordinating specialized labor. It traces some landmark contributions to the theory of economic organization in order to show under what conditions the organization of labor takes place in firms rather than through the market. Section 2.3 concentrates on key aspects of the employment relationship between the firm and workers, which is shaped by contractual agreements that are necessarily incomplete and implicit. The section reviews mechanisms proposed in agency theory and contract theory to cope with enforcement, commitment, and motivation problems, which stem from the special nature of employment contracts. But before doing so, the section considers relationship-specific capital, as its presence often reinforces such problems. The section also discusses implications of specific investments for worker turnover, which is a key aspect of labor market careers. (Predictions of turnover models are tested empirically in chapter 4 of this dissertation.)

Sections $2.4-2.6$ deal with the internal organization of labor. This literature is especially relevant for the model of careers in internal labor markets that is developed in chapter 7 of this dissertation. Section 2.4 considers theoretical approaches to the hierarchical internal organization that have roots in the literature on the theory of the firm. Section 2.5 then reviews the institutional perspective on the internal organization of firms, which stresses the importance of formal rule structures concerning jobs, careers, and compensation. Section 2.6 centers on the job as a concept. It considers aspects that affect the optimal assignment of workers to jobs, and hence career mobility.

Section 2.7 reviews different predictions about compensation that derive from a variety of approaches to the employment relation and the organization of labor. Determining the relationship between wages, individual worker characteristics, and jobs is a major empirical concern as different theories sometimes generate conflicting results. Section 2.8 surveys empirical studies looking at internal labor markets. This literature has uncovered a number of 
stylized facts that are often in conflict with the standard labor market model, and that therefore have raised new research questions and have stimulated the new theoretical literature on careers in organizations. Section 2.9 reviews the growing body of theoretical work and focuses especially on new models of careers that are related to the model that is developed in this dissertation. Section 2.10 summarizes.

\subsection{The Allocation and Organization of Spe- cialized Labor - Markets versus Firms}

The allocation and organization of labor is a key aspect of modern economic life. Adam Smith noted in The Wealth of Nations that improvements in labor productivity are to a large extent the result of an increased division of labor. (see Smith, 1976: Book 1, Chapters 1-3). The accumulation of knowledge in society stimulates increasing degrees of specialization and further division of labor (Becker, 1964). When individual workers learn more about a narrow range of problems, the coordination of disparate specialized knowledge becomes a major task of economic organization, as Hayek (1945, p. 520) observed. The costs of coordination limit the division of labor (Becker and Murphy, 1992). Workers who perform specialized tasks in the production process have to be organized as "teams" to fabricate a good. The cooperation between specialists of the team can be achieved within firms by internal arrangements or across markets through external arrangements. Which of these alternative forms of contracting prevails, depends on coordination costs and the capability to allocate rewards among team members in line with their productivity. This idea can be traced to Ronald Coase, who, rather than dwelling on aspects of team production, proposed in his influential 1937 article "On the Nature of Firms" that firms exist whenever using markets to form contracts is more costly. Arrow (1974) added that organizations evolve when markets fail or where markets do not exist. Williamson (1975, 1979) later formalized Coase's cost argument and showed that differential transaction costs are key to the allocation of ecomomic activity between
the firm and the market.

The desire for long-term contracting is another important motive for the

${ }^{1}$ Coase (1937) argued that "the main reason why it is profitable to establish a firm would seem to be that there is a cost of using the price mechanism" (Coase, 1937, p. 390). p. 390) and "costs of include "discovering what the relevant prices are" (Coase, 1937, transaction which takes place on a market" (Coase, 1937, p. 391). 
emergence of firms, according to Coase. Such long-term arrangements are necessarily incomplete due to forecasting difficulties and the impossibility to specify all contingencies. Firms then evolve because internal contractual agreements which only specify general terms can better deal with these contractual difficulties. Because of incompleteness there will be bargaining in situations that are not covered by an initial contract. Costly bargaining can be avoided when one party has all the power in such a situation. Grossman and Hart (1986) argued that the frrm gains such power or authority from asset ownership, which gives them the residual rights of control, i.e. the right to make any decision concerning the assets that are not assigned to another party by law or by a contract. From their point of view, asset ownership identifies the firm and defines its boundaries. ${ }^{2}$ Hart and Moore (1990) advanced this line of research and studied how changes in ownership affect the incentives of owner-managers as well as those of their employees.

Regarding the firm as a nexus of contracts, Alchian and Demsetz (1972) were the first to stress the contractual character of the firm. The firm is a legal entity that enters bilateral contractual agreements with employees, investors, suppliers, and customers. These bilateral agreements replace multilateral agreements among all these owners of joint inputs to the team productive process. Such an organization can only exist if it provokes a superior productivity response. This requires a proper allocation of rewards among input owners. In order to motivate all contractual partners to provide efficient levels of input and to avoid shirking or free-riding, marginal productivities of resources and services of all input owners have to be brought into line with their marginal costs. Allocating rewards according to productivity requires correct measurement of productivity. Alchian and Demsetz (1972) emphasized the crucial role of monitoring or metering productivity and thus drew attention to motivation costs, a further important dimension of the cost of organizing labor. The role of performance monitoring had a bearing on different strands of the subsequent literature, influencing, for example, work on optimal firm size or internal organization. Motivation costs primarily inspired research on incentive provision and supervision in individual employment relations.

The question of who monitors the monitor becomes a key issue in Alchian and Demsetz's argument. They propose that the monitor should receive the residual returns because this provides appropriate incentives to perform his function efficiently. The monitor becomes the decision maker, who super-

\footnotetext{
${ }^{2}$ The theory of the firm was subsequently developed further in a segment of the literature that discussed the boundaries of the firm. Holmstrom and Tirole (1989) and Holmstrom and Roberts (1998) survey this literature.
} 
vises, controls, and manages members of the team productive process, and is entitled to hire and fire. His decisions will be efficient if he has residual control and is the residual claimant. Combining ownership and residual returns creates proper incentives.

Holmstrom and Milgrom (1994) viewed the firm as a system for managing and balancing incentives stemming from asset ownership, job design, and pay according to performance. They studied how issues of control, monitoring; and compensation are intertwined; and they tried to explain why employment relationships differ from contractor relationships along several dimensions. Differences include, for example, that agents in employment relationships typically do not offer their services beyond the scope of the firm, do not maintain control over the production process, and are often paid a fixed wage rather than being rewarded based on the value of the service they complete.

\subsection{The Employment Relationship}

The employment relationship has a special contractual nature, which stems from the inevitable incompleteness of an employment contract. Simon (1951) argued that bounded rationality precludes complete contracting. Grossman and Hart (1986) added that such incompleteness is inevitable due to transaction costs. As a result, an employment contract typically defines only generally valid provisions that frame the relationship. It is habitually accompanied by an implicit contract: a set of unwritten agreements concerning the employment relationship that is shared by both parties. ${ }^{3}$

Since implicit agreements are commonly not enforceable by third parties (e.g. courts) - not least because the behavior of contracting parties is often not verifiable - hold-ups and opportunism are prone to emerge. For example, the initial agreement might entail that workers are rewarded for investing in productivity enhancing firm-specific skills. But once these investments have been made, the firm has an incentive to renege on its earlier promise, knowing that the worker cannot capture the returns from his specific investments elsewhere. Similarly, opportunistic behavior can disturb principal-agent relationships and conflict with incentive contracting. The principal might, for taken the desired actions defined in the initial agreement.

To prevent opportunistic behavior, contracting parties have to design mechanisms that commit them to their initial agreement. Relational contracts in repeated games (see Bull, 1987 or MacLeod and Malcomson, 1989)

\footnotetext{
'Early breakthroughs in the theory of implicit contracts, as reflected in work by Baily
} 
offer such a device if they are self-enforcing. A firm can be prevented from reneging on its earlier promises if workers can effectively pumish the firm in the future. ${ }^{4}$ Likewise, reputation can serve as a commitment device. Some economists (e.g. Kreps, 1990) have even argued that firms exist because they can build up a reputation necessary to achieve commitment and enforce relational contracts. ${ }^{5}$

Which mechanisms are suited most to motivate workers to act in the firm's interest crucially depends on the costs and availability of monitoring devices (Alchian and Demsetz, 1972). Different prevailing conditions, under which a motivation device has to be designed, give rise to alternative mechanisms. If monitoring is not costly and performance measures are reliable, workers can be rewarded based on their input. When there is a positive probability of detecting a worker who is shirking, firms might opt for deferred compensation schemes or efficiency wages, even ill monitoring was costly. The efficiency wage argument was initially proposed in a macroeconomic context by Shapiro and Stiglitz (1984). Firms pay a wage rate above the marketclearing level, but threaten to dismiss the worker if his performance is not adequate. Workers provide effort as they fear to lose their wage privileges when caught shirking. The wage rate is independent of output, so that workers are solely motivated by the threat of not receiving the wage premium in the future.

But in situations in which monitoring is not perfect, so that workers can alter their effort without being detected, output based measures are better suited. This is the focus of agency theory. Finally, if costs of measuring output are very high, the benefits from better performance induced by output-based pay might not compensate for the risk-sharing losses. Rankorder toumaments (Lazear and Rosen, 1981) can then be a superior incentive mechanism. I will return to the design of commitnent devices and motivation mechanisms in more detail in section 2.3.3. But before doing so, I discuss critical features of relationship-specific human capital accumulation and the related problem of worker turnover.

\subsubsection{Human Capital and Specific Investments}

An essential element of most employment relationships is the acquisition of human capital within the firm as analyzed in Becker's seminal work (see Becker, 1962, 1964). Becker's distinction of firm-specific and general human capital marks the beginning of the modern account of human capital acqui-

\footnotetext{
"This requires that firms do not discount the future too heavily.

See Tirole (1988) for a thorough discussion of the commitment problem.
} 
sition. Completely firm-specific human capital improves productivity only in the current firm, but is worthless at other firms. General capital, in contrast, is valued by all firms in the market and, consequently, raises wages with any employer. As a result, workers pay for general training because they seize all the returns from the investment. Later research, assessed by Weiss (1986) but not surveyed here, advanced general human capital theory by throwing light on optimal investment decisions, addressing, for example, the allocation between time spent investing and working (Ben-Porath, 1967) or leisure (Weiss, 1972), the timing of general human capital accumulation, the effect of uncertainty (Levhari and Weiss, 1974), and credit constraints (Wallace and Ihnen, 1975). For the purpose of this dissertation, I will focus on the literature that centers on relationship-specific human capital.

Unlike the case of general human capitall acquisition, firm-specific human capital accumulation is typically accompanied by incentive problems to bear the costs of the investment. ${ }^{7}$ Since firm-specific human capital is of no value outside the employment relationship, investments in it are irreversible and investment costs are sunk. There is a "[s]urprisingly large variety of situations that come under the rubric of specific investment" (Becker, 1964, p.41). Specific training, as defined by Becker (1964), on-the-job learning (Mincer, 1962 and Arrow, 1962), hiring and screening workers (Oi, 1962), experiencing match quality (Jovanovic, 1979a), as well as accumulation of knowledge about the organization and developing work relations with colleagues (see e.g. Prescott and Visscher, 1980) are all different types of investment in relationship-specific capital. Its costs come in various forms, including monetary expenditures, foregone earnings, time, and effort.

Becker proposed that the financing of specific investments is intimately related to turnover - as investments in human capital are not separable from the individual - and that the firm and its workers, consequently, share the costs and returns from the investment to minimize turnover. He reasoned as follows: ${ }^{8}$

"If a firm had paid for the specific training of a worker who quit to take another job, its capital expenditure would be partly

\footnotetext{
${ }^{6}$ See also Mincer (1962) and Schultz (1963).

Tncreases in future productivity that require no outlay in terms of money or foregone production time, e.g. some forms of on-the-job-learming that materialize as externalities,
are not subject to this caveat.

'Hashimoto (1981) worked out Becker's argument in a formal model with uncertainty be specified contingent on the realized post-training productivity.
} 
wasted, for no further return could be collected. Likewise, a worker, who is fired after he had paid for the specific training, would be unable to collect any further return and would also suffer a capital loss. The willingness of workers or firms to pay for specific training should, therefore, closely depend on the likelihood of labor turnover." (Becker, 1964, p. 43).

Sharing costs and returns is easier said than done because it requires detailed long-term contracts to be written, which define in advance how the quasi rents from specific investments are to be divided up. Complete contracting is, however, too costly (Grossman and Hart, 1986), and even impossible because of bounded rationality (Simon, 1951). ${ }^{9}$ Moreover, ex post contract enforcement problems are prone to arise, which lead to opportunistic behavior and hold-up problems as described by Williamson $(1975,1979)$ and Klein, Crawford and Alchian (1978). ${ }^{10}$

Because relationship-specific capital creates rents to continuing the employment relation, there is no unique equilibrium wage. Only a lower bound - the lowest wage for which the worker is willing to continue employment and an upper bound - the highest wage the firm is willing to pay - exist. These bounds are determined by the value of the worker's and firm's outside option. " The difference between the value of both outside options is the joint surplus of the employment relation. If no enforceable contract specifies ex ante how the joint surplus that is generated by any party's specific investments is to be divided, wages are determined in post-investment bargaining. A hold-up arises when the bargained wage depends on the size of the returns of the investment, so that the non-investing party captures some of the benefits of the investment. This is, for example, the case when wages are determined by Nash bargaining, as it allocates to each party a fixed share of the surplus.

Hold-ups generate inefficiencies above and beyond the cost of bargaining because parties tend to invest too little in specific capital if the investing party is not assured that it will capture the full returns from its investment.

\footnotetext{
${ }^{9}$ Asymmetric information about costs and returns or the fact that speciffc investments are sometimes not verifiable (e.g. efforts to establish good work relations with colleagues) adds more dimensions to the problem.

${ }^{10}$ Williamson (1985) used the term 'hold-up'.

${ }^{1}$ The value of the worker's outside option depends on the expected wage if finding employment elsewhere, the size of benefits in case of unemployment and the probability of being unemployed in future periods. The value of the firm's outside option depends on turnover cost, i.e. the cost of firing the worker and recruiting and training a new worker so that he can adequately replace the worker who separated.
} 
Contracts can lessen such inefficiencies. ${ }^{12}$ But contractual agreements give rise to separations when one parties contractual share of the surplus has a lower value than his outside option, even if the joint surplus is positive. In fact, But they may give rise to inefficient separations. Such situations arise because contracts are incomplete - due to complexity and non-verifiability - so that the allocation of surplus shares cannot be specified for all contingencies. If renegotiation of contract terms is possible, inefficient separations can be avoided. But this is in general only achieved at the cost of adversely affecting incentives to invest, because anticipation of possible renegotiation disturbs the expected distribution of rents.

\subsubsection{Separations}

Theoretical models of worker turnover can be dichotomized into models with efficient separations and those with inefficient separations. An efficient separation occurs if the joint expected surplus falls below the sum of separation costs and the option value associated with a separation. ${ }^{13}$ Inefficient separations can result when there are informational asymmetries about outside options, or when specific investments are not verifiable. ${ }^{14}$ Models with inefficient separations distinguish between layoffs and quits. In recent theories of optimal quitting behavior (e.g. McLaughlin, 1991), voluntary turnover results from censored wage increases that do not match the outside offer.

Prominent models in the early literature on worker turnover have typically avoided a distinction between layoffs and quits by focusing on efficient separations. Since the turnover decision is intrinsically related to the size of the surplus that the employment relation creates on top of the joint value of both parties" outside options, turnover rates are predicted to be lower the higher the value of specific investments. Mortensen $(1978,1988)$ has worked this out for the accumulation of specific human capital.

Jovanovic (1979a) argues that match-specific capital influences the separation hazard. Jobs are experience goods in his model. Workers and firms are uncertain about the quality of their match. They learn about a worker's

${ }^{12}$ In principle, efficiency with unilateral specific investments can be achieved by giving one party all the bargaining power (Grossman and Hart, 1986). Such a contract might the worker to quit (e.g. Hall and La wage in the post-investment period but allowing Malcomson (1997) survey more approar, 1984). MacLeod and Malcomson (1993b) and

${ }^{13}$ The option value is due to uncertainty that developed in contract theory.

${ }^{14}$ See, for example, the model by Hall and Lazear (1984) the surplus in future periods. also discuss these issues and illustrate how ind Lazear (1984). Teulings and Hartog (1998) (1984) modlel can be prevented if both parties agree on a that result in Hall and Lazear's true values of the employment relation and alternatives are revealed. 
productivity only after the match is formed. Since knowledge of productivity in the current match is uninformative of productivity at any other firm, the informational capital is completely match-specific. The current employment relation is terminated if sufficient negative information about a worker's productivity has accumulated, such that he is expected to be more productive elsewhere. The turnover probability falls with job tenure because 'bad' matches are terminated early. In other words, conditional on continuing the employment relation, expected match quality is higher the older the match. The separation probability is independent of labor market experience because a worker's productivity across different matches is independent.

If specific skills are accumulated on the job, separations become less likely the longer the employment relationship continues. This negative structural dependence of the separation hazard on job tenure is reinforced by reduced search effort, as Jovanovic (1979b) works out in his analysis that combines job-specific human capital accumulation and search behavior. A crucial determinant of search behavior is match heterogeneity since it affects the size of the joint surplus. But contrary to the pure matching model (Jovanovic, 1979a), job separation rates are also predicted to fall with experience, or better, time spent in the labor market.

\subsubsection{Motivation Mechanisms and Incentives}

In the presence of specific investment and turnover costs, firms would like to reduce turnover to efficient levels. Several models show how rising tenurewage profiles can encourage the provision of effort and discourage turnover. In deferred compensation schemes, workers are not immediately rewarded fully for enhanced productivity, that stems, for example, from the acquisition of specific skills, but are promised future wage raises instead. In order to capture the full rewards, workers have to continue the employment, relationship.

The idea of rising wages in finite careers goes back to Becker and Stigler (1974). They proposed a bonding scheme in which the firm awards workers wage premia throughout their finite careers until they are detected shirking. To compensate for the discounted value of wage premia, the firm charges an entrance fee of equal value. Desired effort levels can be enforced because this wage schedule aligns the firm's goals and the worker's self-interest. Wages increase in the last employment period in order to prevent workers from shirking. Since workers cannot be motivated by the threat of foregoing future wage premia if caught shirking in the last period, the last period's wage 
premium must be bigger to offset the decline in the cost of shirking that is caused by the fall of future foregone income. The argument is related to the efficiency wage argument, but Becker and Stigler's model is one of deferred compensation as a bond is paid initially.

Lazear (1979) continued this line of research and showed that efficient effort levels can be induced when the firm, rather than charging an entrance fee, pays a wage below' a worker's marginal product of labor during the first years of the relationship and higher wages towards the end. Compensation is deferred in such a way that the discounted value of wages equals the discounted value of productivity. Thereby, he shows that the wage profile in bonding schemes as suggested by Becker and Stigler is not unique, but that countless feasible wage schedules exist, in which pay rises with seniority. Besides, he provides a rationale for mandatory retirement and thus endogenizes the finiteness of workers' careers which Becker and Stigler had assumed.

An important assumption of models that use compensation schemes to induce efficient levels of effort and prevent shirking is that effort provision can be - potentially at a cost - monitored; or in other words, that workers can be caught shirking. Compensation schemes that induce workers to act in the interest of their employer when effort levels cannot be observed or verified easily have been developed in agency theory.

Even if any contingency of a transaction can be foreseen and contracted, private information can be a source of inefficiency causing adverse selection if informational asymmetries are pre-contractual (Akerlof, 1970), ${ }^{15}$ or provoking moral hazard in situations in which post-contractual information about actions is costly to acquire or inadequate (Holmstrom, 1979). ${ }^{16}$ Workers can exploit their informational advantage in principal-agent relationships to pursue their own interest rather than the goals of the principal. This leads to severe distortions if the agent's and principal's interests are not aligned. As a remedy, contracts that establish congruence of objectives by providing adequate incentives can be designed in many cases. Such incentive contracts that induce the agent to act in the interest of his principal shift some of the variation in income from the principal to the agent. The costs of bearing the risk of income variability has to be balanced against the benefits from better performance. This trade-off between risk and incentives is the focus of early

\footnotetext{
${ }^{15}$ See Spence $(1973,1974)$ for applications to labor markets.

${ }^{16}$ Strictly speaking there is a difference between informational asymmetries taking the form of hidden actions - the case of moral hazard -- and hidden information. In the latter case, agents, for example, acquire better information than owners about the profitability of a collection of actions. Mas-Colell, Whinston and Green (1995) make this distinction explicitly. However, the literature often refers to both cases as moral bazard.
} 
contributions to a large literature. ${ }^{17}$

Holmstrom's (1979) analysis of loss of control in principal-agent relationships is one of the first rigorous contributions to the study of employment contracts that enable principals to elicit optimal productivity responses from their agents. ${ }^{18}$ His analysis develops the Informativeness Principle, which. holds that total value is always augmented if all measures that reveal information on the agent's choices are included in the compensation contract with appropriate weighting, whereas all other measures other measures are excluded that only reflect randomness which cannot be controlled by the agent. Holmstrom's approach to investigate the optimal responsiveness of compensation to contractible objective performance measures has become a prototype for a considerable fraction of the agency theory literature. ${ }^{19}$ The subsequent literature (see Prendergast, 1999 for a detailed survey) focused on the optimal design of linear incentives contracts in different or less stylized settings - Holmstrom (1982) considers, for example, relative performance evaluation - and explored performance measures when clear objectives are lacking or when the principal's objectives are multi-dimensional (e.g. Holmstrom and Milgrom, 1991). ${ }^{20}$ Holmstrom and Milgrom's analysis of multitasking shows the limits of linear incentive contracts: Even if there are only two equally important tasks to be implemented, which are measured with different degrees of variability, a linear incentive contract cannot optimally trade off risk and incentives. For compensation should give more weight to the activity with the more accurate performance measure. But that would induce agents to reallocate all their effort to the higher rewarded task. If there are multiple tasks to be performed, optimal contracts have to prevent agents from reallocating their effort to tasks in undesirable ways.

Baker (1992) approached the same problem somewhat differently. His argument starts with the observation that the principal's objectives are fre-

\footnotetext{
"The standard test for this trade-off is to examine whether incentive pay is lower in more uncertain environment. Empirically, however, this negative relation between risk and incentives is not found. Instead the data suggest a positive correlation between measures of uncertainty and incentives. Recently, Prendergast (2002) has argued thet this is causecl by another effect of uncertainty on incentives that the earlier literature neglects: Firms are more likely to delegate responsibility to employees and base pay on output measures to constrain their discretion the more uncertain the environment. But furms assign tasks to workers and monitor inputs in more certain environments.

${ }^{18}$ See also Mirrlees (1976). Shavell (1979) originated the informativeness principle alongside Holmstrom (1979). Among early contributions describing the principal-agent problem are Mirrlees (1971), Spence and Zeckhauser (1971), and Ross (1973).

${ }^{19}$ Hart and Holmstrom (1987) survey the early agency theory literature.

${ }^{20}$ Linear incentives contracts are a special case - see Grossman and Hart (1983) for dotails - but are typically considered in the literature because of theit analytical tractability.
} 
quently not contractible. This happens, for example, when agents have informational advantages and can, based on their superior knowledge, choose optimal actions. Non-contractibility can also result if the set of actions available to the agent is so large and the range of outcomes so complex that no incentive contract can completely specify rewards contingent on actions and outcomes. Workers can then game the contract by allocating their effort to those tasks that promise highest rewards, but ignoring other tasks that the principal wants to be performed. At the root of the problem is a performance measure that does not always respond to the effort choice in the same way as the value of output. Baker explains that linear incentive contracts are not efficient if objective measures and the effort function are not perfectly aligned, even if agents are risk-neutral. ${ }^{21}$ Baker's analysis provides a rationale for the widespread use of straight salary systems (e.g. when adequate performance measures do not exist) or the reliance on subjective performance measures, which often allow a more comprehensive assessment of the agent's performance which takes into account several actions and conditions that prevailed when actions had to be taken. Subjective judgment might, however, be subject to favoritism, a dilemma discussed by Prendergast and Topel (1996). ${ }^{22}$ In addition, workers are prone to engage in costly influencing activities, as described by Milgrom and Roberts (1988), or waste resources in rent-seeking activities to obtain their supervisor's favor and improve their ratings (e.g. Prendergast, 1993b) knowing that supervisors have discretion about the allocation of bonuses. ${ }^{23}$

Deferred compensation schemes and incentive contracts that promise rewards for adequate performance, but that are not enforceable in court, raise a major concern: the threat that the firm reneges. Workers will only accept such compensation schemes if they believe that the firm commits to its promise of paying higher wages in the future. Commitment can be established in self-enforcing relational contracts. ${ }^{24}$ Bull (1987) argued that contracts become self-enforcing if the firm discounts the future not too heavily so that future generations of workers can punish the firm for not living up

\footnotetext{
${ }^{24}$ Linear incentive contracts often lead to undesired outcomes when agents can exploit their informational advantage and game the incentive contract. Examples of dystunctional responses to incentive schemes are provided in the survey by Prendergast (1999).

${ }^{22}$ Garicano et al. (2001) and Dohmen (2002) provide evidence that agents are influenced. by social pressure.

${ }^{23}$ Concerms about reputation (Fama, 1980) are according to Holmstrom (1982b) most important early in the career when uncertainty about the worker's ability are greatest and the effect of inftuencing the firm's beliefs are strongest because the length of the remaining
career is longest.

${ }^{24}$ See Carmichael (1989) for a survey on self-enforcing contract design with life cycle incentives.
} 
to its promises in the current period. In Bull's model, workers are rewarded for performance by a bonus that is paid at the end of the period. MacLeod and Malcomson $(1989,1993 \mathrm{a})$ extended this argument by showing how firms can use efficiency wages to prowide incentives when the employment relation generates sufficient rents.

MacLeod and Malcomson (1998) advanced the literature on self-enforcing contracts by introducing labor market conditions to determine what form of compensation - bonus payments or efficiency wages - is selected. A compensation scheme with bonus payments emerges if there is excess labor demand. Efficiency wages are paid when there is excess labor supply. A key element of both schemes is the separation decision at the end of the period. With efficiency wages, the firm fires a worker if he has shirked, thus punishing him effectively because he will not capture rents, which are only generated if the employment relationship is continued. Bonus payments are not credible under excess labor supply conditions because the firm can easily replace a worker who quits when the firm does not pay the bonus. Workers anticipate the firm's incentive to renege on its promise of paying a bonus, and, consequently, they shirk. But if there is excess demand, bonus payments are efficient. If the firm does not pay the promised bonus at the end of the period, although the worker has not shirked, he quits so that the firm does not earn rents in the future.

Fairness is crucial for sustaining an equilibrium, as a convention is needed that prevents firms from lowering wages in the current period when efficiency wages are paid and that keeps workers from bidding up wages when bonus payments are used. The reason is that workers who are paid efficiency wages are motivated by future rents, not by current wages, so that firms are tempted to lower wages in the present period. But firms take into account that workers perceive a wage cut as unfair so that they will shirk in the future. ${ }^{25}$ This keeps firms from cutting wages. Similarly, workers have an incentive to bid up wages once they have received the bonus payments. But that would undermine the firm's rent from continuing employment in the future.

If metering performance by output measures is too costly, the firm might revert to tournaments in which wages are based on the productivity rank order of workers. The design of rank-order tournaments to elicit effort was proposed by Lazear and Rosen (1981). The firm attaches higher wages to higher job levels. Workers compete for future positions on the current job

\footnotetext{
${ }^{25}$ Survey evidence by $B$ linder and Choi (1990) suggest that workers would wiew at wage cut as unfair and reduce effort. Empirical evidence of this kind of reciprocity is provided by Fehr, Gächter and Kirchsteiger (1997), while Fehr and Schmitt (1999) give a theoretical treatment. For empirical evidence about effort provision and discipline devices in longterm incomplete contracting relations, see especially Brown, Falk and Fehr (2002).
} 
and exert optimal levels of effort in their strive for a promotion to a higher job level; which is associated with a wage premium. ${ }^{26}$ Rosen (1986) extended the analysis to a multi-period model with a sequence of elimination tournaments in which wages of the surviving workers rise as they proceed to the next round. Meyer (1992) examined the consequences of sequential toumaments without elimination on career earnings profiles. ${ }^{27}$

Attaching wages to jobs and using promotions to assign workers to jobs can be used to achieve other goals in addition to eliciting effort. Carmichael (1983) showed how a fixed compensation structure that ties wages to job levels can induce workers to invest in specific skills. If the firm can commit to a fixed wage structure and use promotions to assign more productive workers to higher job levels, workers are willing to invest in productivity augmenting skills being assured that they will capture the rewards of their investment upon promotion. Prendergast (1993a) illustrated how promotions can encourage workers to make non-verifiable investments to acquire productivity enhancing skills when the firm can assign workers to two different tasks, one of which requires more skills than the other but carries a wage premium. Similarly, an 'up-or-out' promotion policy, as proposed by Kahn and Huberman (1988), motivates workers to invest efficiently and helps to solve hold-up problems.

More recently, Fairburn and Malcomson (2001) argued that the use of promotions to reward workers for performance has advantages over monetary bonuses when performance assessment is delegated to managers whose private goals might not be perfectly in line with the interests of the principal, i.e. the owner of the firm. This is often the case in large firms. Managers might misallocate bonuses, because they do not care about the firm's long-term reputation of rewarding workers adequately for performance. As a result, supervisors might act on favoritism rather than on the firm's objectives (see Prendergast and Topel, 1996). Such behavior biases performance assessment and distorts the incentive structure of the reward system. However, when performance is rewarded only upon promotion to better paying jobs involving different tasks, alignment of the supervisor's and the firm's interest can be achieved if the supervisor's compensation depends on the productivity of his division. In that case, he has an incentive to report performance objectively; for dishonest assessment leads to the promotion of a less productive worker, which has negative repercussions on group output and, hence, on his pay. However, the simultaneous use of promotions for incentive provision

\footnotetext{
"Carmichael (1989) discusses further developments of this line of research.

27 There has been substantial development in tournament theory, especially in contest design. Sea, for exmple, Moldowanu and Sela (2001).
} 
and job assignment triggers a distortion known as the Peter Principle. The term Peter Principle goes back to the account of Peter and Hull (1969), who argued that workers are promoted to their level of incompetence. Fairburn and Malcomson show that the Peter Principle becomes a relevant concern if workers are risk-averse. The firm then has to consciously assign some workers to higher job levels in order to provide sufficient incentives for effort provision although these workers would be more productive on the lower level. Using promotions as a mechanisms for the provision of incentives presupposes a hierarchical internal organization of firms, in which positions are grouped on different job levels. The next section scrutinizes the literature on internal organization and illuminates some explanations for a hierarchical job structure.

\subsection{Internal Organization}

\subsubsection{Hierarchies and Firm Size}

Although most early contributions to the literature on the internal organization of firms take a hierarchy structure as given, these models yield important insights into the wage structure and the distribution of talent across the hierarchy. But initially the focus of these models was on the relationship between optimal firm size and coordination costs, an old dispute in the economics literature. ${ }^{28}$ Williamson (1967) proposed a formal model in which loss of control across successive hierarchical levels limits firm size. Loss of control arises because at all levels because compliance with supervisor's intentions is not perfect. Williamson assumes that the number of employees a supervisor can manage effectively - termed span of control in the literature - is fixed. The hierarchical organization results from a recursive production technology, in which the final good is only produced on the lowest hierarchical level. Employees on higher levels engage in administrative activities and supervision. The firm has to optimize the number of hierarchical levels to trade off the volume of supervisors' intentions that is processed through the hierarchy and the cumulative loss of productivity that occurs because compliance with supervisors" objectives is not perfect. This trade-off limits the number of hierarchical levels and ultimately, due to a fixed span of control,

\footnotetext{
${ }^{28}$ Many economists had focused on the question raised by Coase "[... whether it is possible to study the forces which determine the size of the firm" (Coase, 1937, p. 393). Among other economists, Robinson (1934) and Kaldor (1934) had disputed the effects of coordination costs on optimal firm size even before Coase's article on "The Nature of the Firm" wass published in 1937.
} 
firm size. Calvo and Wellisz (1978) pointed out that Williamson's limits-tofirm-size result depends on features of the supervision process. ${ }^{29}$ Moreover, they endogenize the span of control and provide a rationale for hierarchical wage differentials, but assume that the number of hierarchical levels is fixed.

Lucas (1978) added another aspect to the debate, namely an individ«al's coordinating ability. He argues that better coordinators become entrepreneurs who employ the others as workers. Calvo and Wellisz (1979) and Rosen (1982) analyzed the implications of such worker heterogeneity for the allocation of labor in hierarchies, for the span of control and for the distribution of rewards. Their models conclude that the quality and wage per effective laborer increases with his hierarchical position. ${ }^{30}$ This is because decisions made at top levels have multiplicative effects on productivity in lower ranks.

In addition, jobs in higher hierarchical positions typically require more talented workers as tasks are more complex or involve more responsibility. Knowledge about workers' talents and skills is thus crucial to allocate them to the right positions. Prescott and Visscher (1980) claim that the accumulation of information about employee and task characteristics provides a reason for the existence of firms. The accumulated stock of information, for example, the firm's knowledge of worker ability and team composition, is an asset to the firm that affects productivity. This asset, which they named "organization capital", is specific to the organization and only created within the bounds of the firm. Another form of organization capital is workers' knowledge of the functioning of organization. Organization-specific knowledge or organization culture is transferred from one generation to the next.

\subsubsection{Knowledge, Information, and Coordination}

The transmission of information also becomes an essential problem in the day-to-day production of output when relevant knowledge within the organization is disparate and specialized. Issues related to the optimal design of a mechanism for the acquisition and transmission of such knowledge lead to an explanation of the hierarchical organization of firms. A trade-off exists between specialization of knowledge and communication. Keren and Levhari (1979) modelled the firm as a communication network. They redirected attention to the implications of coordination costs on internal organization and

${ }^{29}$ Mirrlees (1976) had challenged the limit-to-firm-size conclusion before. Prescott and Visscher (1980) argued that the cost of expanding organization capital - the information stock specific to the firm and its workforce - Jimits the firm's growth rate.

30 Simon (1957) had initiated the study of hierarchical organizations to shed light on the relation between the skewness of the income distribution and internal firm arrangements. 
offered an explanation why the firm creates a supervision system (see also Keren and Levhari, 1983). They assume a hierarchical organization of the firm, in which agents at each level communicate with the same number of subordinates, and show how the firm chooses the optimal number of hierarchical levels for a fixed workforce. Whereas they still restrict their analysis to the same pyramidal organization as assumed in models discussed in the previous section, a more recent literature extends this research to more general forms of internal organization.

Bolton and Dewatripont (1994) showed how firms can minimize costs of processing and communicating information. Agents in their model specialize in the processing of particular types of information. They illustrate that the design of an efficient communication network involves the trade-off between specialization and coordination and requires that the number of communication links between agents cannot be reduced without affecting performance, while the average number of agents through which a piece of information must percolate is minimized. They argue that efficient networks are pyramidal and that each agent in an efficient network has at most one direct supervisor.

Garicano (2000) focused on the organization of the acquisition of specialized knowledge when matching problems with problem solvers is costly. Workers specialize either in production or in solving problems in such a way that workers learn how to solve common problems, while supervisors deal with exceptional problems. Those in higher hierarchical positions focus on more and more exceptional problems. Garicano shows that the organization. has a pyramidal structure in which information flows from supervisors to subordinates as this limits communication costs. How the staffing and optimal allocation of workers inside organizations with a pyramidal structure is achieved, is the subject of the following two sections.

\subsection{The Firm as an Institutional Labor Mar- ket}

Internal labor market theory as advocated by Doeringer and Piore (1971) holds that the internal organization of labor is governed by a set of rules and procedures. Internal labor markets create noncompeting groups, as institutional rules delineate who enters or exits, regulate movement within internal. labor markets and award members of internal labor markets certain rights concerning job security and career perspectives that outsiders cannot claim. That movement between the internal and external market takes place in dis- 
tinct jobs; is a key feature of internal labor markets according to Doeringer and Piore. These jobs - called ports of entry and exit - are at the boundary of the two different markets:

These two markets are interconnected, however, movement between them occurs at certain job classifications which constitute ports of entry and exit to and from the internal labor market. The remainder of jobs within the internal market are filled by promotion or transfer of workers who have already gained entry. Conscquently, these jobs are shielded from the direct influence of competitive forces in the external market" (Doeringer and Piore, 1971, p.2; emphasis added)

The concept of internal labor markets is for that reason related to the theory of segmented labor markets and especially to dual labor market theory, which distinguishes between jobs in a primary and in a secondary labor market. Jobs in the secondary labor market segment are characterized by intense competition and are relatively unattractive. Workers prefer employment in the primary sector where wages are higher and working conditions are better. Jobs in large firms or internal labor markets are commonly primary sector jobs.

Doeringer and Piore portray facets of an internal labor market and argue that internal labor markets originate because of skill-specificity, on-the-job training, and customary law. The first two elements are closely related, and it is useful to recapitulate these elements under the broader concept of relationship-specific investments. Section 2.3 .1 has already addressed potential hold-ups and the kind of contractual enforcement problems that arise in the presence of specific knowledge and skills because of opportunistic behavior. Such transaction costs give rise to internal labor markets. Williamson, Wachter and Harris (1975) illustrated how formal rules help restraining the need for ex-post bargaining. This is achieved, for example, by attaching wages to jobs and setting up promotion perspectives to create incentives, or by establishing implicit contracts. The formal rule structure emphasized in the institutional approach to labor markets substitutes for a complicated set of written contractual agreements.

While the transaction cost perspective (Williamson, 1975) emphasizes the avoidance of inefficient "opportunism" and hold-ups as a reason for the existence of internal labor markets, which are characterized by long-term attachments between workers and firms, Doeringer and Piore stress costs of generating skills and benefits from reduced turnover in their explanation for the origin of firm internal labor markets. They reason that internal markets can achieve hiring, screening, and training more efficiently relying on 
internal recruitment, screening, and a job design that fosters learning and skill accumulation. In addition, they state that firms can reduce turnover and so increase the returns from specific investments. In particular, they claim that custom, "an unwritten set of rules based largely upon past practice or precedent" (Doeringer and Piore, 1971, p.23), sustains employment stability. Custom constitutes implicit agreements that characterize relational contracts.

An essential part of the formal rule structure in an internal labor market, as described by Doeringer and Piore (1971), is the definition of jobs and job ladders. The allocation of workers to jobs is realized by internal mobility or external hiring. In a closed internal labor market, hiring from the external labor market occurs only into distinct jobs, whereas all other jobs are staffed by assigning (i.e. promoting, demoting or transferring laterally) incumbent employees to vacant job positions. A vacancy chain is initiated when a vacant position is filled by an internal transfer, for it creates a new vacancy, and so forth. The chain ends when the most recent vacancy is either filled by hiring from the external market or is not filled at all. Such staffing actions shape individual mobility within the firm. ${ }^{31}$

\subsection{Job Ladders and Assignment}

Staffing policies in which workers climb job ladders in a hierarchical internal organization evolve because higher level jobs often require specific knowledge and skills that can only be acquired on lower ranks of the hierarchy. The assignment of a worker to a different position, which initiates career mobility, occurs only when the candidate satisfies the knowledge and skill requirements for the new position. At the same time, the firm bases its staffing decision on a judgement of relative capabilities of potential job candidates. In other words, the firm has to determine which worker is best suited for a particular job..$^{32}$

A large literature, which is not confined to an internal labor market context, has studied the problem of assigning heterogeneous workers with distinct skills and inherent characteristics to heterogeneous jobs that require different competencies (e.g. Rosen, 1982). This literature, which is reviewed

\footnotetext{
${ }^{31}$ See White (1970) for theoretical models and Pinfield (1995) for a discussion and an empirical assessment.

${ }^{32}$ The job has also become a key concept in personnel economics (see Lazear, 1992, for example). This is evident by the substantial body of the theoretical literature, surveyed by Gibbons and Waldman (1999b), that focuses on job ladders, career movements, promotions, and their relation to compensation. A thorough discussion of compensation during employment relationships is postponed to section 2.7 .
} 
by Sattinger (1993), commonly treats static assignment problems and distinguishes between comparative and absolute advantage as the driving force for job assignment (e.g. Sattinger, 1975). Job assignment becomes a dynamic challenge, and hence a source of job mobility, when true worker characteristics - or perceived characteristics in uncertain environments - change. This happens, for example, when workers accumulate skills during their labor market career, or when their talents are only revealed in employment relationships.

A prominent view of careers holds that workers climb an occupational ladder, on which they move from simpler tasks to more complex and difficult jobs on higher rungs, as they become more experienced. Rosen (1972) concentrates on the implications of learning from working experiences for occupational mobility. At the center of his argument is that alternative jobs offer different learning opportunities. Workers are willing to pay for these opportunities in terms of lower current wages, i.e. accept lower wages the more valuable knowledge can be accumulated, because learning enhances their marketable skills and hence their future income. Market prices, i.e. equilibrium wage differences, for jobs that offer different rates of skill accumulation are determined by supply and demand. Since workers have finite careers, retums to further investments in skills decrease - even if on-the-job learning capacity of workers remains constant - because of the shorter period over which returns to higher skills can be amortized. When, as a result, a worker's investment costs in a particular job fall below returns, he switches to a job that offers less learning opportunities but a higher wage. Returns to skill enhancing investments are, therefore, (partly) realized by changing work activities.

The notion of skill enhancement on-the-job is also central to Sicherman and Galor's (1990) model of planned careers. Jobs on an occupational ladder differ in required levels and types of human capital. Different types of firms, that can be ranked according to productivity requirements, offer two occupations each. Workers' careers advance either if they are promoted internally to the higher-level job or if they quit to work in the same occupation at a higher ranked firm. A final decision on intrafirm promotion is made by the employer after a specified period of time. The probability of intrafirm promotion rises with higher levels of schooling, ability, and job experience. If an employee is promoted, he works in the higher-level job until he quits to take a higher-level job in a higher ranked firm. If promotion is denied, the worker either stays in the job or quits for the same job in another firm of the same type, hoping to be promoted after the pre-specified working period. The optimal quitting time of promoted workers depends on mobility costs and the degree of skill transferability since only a fraction of skills acquired in the current firm is useful in firms of a different type. 
The transferability of skills pllays a crucial role when one job serves as a stepping stone for a more complex job on a career ladder. Jovanovic and Nyarko (1997) showed formally that stepping-stone mobility requires a minimum correlation between knowledge needed in adjacent rungs of the job ladder. Their stepping stone model centers on the assumption that experience obtained in one activity helps to avoid mistakes in a related activity. Occupational mobility takes the form of switching from a starting activity, in which foregone output associated with mistakes is small, to more risky jobs, once sufficient related experience has been gained. Job mobility is hence driven by learning how to perform a task and how to avoid mistakes. Expertise, rather than innate absolute or comparative advantage to perform particular tasks, initiates occupational mobility.

Learning about different worker talents is at the root of an alternative model, which Jovanovic and Nyarko refer to as the bandit model. In this model, young workers move from a risky occupation to a less risky occupation. New entrants to the labor market face greater uncertainty about their talents. Hoping that they come from the right tail of the ability distribution they are optimistic about being successful in the risky occupation and begin their career there. Subsequently, they switch to the less risky task when they find out that they are not talented enough to thrive in the risky task. Bandit models imply job-shopping (Johnson, 1978) and can explain why young workers initially try jobs in which the success rate is low. ${ }^{33}$ Empirical studies suggest evidence for both forces to be relevant. While Keane and Wolpin (1997) and Neal (1999) suggested that skill transferability affects mobility; Murnane, Levy and Willett (1995) and Altonji and Pierret (2001) found that wages are increasingly determined by cognitive skills as people spend time in the labor market.

Consequently, we should conclude that acquiring expertise and learning about innate ability are both important forces in employment relationships. Lateral job mobility, also known as job rotation, can serve as a means to promote both. ${ }^{34}$ If tasks on a higher rung of the job ladder require, for example, expertise in different areas, which can be acquired in different activities on the lower job level, workers are rotated to different jobs on the same levels to

\footnotetext{
${ }^{33}$ Miller's (1984) model of occupational choice is related to Johnson's (1978) argument. Its basic idea can be cast in terms of a multi-period Roy (1951) model with two occupations. Workers only know the joint population distribution of productivity in clifferent jobs, but not the realization of their draw. They learn about their productivity in the job in which they start infer their expected productivity in the other job from knowledge of variance matrix of the joint distribution, and base their job change decision on that.

${ }^{34}$ Worker motivation has been proposed as another reason for job rotation in the management literature.
} 
prepare them for upward mobility. Developing expertise is also the motive for job rotation if there are diminishing returns to learning in the same job.

Another motive for job rotation is employer learning about workers' abilities. Ortega (2001) stressed this aspect of job rotation. He illustrates that job rotation is preferred to specialization, and that the gains from job rotation are higher the greater the initial uncertainty about employees' abilities is. Assigning a worker to different tasks (or teams) generates more different signals about a worker's type. But since the employee is engaged in a particular activity for a shorter period, the firm obtains fewer information signals on productivity in the same job. Firms have to trade off the number of signals on a single job against the variety of signals in different jobs (Meyer, 1994).

Learning about talents, gaiming expertise and acquiring productivity enhancing skills during employment are key elements of the model of internal labor market careers developed in chapter 7 and of modern models of careers that are portrayed in section 2.9. Before discussing these modern accounts, the next section considers the implications of the various aspects of the employment relationship, that have been discussed so far, for life cycle earnings profiles.

\subsection{Compensation and the Employment Re- lationship}

Since wages depend both on personal traits of workers and job characteristics in job assignment models, which match talents to jobs (see e.g. Sattinger, 1975; and Rosen, 1982), career earnings are closely related to job mobility. ${ }^{35}$ Internal job mobility seerns to be especially important because much of a worker's career wage growth builds up during an employment relationship with a single firm.

As both job and personal characteristics determine wages, the approach can be viewed as a hybrid approach of the two polar cases that the literature surveyed in the previous sections suggests: On the one hand, the neoclassical labor market model, in which wages equal marginal productivity and reflect individual characteristics, and, on the other hand, the institutional view in which wage setting is governed by formal rules. According to internal labor market theory, as advocated by Doeringer and Piore (1971), job change is the source of wage growth when wages are attached to jobs. Job ladders,

\footnotetext{
35Theulings (1995) illustrates how the assignment of skills to jobs affects the wage distri-
bution.
} 
vacancy chains and staffing actions (Pinfield, 1995) govern earnings dynamics of workers. Consecuently, individual skill and productivity matter only to the extent that they promote assignment to a particular job with a fixed wage attached to it.

In the neoclassical view, which is strongly associated witli work on the human capital model of earnings by Becker $(1962,1964)$, Mincer $(1958,1962$, 1974), and Schultz $(1960,1961)$, life cycle earnings profiles reflect changes in individual productivity during the labor market career. The return to experience and job tenure is central in this approach. Theoretical treatments by Ben-Porath (1967) and Mincer (1974) suggest a life cycle log-earnings profile that is increasing and concave in experience, because investment in general human capital is positive but decreasing over the life cycle. Therefore, Mincer (1974) suggested to use the following relation between earnings and experience to estimate the returns to general human capital:

$$
\ln (W)=\beta_{0}+\beta_{1} E D U+\beta_{2} E X P+\beta_{3} E X P^{2}+\epsilon,
$$

where $W$ denotes the wage rate, $E D U$ years of education, $E X P$ represents years of labor market experience, and $\epsilon$ captures a random error.

By analogy to Mincer's suggestion of using labor market experience to proxy the accumulation of general skills, the dominant empirical strategy to test for the relevance of firm-specific capital has been the estimation of an augmented version of equation (2.1):

$$
\ln (W)=\beta_{0}+\beta_{1} E D U+\beta_{2} E X P+\beta_{3} E X P^{2}+\beta_{4} T E N+\beta_{5} T E N^{2}+\epsilon,
$$

where TEN measures years of firm-specific tenure. This analogy is flawed even if firm-specific tenure proxies the accumulation of firm-specific capital because a tight theoretical link between tenure and accumulated specific capital lacks. ${ }^{36}$ The wage rate is indeterminate in the presence of specific capital. ${ }^{37}$ As argued above, the firm might use its wage policy to discourage quitting. In addition, search models suggest that workers who earn high wages are less likely to separate. Consequently, they have long tenure, so

\footnotetext{
${ }^{36}$ See also Farber (1999) for a discussion of this point.

${ }^{37}$ Another problem with the approach is that investments in specific human capital might not decrease over time during an employment relation. Moreover, even if the conditions that give rise to Hashimoto's 1981 sharing rule prevail, the estimated tenure-wage profile only reflects a share of the returns on the investment equaling the share of the investment costs born by the worker. It is, therefore, problematic to use the tenure-wage profile to infer the size of specific investments or the return to such investment, without knowledge about the worker's share in the cost of the investment.
} 
that firm-tenure is endogenous to wage determination. In addition, confounding unobserved characteristics, which prolong tenure and raise wages, might bias coefficients of OLS estimations of equation (2.2) upward. Nevertheless, equation (2.2) has often been estimated by OLS, and typically estimates that imply a return of 2 percent per year of tenure, were obtained.

Abraham and Farber (1987) and Altonji and Shakotko (1987) challenged the finding of such substantial returns to firm-specific seniority (tenure) and initiated a heated debate that centered on econometric disputes. Controlling for the spurious relation between job tenure and wages by instrumenting for tenure (Abraham and Farber, 1987) or by including the actual length. of completed job spells and the expected length of uncompleted job spells as proxies for match quality (Altonji and Shakotko, 1987) in the regression, their estimates for the effect of tenure on wages were close to zero. Employing yet a different method, Topel (1991) challenged their conclusion and found substantially larger estimates, which are close to OLS-estimates. He thus revitalized the specific capital model. In an attempt to explain differences between the estimates of Altonji and Shakotko (1987) and Topel (1991), Altonji and Williams (1997) revived the discussion. They concluded that wages grow with seniority, but that the return to job tenure plays only a modest role in wage determination ( 1 percent per year). The general conclusion to be drawn from almost two decades of debate is that empirical findings are very sensitive to the estimation technique, the wage measures used, and the instruments employed. How much wages rise with tenure remains an open question.

Other mechanisms - beyond the human capital explanation - have been proposed that cause wages to grow with firm-specific tenure or labor market experience without invoking a strong link between wages and contemporaneous productivity. In the following discussion of such models, I typify three different justifications for upward sloping life cycle earnings profiles: (1) the sorting explanation, (2) the matching explanation, and (3) the incentive explanation.

The sorting explanation rests on the iclea that agents with certain characteristics self-select into particular jobs. Salop and Salop (1976), for example, propose a mechanism that repels workers with high turnover intentions. The firm offers a tilted wage schedule with low wages in the beginning of the $\mathrm{em}$ ployment relationship. Accepting such a compensation scheme is worthwhile only if the employment relationship lasts sufficiently long. The sorting argument is relevant for other settings. For example, if employers are initially asymmetrically informed about the productivity of new hires, they can design their wage and firing policies to attract high-ability workers. To do so, the firm sets starting wages below the expected level of marginal productiv- 
ity. When true productivity is revealed, the firm fires workers whose ability turns out to be below a predetermined cut-off value, and it raises wages for retained workers above their marginal productivity to compensate them for lower wages early in the employment relationship.

Another kind of sorting derives from search for better jobs as in Burdett's (1978) model. Workers receive offers that pay a fixed wage until separation from the job. The probability that a worker holds a high-wage job rises with time spent searching. Burdett considers search across different firms in the economy, so that his model predicts an upward sloping experiencewage profile. But the idea is more general and also applies to job mobility in internal labor markets. Upward-sloping tenure-wage profiles thus result because the probability of having been assigned to a better job rises with time spent in the firm..$^{38}$ A related mechanism is suggested by Jovanovic's (1979a) matching approach, in which information about the quality of a job match is only gradually revealed. If firms adjust wages to expected productivity, wages rise on average because good matches have a higher survival probability. Note that upward sloping tenure-wage profiles result from changes in expectation, not from changes in true productivity in Jovanovic's model.

This is also true for learning models in which firms and/or workers obtain information about individual productivity over time. Learning about workers' talents often triggers wage changes and might lead to reassignment of workers to different jobs. Harris and Holmstrom (1982) constructed a model in which risk-averse workers and risk-neutral firms learn symmetrically about a worker's value by observing noisy signals about his true productivity. Wages of long-term implicit labor contracts never decrease over time under these conditions, but increase if the worker's market value rises above the current wage. Since information is common knowledge, high output, realizations raise the market wage, which the firm then matches by bidding up its initial contract wage offer. Downward rigidity stems from the insurance motive to avoid wage variation, which is due to random fluctuation of perceived productivity. Wages rise with experience for two reasons: First, the probability that sufficient positive information has accumulated, so that wages are bid up, rises with time spent in the labor markets. Second, the insurance premium, which must be paid by the worker because he cannot commit to staying with the firm, falls as the worker ages and approaches retirement. Earnings rise when the insurance premium falls. ${ }^{39}$

\footnotetext{
${ }^{38}$ Many large companies solicit applications from their incumbent workforce for internal vacancies and encourage their employees to change jobs within the firm after regular time intervals.

${ }^{39}$ Freeman (1977) had initiflly suggested the learning and insurance argument in a twoperiod model in which he derived clownward rigid wages in the second period. As in Harris
} 
Waldman (1984b) analyzed wage dynamics with asymmetric leaming. In his two-period model with two jobs, only the current firm receives an signal that informs about a worker's productivity after the first period. However, some information concerning the worker's productivity is revealed to the market by job assignment in the second period when it is observed by all firms. Since the expectation of ability conditional on promotion is higher than the unconditional expectation of ability, the market bids up a worker's wage accordingly. Waldman's asymmetric information setup produces inefficient assignments since firms avert large wage increases of promoted workers. Bermhardt and Scoones (1993) built on Waldman's insight and showed that preemptive wage offers raise earnings upon promotion when competing firms can learn about a worker's ability at a cost. Lifetime earnings of workers depend on the cost which competing firms have to incur to acquire information about the productivity of potential managers. An increase in these costs lowers competition for workers in the second period, so that fewer workers will be poached by competing firms in the second period. Lifetime earnings of all workers rise because their first period wage is increased. This is because ex ante rents of a new match are higher if the probability falls that the workers is poached away. Bernhardt (1995) showed that Waldman's result of strategic promotions continuous to hold in a multi-period model and explains the existence of promotion fast-tracks. These are in part a consequence of the informational content of the first promotion to job 2 . Since the market has already positive believes about the worker after the first promotion, the costs from sending the signal of a second promotion to the market is lower.

The latter point has been stressed by Pencavel (1972) and can be interpreted as an incentive explanation for upward sloping tenure-wage profiles. Attempts to design wage schedules that promote optimal levels of investment in specific capital in the presence of potential hold-up problems can be similarly characterized (see the discussion of models by Carmichael, 1983, and Prendergast, 1993a, in section 2.3.3). However, the incentive explanation is commonly connoted with wage structures designed to induce desirable effort levels throughout the employment relationship. Prominent examples are Becker and Stigler (1974) and Lazear (1979). Their proposal of bonding schemes with deferred compensation, which result in upward sloping experience-earnings profiles, to motivate workers has been scrutinized in section 2.3.3. This section has also discussed toumament models (e.g. Lazear and Rosen, 1981), in which upward sloping earnings profiles result on average and Holmstrom (1982), wages of workers, who are revealed to be of high ability after the
first period rise since workers cannot commit to staying with the firm if competitors offer
lnigher wages. 
because the firm attaches higher wages to scarce jobs on higher hierarchical positions. This creates incentives to work hard as those who perform best, the winners of the tournament, are promoted to higher job levels and are rewarded by higher wages.

Given the variety of mechanisms that generate rising experience-earnings profiles, it is not surprising that the question of whether experience-earnings profiles reflect contemporaneous productivity growth or institutional arrangements, which Mincer (1974) raised almost three decades ago, is still debated. Medoff and Abraham $(1980,1981)$ try to find an answer empirically, using personnel data from three different large US firms. Their strategy is to test whether a statistically significant positive correlation between wage growth and experience exists that is not explained by productivity. Their argument is based on the assumption that performance evaluation scores truly reflect contemporaneous productivity. They first establish that a positive relation between wages and experience exists, and then claim that this relation is not explained by higher productivity of more experienced workers as the estimated effect of experience on wages is independent of controls for performance rankings. This indirect testing strategy is rather fragile. For example, the test breaks down if performance ratings also reflect a supervisor's assessment of future potential, or if more experienced workers are assigned to more difficult tasks in the same job because they are more productive while the performance rating is task-specific, i.e. indicates only how well a worker carries out a particular task. If one believes Medoff and Abraham's critical assumption about what the performance indicator really measures, their result should be strictly speaking not only be interpreted to reject the human capital model, but also sorting and matching models, in which wages grow because perceived productivity of retained workers rises.

In contrast, Brown (1989) concludes that within-firm wage growth is mainly determined by contemporaneous productivity improvements. This conclusion rests on the empirical finding, based on the Michigan Panel Survey of Income Dynamics (PSID), that wage growth almost exclusively occurs during periods of on-the-job training. The amount of on-the-job training is inferred from a survey question that asks how long it would take an average new person to become fully trained and qualified on the current job. ${ }^{40}$ Based on the answer to this question and information on a person's tenure, it can be deduced whether a person is currently becoming fully trained or whether the training period has already ended. Brown's empirical strategy is then

\footnotetext{
${ }^{40}$ This question was only asked in the 1976 and 1978 waves so that the sample is selected on the condition that respondents to the interviews in later waves remain in the same position that they held when they answered the question in 1976 or 1978.
} 
to estimate whether wage growth is higher during the average training period than thereafter. His regression results are mixed. Training has only a very small impact on wages for workers with pre-entry training requirements or prior experience. But the effect of training on wage growth is strong for workers without other training requirements and prior experience. Again, the test, whether wage growth mirrors productivity growth, is indirect because productivity is not measured.

\subsection{Empirical Studies of Internal Labor Mar- kets}

Empirical studies of the economic organization of labor in firms based on firm-level micro data had been rare until recently. Early exceptions include Osterman (1979) and Medoff and Abraham (1980, 1981). This scarcity was largely due to lack of access to firms' personnel records. Most data sets that have lately become available are from firms based outside the U.S.: Ariga, Ohkusa and Brunello (1999) investigate promotion fast-tracks in a Japanese manufacturing firm. Seltzer and Merrett (2000) analyze the records of a large Australian bank; Flabbi and Ichino (2001) study data of an Italian bank, and Treble et al. (2001) those of a British financial institution. Lima (2000) has a data set on a Portuguese firm, and Lin (2002) has personnel records from a Taiwanese automobile sales and maintenance company. The important impetus for this contemporary body of empirical studies had come from research on U.S. data by Lazear (1992) and especially by Baker, Gibbs and Holmstrom (1994a, 1994b).

Lazear (1992) examines a panel of 13 end-of-the-year snapshots of personnel data from a major American corporation to shed light on the role of jobs. He finds that wages are related to jobs, that job change is key to wage growth, and that the hazard of intrafirm job mobility decreases with job tenure. There is also evidence that promotion probabilities are higher in some jobs than in others.

Baker, Gibbs and Holmstrom (1994a, 1994b) analyze a panel of yearend personnel data of management employees from a large U.S. company, which expands employment during the observation period of twenty years. The firm's simple hierarchical structure, which they infer from the pattern of job transitions, remains stable throughout the expansion. Workers perform various jobs in their career. Job mobility is almost exclusively to higher levels of the hierarchy and shaped by the existence of career paths and promotion fast-tracks. They do not find evidence for distinct ports of entry and exit, as 
described in Doeringer and Piore's account. Yet they claim that workers are partly shielded from conditions in the external labor market. While starting wages respond to market-induced variation in marginal product, there are strong cohort effects, meaning that gaps in starting wages between workers entering in different years persist. This indicates that wages are not solely determined by contemporaneous productivity. Interestingly, nominal wages seem to be downward rigid, bit that is not true for real wages.

Baker, Giblss and Holmstrom (BGH hereafter) encounter a strong relation between job levels and pay, so that promotions secure sustained wage growth. Still, wage growth upon promotion is small relative to the difference in average wages of adjacent job levels because substantial wage variation remains within hierarchical job levels, meaning that wages are not strictly attached to jobs. They report that promotions come from and go to all deciles of the wage distributions for the lower and upper levels. Yet, they come predominately from the higher end of the lower level's wage distribution and go to the lower end of the higher level's wage distribution. Another important finding is serial correlation in wage growth and the fact that wage growth forecasts promotions. Moreover, firm-specific capital does not seem to play an important role in their case study because external hires do not differ much from incumbent workers who were promoted to the same job. But formal rules and procedures seem important. Wage raises, for example, depend on the level of current wages, which suggests an administrative wage policy.

The firm's wage policy is studied in more depth in their companion paper (BGH, 1994b). They find that the serial correlation in wage growth cannot be attributed to worker heterogeneity on observable characteristics since wage residuals from regressions that control for observable differences remain positively correlated. ${ }^{41}$ They interpret this evidence to suggest that a latent variable, such as ability, drives wage growth. However, real wages are not downward rigid, which contradicts Harris and Holmstrom's (1982) learning model, so that they conclude that neither human capital theory, nor learning theory, nor a stationary incentive model alone can explain the entire set of findings.

An array of aspects addressed by BGH have been re-assessed with data from different firms, operating in different industries, markets, and periods. Many of their results hold true in these different settings. All studies, as far as I am aware, report a hierarchical organization of firms. Upward job mobility is typically important, largely defined by career ladders, and much

\footnotetext{
${ }^{41}$ Chapter 6 shows how such a pattern can follow from a formal salary system that defines raises based on position and performance.
} 
larger than downward mobility. This does not mean that promotion follows automatically. In contrast, a majority of workers in the Australian bank that Seltzer and Merrett (2000) scrutinize is never promoted beyond the lowest level. Personnel records for these workers span almost six decades.

Ariga et al. (1999) focus on promotion dynamics in a high-tech Japanese manufacturing firm. They also report evidence for fast-tracks. But they claim that fast-tracks cannot be explained by fixed ability differences. This result suggests that a pure learning model (e.g. Farber and Gibbons, 1996) has to be augmented by other factors, like the accumulation of productivity enhancing human capital, which more than proportionately raise the productivity of fast-trackers.

Most studies, including Seltzer and Merrett (2000), Treble et al. (2001), Lima (2000), Gibbs and Hendricks (2001), and Lin (2002), find a strong relation between hierarchical job levels and wages, but generally report substantial within job level wage variation. Interestingly, Seltzer and Merrett (2000) find substantial wage growth late in the career, which, as they conjecture, results from a deferred compensation scheme with mandatory retirement. They maintain that implicit and explicit rules govern pay and promotion dynamics.

Evidence in conflict with BGH is reported as well. Seltzer and Merrett (2000) do, for example, find evidence for limited ports of entry analyzing careers of 950 workers ascending to the Union Bank of Australia between 1887 and 1900. Yet, they claim that the firm's wage policy also shields workers from external labor market conditions throughout their career.

Gibbs and Hendricks (2001) explore whether a formal salary system has real effects. They argue that the salary rules impose substantial constraints on supervisors as they limit their discretion to award wage raises. They show that upward job mobility is crucial for sustained wage growth as the formal salary system defines wage ranges for jobs. ${ }^{42}$ Since the firm sticks to the rules of the system, workers at the top of the job wage range can enjoy wage raises only when they advance to jobs with a higher wage range. ${ }^{43}$

Van Veen (1997) focuses on impact of a formal rule structure on the allocation of labor in a Dutch manufacturing company. The rule system affects job mobility and the wage structure. Analyzing the stability of the

4Mc Cue (1996) claims that intrafirm job mobility accounts for less than $20 \%$ of an average worker's life cycle wage growth. Her enpirical evidence is based on the Michigan Panel Survey of Income Dynamics (PSID) rather than on firm-level data. It is probable that data problems render these results less reliable than warranted.

long tenure have wages the $5 \%$ of recently hired workers and about $4 \%$ of workers with construction of at panel data set withe range, but attribute this to errors arising from the 
system of rules over a 15 year period, he finds, however, that the rule structure is changed in response to structural adjustments within the organization. ${ }^{4}$ These changes have strong effects on career outcomes of workers. Van Veen argues that the system of rules is instable because it reflects a compromise between conflicting goals of the organization.

Given the case study character of this line of research and the fact that the few available personnel data sets from different countries and industries are collected in different ways and have sometimes different variable definitions, Gibbons (1997) suggested that, "[i]t would be a great service if empirical researchers would provide evidence on a core set of questions before studying specific issues of their own." (Gibbons, 1997, p. 21). He proposes, largely influenced by the research agenda and findings of Medoff and Abrallam (1980, 1981) and BGH (1994a, 1994b), ten core questions that should be addressed: (1) is there a fast track?, (2) are nominal wage cuts rare?, (3) are changes in wage residuals serially correlated?, (4) are there cohort effects in wages?, (5) are wage increases upon promotion large compared to normal increases but small compared to the difference in average wage between the two levels?, (6) do wage increases forecast promotions?, (7) do promotions come from and go to all deciles of the wage distributions for the lower and upper levels?, (8) are wage increases smaller for those who begin in higher quartiles of the wage distribution for that level?, (9) do wages increase and are promotions more likely with higher performance evaluations (both in cross-section and in time-series?, and (10) is the effect of seniority on wages independent of the presence of controls for performance evaluation?

BGH answer the first eight questions affirmatively, while Medoff and Abraham find evidence in favor of the last two questions. A contemporary study by Gibbs and Hendricks (2001) provides evidence in favor of all questions. Unfortunately, no other study addresses questions 3 and 6 . Evidence for fast tracks (question 1) is also found by Ariga, Ohkusa and Brunello (1999), Seltzer and Merrett (2000), Treble et al. (2001), Lima (2000), and Lin (2002). All of them also - except for Treble et al. (2001) who do not address this question - report that nominal wage cuts are rare (question 2). Cohort effects (question 4) are found by Kwon (2001). All studies that I am aware of find that wage increases upon promotion are large compared to normal increases but small compared to the difference in average wage between the 2 levels (question 5). Treble et al. (2001) and Kwon (2001) find affirmative evidence for questions 7 and 8 . Seltzer and Merrett (2000), Kwon

\footnotetext{
${ }^{4} \mathrm{~A}$ major structural change at the plant studied is the employment expansion from about 400 employees in 1983 to more than 900 employees in 1992, while employment at the company level shrinks considerably wing the same period.
} 
(2001), and Lin (2002) also claim that promotions become more likely with higher performance evaluations. Finally, Lin (2002) suggests that the effect of seniority on wages is independent of controls for performance evaluations.

This collage of evidence that has emerged from the recent empirical literature on the internal workings of firms has renewed the interest in building models of careers in organizations that are consistent with the entire set of stylized facts. Models that intend to explain the broad pattern of evidence about careers in organizations have been built only just, and are especially inspired by the empirical findings of Baker, Gibbs and Holmstrom (1994a, 1994b). These theoretical approaches are reviewed in the next section.

\subsection{Careers in Internal Labor Markets}

Although theoretical work has advanced our knowledge about numerous aspects of the employment relation - including the acquisition of human capital, the consequences of contractual difficulties, incentive problems, the internal organization of labor in firms and the assignment of workers to jobs (see sections $2.3-2.7$ ) - no single approach alone can account for all empirically observed phenomena and stylized facts that have crystallized in the modern empirical literature discussed in the previous section. Joining together these different concepts - thereby profiting from important breakthroughs in various strands of the literature (e.g. in human capital theory by Becker, 1962 and 1964, and Mincer, 1962; in agency theory by Mirrlees, 1976, Holmstrom, 1979, Holmstrom and Milgrom, 1991, and Baker, 1992; in contract theory by Bull, 1987, MacLeod and Malcomson, 1989, and 1998; in job assignment by Sattinger, 1975, or Rosen, 1982) - seems a promising route towards developing a single theoretical framework that is consistent with most of the evidence about careers in internal labor markets. Integration of concepts is also necessary since career assignments, reward structures, turnover, and incentives must be analyzed in the context of a personnel system (Rosen,
1988 ).

Theoretical contributions in this spirit by Demougin and Siow (1994), Bernhardt (1995), and Gibbons and Waldman (1999a) combine concepts from different strands of the literature and take advantage of significant breakthroughs in human capital theory. Demougin and Siow (1994) integrate training, screening, and job assignment to develop a model of career mobility, in which workers, who only live for two periods, can be assigned to two types of jobs: production and management. Only skilled workers can become managers. Since all workers enter the labor market unskilled, they all start in unskilled jobs. Unskilled and skilled workers are not perfect substi- 
tutes, so that the relative number of slots in different jobs is fixed. The firm can train the unskilled at some cost. Successfully trained workers qualify for positions in management and can be promoted internally. Alternatively, the firm can hire managers, but it then has to pay hiring costs, so that it might: be optimal for the firm to train at least some young workers. Depending on the success rate of training, the availability of training slots, and the relative scarcity of unskilled job slots, different regimes emerge: A fast-track regime materializes if there are sufficient unskilled job slots so that unsuccessful trainees can stay with the firm in the second period moving laterally from an unskilled training position to an unskilled job in production. An up-or-out regime results if unskilled slots are scarce. The firm then prefers to fill these slots with trainees because it thus saves on hiring costs for managers when it can promote successfully trained workers internally.

Since Demougin and Siow (1994) consider only a two period model, they cannot address a number of interesting empirical findings. For example, they cannot focus on the relative frequency of demotions, and more importantly, their model does not generate predictions about the timing of a second promotion. Bernhardt (1995) allows workers to be in the labor force for more periods. Bernhardt's model of strategic promotion combines the accumulation of specific and general skills on-the-job with firm learning about workers' abilities. As in Demougin and Siow's model, firms organize production on two hierarchical levels. More able workers enhance skills in a shorter period of time and have a comparative advantage in the higher level, which is referred to as management. The information structure is as in Waldman. (1984b), i.e. only employers observe productivity signals, whereas other firms can infer ability only from the history of wages and job assignments. Bernhardt argues that fast-tracks exist when there are three job levels. This is because the most able workers, i.e. those who have the best prospects to ever reach the highest level, are promoted early. In addition, their initial promotion sends a very positive signal to the market, which makes it less costly to promote them again - rather than late career movers - because the information entailed in the positive signal about their ability that is sent to the market at the second promotion is less valuable for competitors whose believes about early promoted workers' abilities are already very high.

Gibbons and Waldman (1999a) integrate learning, human capital acquisition, and job assignment in order to explain careers. There are no hiring and firing costs, no costs of reassignment, and no specific investments. Moreover, firms and workers are risk-neutral. Workers can be assigned to three different jobs that constitute a job ladder. The same type of output is produced in all jobs. A worker's output depends on his effective ability, which is determined as the product of his innate ability and his stock of general human capi- 
tal, which accumulates at a decreasing rate with labor market experience. Therefore, innate ability determines the rate of return to the stock of accumulated general human capital. Due to job technology differences - a crucial assumption of their model - effective ability is used with higher intensity, and is hence more valuable, in higher job levels. Since the amount of output that is produced independent of individual skills, i.e. worker's output that is produced when he is only present at the workplace, is higher in lower job levels, high-ability workers have a comparative advantage in high job levels. Since the relation between effective ability and productivity is stronger in higher job levels, the three different jobs map out a piece-wise linear convex productivity frontier that is increasing in effective ability. In each period, the wage rate equals the expected output.

Workers with low effective ability are assigned to the lowest job level, where productivity is least sensitive to worker characteristics. Inexperienced workers thus start their career on lower rungs. But as they acquire skills on-the-job, their effective ability rises during their labor market career, so that they will eventually proceed to a higher job level, i.e. to a steeper section of the productivity frontier. Their wages, therefore, jump somewhat at the promotion. Since workers keep on developing general skills, their wages continue to rise after the promotion. Wages would even rise at a higher rate than before the promotion since the marginal return to effective skills is higher on the higher job level. But this effect is thwarted because human capital is accumulated at decreasing rates.

High-ability workers improve their skills faster and are therefore promoted earlier during their labor market career. Since they also advance faster on the productivity frontier in a given job, their wages already increase at a faster rate prior to the promotion, so that wage growth predicts promotions. Fast-tracks exist, because the most able workers, who are the first to attain a level of effective ability that justifies the initial promotion, will also be the first to become more productive in the next higher level, because the rate of human capital accumulation is identical at any stage in the career of workers of the same cohort, only the effectiveness of experience, i.e. the rate of return, differs among cohort members. If there was certainty about workers' innate ability, which determines the rate of return to a given stock of human capital, no demotions occurred in equilibrium as all workers always become more productive. Uncertainty about ability is necessary to explain equilibrium demotions and real wage decreases. Therefore, Gibbons and Waldman assume that neither firms nor workers observe a worker's ability when he enters the labor market. But the worker and all firms learn symmetrically
about his innate ability as they receive noisy measures of output each period.
Unlike in Demougin and Siow's (1994) Unlike in Demougin and Siow's (1994) model, job slots are not limited 
in Gibbons and Waldman's analysis. Since workers are assigned to jobs according to their comparative advantage, a firm could in principle employ only workers in one particular job if its entire workforce has effective ability such that all workers have comparative advantage in that job. Therefore, Gibbons and Waldman' model is not particularly suited to address questions related to the structure and stability of the job hierarchy within a firm. Furthermore, they admit that their model cannot explain several aspects observed by Baker, Gibbs and Holmstrom (1994a and 1994b) including cohort effects, green-card effects, and nominal wage rigidity. They also explain that their model is not consistent with the findings of Medoff and Abraham (1980, 1981). A more serious problem with the model concerns turnover, as there is no mechanism that ties workers to firms. Although specific investments and long-term relationships are argued to characterize employment relationships (e.g. Farber 1999), their model of careers in organizations completely neglects these aspects. Like all the models on careers discussed in this section, they also abstract from incentive issues.

\subsection{Conclusion}

The division of labor is key to the economic advancement of today's western societies. Further degrees of specialization pose challenges to the organization of specialists in a team productive process. Much scientific effort has been devoted to understanding what forms of organization foster an optimal allocation of labor. In certain settings, firms represent a superior form of contracting between different input owners than markets. The organization of labor in firms is often associated with long-term employment relationships. Resulting relational contracts have a special nature, which bring about particular problems relating inter alia to enforcement problems, motivation costs, and transaction costs. Many characteristics of employment relationships have been studied in different areas of the economics literature.

Although a large theoretical literature has studied many distinct aspects of employment relationships and careers in internal labor markets, a coherent theoretical framework that is consistent with the reported empirical evidence growing out from an expanding but still tenuous set of studies is still to be developed. Lately, progress into that direction has been made by building models which integrate different theoretical concepts. This modeling approach is a promising route to follow. Especially integrating learning, human capital acquisition, and job assignment into one model seems worthwhile because the available empirical evidence about career mobility and wage dynamics suggests that all these factors are relevant. 
Despite much recent progress, some problems with modern models of careers in organizations remain. For example, Demougin and Siow (1994) cannot assess whether promotion fast-tracks exist and whether wage increases predict the speed of future promotions because their model only has two job ladders. Gibbons and Waldman (1999a) solve this issue in their model, but their model makes it difficult to generate predictions about turnover: as nothing ties workers to firms. In fact, firms play no role, because their boundaries are blurred. Their model with a collection of different jobs does not incorporate the effect of internal labor markets on individual careers, but rather describes worker mobility on a job ladder in an institution-free, competitive market setting. Therefore, their model falls short to explain phenomena like nominal rigidity or cohort effects.

At the same time there is need for further empirical evidence, because much of what we know derives from case studies. Although case studies have their advantages - they benefit, above all, from comprehensive and rich data that allow to precisely evaluate closely defined issues - they have a cost associated with them that generalizing from one case study is problematic as findings might be idiosyncratic. Repetition with different data sets and comparison of results is particularly important to filter out idiosyncrasy and determine what holds true in general. Further empirical work is particularly needed where different types of data have suggested contesting implications. This holds, for example, for an empirical analysis of the relation between productivity, performance, institutional factors and individual life cycle earnings profiles.

Chapters $4-6$ of this dissertation will add to the empirical literature on the functioning of internal labor markets, while 7 provides a theoretical account that is consistent with a collection of empirical findings and stylized facts. The model that is developed amalgamates different theoretical concepts, including human capital accumulation, learning, job assignment, and a hierarchical model with scale of operations effect, to analyze the impact. of corporate expansion and contraction on wage and promotion dynamics in an internal labor market. In addition, the framework is suitable to derive interesting propositions for the provision and timing of (firm-specific)
training. 
Chapter 3

The Firm and Its Personnel

Data 


\subsection{Introduction}

The empirical analysis of this dissertation profits from the availlability of rich personnel records from the Dutch national aircraft manufacturer N.V. Koninklijke Vliegtuigenfabriek Fokker (Fokker N.V.). These personnel data span the final years of the firm's proud and lively history from January 1 , 1987, when the firm introduced its electronic personnel system, until March 15, 1996, when the firm was officially declared bankrupt. The company's bankruptcy trustees granted access to the data for scientific use. This chapter describes the data and provides some valuable background information about the firm, which is largely obtained from the published report of the bankruptcy trustees that studies the causes of the bankruptcy (Deterink et al., 1997) and various other public reports of the trustees. ${ }^{1}$

Section 3.2 provides information about the firm's history predating the period for which its personnel data are available, thereby illustrating some peculiarities of the aircraft manufacturing market. Section 3.3 portrays the market conditions that the firm faced during the period for which the personnel data are analyzed in this dissertation. ${ }^{2}$ Section 3.4 describes the development of the workforce for the period from 1987 until the bankruptcy. Section 3.5 explains the personnel data in some detail.

\subsection{Some Historical Background of the Firm until 1987}

When Fokker N.V. filed for bankruptcy on March 15, 1996, it was the world's oldest existing aircraft manufacturer. The name of its founder, Anthony Fokker, did not appear in the firm's official name when it was incorporated as N.V. Nederlandsche Vliegtuigenfabriek on July 21, 1919. The reason was his inglorious past of designing military aircraft for the German air force in the German based Fokker Werke GmbH. The newly founded Dutch firm was to build commercial aircraft. Exploiting its advantage of an uncomplicated assembly procedure, Fokker soon became the world's largest aircraft manufacturer. However, paying too little attention to further technological advancement, it lost this position in the 1930s to Douglas, which had developed a modern, streamlined, all-metal aircraft, the DC-2. For some time, Fokker managed to compensate for its loss of market share for commercial

\footnotetext{
These reports are posted on the webpage http://www. fokkernl.com.

${ }^{2}$ More detailed historical information can be found in Deterink, Knüppe, Leuftink and Schimmelpenninck (1997) on which the description in sections 3.2 and 3.3 is largely based.
} 
aircraft by producing military aircraft, a market that was growing due to rearmament on the eve of the Second World War.

At the end of World War II, Fokker saw its factory destroyed by the Germans. But Fokker restarted soon thereafter, initially refitting DC- $3 \mathrm{~s}$, converting military aircraft into passenger aircraft and producing military aircraft under license. It was not until 1958 that Fokker that delivered an independently developed and constructed aircraft, the F27. This 40-52 seat passenger aircraft became a success; Fokker built 581 aircraft and Fairchild constructed an additional 205 under license until 1986. Its technologically advanced successor F28, the first jet engine with a capacity of 65-85 passengers, was less profitable. Although Fokker delivered 241 F28s between 1969 and 1986 , the development loan was not yet repaid when production of the F28 was stopped.

This brief sketch of the firm's history until the 1980s portrays a principal characteristic of the aircraft manufacturing industry: The development of new products is indispensable in order to remain a viable and independent player in the market. However, the time consuming development process involves enormous financing requirements, a long planning horizon and demand uncertainty. These investments are typically only recovered after a Iong period of successfully selling the product.

After the intended collaboration with McDonnell Douglas to develop new aircraft for the 130-160 seater segment had failed, Fokker saw its only strategic option in the simultaneous development of the Fokker 50 and Fokker 100 as successors of the F27 and the F28, because the necessity of modernization of its products was apparent in 1983. However, the decision to build two new types of aircraft at the same time was very risky and turned out to become extremely burdensome on the firm's financial position, especially after 1986 when the termination of F 27 and F28 delivery dried up the firm's most important stream of revenue. Actual development costs exceeded projected costs by far because the development process of the aircraft was everything else but smooth, partly due to lack of experience of the workforce in designing a completely new aircraft and due to bad organization of the process. ${ }^{3}$ First deliveries had to be postponed due to delays in the development process, which triggered price concessions and adversely affected the production plan resulting in extra costs. Moreover, its incumbent workers' experience with the production of the old types of aircraft was less useful in the production

\footnotetext{
${ }^{3}$ Government support amounting to $45 \%$ of projected in financial aid and $45 \%$ in stateguaranteed loans had been approved early on. But unforeseen extra casts were to be borne by Fokker; so that Fokker's share in the development costs rose to 750 million Dutch guilders, about ten times more than originally forecasted. Financial detals of the project are publicized in the report of the bankruptcy trustees in Deterink at al, 1997.
} 
of the new types than initially expected, further contributing to a highe than expected cost price. Government intervention in 1987 put a brake on Fokker's financial nose-dive into insolvency.

\subsection{Idiosyncratic Circumstances and Market Conditions from 1987 until 1996}

Fokker's financial situation had become increasingly tense, so that more aircraft had to be sold to compensate for overruns in development costs and to reduce the per unit cost price. The initial plan to deliver 24 aircraft of both types, the Fokker 50 and the Fokker 100, already required an expansion of production capacity which had been geared to no more than 36 aircraft per year since the early 1970s. Initial orders were large enough to justify such an expansion as Fokker was successful in winning new customers: 45 Fokker 50 had been ordered by 1987 when its delivery began and 47 Fokker 50 aircraft were ordered in 1988. Demand forecasts for the market segment of 50 seaters, for which Fokker had developed its Fokker 50, were promising. The firm believed that its Fokker 50 had more to offer in terms of quality than its competitors and thought a minimum annual sales rate of 33 Fokker 50 realistic for the coming years. Consequently, a planned capacity expansion to produce 40 Fokker 50 per year was announced in the 1989 annual report.

Production capacity for the Fokker 100 was to be enlarged even further. After having obtained two large orders for Fokker 100 aircraft from American Airlines (AA) and Guiness Peat Aviation (GPA) in 1989, Fokker planned to manufacture 67 aircraft a year from 1993 onwards. American Airlines had ordered 75 Fokker 100 with an option to buy an additional 75 aircraft. The agreement with GPA comprised the purchase of 48 aircraft to be delivered between November 1989 and October 1994 plus an option on 52 aircraft to be delivered from March 1990 through 1996. Orders, especially for the Fokker 100 , were encouraging at the turn of the decade.

However, optimistic demand forecasts for both types of aircraft never materialized. Demand conditions began to change adversely in 1990. Before long, demand was expected to recover soon after the Gulf War, so that the marketing department held a production rate of 34 aircraft per year as justified despitie fewer current orders. But the crisis turned out to be more severe. Part of the GPA agreement was cancelled, and neither AA nor GPA ever exercised their option on additional aircraft. Expected new orders did not materialize after 1991 as some airlines went bankrupt or postponed orders during the crisis in the aviation industry in the wake of Gulf War and 
the episode of deregulation and liberalization. The sharp global decline in demand for 40-70 and 70-125 seaters persisted for 5 years as Figure 3.1 shows, which plots world orders in the two market segments for which produced its aircraft.

Never were more than 23 Fokker 50 ordered in a single year - and only 16 Fokker 50 were ordered on average per year - from 1990 until 1995. As a result, the first unsold aircraft left Fokker's production line in 1990 and the stock of unsold aircraft kept on rising thereafter. Between 1991 and 1996, 39 unordered Fokker 50 were produced and remained in storage for an average period of 14.5 months, while 25 Fokker 100 were stored from 1990 to 1994 for an average time of 20.7 months. Fokker was not only hit by a negative demand shock in the market for civilian aircraft, but lucrative military orders neither materialized, possibly a result of defense budget cuts after the fall of the Berlin Wall.

The unexpected global slump in aircraft demand forced the firm to reduce capacity and affected Fokker's liquidity position adversely. Production capacity of the Fokker 50 was reduced to an annual of average of 26 aircraft in 1992, capacity for the production of the Fokker 100 was reduced to 42 aircraft in 1994. Although it was planned at the same time to start the production of the Fokker 70 , a shortened version of the Fokker 100, which was remarkably rapidly developed from June 1993 until its first delivery was in October 1994, workforce reductions were inevitable. The firm announced the first of a series of downsizing operations on March 1, 1991. More rigorous reorganizations involving involuntary dismissals were to follow in 1993,1994 and 1995.

The firm's financial situation was further burdened by the weakness of the U.S. dollar against the Dutch guilder. The unfavorable dollar-guilder exchange rate reduced sales revenue substantially, as the sales price for an aircraft was usually fixed in U.S. dollars, but had a much smaller impact on the cost price. ${ }^{4}$ American Airlines contracted a price in dollars but had the choice to pay in guilders if the exchange rate exceeded 2.25 guilders per dollar, which was the exchange rate at the time when the contract was signed. Soon thereafter, the exchange rate dropped to a level of 1.80 to 1.90. Hoping that the dollar would recover, the management stopped hedging a large part of its dollar position in 1991. However, the averaged annual exchange rate fluctuated between 1.74 and 1.87 guilders/dollar during the years 1992-1994, thus falling short of the target exchange rate in these years of $1.90-2.00$ on which business plans were based. In April 1995, the guilder-dollar exchange

\footnotetext{
${ }^{4}$ Deterink et al. (1997) report that the elasticity of the cost price with respect to the exchange rate was 0.25 for the Fokker 50 and 0.18 for the Fokker 100 .
} 
Figure 3.1: World Aircraft Market, Orders and Fokker Deliveries

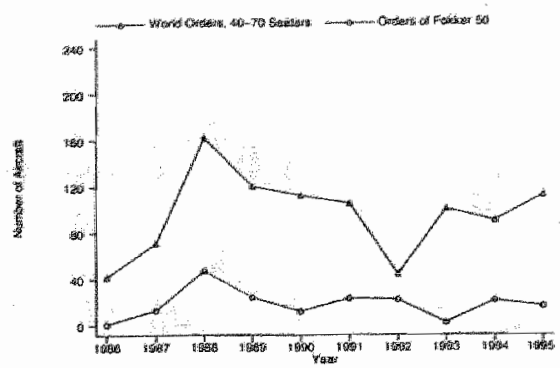

(ail) Orders in the $40-70$ Seaters Market Segment

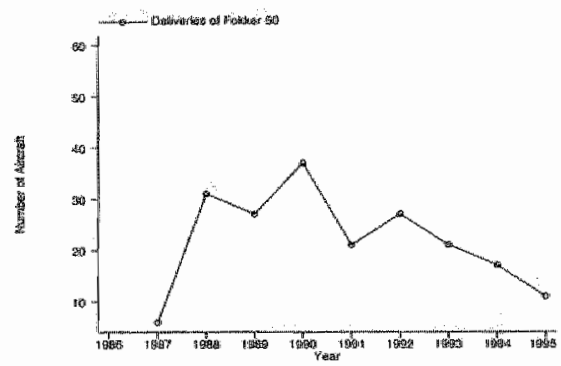

(c) Deliveries of Fokker $50(40-70$ Seaters Market Segmont)

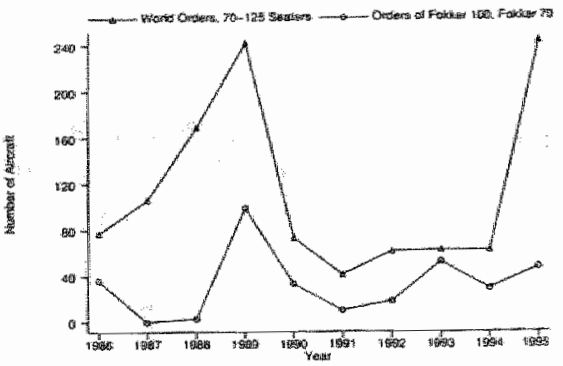

(b) Orders in the 70-125 Setters Market Segment.

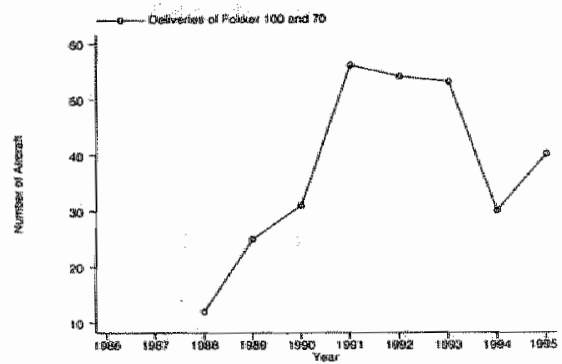

(d) Deliveries of Fokker 100 and Fokken 70 (70-125 Seaters Market Segment)

Notes:

1. Panels (a) and (b) show world orders and orders of Fokker aircraft for the market segments of 40-70 seaters and 70-125 seaters respectively. The lower two panels plot deliveries of Fokker aircraft: Fokker 50 for the 40-70 seater market segment (c); Folkker 100 and Fokker 70 for the $70-125$ seaters market segment (d). The first of a total of 27 Fokker 70 was delivered in 1994; 71 Fokker 70 had been ordered by the end of 1995 , of which 22 initial orders were placed in 1993.

2. Fokker's competitors in the 40-70 seaters market include the ATR 42, ATR 72, BAe ATP, Dash 8-300, Saab 2000, Bombardier CRJ, and Embraer 145. Competitors for Fokker aircraft in the $70-125$ seaters market segment comprise Boing-737-500/600, BAC-146/RJ, and MD-87/95.

3. Orders shown in the Figure are corrected for cancellations. Thus, the numbers do not include the option of 127 Fokker 100, which were part of the orders by American Airlines and Guiness Peat Aviation, placed in 1989 but never exercised. The numbers in the Figure are based on information provided in Deterink et al. (1997). 
rate even dropped to 1.52 so that an enormous exchange rate loss of about NLG 900 million had to be covered.

Competitive pressure rose. Bombardier boosted its market share in the 40-70 seater market segment from about $10 \%$ in 1990 to more than $30 \%$ in 1995 and ATR produced an aircraft, the ATR-42, that was significantly cheaper than the Fokker 50. When Fokker tried to penetrate the U.S. market, ATR undercut any tender. Price pressure in the 70-125 seater segment was particularly exercised by larger airlines. Fokker had to win them as new business partners as the small orders of its traditional customers would not produce the required sales volume for its Fokker 100. Due to their stronger bargaining position, larger airlines could not only negotiate substantial price cuts, but their special requirements in terms of design also generated extra costs which Fokker had to bear. The trend towards leasing aircraft constituted another adverse effect as the financing requirements fell largely on the manufacturer.

Consequently, Fokker faced a number of financial bottlenecks. The Dutch State, which had supported Fokker in several economic struggles prior to 1987 and had contributed to funds for the development of the Fokker 50 and Fokker 100, continued to provide financial assistance as Fokker's majority shareholder throughout 1993. A number of agreements between the Dutch State and Deutsche Aerospace AG (DASA), including the takeover agreement of April 27, 1993, in which the German aerospace company acquired a controlling interest in Fokker, alleviated severe financial pressure by endowing Fokker with liquid assets throughout 1994. ${ }^{5}$

Many believed that the Dutch State and DASA would continue bailing out Fokker when its liquidity problems sharpened dramatically in late 1995 despite harsh downsizing operations in previous years, especially since Fokker's future as a key niche player in the 40-70-125 seaters aircraft market segment, for which demand was predicted to be very high towards the turn of the century, was expected to be prosperous. Most financial analysts, therefore, anticipated Fokker to survive when the Dutch government and DASA started negotiating a bailout plan in September 1995. A comment in the Wall-Street Journal on September 4, 1995, describes the market sentiment: "Few, however, expect DASA, the aerospace arm of German industrial giant Daimler-Benz AG, will let Fokker go bust. The Dutch company [...] fills a key niche in a market segment expected to show strong growth in the next few years." (du Bois, 1995).

\footnotetext{
5As a result of the takeover agreement, DASA controlled $77.78 \%$ and the State of the Netherlands the remaining $22.22 \%$ of Fokker Holding B.V., which in turn held $51 \%$ of the shares in N.V. Koninklijke Nederlandse Vliegtuigenfabriek Fokker on December 31, 1995.
} 
Fokker reported in the press that it could meet financial requirements at least until the end of the year on September 29, 1995. Press comments speculated that DASA would take responsibility for the financing of Fokker after a loan of 750 million guilders had been repaid on December 15, 1995. Agreements concerning the economic transfer of aircraft in Fokker's lease portifolio were reached in the last two weeks of 1995, and the proceeds were used to repay loans of different banks. Talks between Fokker, DASA and the Dutch State were re-commenced on January 15, 1996. The German company: demanded a 1.3 billion guilder contribution of the Dutch State to Fokker's equity. However, talks ended on January 19, 1996, without an agreement being reached. Three days later, DASA decided to discontinue financial aid, call in its loans to: Fokker and denounce all loan guarantees. Fokker was forced to file for protective bankruptcy on January $23,1996$.

Fokker N.V. was then structured in an administration unit (Fokker Administration B.V.), an aircraft production unit (Fokker Aircraft B.V.) as well as three other subsidiaries (Fokker ELMO, Fokker Aircraft Services; and Fokker Special Products). The core business, aircraft manufacturing, accounted for the largest part of employment and was organized in different plants of Fokker Aircraft B.V. (FAC) in Schiphol, Papendrecht/Dordrecht and Ypenburg. Its headquarters, Fokker Administration B.V., were located in Amsterdam. Fokker ELMO (ELMO) designed and produced electrical systems for the civil and military aircraft industry in Woensdrecht. Fokker Aircraft Services (FAS), also situated in Woensdrecht, was responsible for maintenance, technical support and aircraft services. Employees of Fokker Special Products (FSP), a technology company, designed and manufactured high-performance structures advanced composites in Hoogeveen. ${ }^{6}$ The firm's organizational structure had largely remained unaltered since January 1 , 1987. The only major change during this period was the spin-off of Fokker Space and Systems, located in Leiden, in December $1995 .^{7}$

Fokker N.V. and its subsidiaries Fokker Aircraft B.V. and Fokker Administration B.V. filed for bankruptcy on March 15, 1996, affecting the majority of Fokker's workforce. The other viable parts of the firm - Fokker ELMO (ELMO), Fokker Special Produets (FSP) and Fokker Aircraft Services (FAS) - did not enter the bankruptcy procedure. Shares of these companies were transferred to Fokker Aviation, a holding company set up by the bankruptcy trustees on March 17, 1996. Two other divisions of this new holding company - Fokker Product Support B.V. and Fokker Aerostructures B.V. - were es-

\footnotetext{
Table A.1 in Appendix A.1 provides an overview of the different subsidiaries and their locations.

${ }^{7}$ Workers ermployed at this division leave our data files on that date.
} 
tablished from viable subdivisions of the bankrupt Fokker Aircraft B.V. and recruited 980 workers from its workforce. In total, Fokker Aviation had 2644 employees. The company was eventually sold to Stork N.V. on June 17, 1996. Another group of about 750 workers from bankrupt parts of Fokker N.V. was selected to work for the bankruptcy trustees for a limited period, mainly to finish 18 aircraft in an advanced stadium of the construction process. ${ }^{8}$

\subsection{The Development of the Workforce}

The production capacity expansion, necessary to meet contracted deliveries in the late 1980s and early 1990s, required employment growth despite productivity improvements in the years 1988 until 1994. The average annual output rate of 28 aircraft of the years 1980 to 1986 was raised to an average of 63 aircraft assembled annually between 1988 and 1994. The throughput time for the Fokker 100 was reduced from 100 to 52 working days and that for the Fokker 50 declined from 100 to 50 working days during these years. In fact, Fokker claimed to be one of the most productive aircraft manufacturers in the world. But the global slump in aircraft at the beginning of the $1990 \mathrm{~s}$ initiated a capacity reduction.

The time period spanned by the data - from January 1, 1987, when the firm introduced its electronic personnel system, until the bankruptcy on March 15, 1996 - is divided into an episode of employment growth followed by an episode of severe downsizing. Figure 3.2 depicts the employment dynamics stacked by ten broad activities into which jobs are categorized.

The number of workers with permanent contracts in the personnel files rose during the expansion from 10275 in January 1987 to 12852 at the peak in February 1991. On March 1, 1991, the firm announced its first reorganization which intended the reduction of 1000 full-time equivalent (FTE) jobs without compulsory dismissal. The reduction of $182 \mathrm{FTE}$ jobs was to be accomplished by a special early retirement plan and 818 by attrition which includes retirement, an existing early retirement plan (SUM), but also retraining. A further reduction of 950 FTE jobs was announced on October 1, 1992. This time 220 involuntary dismissals were planned. According to the Dutch law, downsizing operations involving involuntary dismissals have to be announced and negotiated with the unions about six month before actual firing took place. Further downsizing operations were announced on

\footnotetext{
${ }^{8}$ Initially, it was planned to complete the production of two Fokker 100, ten Fokker 70 , four Fokker 60 (a military version of the Fokker 50) and two Fokker 50. Two staggered decisions in April 1996 and June 1996 were made to finish a total of 15 additional aircraft, as is described in the first public report of the bankruptcy trustees.
} 


\section{Figure 3.2: ReManing ORders and SizE of the WORKForce}

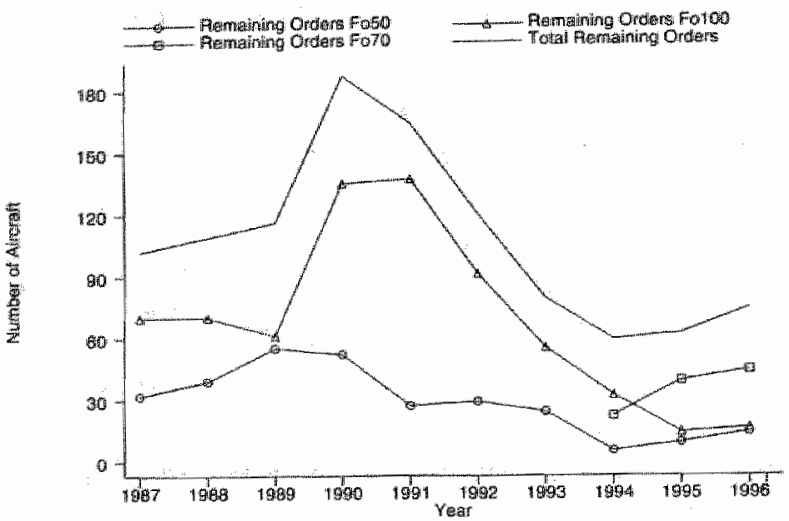

(a.) Kenaining Orders

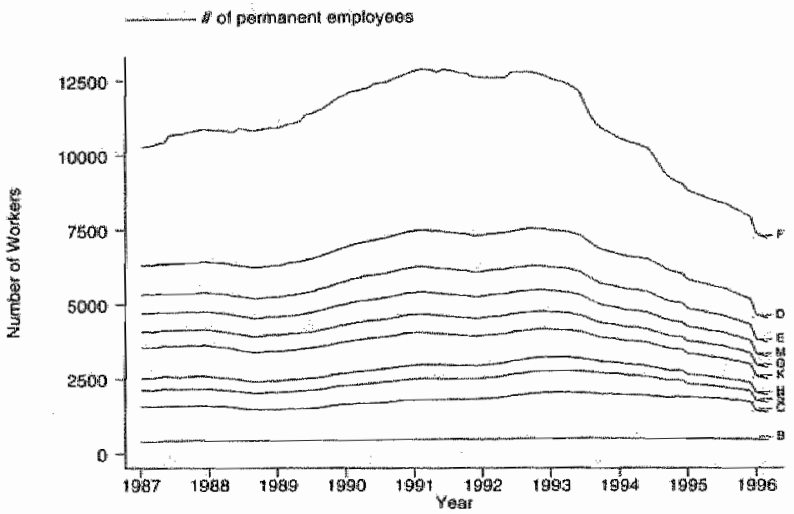

(b) Wonforde

Notes:

1. The upper panel shows the number of pometning ancraft ordens at the begnning of each yex from 1987 until 1995. These numbers are calculated as the acoumulated sum of orders minus the accumulated number of atrcraft deliwed until the respectiwe date. The numbers sown in the Figua are corrected for cancellations.

2. Tha lower panel plots the mumber of workers with a permanent contract empllowed at the beginning of each month from Janury 1987 until March 1996 stacked by the diflerent job activities defined in the data. Job activities comprise: Sales $\&$ Customer Relations (B), R\&D (C), Management \& Infonaton Processing (S), Humen Resources \& Support (H), Finances and Administration (K), Support \& Suppties (G), Quality (M), Planning \& Coordination (E), Production Preparation (D), Assembly $\left(F^{2}\right)$. Labels an in prevtheses. The distance to the next lower line represents the number of workers in a particula job activity. Total employment, th the firm is, therefore, characterized by the top line, labelled as "fin". 
April 23, 1993, involving a cut of 2118 FTE jobs of which 1350 dismissals were planned, on April 13, 1994 (reduction of 1900 FTE jobs including 1100 planned dismissals), and in 1995 (reduction of 1760 FTE jobs including 450 dismissals). The number of employed workers fell during this episode of workforce contraction to 7141 on the day before the bankruptcy.

Most workers were employed in one of the five production activities (Assembly (F), Support \& Supplies (G), Production Preparation (D), Plaming \& Coordination (E), and Quality (M)). Employment changes in production activities, increasing steadily from 6684 workers in Jamuary 1987 to a peak of 8838 workers in June 1991, and then falling to 4651 workers on the day before the bankruptcy, accounted for the largest part of the workforce expansion and its subsequent contraction. Employment in the three administrative activities (Finances and Administration (K), Human Resources \& Support (H), and Management \& Information Processing (S)) rose from 1966 workers in January 1987 to 2252 workers in February 1991 and fell subsequently to 1113 workers in March 1996. Employment in R\&D (C) and in Sales \& Customer Relations, on the other hand, grew for a prolonged period (peaking not until the second quarter 1993), and declined only moderately until the end of 1995. As a result, the employment share of production related activities fell during the episode of downsizing from a peak of $68.8 \%$ in mid 1991 to $62.3 \%$ in December 1995 and that of administrative activities fell from $17.1 \%$ in mid 1991 to $15.9 \%$ by the end of 1995 .

\subsection{The Data}

The personnel files of the Dutch national aircraft manufacturer Fokker N.V. contain detailed information on the work histories of all 17610 workers who had a permanent work contract with the firm at some time in the period from January 1, 1987, until March 15, 1996, when the firm filed for bankruptcy. Information on each employee's job, compensation and demographics is contained in different files. The job position file records every worker's job code, job title, organization code, organization name, the activity his job belongs to, the plant name, as well as the starting and end date of all his job positions within the company during the observation period. The wage files contain information on the salary grade, the nominal wage rate, the start and ending date of the wage contract, the reason for a change in the wage contract, and a performance measure that refers to performance in the previous year. A separate file contains educational background information for most employees. Vocational and schooling degrees are recorded together with the date of completion and an explanatory description. In addition, training experiences 
and their timing are coded. The file of demographic characteristics has the date of birth, gender, marital status and the hiring date for every employee. Additional variables in each data file record the dates on which changes in individual or job characteristics take place. All files include a unique identification code for each worker, so that data from the personnel files can be merged. Because of the exact knowledge of the timing of events, the data can be transformed into an event history data set. Cross-sectional data sets with present-day information can be obtained at any day, and panels at different: frequencies thus be constructed. Above all, the data are very valuable for empirical research because of their high degree of reliability and detail.

This will prove useful in different ways for the empirical analyses of this dissertation. Chapter 4 exploits the fact that the data lend themselves for duration analysis as they record each worker's accession and job separation date, birth date, as well as the timing of other relevant events, i.e. changes in individual characteristics (like, education, training courses, marital status, and a performance measure), job characteristics (hours worked, location of work) and compensation (wage scale in the salary system). Chapter 5 also profits from the of data structure. The knowledge of the exact timing of events not only makes it possible to detect whether job changes and wage changes occur simultaneously, but the event history format of the data also ensures that no information about events that happen in the time-span between two cross-sections of panel data is lost. Chapter 6 takes advantage of the richness and accuracy of the data to analyze how individual wages are determined within the formal salary system of the firm. 
Chapter 4

Worker Separations in a Nonstationary Corporate Environment 


\subsection{Introduction}

This chapter asks how determinants of worker turnover differ between times of corporate expansion and corporate decline. We exploit a unique data set from a very large firm that has personnel data for ten years on more than 17580 employees to analyze the determinants of job separations. During this period, the firm went through an expansion phase and a period of severe downsizing leading to bankruptcy in the end. These data allow us to investigate empirically the content of a number of turnover theories, which often stress different aspects and mechanisms that lead to job separations. Above all, we can assess how the determinants of separation rates modify when economic conditions change.

At least two important aspects differentiate our study from previous empirical work that investigated the relationship between separation rates of workers and their characteristics (e.g. Farber, 1994; Gautier et al., 1999). First, rather than using data sampled over different firms and/or over different industries, we have data on the entire population of workers from a single firm during a period of almost ten years. Heterogeneity emanating from firm-specific or industry-specific effects is less of a concern since all workers face the same set of personnel policies. In addition, the personnel data are less prone to measurement error and recall problems than survey data. The second new characteristic of our analysis is that our data cover a period of corporate growth and an episode of corporate decline. The analysis of such data not only adds an additional dimension to the evaluation of theories of worker turnover, but is also relevant for labor market flow theories in general. ${ }^{1}$

We estimate hazard rates for the event of a job separation. In order to allow for a flexible baseline hazard, we choose a Cox proportional hazard model and reverse the role of calendar time and tenure duration to control for the nonstationary environment. We prefer a flexible parameterization of the duration dependence and the functional form of the dependence on other covariates. Although flexibility comes at the price of efficiency loss, the size and quality of our data set enables us to achieve a high degree of estimates" precision.

The results suggest important discontinuities of separation hazards at

"How the determinants of worker turnover vary with the level of economic activity is a relevant question for flow theories of unemployment as developed in Pissarides (2000), Mortensen and Pissarides (1994), and Blanchard and Diamond (1990). That firm-level data can enlighten our understanding of aggregate outcomes has been illustrated by the pioneering work of Dunne et al. (1989), Dawis and Haltiwanger (1992), and Davis et al. (1996). 
older age resulting from early retirement or buyout options. Such institutional arrangements and the anticipation of them have importiant implications not only for the design of human resource policies, but also for empirical work because simple functional forms that may follow from some model such as a quadratic age effect - do not describe the data well and miss important features of reality.

The chapter is organized as follows. The next section describes the data. Section 4.3 discusses testable implications of different models that can be tested directly with the data. Section 4.4 presents the econometric model, a Cox proportional hazard model with calendar time dependence, which the data lend themselves to. Section 4.5 describes the characteristics we control for in the empirical application in more detail. Section 4.6 discusses the estimation results and their implications for the theoretical models. Section 4.7 concludes the chapter.

\subsection{The Data}

The data come from the personnel files of the Dutch national aircraft manufacturer N.V. Koninklijke Nederlandse Vliegtuigenfabriek Fokker (Fokker N.V.). These files contain detailed information on the work histories of all 17610 workers who had a permanent work contract with the firm at some time in the period from January 1, 1987, until March 15, 1996, when the firm filed for bankruptcy. ${ }^{2}$. During this period, Fokker N.V. was structured in an administration unit (Fokker Administration B.V.), an aircraft production unit (Fokker Aircraft B.V.) as well as four other subsidiaries (Fokker Space and Systems, Fokker ELMO, Fokker Special Products, and Fokker Aircraft Services). The core business, aircraft manufacturing, is organized in 3 plants of Fokker Aircraft B.V. (Schiphol, Papendrecht/Dordrecht, and Ypenburg) with headquarters, Fokker Administration B.V., in Amsterdam. The other four subsidiaries are vested in different locations. Table A.1 in Appendix A.1 provides an overview of the different subsidiaries and their locations.

Figure 4.1 shows that employment in the entire company grew steadily from 10215 permanent workers to 12813 permanent workers from 1987 until 1991. The vast majority of workers is employed in the company"s core business operation, Fokker Aircraft (FAC), and works in one of its three plants which we call FAC1, FAC2, and FAC3 (see Appendix A.1). Forced by the sharp global drop in aircraft demand, the firm announced the first of a se-

\footnotetext{
"The data were made available to us for academic purposes by the company"s bankruptcy trustees. The report of the bankruptcy trustees is publicly available (Deterink et al. 1997).
} 
Figure 4.1: DEVELOPMENT OF THE WORKFORCE

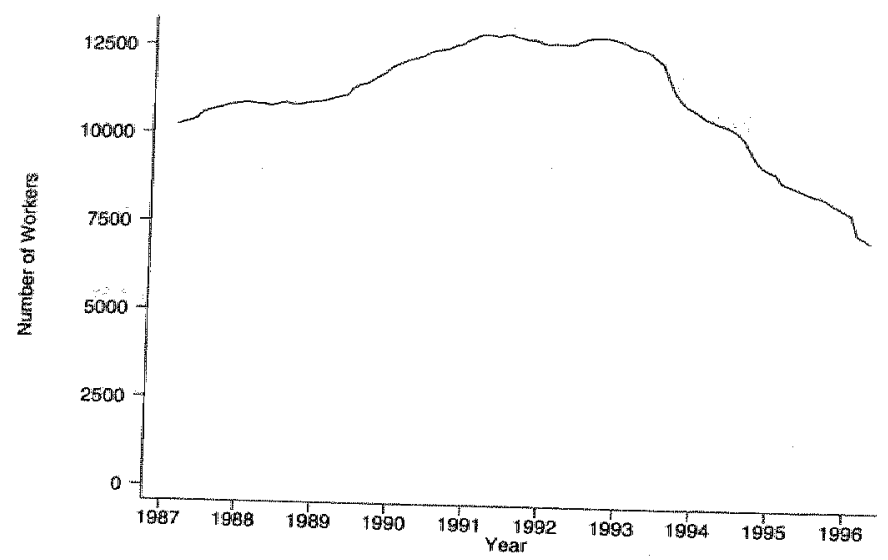

(a) Workforce in the Entire Company

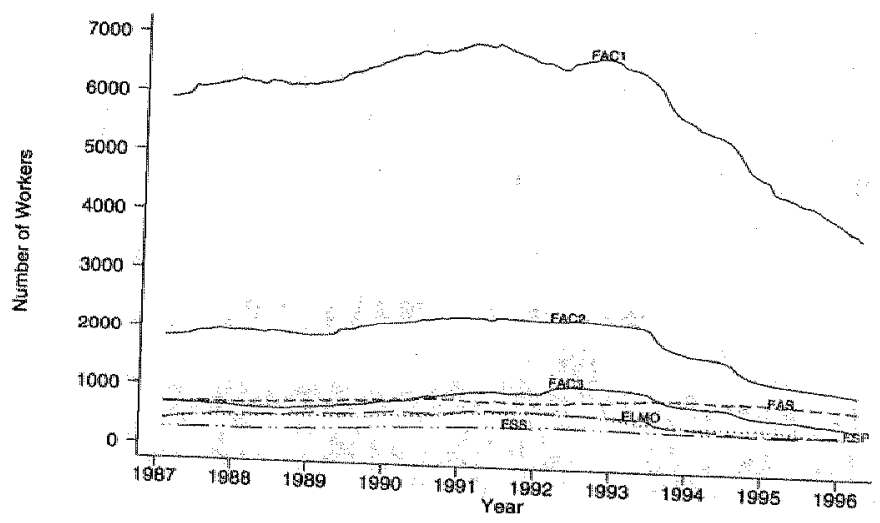

Notes:

(b) Workforce in Subsidiaries

1. Panel (a) shows the total number of workers with a permanent employment contract
at the firm.

2. Panel (b) plots the number of workers at the different plants. Labels of subsidiaries
are defined in Appendix A 1 . 
ries of reorganizations with workforce reduction on March 1, 1991. The core activity was most affected by the severe downturn which eventually led to the bankruptcy of Folker N.V., its production unit, and its administration unit on March $1,1996^{3}$ The other viable parts of the firm - Fokker ELMO (ELMO), Fokker Special Products (FSP), and Fokker Aircraft Services (FAS) - did not enter the bankruptcy procedure and were sold. Fokker Space and Systems (FSS) had already been spun off in December 1995.4

The data lend themselves for duration analysis as they record each worker's accession and job separation date, birth date, as well as the timing of other relevant events, i.e. changes in individual characteristics (like, education, training courses, marital status, and a performance measure), job characteristics (hours worked, location of work), and compensation (wage scale in the salary system).

\subsection{Testable Implications from Turnover Mo- dels}

Different mechanisms that lead to job separations have been stressed in alternative theories. In general, however, most models fit a simple framework, which centers around the joint surplus that the employment relation creates on top of the value of alternative options for workers and firms. The joint expected surplus $S_{t}^{i}$ of the employment relation between the firm and worker $i$ at time $t$ can be expressed as

$$
S_{i t}=V_{i t}-A_{i t}+\int_{t}^{T} E_{t}\left(V_{i s}-A_{i s} \| \Omega_{s}\right) d s
$$

where $V_{i t}$ denotes the value of the worker $i$ to the firm in period $t$ and $A_{i t}$ the value of the outside option to the worker. ${ }^{5} E_{t}\left(\cdot \mid \Omega_{s}\right)$ denotes the expectation

\footnotetext{
3This might prompt the criticism that the firm is not a representative example of a downsizing firm as it fails eventually. However, there is reason to believe that the collapse came suddenly and unexpectedly. Most analysts expected even in September 1995 that Fokker would survive when the major shareholders, the Dutch government and Deutsche Aerospace AG (DASA), started negotiating a bailout plan. A comment in the Wall Street Journal on September 4, 1995, describes the market sentiment: "Few, however, expect DASA, the acrospace arm of German industrial giant Daimler-Benz AG, will let Fokker go bust. The Dutch company [...] fills a key niche in a market segment expected to show strong growth in the next few years." (du Bois, 1995)

"Workers employed at this division leave our data files on that date.

${ }^{5}$ Without loss of generality, we have normalized the alternative option of the firm to equal zero. Further, $A_{t}$ is determined by a number of factors including expected returns
} 
of - conditional on the information available at $t, \Omega_{t}$. The expected surplus is stochastic as future realizations of $V$ and $A$ depend on random shocks to productivity, demand, and prices. The expected surplus changes with the arrivall of new information about future values of $V$ and $A$. Therefore; there exists an option value, which we denote by $O_{i t}$, as the losses of firms and workers are truncated since they can decide to separate in the future. The option value of a separation is higher, the larger the variance of future surphises.

An efficient separation takes place if the joint expected surplus falls below the costes of separation $C$ and the option value $O$ associated with a separation. Inefficient separations can result when there are informational asymmetries about the outside options, ${ }^{6}$ or when specific investments are not verifiable. ${ }^{7}$ Throughout the remainder of the chapter, we assume that separations are efficient and we do not distinguish between layoffs and quits. ${ }^{8}$ This implies that the probability that worker $i$ separates at time $t$ given that he did not separate before, $P_{i t}$, is a function of the joint expected surplus net of separation costs and the option value of the separation, i.e.

$$
P_{i t}=F\left(S_{i t}-C_{i t}-O_{i t}\right) \text {. }
$$

$P_{i t}$ is the hazard of job separation of worker $i$ at time $t$. Factors that augment the joint surplus are predicted to reduce the hazard of job separation. While this notion is pervasive in the turnover literature, theories have focused on various aspects and mechanisms, which lead to different predictions about the shape and the determinants of the separation hazard. We will focus on those theoretical aspects that we can assess with our data.

An important theoretical insight is that relationship-specific investments, which become sunk when the relationship is ended, are inversely related to turnover rates (Oi, 1962). Human capital models (e.g. Becker, 1962) predict that turnover rates fall the more specific human capital is accumulated, as is worked out by Mortensen $(1978,1988)$. Hence, separation rates should be lower for workers with more specific training holding everything else constant,

from alternative employment or from other benefits associated with non-employment as well as the wage equivalent to the utility loss associated with not working at the firm.

See, for example, Hall and Lazear (1984).

Tee Toulings and Hartog (1998), who discuss these issues and also illustrate how inefficient quits that result in Hall and Lazear's (1984) model can be prevented if both parties agree on a fixed-wage contract before the true value of the employment relation and the altemative is revealed.

${ }^{8}$ Implicitly we assume that workers and frms maximize the total surplus. The share of the expected surplus that the worker and the firm receives might depend on their relative bargaining power. 
a hypothesis that will be tested in our empirical analysis. If specific skills are acquired on the job, we expect turnover rates to fall with tenure, holding other investments in training constant. We should also expect heterogeneous rates of human capital accumulation in different jobs to affect turnover decisions (Dustmann and Meghir, 1998). This cannot be tested directly with our data. But the mechanism suggests that separation rates are affected differently for different types of workers when new information about random future surpluses arrives. For example, younger workers are affected more severely if "bad news" about their rate of return of specific capital investments arrives as their amortization horizon is longer. Our analysis will shed light on such issues. The negative dependence of the separation hazard on job tenure is reinforced by decreasing search behaviour in Jovanovic's (1979b) analysis which combines job-specific human capital accumulation and search behavior.

A crucial determinant of search behaviour - and hence of the hazard of job separation - is match heterogeneity as a source that affects the size of the joint surplus. The idea that match-specific capital is important was initially worked out in Jovanovic (1979a) where jobs are considered to be experience goods. However, this model generates much different turnover patterns than Jovanovic's (1979b) model. Job search is a renewal process because knowledge of match quality in the current job is not informative of match quality of all other jobs. Therefore, the separation hazard is independent of labor market experience, whereas Jovanovic (1979b) predicts a negative structural dependence of the job separation hazard on labor market experience as the probability of having found a good match increases with time spent searching (and because of the shorter remaining lifetime over which investments in job-specific skills can be amortized).${ }^{9}$ Second, with match-specific capital (Jovanovic, 1979a) the separation hazard rises initially before starting to decrease monotonically because matches end only once sufficient bad information has arrived, while good matches survive. Whether separation rates fall with labor market experience, holding tenure constant, and whether the separation rate increases initially with job tenure before it falls monotonically, will be tested with our data.

Another type of specific capital is organization capital (Prescott and Visscher, 1980) which one could interpret broadly to also include knowledge of the organization, work relations to colleagues, and the like. This is difficult to measure in our data. But it is reasonable to assume that organization

\footnotetext{
${ }^{9}$ Pfann (2001) shows how uncertininty about the future creates an option value of waiting when separations are irreversible, thereby offering a closed form solution of Jovanovic's model.
} 
capital is accumulated with job tenure and is also likely to be positively telated to careers. We expect workers who have made careers within the firm (which we measure by upward mobility in the firm's salary scales) to have lower separation rates, ceteris paribus. Clearly, having made career in a firm. also suggests a high value of match-specific capital, and so it is not possible to distinguish empirically which force-organization capital or match capital - drives the relation between career attainment and separation hazards.

If internal labor markets, in which careers are important (Baker et al, 1994a), develop to foster investments in job-specific capital (Doeringer and Piore, 1971), workers and the firm clearly would like to reduce turnover rates to ensure optimal levels of specific investments. Lazear (1979) argues that deferred compensation schemes can foster long-term employment relations. ${ }^{10}$ Such schemes do, however, create severe hold-up problems since the firm has an incentive to renegotiate the wage contract or even dismiss workers once it has to start repaying workers. Solving this hold-up problem requires a credible commitment by the firm to fulfill its promise. Reputation might be such a device. If the hold-up problem can be solved, we would expect separation rates to be lowest when the firm starts repaying the worker.

None of the models discussed so far takes changing conditions and shocks into account. A model with deferred compensation suggests that separation rates are higher for older workers and workers with longer tenure when the firm is hit by a shock affecting the marginal value product. ${ }^{11}$ Lazear's model, therefore, suggests a quadratic effect of age on the hazard of job separation holding tenure constant, which has been implemented in a host of empirical studies. We show in our empirical analysis that this might be misleading as workers and firms value the option of a buyout, which generates important discontinuities. An important aspect of our empirical analysis is to assess whether the determinants of worker separations change in a nonstationary economic environment.

\subsection{The Econometric. Model}

The hazard of job separation is expected to change substantially with calendar time. Therefore, it is natural to estimate a mixed proportional hazard

\footnotetext{
${ }^{10}$ See also Lazear (1995a).

${ }^{11}$ A buyout offer is accepted by the worker if it matches the discounted value of the difference between wages under the (implicit) contract and the worker's alternative from the present until retirement. Firms are willing to offer an amount up to the costs of to the firm after a negative shock to the marginal value product.
} 
model in which we reverse the role of calendar time and duration as worked out by Imbens (1994). Since all workers in the data are employed at the same company, heterogeneity arising from firm-specific and industry-specific effects is ruled out in our application. By reversing the role of calendar time and duration, we control for unobserved heterogeneity that is independent of covariates, not individual-specific, and varying over time. Calendar time effects, i.e. the impact of nonstationary forces on the job separation hazard, enter the hazard rate through the baseline hazard and are not parameterized in the Cox proportional hazard model. A piece-wise constant step function

$$
\omega_{i}\left(t-t_{0}\right)=I\left[d_{i}<t-t_{0} \leq d_{i+1}\right]
$$

is specified to estimate the duration dependence of job tenure $\left(t-t_{0}\right)$ in a flexible way, where $I$ is the indicator function, $d_{i+1}-d_{i}$ a particular period length, and $t_{0}$ and $t$ are the entry date and the calendar date respectively. The hazard rate $\lambda$ depends on calendar time $t$, on the accession date $t_{0}$ (through tenure duration $\left(t-t_{0}\right)$ ), and on a set of time-invariant and time-varying characteristics in our design matrix $X$. The hazard rate is given by

$$
\lambda\left(t, t_{0}, X(t)\right)=\lambda_{0}(t) * \exp X(t) \beta * \exp \sum_{i=1}^{I} \alpha_{i} \omega_{i}\left(t-t_{0}\right)
$$

The baseline hazard absorbs changing conditions in the corporate environment (like demand conditions, productivity changes, or any other market conditions) that affect separation probabilities of all workers on the same calendar date, but are not controlled for by variables in our design matrix. However, since the different parts of the firm might be affected differently by such nonstationary forces, we allow the baseline hazard to differ for workers at different plants. Moreover, we relax the assumption that nonstationary forces affect different groups of workers proportionally by stratifying the sample into white-collar and blue-collar workers. ${ }^{12}$ Since the determinants of relative separation rates might differ between times of expansion and downsizing, we estimate model (4.1) separately for the period of expansion and the period of downsizing, splitting the period on March 1, 1991, the day when the first downsizing operation was announced. Our analysis time of the second period ends one day before the bankruptcy. We censor observations of workers still employed on March 15, 1996, the day of the bankruptcy. ${ }^{13}$

\footnotetext{
${ }^{12}$ Estimating the model separately for blue-collar and white-collar workers improved the fit significantly.

${ }^{13}$ The day of bankruptcy is excluded from the study since results would be misleading as the hazard rate of separation is by definition infinite for workers falling under the bankruptcy.
} 
Workers are in the risk pool from the starting date of analysis time, $F^{s}$ if they are employed at $t^{s}$, or they enter on the day of accession to the firm $t_{0}$ if hired after the starting date $t^{s}$, so that $t_{0} \leq t^{s}$ for workers employed at the starting date of analysis time and $t_{0}>t^{s}$ for workers hired during the analyzed period. Workers leave the risk pool on the day of separation, or if their spell is censored. Such right-censoring occurs due to a worker's death or due to spin-offs in which workers do not lose their job but leave our data files as their employer changes. Since we know the beginning date of an employment spell, $t_{0}$, for all spells, we condition on elapsed tenure duration at the beginning of analysis time $t^{s}$ and, consequently, infer the duration dependence of employment spells.

\subsection{Worker Characteristics}

Before discussing our results, we describe the variables in the covariance matrix. Figures $4.2-4.4$ and Tables $4.1-4.3$ provide information on the distribution of characteristics among workers separating in each of the two periods and among the cross-section of workers employed on March 1, 1991.

In the estimation, we divide tenure duration into 27 intervals. In order to assess whether the separation hazard increases initially, we define intervals of of one week for the first 12 weeks and of 3-months length for the remainder of the first year. Since the distribution of tenure at the firm is skewed (see Figure 4.2, panel (a)) we enlarge the interval length at longer tenure choosing intervals of one-year length for the second until the fifth year and of 5-years length thereafter. Panels (b) and (c) of Figure 4.2 indicate that most separating workers have short tenure, while separations at intermediate tenure are rare. Fewer workers have short tenure during contraction because of lower hiring rates, which explains why average tenure of separating workers is longer in the period of downsizing.

In order to leave the functional form of the dependence on age flexible, we define a step function with yearly intervals. Figure 4.3 shows the age distribution among workers employed on March 1, 1991. It also reveals that the age distribution among separating workers is not unimodal in the two periods. A first peak arises at the age of 25 years in both periods. The modal age at job separation is 60 years in the first period, but becomes 55 in the second period.

We include nine categorical dummy variables for the highest obtained schooling degree (see "Table A.2 in Appendix A.2). We define the category "not reported" in order not to lose valuable information on those whose 
Figure 4.2: Tenure Distrubution

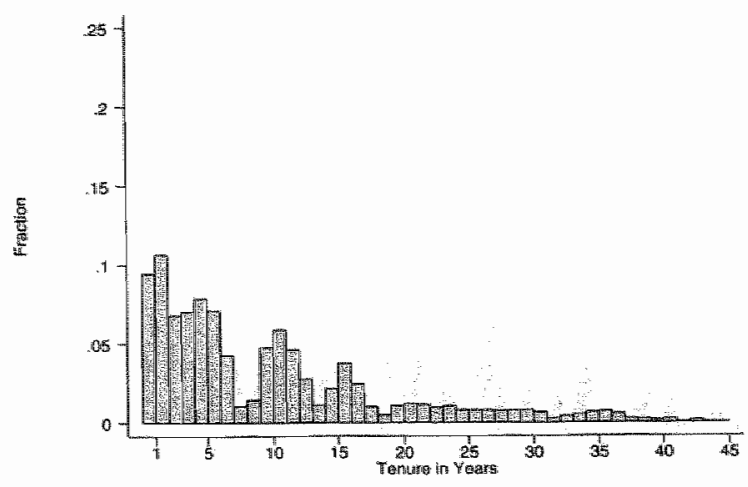

(a) Distribution Among Workforce on March 1, 1991

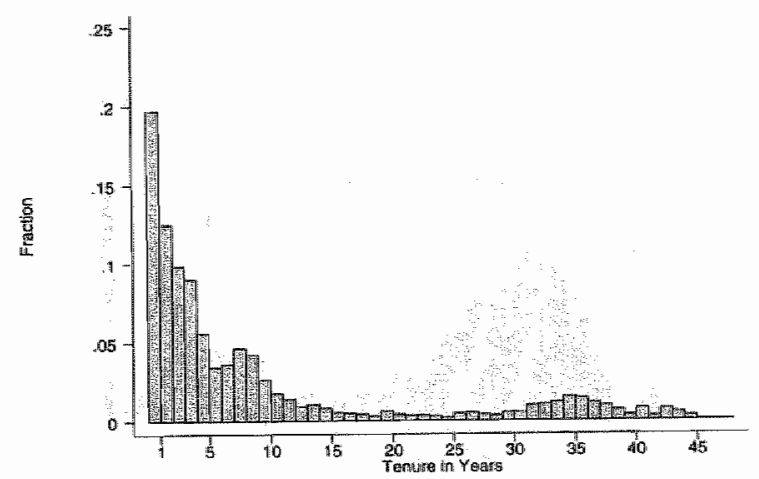

(b) Distribution Among Separations 1987-1991

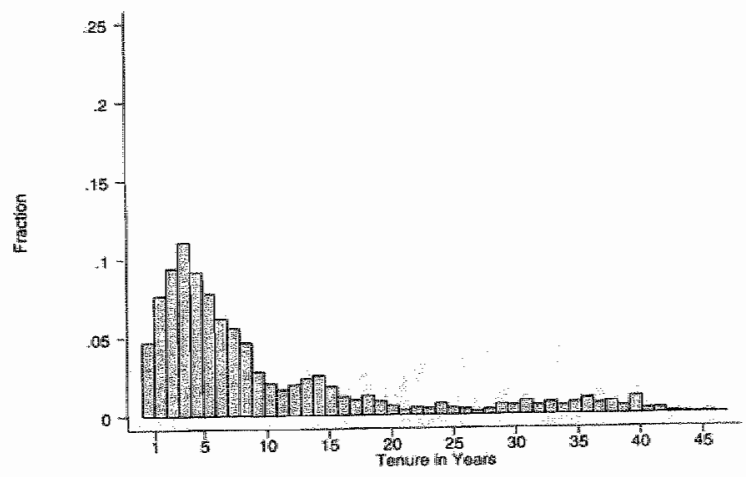

(c) Distribution Among Separations 1991-1996 
Figure 4.3: Age Distribution

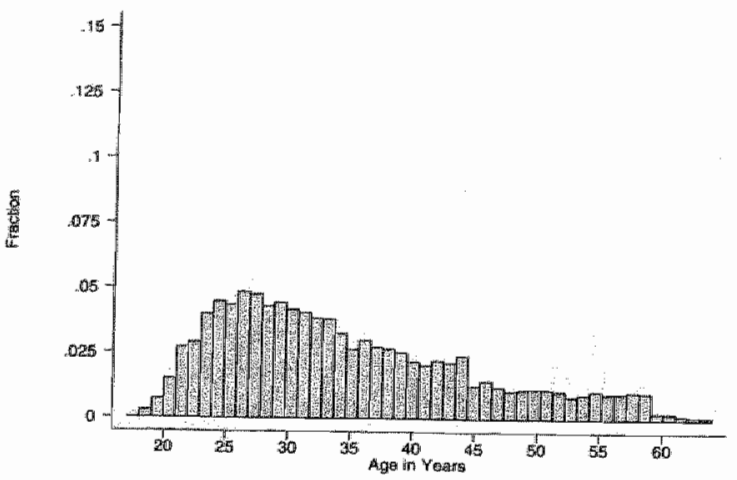

(a) Distribution Among Workforce on March 1, 1991

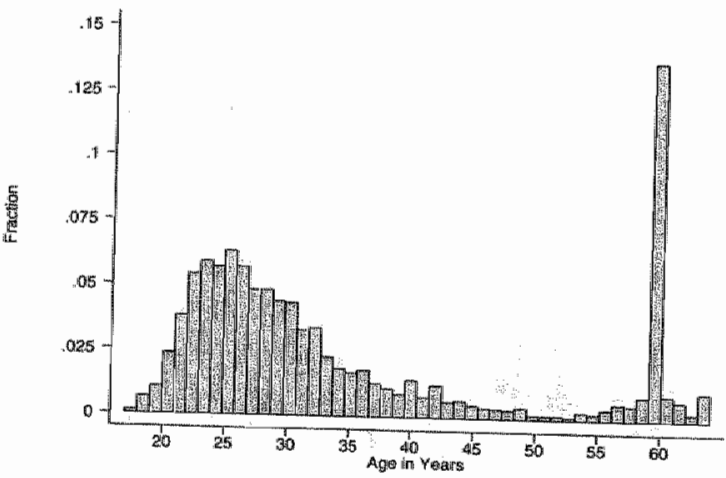

(b) Distribution Among Separation 1987-1991

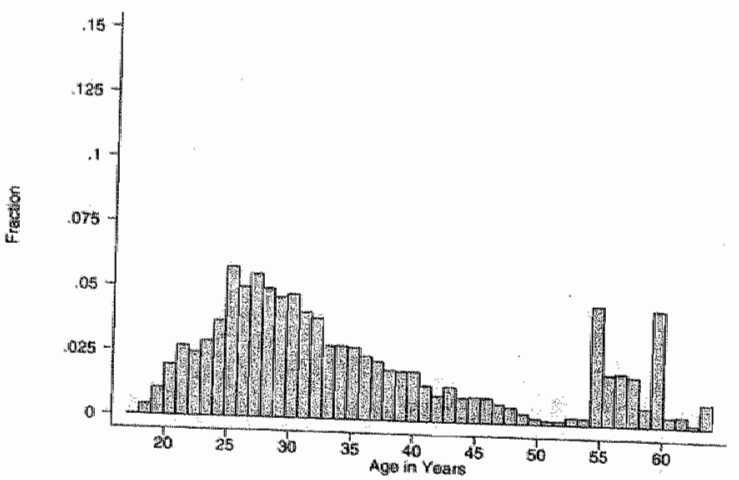

(c) Distribution Among Separations 1991-1996 
schooling degree is not reported in the data. ${ }^{14}$ Table 4.1 shows that most workers employed on March 1, 1991, have a vocational degree.

Table 4.1: Distribution of the Highest Completed Schooling Degree

\begin{tabular}{ll|ccc}
\hline & & $\begin{array}{c}\text { Employed on } \\
\text { Schooling Degree }\end{array}$ & $\begin{array}{c}\text { Separations } \\
\text { March 1, 1991 }\end{array}$ & $\begin{array}{c}\text { Separations } \\
1987-1991\end{array}$ \\
$1991-1996$
\end{tabular}

Notes:

1. The table shows the fraction of incumbent or separating workers that holds a particular schooling degree as their highest completed degree.

2. See Appendix A.2 for definitions of the schooling variables.

We control for work-related training incidences by four variables which count respectively the number of external training courses completed before 1987, of internal training courses completed before 1987, and of external as well as internal training courses completed during the observation period. So the first two variables are time-invariant, while the latter vary over time. Internal courses are training provided at the firm in the company's school, while external instructors are hired for external courses which might also be organized outside the firm. Table 4.2 provides some descriptive statistics.

We account for the 18 different wage scales that exist at the firm. ${ }^{15}$ These wage scales also determine the split into white-collar and blue-collar employment. Workers in the 10 lower wage scales (scales 2-11), referred to as "bluecollar workers", are bound by collective wage bargaining agreements. These workers are predominately employed in production. Workers in the higher scales (12-19) are referred to as "white-collar workers". Their wages are

\footnotetext{
${ }^{14}$ Information on education is missing for workers in all wage classes.

${ }^{15}$ Note that wage grades exist within each scale, so that wage variation exists within wage scales.
} 
Table 4.2: Training Courses

\begin{tabular}{|c|c|c|c|c|c|c|}
\hline \multirow[b]{2}{*}{ Training Courses (\#) } & \multicolumn{2}{|c|}{$\begin{array}{l}\text { Employed on } \\
\text { March 1, } 1991\end{array}$} & \multicolumn{2}{|c|}{$\begin{array}{c}\text { Separations } \\
1987-1991\end{array}$} & \multicolumn{2}{|c|}{$\begin{array}{c}\text { Separations } \\
1991-1996\end{array}$} \\
\hline & Mean & St.Dev & Mean & St.Dev & Mean & St.Dev \\
\hline al courses before 1987 & 2.96 & 5.84 & 1.90 & 4.42 & 1.81 & 4.58 \\
\hline external courses before 1987 & 0.64 & 1.33 & 0.56 & 1.18 & 0.45 & 1.10 \\
\hline internal courses since 1987 & 3.05 & 4.35 & 0.88 & 2.33 & 4.33 & 5.56 \\
\hline external courses since 1987 & 0.38 & 0.88 & 0.11 & 0.44 & 0.51 & 1.10 \\
\hline
\end{tabular}

Notes: The table shows the average number (and standard deviation) of external and internal traming courses that were completed by workers employed on March 1, 1991, and by separating workers.

not bound by collective wage bargaining agreements. Figure 4.4 shows that most workers at the firm are blue-collar workers. We hold the first observed wage scale of a worker constant ${ }^{16}$ and include dummy variables that trace transitions in wage scales. By March 1991, only $0.4 \%$ of those who are still employed moved down the wage ladder. Upward moves are more common: $31.4 \%$ have moved up one scale, $17.7 \%$ two scales, and $7.9 \%$ three or more scales.

There are 6 performance evaluation scores for blue-collar workers and 5 for white-collar workers, for each of which we define a dummy variable (see Table A.3 in the Appendix for a definition). Table 4.3 illustrates that the distribution of evaluation scores is left-skewed, but strongly concentrated around the median: $86.4 \%$ of blue-workers employed on March 1, 1991, have scores in the categories "normal-good" or "good-very good" and $84.7 \%$ of the white-collar workforce employed on the same date was last evaluated as "good".

In addition, we control by dummy variables for marital status (3 categories: married, divorced, and never married), gender, part-time work, and having had a previous employment spell with the firm. There are not many workers (329 over the entire period) who are rehired, and they account for $1.2 \%$ of the workforce in March 1991.

\footnotetext{
${ }^{16}$ This is either the wage scale observed on January 1,1987 , or the entering wage scale of a worker who joins the firm after that date. Scale 12 is a particular one, since most white-collar workers who enter the firm start in that scale.
} 
Figure 4.4: Distribution over WAGE Scales

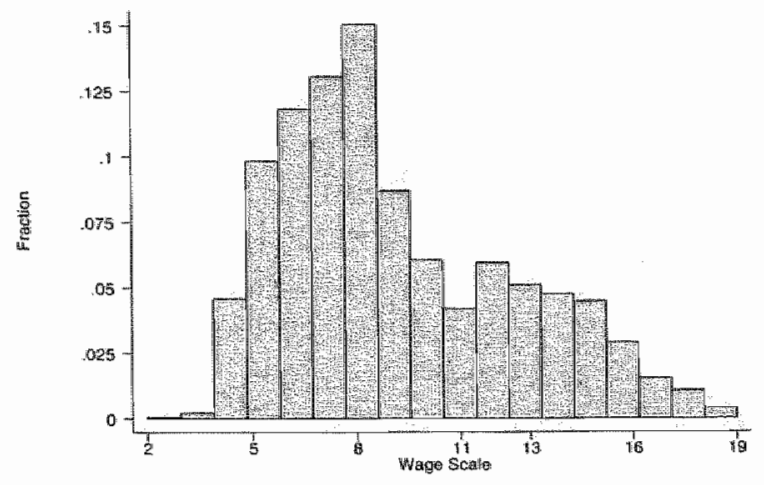

(a) Distribution Among Workforce on March 1, 1991

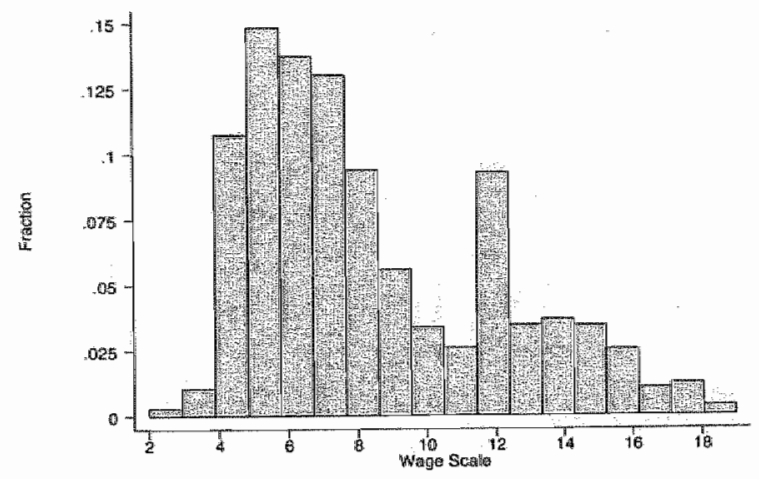

(b) Distribution Among Separations 1987-1991

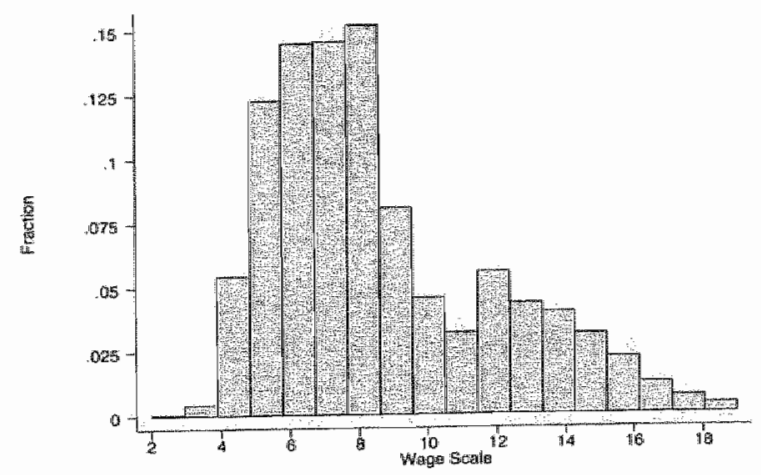

(c) Distribution Among Separations 1991-1996 
Table 4.3: Distribution of Performance Evaluation Scores

\begin{tabular}{|c|c|c|c|c|c|c|}
\hline \multirow{3}{*}{$\begin{array}{l}\text { Evaluation } \\
\text { Score }\end{array}$} & \multicolumn{3}{|c|}{ Blue Collar Workers } & \multicolumn{3}{|c|}{ White-Collax Workers } \\
\hline & Employed & Separations & Separations & Employed & Separations & Soparation \\
\hline & $\begin{array}{l}\text { March } 1 \\
1991\end{array}$ & $1987-1991$ & $1991-1996$ & $\begin{array}{l}\text { March } 1 \\
1991\end{array}$ & $1987-1991$ & $1991-1996$ \\
\hline 1 & 0.13 & 0.46 & 0.21 & 0.15 & 1.85 & 1.17 \\
\hline 2 & 1.14 & 3.77 & 2.76 & 2.89 & 7.77 & 5.77 \\
\hline 3 & 49.84 & 54.18 & 55.77 & 84.65 & 79.04 & 81.99 \\
\hline 4 & 36.52 & 27.59 & 32.22 & 12.14 & 10.11 & 10.72 \\
\hline 5 & 11.06 & 9.36 & 7.63 & 0.15 & 0.49 & 0.34 \\
\hline 6 & 1.31 & 244 & $\mathbb{1} .42$ & & & \\
\hline missing & 0.01 & 2.20 & & 0.03 & 0.74 & \\
\hline Total & 100.00 & 100.00 & 100.00 & 100.00 & 100.00 & 100.00 \\
\hline
\end{tabular}

\subsection{Estimation Results}

The results are summarized as follows. The shape of the baseline hazard differs in periods of workforce expansion and downsizing (Figure 4.5). It is flat and comparably small in the period of employment growth but erratic and much larger in the period of downsizing. ${ }^{17}$ There are important group-specific differences between both periods (Tables $4.4-4.8$ and Figures 4.6 and 4.7 ). Relative separation rates differ between the low and high turnover regimes. Some parameter estimates even change sign between the two regimes. Fol" example, women face higher separation hazards in the low turnover regime, while they are less likely to separate than their male colleagues in the period of downsizing. ${ }^{18}$ White-collar workers have higher turnover rates than their blue-collar colleagues in the first period and lower ones in the second period. ${ }^{\text {th }}$

A generally important result is our finding that age effects are not captured by common parametric specifications or lower order polynomials (see Figure 4.7). Existing studies often fit a quadratic age effect. However, this approach is flawed, as Figure 4.7 suggests, because it ignores the discontinuous drops and jumps around early retirement age, which are not even

\footnotetext{
17The shape of the baseline hazard looks similar if the model is estimated without period-splitting.

${ }^{18}$ This miglat reflect that many women work as secretaries. This job is complementary to many white-collar jobs, which are cut relatively less in the period of restructuring.

19 This result energes also when we estimate the model without stratifying our sample into blue-collar and white-collar workers, and control for white-collax employment by at dumny variable.
} 
captured adequately by a seventh order polynomial. Typically these studies estimate the minimum separation rates to occur at age $35-40 .^{20}$ But our results suggest that hazard rates fall rather than rise for workers past 35 years of age untill becoming eligible for (early) retirement. Results based on a parametric misspecification of the effect of age on separation rate are misleading for theory evaluation. A life cycle incentives model, like Lazear's (1979) model, would predict the minimum separation rate to be around the age of 35-40, when firms start paying back the compensation deferred earlier, but would not predict the fall in hazard rates for workers in their late 40s and early 50 s that we find. Moreover, results based on a misspecified parametric approach miss an important aspect that (downsizing) firms should take into account when they design buyout or early retirement schemes, namely the option value of early retirement.

\section{A. Robustness of the Results}

We checked the robustness of our specification by restricting the parameter vector $\beta$ in different ways and by different forms of stratification. Coefficient estimates are generally robust in the sense that the exclusion of variables does not have a significant effect on other estimated coefficients. For example, leaving out controls for a worker's career, or for gender, or part-time work, does not significantly change the size of other coefficients. The fit, however, worsens significantly when such control variables are left out. Yet, not controlling for wage scales affects estimated coefficients for education levels and measures of career attainment in the period of restructuring. This reflects the fact that high-wage workers face a much lower increase in the hazard of job separation than workers in lower wage scales, while schooling and income class are highly correlated. The impact of education on separation rates can, therefore, be decomposed into two effects: the effect of education given the job level and the effect of education on the probability of attaining a particular job level.

Coefficient estimates are also robust when the baseline hazard is allowed to differ across strata for gender or part-time workers. Allowing the baseline hazard to differ for different strata, while restricting the remaining coefficients to be identical across strata also allows us to assess the proportionality assumption and the sensitivity of other estimates to the vallidity of this assumption. The baseline hazards for men and women, and full-time and part-time workers are similar, implying that the proportionality assumption

\footnotetext{
${ }^{20}$ In fact, we have simulated this approach by also fitting a quadratic age effect in our data and found the minimum to be at age 36.8 for the pooled sample.
} 
is valid. ${ }^{21}$ We did, however, find important differences in baseline hazard rates for blue- and white-collar workers when we stratified the sample with respect to worker status. Therefore, we estimate the parameter of model (4.1) for the sub-samples of blue-collar and white-collar workers separately.

\section{B. Baseline Hazards}

The baseline hazards plotted in Figure 4.5 reveal large differences between the period of workforce expansion and the period of downsizing which highlights the importance of controlling nonstationarity, especially at the subsidiaries FAC1, FAC2, and FAC3 which constitute the core business and account on average for $78 \%$ of employment. The hazard rate for a job separation is rather flat in the period of expansion until 1991, while it is much more erratic and considerably higher during downsizing, especially from 1993 onwards. The baseline hazard does not rise sharply between 1991 and 1993 when employment is contracting which suggests that workforce reductions prior to 1993 are mainly accomplished by reducing hiring and/or that job cuts are born largely by particular groups of workers. The latter is reflected in changing relative separation rates implied by changing estimated coefficients. This squares nicely with our prior knowledge that workforce reductions were mainly accomplished by usual attrition including retirement, but also early retirement prior to 1993 (Deterink et al., 1997) which shows up in an increase in the estimated age coefficient for workers at early retirement age.

The figure also makes clear that separation hazards of white-collar workers are affected less during downsizing, especially early in the downsizing period at Fokker Aircraft (FAC1, FAC2, FAC3). In fact, while white-collar workers are more likely to separate than blue-collar workers during expansion, the opposite is true during downsizing. The baseline hazard rate peaks in 1993, 1994, and 1995 for both types of workers, but these peaks are much larger for blue-collar workers, especially in the earlier years 1993 and 1994. Downsizing is asymmetric in this period, which may result from differences in adjustment costs and a perception that the crisis is temporary (cf. Hamermesh and Pfann, 1996). ${ }^{22}$ Hazard rates increase most markedly in 1993 at production sites constituting the core business (FAC1, FAC2, and FAC3). ${ }^{23}$

\footnotetext{
${ }^{21}$ This is encouraging if our aim is to quantify the effect of particular characteristics on separation rates.

${ }^{22}$ Asymmetries are also found within the group of blue-collar workers. If we straltify according to wage scales, we find that workers in lower wage scales face higher hazard
rates earlier during the downsizing episode.

${ }^{23}$ The hazard rate is highest at location FAC3 in 1995 when there were plans of closing that site. See Deterimk et al. (1997) for more details on such plans.
} 
Figure 4.5: Baseline Hazards at Different Subsidiaries
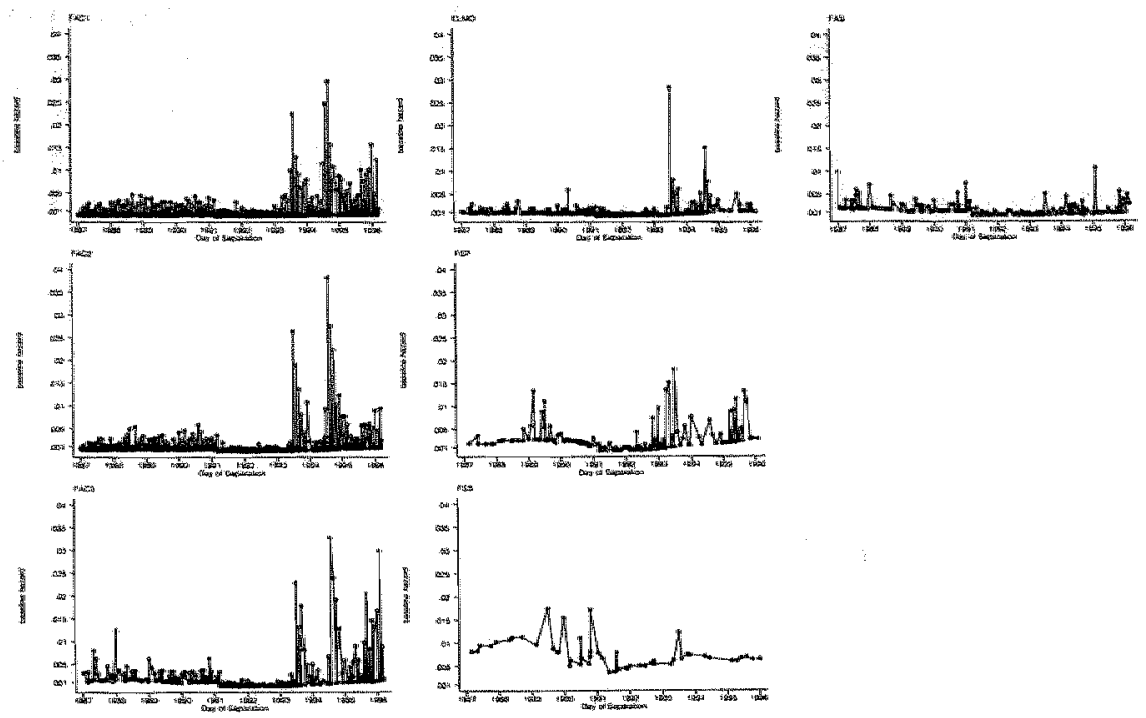

(a) Blue-Collar Workers
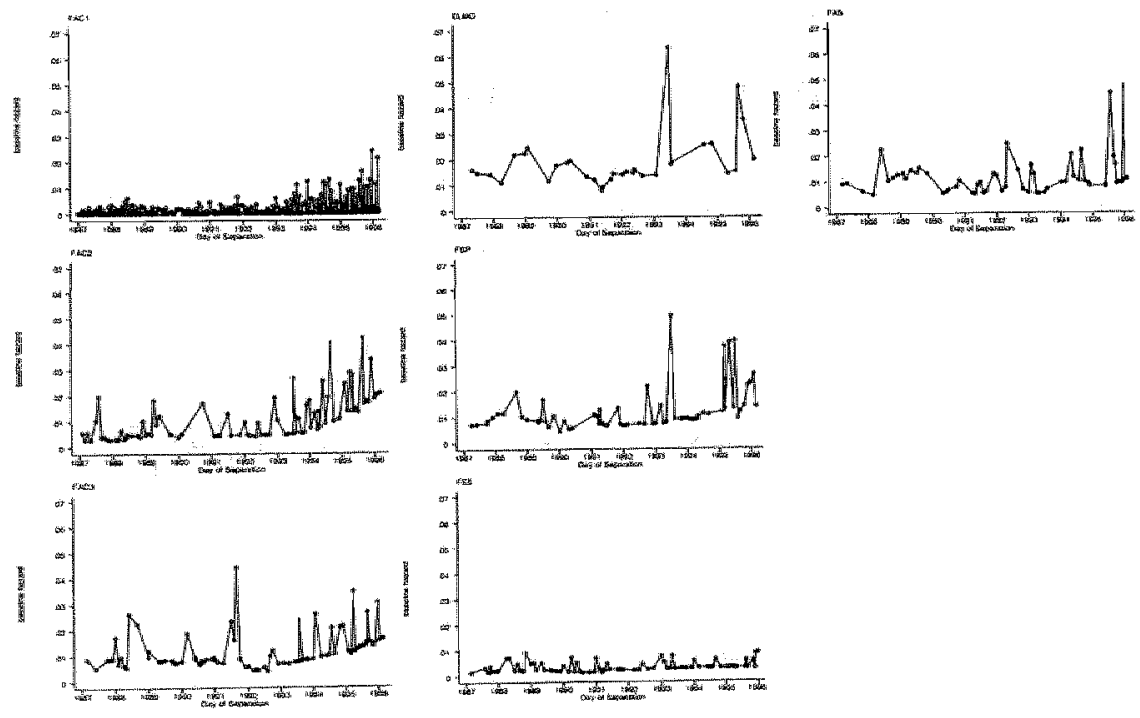

(b) White-Collar Workers 
Tables $4.4-4.8$ report the estimated coefficients of individual characteristics for the different groups of workers and sub-periods. In addition, Figures 4.6 and 4.7 plot the coefficient estimates from Tables 4.4 and 4.5 respectively to give a more accessible graphical representation of the results. All coeffcients are estimated jointly, but reported in various Tables and Figures for expositional convenience. These coefficients measure the effect on the log hazard and ought to be interpreted as follows: $A$ unit change in a covariate $x$ changes the log hazard by the amount of $\beta_{x}$, where $\beta_{x}$ is the estimated coefficient of covariate $x$. Since a unit change in $x$ changes the hazard by approcimately $\beta * 100 \%$ for values of $\beta$ close to zero, we can interpret coefficients of categorical variables as semi-elasticities.

\section{Duration Dependence of Job Tenure}

The duration dependence of job tenure is inferred from the estimated $\alpha$ in equation (4.1). The coefficient estimates for the different periods and strata of the workforce are reported in Table 4.4 and plotted in Figure 4.6. Columns (3) and (6) of Table 4.4 report the p-values for the test that the coefficient in the second period equals the point estimate of the coefficient in the first period, which gives an indication whether coefficients, and hence relative separation rates, differ in the two sub-periods.

Table 4.4: FIrm-Specific Tenure

\begin{tabular}{|c|c|c|c|c|c|c|}
\hline \multirow[b]{2}{*}{ Tenure } & \multicolumn{3}{|c|}{ Blue-Collar Workers } & \multicolumn{3}{|c|}{ White-Collar Workers } \\
\hline & $1987-1991$ & $1991-1996$ & p-values & $1987-1991$ & $1991-1996$ & $p$-values \\
\hline $0-1$ week & $\begin{array}{c}0.910 \\
{[0.440]^{*}}\end{array}$ & $\begin{array}{c}1.463 \\
{[1.008]}\end{array}$ & 0.583 & 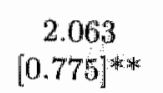 & $\begin{array}{c}2.931 \\
{[0.581]^{*} *}\end{array}$ & 0.136 \\
\hline $1-2$ weeks & $\begin{array}{c}1.722 \\
{[0.293]^{*} \text { *⿻一𠃋十 }}\end{array}$ & $\begin{array}{c}2.504 \\
{[0.515]^{*}}\end{array}$ & 0.129 & $\begin{array}{c}2.098 \\
{[0.654]^{* * *}}\end{array}$ & $\begin{array}{c}1.427 \\
{[1.023]}\end{array}$ & 0.512 \\
\hline $2-3$ weeks & $\frac{1.324}{[0.332] *}$ & $\begin{array}{c}1.916 \\
{[0.727]^{*}}\end{array}$ & 0.416 & $\begin{array}{c}0.888 \\
{[1.044]}\end{array}$ & $\begin{array}{c}1.379 \\
{[1.021]}\end{array}$ & 0.631 \\
\hline $3-4$ weelks & $\begin{array}{c}1.564 \\
{[0.272] * *}\end{array}$ & $\begin{array}{c}0.473 \\
{[1.008]}\end{array}$ & 0.279 & $\begin{array}{c}1.251 \\
{[0.776]}\end{array}$ & $\begin{array}{c}2.559 \\
{[0.615]^{\text {*a水 }}}\end{array}$ & 0.033 \\
\hline $4-5$ weoks & $\begin{array}{c}1.694 \\
{[0.259]^{* * *}}\end{array}$ & $\begin{array}{c}1.588 \\
{[0.521]^{* *}}\end{array}$ & 0.840 & $\begin{array}{c}0.496 \\
{[0.765]}\end{array}$ & $\begin{array}{c}0.891 \\
{[1.019]}\end{array}$ & 0.698 \\
\hline $5-6$ weeks & $\begin{array}{c}2.008 \\
{[0.273] * *}\end{array}$ & $\begin{array}{c}2.658 \\
{[0.516]^{* *}}\end{array}$ & 0.208 & $\begin{array}{c}1.386 \\
{[1.058]}\end{array}$ & $\begin{array}{c}0.961 \\
{[1.028]}\end{array}$ & 0.679 \\
\hline $6-7$ weels & $\begin{array}{c}2.170 \\
{[0.255]^{* * *}}\end{array}$ & $\begin{array}{c}3.163 \\
{[0.369]^{*}}\end{array}$ & 0.007 & $\begin{array}{c}1.745 \\
{[0.668]^{* *}}\end{array}$ & $\begin{array}{c}1.771 \\
{[0.767]^{*}}\end{array}$ & 0.973 \\
\hline $7-8$ weeks & 1.826 & 2.745 & 0.011 & 1.656 & 2.290 & 0.394 \\
\hline
\end{tabular}


(CONTINUED)

\begin{tabular}{|c|c|c|c|c|c|c|}
\hline \multirow[b]{2}{*}{ Tenure } & \multicolumn{3}{|c|}{ Blue-Collar Workers } & \multicolumn{3}{|c|}{ White-Collar Workers } \\
\hline & $1987-1991$ & $1991-1996$ & p-values & $1987-1.991$ & $1991-1996$ & $\mathrm{p}$-values \\
\hline \multirow{3}{*}{ 8-9 weeks } & {$[0.278]^{*} \cdot{ }^{*}$} & {$[0.361]^{* *}$} & \multirow{5}{*}{0.832} & {$[0.774]^{*}$} & {$[0.742]^{* * *}$} & \multirow{3}{*}{0.804} \\
\hline & 2.043 & 2.128 & & 1.643 & 1.793 & \\
\hline & {$[0.222]^{* *}$} & {$[0.400]^{* *}$} & & {$[0.476] * * *$} & {$[0.608]^{* * *}$} & \\
\hline \multirow[t]{2}{*}{9 - 10 weeks } & -0.947 & -43.047 & & -43.031 & 1.283 & \multirow[t]{2}{*}{0.000} \\
\hline & {$[1.014]$} & {$[0.000]$} & & {$[0.000]$} & {$[1.025]$} & \\
\hline \multirow[t]{2}{*}{$10-11$ weeks } & -0.053 & 0.952 & \multirow[t]{2}{*}{0.317} & 0.666 & -43.081 & \\
\hline & {$[0.600]$} & {$[1.005]$} & & {$[1.062]$} & {$[0.000]$} & \\
\hline \multirow[t]{2}{*}{$11-1.2$ weeks } & 0.059 & 0.671 & \multirow[t]{2}{*}{0.545} & 0.672 & 1.821 & \multirow[t]{2}{*}{0.263} \\
\hline & {$[0.600]$} & {$[1.012]$} & & {$[1.052]$} & {$[1.026]$} & \\
\hline \multirow[t]{2}{*}{$3-6$ months } & 0.609 & $1.669^{\circ}$ & \multirow[t]{2}{*}{0.000} & 1.035 & 1.550 & \multirow[t]{2}{*}{0.064} \\
\hline & {$[0.188]^{* *}$} & {$[0.164]^{* *}$} & & {$[0.353]^{* *}$} & {$[0.279]^{* * *}$} & \\
\hline \multirow[t]{2}{*}{$6-9$ months } & 0.810 & 1.548 & \multirow[t]{2}{*}{0.000} & 1.108 & 1.149 & \multirow[t]{2}{*}{0.892} \\
\hline & {$[0.183]^{* *}$} & {$[0.157]^{* * *}$} & & {$[0.361]^{* * *}$} & {$[0.306]^{* *}$} & \\
\hline \multirow[t]{2}{*}{$9-12$ months } & 1.049 & 1.884 & \multirow[t]{2}{*}{0.000} & 1.493 & 1.420 & \multirow[t]{2}{*}{0.782} \\
\hline & {$[0.177]^{* *}$} & {$[0.133] * *$} & & {$[0.335]^{* *}$} & {$[0.266]^{* *}$} & \\
\hline \multirow{2}{*}{$1-2$ years } & 0.692 & 1.748 & \multirow[t]{2}{*}{0.000} & 1.375 & 1.180 & \multirow{2}{*}{0.326} \\
\hline & {$[0.162]^{* *}$} & {$[0.090]^{* * *}$} & & {$[0.289]^{* *}$} & {$[0.198]^{* * *}$} & \\
\hline \multirow[t]{2}{*}{$2-3$ years } & 0.847 & 1.719 & 0.000 & 1.626 & 1.501 & 0.512 \\
\hline & {$[0.164]^{* *}$} & {$[0.084]^{* * *}$} & & {$[0.289]^{* *}$} & {$[0.191]^{* * *}$} & \\
\hline $3-4$ years & 0.710 & 1.342 & 0.000 & 1.544 & 1.231 & 0.092 \\
\hline & {$[0.165]^{* * *}$} & {$[0.080]^{* *}$} & & {$[0.285]^{* *}$} & {$[0.186]^{* * *}$} & \\
\hline $4-5$ years & 0.640 & 0.928 & 0.000 & 1.268 & 1.065 & 0.277 \\
\hline & {$[0.173]^{* *}$} & {$[0.080]^{* *}$} & & {$[0.296]^{\text {k* }}$} & {$[0.186]^{* * *}$} & \\
\hline 5 - 10 years & 0.343 & 0.389 & 0.513 & 1.389 & 0.967 & 0.009 \\
\hline & {$[0.148]^{*}$} & {$[0.070]^{* * *}$} & & {$[0.265]^{\text {** } *}$} & {$[0.162]^{* *}$} & \\
\hline $10-15$ years & 0.021 & 0.114 & 0.182 & 0.521 & 0.482 & 0.814 \\
\hline & {$[0.158]$} & {$[0.070]$} & & {$[0.296]$} & {$[0.165]^{3 *}$} & \\
\hline $15-20$ years & $\begin{array}{c}\text { reference } \\
\text { group }\end{array}$ & $\begin{array}{l}\text { reference } \\
\text { group }\end{array}$ & & $\begin{array}{l}\text { reference } \\
\text { group }\end{array}$ & $\begin{array}{l}\text { reference } \\
\text { group }\end{array}$ & \\
\hline $20-25$ years & -0.379 & -0.177 & 0.060 & 0.219 & 0.064 & 0.439 \\
\hline & {$[0.220]$} & {$[0.108]$} & & {$[0.340]$} & {$[0.200]$} & \\
\hline 25 - 30 years & -0.151 & -0.070 & 0.509 & 0.481 & -0.128 & 0.004 \\
\hline & {$[0.200]$} & {$[0.123]$} & & {$[0.341]$} & {$[0.213]$} & \\
\hline $30-35$ years & -0.030 & 0.436 & 0.000 & 0.257 & 0.339 & 0.673 \\
\hline & {$[0.177]$} & {$[0.111]^{* * *}$} & & {$[0.302]$} & {$[0.194]$} & \\
\hline $35-40$ years & -0.258 & 0.461 & 0.000 & 0.451 & 0.828 & 0.052 \\
\hline & {$[0.183]$} & {$[0.112]^{* * * *}$} & & {$[0.311]$} & {$[0.194]^{3 *}$} & \\
\hline$>40$ years & 0.264 & 0.853 & 0.000 & $\begin{array}{c}0.999 \\
{[0.329]^{*} *}\end{array}$ & $\begin{array}{c}1.377 \\
{[0.221]^{* *}}\end{array}$ & 0.087 \\
\hline & $\frac{[0.210]}{189088}$ & $\frac{[0.14]}{135195}$ & & 60706 & 63192 & \\
\hline
\end{tabular}

Notes: Standard errors are in parentheses. An asterisk denotes significance

at the 5 percent level, two asterisks denote significance at the 1 percent level. 

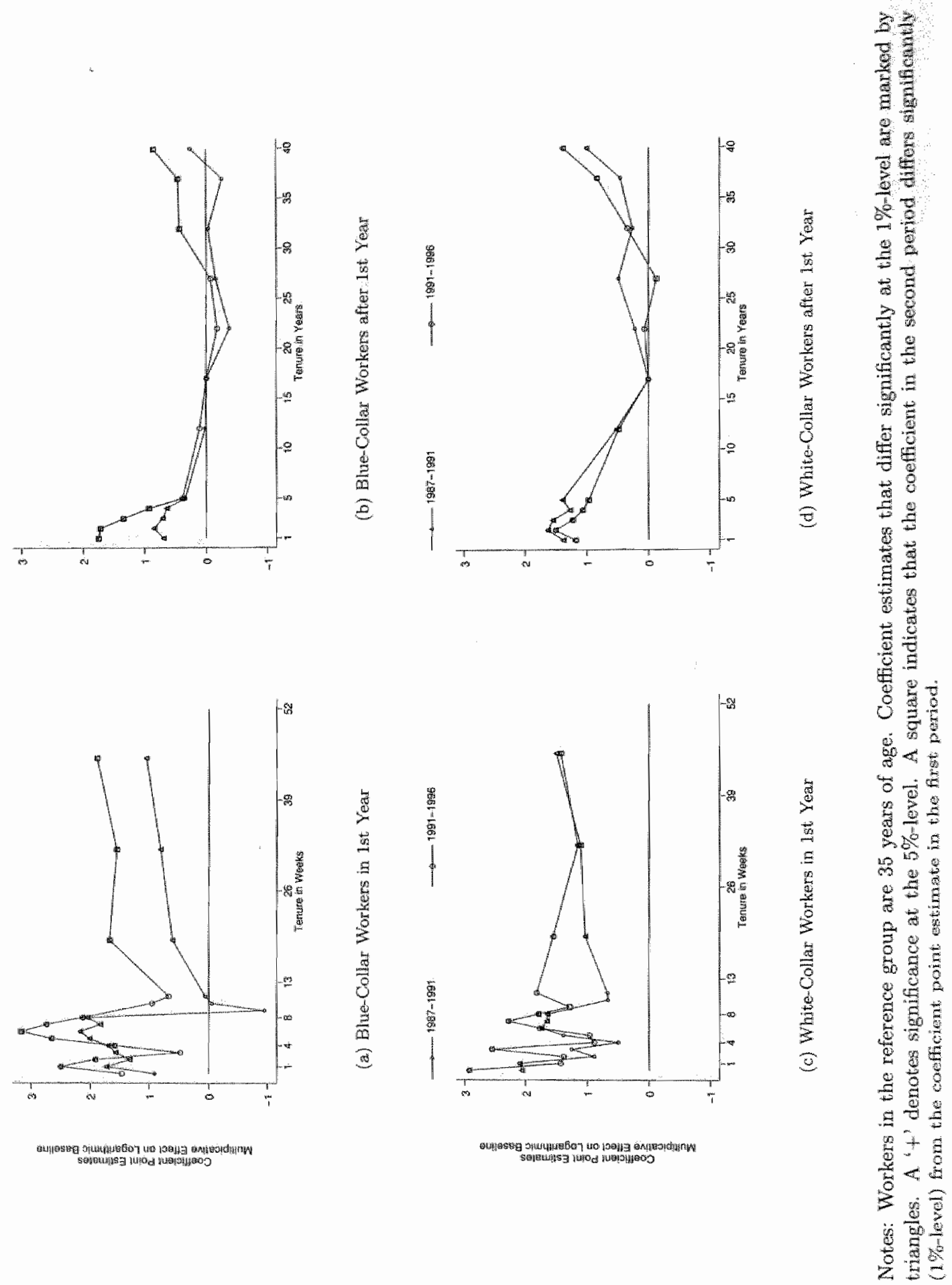
Figure 4.6 illustrates that hazard rates for blue-collar workers increase in the first seven weeks, drop in the 3rd month of the employment relation, but remain high thereafter throughout the first year. Hazard rates for whitecollar workers fall in the first month, rise in the second, fall in the third, but remain high throughout the first year. After 1-2 years of tenure, the duration dependence is u-shaped for both strata of workers in both periods. Hazard rates remain significantly higher for blue-collar workers in their first 5 years during the period of downsizing as the p-values in column (3) of Table 4.4 accentuate. After 10-15 years of job tenure, the hazard rate is rather low and remains flat only to rise again at very long tenure duration, a feature that can be ascribed to retirement. This effect sets in at lower tenure in the downsizing episode, especially for blue-collar workers. Our results illustrate that different cohorts are affected differently. This points at a dependence relation between a worker's past career path within the firm and turnover (costs).

Jovanovic's (1979a) model is consistent with rising separation rates in the first weeks of the employment relation, as it takes time for workers to accumulate sufficient "bad" information about their match that makes a separation optimal. This model also explains a diminishing hazard rate after the peak has been reached, and it would generate an increasing hazard after long tenure when it takes into account that workers retire. But the model does not predict the negative dependence of experience or age on the job separation hazard of which we report some evidence below. In addition, it neglects human capital accumulation. The model in Jovanovic (1979b) takes this into account, and can, like other turnover models with on-the-job learning (e.g. Mortensen, 1978) or other forms of specific capital accumulation, explain the pattern of decreasing job hazards that we observe after the first year. Other findings in this study on the effect of schooling and training, also support the model with specific skill investments. Yet, this class of models does not generate the turnover pattern at the beginning of the match that Jovanovic (1979a) predicts and that we observe in our data.

A life cycle incentives model, as for instance proposed by Lazear (1979), also generates a negative duration dependence, but does not predict hazard rates to rise early on. Separation rates should fall with tenure in Lazear's model until the worker is repaid for the effort he provided early in his career. Then it may rise if buy-outs are feasible. In absence of shocks that make such buy-outs optimal for both parties, we should expect the hazard rate to remain flat until retirement. When shocks are large, separation probabilities should be higher the more feasible a buy-out opportunity becomes. This is more likely the shorter the period until mandatory retirement and hence the longer tenure (at given age). This is roughly what the hazard rates for the 
period of downsizing suggest. So the model explains the pattern at longer tenure, but is not entirely consistent with our findings on age (section 4.6.D).

Relative separation rates for blue-collar workers differ in the two subperiods as column (3) of Table 4.4 shows. Workers with $1-5$ years of tenure and workers with more than 30 years of tenure become relatively more likely to separate during downsizing. Relative hazard rates for white-collar workers ehange after 25 years of tenure. The increase in the hazard rate at long tenure suggests that early retirement occurs more frequently in the period of downsizing. The higher hazard at short tenure, especially during the first 5 years, indicates that those who were hired in the previous expansion are hit more severely in the period of downsizing than workers who had joined the firm before 1987. This would be consistent with the LIFO-layoff model of Kulun (1988) and Kuhn and Roberts (1989). Since unions impose the LIFO-layoff rule in these models to extract rents from the firm, we expect that the relative increase of the separation rate for workers with short tenure in periods of downsizing is stronger for blue-collar workers, who are covered by collective bargaining agreements, than for white-collar workers who are not bound by such agreements. This is indeed what we find. There are two caveats, however. First, we should keep in mind that differences in absolute separation rates are generally smaller (see the discussion in the previous section), which potentially explains that relative separation rates also change less for white-collar. Second, as will become obvious from the discussion of other characteristics on job separation rates, especially of schooling degrees and performance evaluation, there is no evidence of an unconditional LIFOlayoff rule in our data, as workers with poor performance scores and workers with lower level educational degrees also become more likely to separate during downsizing.

\section{Age Effects}

The effect of age on separation rates produces novel results. The effects are not smooth. Figure 4.7 plots the coefficient estimates for the different age categories for blue-collar (Panel (a)) and white-collar workers (Panel (b)). It illuminates that discontinuities are especially important for older workers.

The hazard rate for blue-collar workers younger than 40 years of age is rather flat and decreases only gradually with age during the period of expansion. The hazard rates for these workers (given their characteristics we control for) do generally not differ significantly from the hazard rate of workers in the reference group, who are 35 years old. Hazard rates of white-collar workers decrease more with age, especially during expansion, but differences relative to the reference group and differences between relative separation 
Figure 4.7: AGE EFFECTS

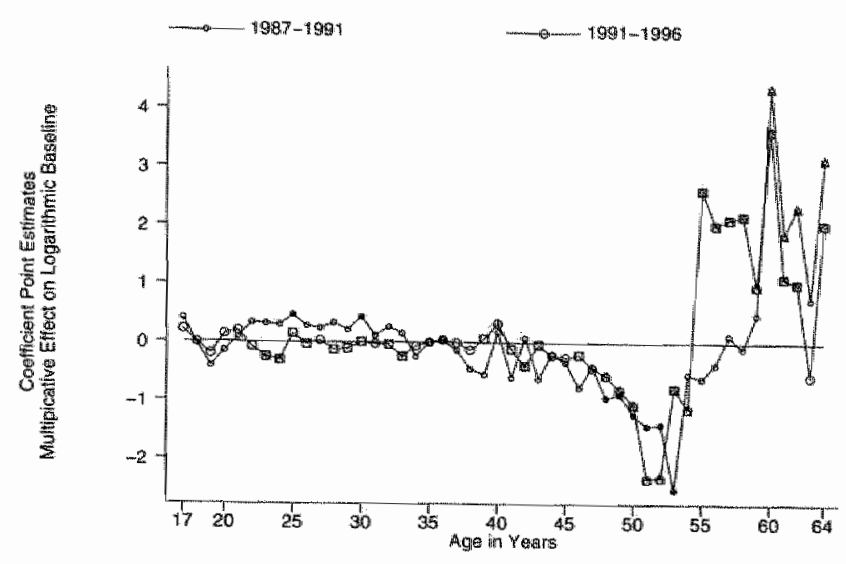

(m) Blue-Collan Workers

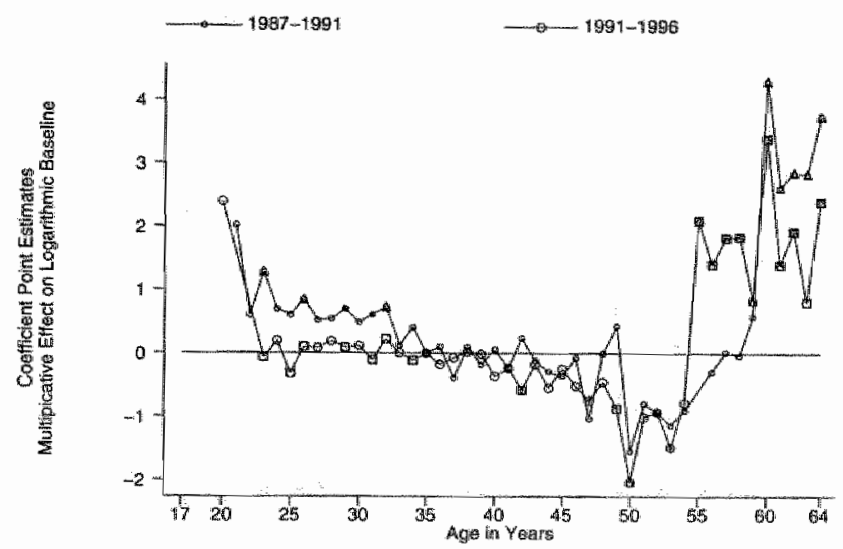

(b) White-Collar Workers

Notes: Workers in the reference group are 35 years of age. Coefficient estimates thal differ significantly at the $1 \%$-level are narked by triangles. A + denotes significance at the $5 \%$-level. A square indicates that the coefficient in the second period differs significantly (1\%-level) from the coefficient point estimate in the first period. 
rates in the two sub-periods are rarely significant. White-collar workers have usually completed higher education and probably acquire relatively less firmspecific skills on the job. They probably make fewer firm-specific investments than their blue-collar counterparts early in their career. Consequently, the surplus of the current match over the outside option, given tenure in the current match, tends to be smaller for white-collar workers. Therefore, jobshopping is a more common phenomenon early in the career of a white-collar worker.

Different from the results in other studies, we find that hazard rates decline for workers in their forties and drop markedly at the age of 50. This drop is even more severe in the period of downsizing for blue-collar workers. A negative dependence of job separation hazards on age are consistent with job search models like Jovanovic (1979b) as age is highly correlated with experience in the labor market and the probability of being matched well increases with the time spent searching. But this result cannot be explained when jobs are pure experience goods as in Jovanovic (1979a). It is also not obvious that these results are consistent with a deferred compensation model since turnover rates should rise once the firm starts repaying workers. Some empirical studies find such an effect when they fit a quadratic age effect. If we force a quadratic effect on our data, we also find the minimum to occur between the age of 35 and 40 , but that is not what Figure 4.7 suggests. Instead we observe discontinuous drops and jumps in the hazard rate for workers in their fifties.

Relative separation rates for blue-collar workers older than 52 and whitecollar workers older than 54 differ significantly between the periods of expansion and contraction, as the p-values for the test that the estimated coefficient in the period of downsizing is equal to the point estimate for the corresponding coefficient in the period of expansion show.

During the period of expansion, the hazard rate rises for workers aged 54 to 59 , but it is statistically not significantly different from the hazard rate of workers in the reference group aged 35 . Hazard rates jump at the age of 60 suggesting that most workers retire then and take advantage of an institutionalized early retirement scheme. This is different during downsizing when the hazard jumps up for workers aged 55 and remains high thereafter. The p-values in column 4 indicates that this difference is significant for workers aged 55 to 58 . In the period of downsizing, the firm offers early retirement plans or buyouts for workers aged 55 or older, in which workers are guaranteed $85 \%$ of their wages as they receive the capitalized value of $15 \%$ of their wages for the time until they turn 60 and become eligible for "regular" early retirement as a lump sum payment from the firm and $70 \%$ from various benefits schemes if they decide to stay unemployed. Such a buyout or pension 
scheme explains the discrete jump in exit rates at age 55.

However, early retirement also seems to have an option value. The value of the option to wait for becoming eligible for early retirement seems to be highest for workers aged 50-54 and their separation probabilities are, consequently, lowest. ${ }^{24}$ This result has important personnel policy implications for the design of early retirement plans. Early retirement schemes have strong spill-over effect on slightly younger workers that should be taken into account. Downsizing firms may want to offer less generous early retirement schemes to a broader group of workers in order to retain productive workers.

Table 4.5: PARAMETER Estimates for Age

\begin{tabular}{|c|c|c|c|c|c|c|}
\hline \multirow[b]{2}{*}{ Age in Years } & \multicolumn{3}{|c|}{ Blue-Collar Workers } & \multicolumn{3}{|c|}{ White-Collar Workers } \\
\hline & $1987-1991$ & $1991-1996$ & $\mathrm{p}$-values & $1987-1991$ & $1991-1996$ & p-values \\
\hline \multirow[t]{2}{*}{17} & 0.408 & 0.216 & 0.789 & & & \\
\hline & {$[0.535$} & {$[0.718]$} & & & & \\
\hline \multirow[t]{2}{*}{18} & -0.035 & -0.010 & 0.909 & & & \\
\hline & {$[0.286]$} & {$[0.217]$} & & & & \\
\hline \multirow[t]{2}{*}{19} & -0.419 & -0.201 & 0.164 & & & \\
\hline & {$[0.251]$} & {$[0.157]$} & & & & \\
\hline \multirow[t]{2}{*}{20} & -0.150 & 0.135 & 0.034 & & 2.399 & \\
\hline & {$[0.215]$} & {$[0.134]$} & & & {$[1.282]$} & \\
\hline \multirow[t]{2}{*}{21} & 0.086 & $0.195^{\circ}$ & 0.381 & 2.020 & -41.230 & \\
\hline & {$[0.201]$} & {$[0.124]$} & & {$[1.170]$} & {$[0.000]$} & \\
\hline \multirow[t]{2}{*}{22} & 0.334 & -0.076 & 0.001 & 0.597 & -43.918 & \\
\hline & {$[0.193]$} & {$[0.124]$} & & {$[0.767]$} & {$[0.000]$} & \\
\hline \multirow[t]{2}{*}{23} & 0.315 & -0.252 & 0.000 & 1.285 & -0.066 & 0.006 \\
\hline & {$[0.191]$} & {$[0.119]^{*}$} & & {$[0.386]^{* *}$} & {$[0.489]$} & \\
\hline \multirow[t]{2}{*}{24} & 0.299 & -0.303 & 0.000 & 0.692 & 0.197 & 0.096 \\
\hline & {$[0.192]$} & {$[0.115]^{* *}$} & & {$[0.358]$} & {$[0.297]$} & \\
\hline \multirow[t]{2}{*}{25} & $0.465^{3}$ & 0.148 & 0.003 & 0.606 & -0.321 & 0.001 \\
\hline & {$[0.190]^{*}$} & $\llbracket 0.106 \rrbracket$ & & {$[0.323]$} & {$[0.279]$} & \\
\hline \multirow[t]{2}{*}{26} & 0.282 & -0.034 & 0.004 & 0.850 & 0.101 & 0.000 \\
\hline & {$[0.193]$} & {$[0.109]$} & & {$[0.298]^{* * *}$} & {$[0.215]$} & \\
\hline \multirow[t]{2}{*}{27} & 0.245 & 0.033 & 0.049 & 0.522 & 0.085 & 0.032 \\
\hline & {$[0.196]$} & {$[0.107]$} & & {$[0.301]$} & {$[0.204]$} & \\
\hline \multirow[t]{2}{*}{28} & 0.335 & -0.127 & 0.000 & 0.545 & 0.189 & 0.065 \\
\hline & {$[0.196]$} & {$[0.110]$} & & {$[0.296]$} & {$[0.193]$} & \\
\hline \multirow[t]{2}{*}{29} & 0.219 & -0.103 & 0.003 & 0.699 & 0.091 & 0.002 \\
\hline & {$[0.202]$} & {$[0.110]$} & & {$[0.282]^{*}$} & {$[0.193]$} & \\
\hline
\end{tabular}

\footnotetext{
${ }^{24}$ Stock and Wise (1990) develop a retirement model which takes into account the option walue of continuing work and thereby keeping the option to retire on better terms alive. Their model fits firm retirement data, marked by sharp discontinuous jumps in retirement rates at specificic ages, well.
} 
(OONTINUED)

\begin{tabular}{|c|c|c|c|c|c|c|}
\hline \multirow[b]{2}{*}{ Age in Years } & \multicolumn{3}{|c|}{ Blue-Collar Workers } & \multicolumn{3}{|c|}{ White-Collar Workers } \\
\hline & $1987-1991$ & $1991-1996$ & p-values & $1987-1991$ & $1991-1996$ & $p$-values \\
\hline \multirow[t]{2}{*}{30} & 0.435 & 0.006 & 0.000 & 0.491 & 0.115 & 0.044 \\
\hline & {$[0.199]^{*}$} & {$[0.110]$} & & {$[0.286]$} & {$[0.187$} & \\
\hline \multirow[t]{2}{*}{31} & 0.123 & -0.024 & 0.190 & 0.610 & -0.108 & 0.000 \\
\hline & {$[0.214]$} & {$[0.112]$} & & {$[0.281]^{*}$} & {$[0.192]$} & \\
\hline \multirow[t]{2}{*}{32} & 0.264 & -0.035 & 0.010 & 0.732 & 0.225 & 0.005 \\
\hline & {$[0,213]$} & {$[0.115]$} & & {$[0.275]^{* * *}$} & $\lceil 0.179 \rrbracket$ & \\
\hline \multirow[t]{2}{*}{33} & 0.155 & -0.243 & 0.001 & 0.125 & 0.007 & 0.533 \\
\hline & {$[0.223]$} & {$[0.124]^{*}$} & & {$[0.307]$} & {$[0.189]$} & \\
\hline \multirow[t]{2}{*}{34} & -0.241 & -0.062 & 0.138 & 0.408 & -0.114 & 0.008 \\
\hline & {$[0.251]$} & {$[0.121]$} & & {$[0.295]$} & {$[0.196]$} & \\
\hline 35 & reference & reference & & reference & reference & \\
\hline \multirow[t]{2}{*}{36} & 0.032 & 0.039 & 0.954 & 0.100 & -0.180 & 0.176 \\
\hline & {$[0.238]$} & {$[0.125]$} & & {$[0.322]$} & {$[0.206]$} & \\
\hline \multirow[t]{2}{*}{37} & -0.133 & -0.003 & 0.310 & -0.392 & -0.071 & 0.125 \\
\hline & {$[0.251]$} & {$[0.129]$} & & {$[0.373]$} & {$[0.209]$} & \\
\hline \multirow[t]{2}{*}{38} & -0.455 & -0.131 & 0.018 & 0.096 & 0.022 & 0.726 \\
\hline & {$[0.285]$} & {$[0.137]$} & & {$[0.343]$} & {$[0.210]$} & \\
\hline \multirow[t]{2}{*}{39} & -0.551 & 0.063 & 0.000 & -0.180 & -0.012 & 0.444 \\
\hline & {$[0.296]$} & {$[0.136]$} & & {$[0.384]$} & {$[0.220]$} & \\
\hline \multirow[t]{2}{*}{40} & 0.178 & 0.327 & 0.258 & 0.061 & -0.365 & 0.089 \\
\hline & {$[0.245]$} & {$[0.132]^{*}$} & & {$[0.359]$} & {$[0.251]$} & \\
\hline \multirow[t]{2}{*}{41} & -0.596 & -0.114 & 0.001 & -0.230 & -0.236 & 0.980 \\
\hline & {$[0.317]$} & {$[0.151]$} & & $\llbracket 0.387\rceil$ & {$[0.246]$} & \\
\hline \multirow[t]{2}{*}{42} & 0.084 & -0.396 & 0.004 & 0.237 & -0.579 & 0.004 \\
\hline & {$[0.260]$} & {$[0.166]^{*}$} & & {$[0.361]$} & {$[0.286]^{*}$} & \\
\hline \multirow[t]{2}{*}{43} & -0.618 & -0.034 & 0.000 & -0.116 & -0.176 & 0.813 \\
\hline & {$[0.335]$} & {$[0.151]$} & & {$[0.431]$} & {$[0.252]$} & \\
\hline \multirow[t]{2}{*}{44} & -0.200 & -0.213 & 0.937 & -0.289 & -0.546 & 0.385 \\
\hline & {$[0.310]$} & {$[0.169]$} & & {$[0.478]$} & {$[0.296]$} & \\
\hline \multirow[t]{2}{*}{45} & -0.334 & -0.248 & 0.615 & -0.360 & -0.248 & 0.681 \\
\hline & {$[0.347]$} & {$[0.171]$} & & {$[0.511]$} & {$[0.274]$} & \\
\hline \multirow[t]{2}{*}{46} & -0.769 & -0.211 & 0.001 & -0.073 & -0.518 & 0.154 \\
\hline & {$[0.415]$} & {$[0.167]$} & & {$[0.479]$} & {$[0.31 .2]$} & \\
\hline \multirow[t]{2}{*}{47} & -0.401 & -0.434 & 0.860 & -1.030 & -0.743 & 0.401 \\
\hline & {$[0.360]$} & {$[0.186] *$} & & {$[0.750]$} & $[0.342]]^{*}$ & \\
\hline \multirow[t]{2}{*}{48} & -0.948 & -0.563 & 0.063 & -0.001 & -0.453 & 0.161 \\
\hline & {$[0.443]^{*}$} & {$[0.207]^{* * *}$} & & {$[0.514]$} & {$[0.322]$} & \\
\hline \multirow[t]{2}{*}{49} & -0.884 & -0.806 & 0.750 & 0.432 & -0.872 & 0.002 \\
\hline & {$[0.443]^{*}$} & {$[0.242]^{* *}$} & & {$[0.438]$} & {$[0.413]^{*}$} & \\
\hline \multirow[t]{2}{*}{50} & -1.230 & -1.062 & 0.553 & -1.546 & -2.030 & 0.505 \\
\hline & {$[0.530]^{*}$} & {$[0.283]^{* *}$} & & [1.035] & {$[0.727]^{*}$} & \\
\hline
\end{tabular}


(CONTINUED)

\begin{tabular}{|c|c|c|c|c|c|c|}
\hline \multirow[b]{2}{*}{ Age in Years } & \multicolumn{3}{|c|}{ Blue-Collar Workers } & \multicolumn{3}{|c|}{ White-Collar Workers } \\
\hline & $1987-1991$ & $1991-1996$ & $\mathrm{p}$-values & $1987-1991$ & $1991-1996$ & $\mathrm{p}$-values \\
\hline 51 & $\begin{array}{c}-1.426 \\
{[0.604]^{k}}\end{array}$ & $\begin{array}{c}-2.330 \\
{[0.508]^{* *}}\end{array}$ & 0.075 & $\begin{array}{l}-0.795 \\
{[0.755]}\end{array}$ & $\begin{array}{c}-1.006 \\
{[0.442]^{*}}\end{array}$ & 0.634 \\
\hline 52 & $\begin{array}{c}-1.404 \\
{[0.604]^{*}}\end{array}$ & $\begin{array}{c}-2.313 \\
{[0.509]^{* *}}\end{array}$ & 0.074 & $\begin{array}{l}-0.926 \\
{[0.757]}\end{array}$ & $\begin{array}{c}0.927 \\
{[0.441]^{*}}\end{array}$ & 0.998 \\
\hline 53 & {$[1.016]^{-2.518}$} & $\begin{array}{c}-0.782 \\
{[0.260]^{*}}\end{array}$ & 0.000 & $\begin{array}{l}-1.135 \\
{[0.758]}\end{array}$ & {$[0.602]^{*}$} & 0.558 \\
\hline 54 & $\begin{array}{l}-0.541 \\
{[0.418]}\end{array}$ & $\begin{array}{c}-1.131 \\
{[0.304]^{* *}}\end{array}$ & 0.0 .52 & $\begin{array}{l}-0.902 \\
{[0.759]}\end{array}$ & $\begin{array}{l}-0.782 \\
{[0.444]}\end{array}$ & 0.788 \\
\hline 55 & $\begin{array}{l}-0.609 \\
{[0.418]}\end{array}$ & $\begin{array}{c}2.627 \\
{[0.116]^{\text {*水 }}}\end{array}$ & 0.000 & $\begin{array}{l}-45.633 \\
{[0.000]}\end{array}$ & $\begin{array}{c}2.110 \\
[0.211]]^{* *}\end{array}$ & 0.000 \\
\hline 56 & $\begin{array}{c}-0.371 \\
{[0.379]}\end{array}$ & $\begin{array}{c}2.026 \\
{[0.14 .0]^{* * *}}\end{array}$ & 0.000 & $\begin{array}{l}-0.290 \\
{[0.573]}\end{array}$ & $\begin{array}{c}1.418 \\
{[0.248]^{* *}}\end{array}$ & 0.000 \\
\hline 57 & $\begin{array}{c}0.129 \\
{[0.316]}\end{array}$ & $\begin{array}{c}2.130 \\
{[0.147]^{* * *}}\end{array}$ & 0.000 & $\begin{array}{c}0.017 \\
{[0.528]}\end{array}$ & $\begin{array}{c}1.840 \\
{[0.227]^{* *}}\end{array}$ & 0.000 \\
\hline 58 & $\begin{array}{l}-0.092 \\
{[0.343]}\end{array}$ & $\begin{array}{c}2.192 \\
{[0.150]^{* *}}\end{array}$ & 0.000 & $\begin{array}{c}-0.034 \\
{[0.530]}\end{array}$ & $\begin{array}{c}1.852 \\
{[0.230]^{* *}}\end{array}$ & 0.000 \\
\hline 59 & $\begin{array}{c}0.490 \\
{[0.291]}\end{array}$ & $\begin{array}{c}0.981 \\
{[0.217]^{* *}}\end{array}$ & 0.024 & $\begin{array}{c}0.587 \\
{[0.438]}\end{array}$ & $\begin{array}{c}0.848 \\
{[0.282]^{* *}}\end{array}$ & 0.354 \\
\hline 60 & $\begin{array}{c}4.403 \\
{[0.199]^{* *}}\end{array}$ & $\begin{array}{c}3.654 \\
{[0.127]^{* *}}\end{array}$ & 0.000 & $\begin{array}{c}4.325 \\
{[0.299]^{* *}}\end{array}$ & $\begin{array}{c}3.416 \\
{[0.199]^{* *}}\end{array}$ & 0.000 \\
\hline 61 & $\begin{array}{c}1.886 \\
{[0.331]^{* *}}\end{array}$ & $\begin{array}{c}1.119 \\
{[0.274]^{* *}}\end{array}$ & 0.005 & $\begin{array}{c}2.646 \\
{[0.378]^{* * *}}\end{array}$ & $\begin{array}{c}1.410 \\
{[0.365]^{* *}}\end{array}$ & 0.001 \\
\hline 62 & $\begin{array}{c}2.345 \\
{[0.339]^{* *}}\end{array}$ & $\begin{array}{c}1.027 \\
{[0.283]^{* * *}}\end{array}$ & 0.000 & $\begin{array}{c}2.875 \\
{[0.424]^{* * *}}\end{array}$ & $\begin{array}{c}1.943 \\
{[0.324]^{* *}}\end{array}$ & 0.004 \\
\hline 63 & $\begin{array}{c}0.758 \\
{[0.735]}\end{array}$ & $\begin{array}{l}-0.570 \\
{[0.590]}\end{array}$ & 0.024 & $\begin{array}{c}2.861 \\
{[0.487]^{* *}}\end{array}$ & $\begin{array}{c}0.819 \\
{[0.486]}\end{array}$ & 0.000 \\
\hline 64 & $\begin{array}{c}3.178 \\
{[0.289]^{* * *}}\end{array}$ & $\begin{array}{c}2.051 \\
{[0.201]^{* *}}\end{array}$ & 0.000 & $\begin{array}{c}3.780 \\
{[0.409]^{*} \text { * }}\end{array}$ & $\begin{array}{c}2.416 \\
{[0.303]^{*} *}\end{array}$ & 0.000 \\
\hline Observations & 189988 & 135195 & & 60706 & 63192 & \\
\hline
\end{tabular}

Notes: Standard errors are in parentheses. An asterisk demotes significance at the 5 percent level, two asterisks denote significance at the 1 percent level.

\section{E. Effects of Education and Training}

Education has both a direct impact on turnover rates and an indirect one via the assignment to a higher job level. Higher education raises the probability of being in higher wage scales of the firm. Workers in higher wage scales tend to have higher separation rates in the low-turnover regime but lower separation rates in the high-turnover regime (see Table 4.7). Since the wage scales proxy for job complexity, the estimated coefficients quantify the effect 
of education given job complexity. This is the direct effect of education.

We find that vocationally educated workers (lbo, llw, mbo, and hbo) have lower separation rates than those with a general education (lo, mavo, havo, or vwo). Given wage scales, the effect of education is u-shaped, in the sense that separation rates are lowest among workers with medium level education. The lowest rates are for blue-collar workers with an apprenticeship and white-collar workers with an intermediate vocational degree. Apprenticeships are frequently completed at the firm. ${ }^{25}$ Since vocational schooling offered by the firm is likely to teach firm-specific skills and knowledge, our results suggest that separation rates are lower the more firm-specific a worker"s human capital is. This is consistent with the prediction from human capital models.

The impact of the educational level on the separation hazard does not change significantly for white-collar workers in the period of corporate decline, but higher educated blue-collar workers become relatively less likely to separate during downsizing (see Table 4.6). The total effect of education on the job separation hazard changes, however, for all workers since separation rates of workers in different wage scales are affected differently by non-stationary forces. Workers in lower wage scales become relatively more likely to separate in the period of downsizing. The u-shaped total effect of education disappears in the period of downsizing as workers in higher wage scales face relatively lower separation hazards. In periods of turmoil, vocationally trained workers and workers in more complex jobs face lower separation rates. Since higher educated workers have a higher probability of being in a more complex job, higher educated workers are less affected by non-stationary forces that raise the hazard of job separation.

The effects of training courses also supports the theoretical idea that turnover rates fall the more specific capital is accumulated. A completed internal or external training course reduces the hazard rate of all workers significantly in the period of downsizing. Training courses completed prior to 1987 have a smaller effect on separation rates suggesting depreciation of skills acquired in these courses. It might seem puzzling that "external" courses which supposedly teach more general skills have a larger negative effect on the hazard than courses followed at the company. But since we only control for the number of courses, it is possible that courses provided by an external agency represent a larger investment in terms of hours and costs and their content might be partly firm-specific. A more puzzling result is that the effect of training courses is much lower and even insignificant for

25 More than $57 \%$ of the workers who join the firm after 1987 and complete a higher degree during the employment spell complete an apprenticeship, $18 \%$ complete intermediate
vocational schooling, $8 \%$ higher wocational schooling. 
Table 4.6: Education And Training

\begin{tabular}{|c|c|c|c|c|c|c|}
\hline \multirow[b]{2}{*}{ Highest Degree } & \multicolumn{3}{|c|}{ Blue-Collar Workers } & \multicolumn{3}{|c|}{ White-Collar Workers } \\
\hline & $1987-1991$ & $1991-1996$ & p-values & $1987-1991$ & $1991-1996$ & p-values \\
\hline not reported & 0.559 & 0.026 & 0.000 & 0.105 & 0.013 & 0.606 \\
\hline & {$[0.075]^{* *}$} & {$[0.046]$} & & {$[0.320]$} & {$[0.177]$} & \\
\hline 10 & 0.428 & -0.025 & 0.000 & & -41.550 & \\
\hline & {$[0.160]^{* * *}$} & {$[0.124]$} & & & {$[0.000]$} & \\
\hline llbo: & 0.178 & 0.112 & 0.134 & -0.531 & 0.021 & 0.020 \\
\hline mavo & $\begin{array}{c}{[0.076]^{*}} \\
0.299\end{array}$ & {$[0.044]^{*}$} & & {$[0.374]$} & {$[0.237]$} & \\
\hline & {$[0.091]^{\text {将* }}$} & $\begin{array}{c}0.032 \\
{[0.060]}\end{array}$ & 0.000 & $\begin{array}{l}-0.545 \\
{[0.378]}\end{array}$ & $\begin{array}{l}-0.043 \\
{[0.246]}\end{array}$ & 0.041 \\
\hline 11w & $\begin{array}{c}\text { reference } \\
\text { group }\end{array}$ & $\begin{array}{c}\text { reference } \\
\text { groulp }\end{array}$ & & $\begin{array}{l}\text { reference } \\
\text { group }\end{array}$ & $\begin{array}{l}\text { reference } \\
\text { group }\end{array}$ & \\
\hline havo & 0.574 & 0.077 & 0.000 & -0.094 & 0.084 & 0.485 \\
\hline & {$[0.122]^{* *}$} & {$[0.097]$} & & {$[0.443]$} & {$[0.254]$} & \\
\hline mbo & $\begin{array}{c}0.292 \\
{[0.082]^{*}}\end{array}$ & $\begin{array}{l}-0.007 \\
{[0.051]}\end{array}$ & 0.000 & $\begin{array}{c}-0.858 \\
{[0.365]^{*}}\end{array}$ & $\begin{array}{l}-0.271 \\
{[0.188]}\end{array}$ & 0.002 \\
\hline VWO & $\begin{array}{c}0.658 \\
{[0.156]^{* *}}\end{array}$ & $\begin{array}{l}-0.101 \\
{[0.142]}\end{array}$ & 0.000 & $\begin{array}{l}-0.218 \\
{[0.351]}\end{array}$ & $\begin{array}{l}-0.231 \\
{[0.205]}\end{array}$ & 0.950 \\
\hline hibo & $\begin{array}{c}0.349 \\
{[0.168]^{*}}\end{array}$ & $\begin{array}{c}0.153 \\
{[0.134]}\end{array}$ & 0.144 & $\begin{array}{l}-0.421 \\
{[0.325]}\end{array}$ & $\begin{array}{l}-0.260 \\
{[0.180]}\end{array}$ & 0.371 \\
\hline unw/th & $\begin{array}{l}-0.030 \\
{[0.509]}\end{array}$ & $\begin{array}{c}0.826 \\
{[0.282]^{\text {*N* }}}\end{array}$ & 0.002 & $\begin{array}{l}-0.315 \\
{[0.331]}\end{array}$ & $\begin{array}{l}-0.164 \\
{[0.187]}\end{array}$ & 0.419 \\
\hline \multicolumn{7}{|l|}{ Training Courses } \\
\hline int_sum & $\begin{array}{c}-0.067 \\
{[0.009]^{*} *}\end{array}$ & $\begin{array}{l}-0.005 \\
{[0.003]}\end{array}$ & 0.000 & $\begin{array}{c}-0.157 \\
{[0.042]^{* *}}\end{array}$ & $\begin{array}{c}-0.020 \\
{[0.009]}\end{array}$ & 0.000 \\
\hline extsum & $\begin{array}{c}-0.183 \\
{[0.064]^{*}}\end{array}$ & $\begin{array}{c}-0.055 \\
{[0.018]^{*}}\end{array}$ & 0.000 & $\begin{array}{c}-0.197 \\
{[0.063]^{* *}}\end{array}$ & $\begin{array}{c}0.023 \\
{[0.019]}\end{array}$ & 0.000 \\
\hline internals7 & $\begin{array}{c}-0.017 \\
{[0.005] *}\end{array}$ & $\begin{array}{c}-0.009 \\
{[0.004]^{*}}\end{array}$ & 0.020 & $\begin{array}{c}0.006 \\
{[0.013]}\end{array}$ & $\begin{array}{l}0.007 \\
{[0.008]}\end{array}$ & 0.893 \\
\hline axternal 87 & $\begin{array}{r}-0.010 \\
{[0.021]} \\
\end{array}$ & $\begin{array}{l}0.029 \\
{[0.015}\end{array}$ & 0.011 & $\begin{array}{l}-0.012 \\
{[0.029]} \\
\end{array}$ & $\begin{array}{r}-0.007 \\
{[0.021]} \\
\end{array}$ & 0.814 \\
\hline Obserwations & 189988 & 135195 & & 60706 & 63192 & \\
\hline
\end{tabular}

Notes: Standard errors are in parentheses. An asterisk denotes that the coefficient is significant at the 5 percent level, two asterisks denote significance at the 1 percent level. See Appendix. A.2 for definitions of schooling variables. 
some types of courses in the second period.

\section{F. The Effect of Careers}

Workers in higher white-collar scales (15-19) are more likely to separate during expansion than workers in the reference scale 13 . While this difference is not significant, the difference relative to scale 11 is. This suggests that white-collar workers have higher turnover rates than blue-collar workers during expansion. ${ }^{26}$ Especially white-collar workers in scales 18 and 19 become much less likely to separate during the period of downsizing, while blue-collar workers in the lower scales (3-6) become more likely to separate.

Separation rates of workers in higher wage scales - and, therefore, workers in higher hierarchical positions ${ }^{27}$ - are less affected by downsizing. Separation rates are much more homogeneous across wage scales (job level) during expansion. But job complexity seems to matter during downsizing. This result is supported by the observation that a transition to a higher wage scale reduces the separation rate in that period.

Workers who have climbed up in the wage scale of the firm liave lower separation hazards than those who have not progressed from 1987 onwards. Upward transitions in wage scales have a strong and significant negative effect. on separation rates for blue-collar workers in both periods, where the effect is stronger during the period of workforce expansion. Having climbed up more than 1 scale does not affect the separation hazard significantly in both periods, yet moving down the wage scale has a large positive effect during the period of downsizing (Table 4.7).

\section{G. The Effect of Performance Evaluation and Other Characteristics}

Performance evaluation scores have strong and significant effects throughout (Tables 4.8). Hazard rates of blue-collar workers with lowest scores are $78 \%$ higher than for those in the reference group during expansion and $458 \%$ during downsizing. The effect is even larger for white-collar workers in both periods. Evaluation scores have a bigger effect and become more important for blue-collar workers in the period of downsizing as the p-values in column (3) show. This is strong evidence for the general notion that low-surplus matches end early.

\footnotetext{
${ }^{26}$ This result is confirmed when we pool the sub-populations of blue-collar and white collar workers.

${ }^{27}$ Hierarchical job levels and wage scales are strongly correlated.
} 
Table 4.7: WAGE Grades AND CAREer EFfECTS

\begin{tabular}{|c|c|c|c|c|c|c|c|}
\hline & \multicolumn{3}{|c|}{ Blue-Collar Workers } & \multicolumn{3}{|c|}{ White-Collar Workers } \\
\hline & & 1987-1991 & $1991-1996$ & $p$-values & $1987-1991$ & $1991-1996$ & p-walues \\
\hline \multirow[t]{35}{*}{ Ist Grade: } & 2 & $\begin{array}{c}0.775 \\
0.3671 *\end{array}$ & 0.547 & 0.518 & & & \\
\hline & \multirow{2}{*}{3} & $\begin{array}{l}0.044 \\
-0.04\end{array}$ & {$\left[\begin{array}{l}0.303] \\
0.030\end{array}\right.$} & 0.714 & & & \\
\hline & & {$[0.230]$} & {$[0.202]$} & 0.114 & & & \\
\hline & \multirow[t]{2}{*}{4} & 0.117 & $0.596^{2}$ & 0.000 & & & \\
\hline & & {$[0.153]$} & {$[0.133]^{* *}$} & & & & \\
\hline & \multirow[t]{2}{*}{5} & 0.173 & 0.417 & 0.058 & & & \\
\hline & & $\llbracket 0.145 \rrbracket$ & {$[0.129]^{*} *$} & & & & \\
\hline & \multirow[t]{2}{*}{6} & 0.109 & 0.326 & 0.087 & 0.451 & 0.894 & \\
\hline & & {$[0.143]$} & {$[0.127] *$} & & {$[1.058]$} & {$[0.300]^{3 * *}$} & \\
\hline & \multirow[t]{2}{*}{7} & 0.124 & 0.053 & 0.573 & & 0.051 & \\
\hline & & {$[0.140]$} & {$[0.126]$} & & & {$[0.260]$} & \\
\hline & \multirow[t]{2}{*}{8} & 0.038 & $0.025^{\circ}$ & 0.918 & 0.003 & -0.304 & \\
\hline & & {$[0.139]$} & {$[0.124]$} & & {$[0.649]$} & {$[0.269]$} & \\
\hline & \multirow[t]{2}{*}{9} & 0.071 & -0.014 & 0.511 & -0.520 & -0.254 & \\
\hline & & {$[0.148]$} & {$[0.130]$} & & {$[0.761]$} & {$[0.245]$} & \\
\hline & \multirow[t]{2}{*}{10} & 0.205 & -0.136 & 0.016 & -0.984 & -0.354 & \\
\hline & & {$[0.159]$} & {$[0.141]$} & & {$[0.759]$} & {$[0.237]$} & \\
\hline & \multirow[t]{2}{*}{11} & reference & reference & & -0.558 & -0.408 & \\
\hline & & group & group & & {$[0.366]$} & {$[0.172]^{*}$} & \\
\hline & \multirow[t]{2}{*}{12} & & & & -0.103 & -0.188 & 0.472 \\
\hline & & & & & {$[0.157]$} & {$[0.119]$} & \\
\hline & \multirow[t]{2}{*}{13} & & 1.760 & & reference & reference & \\
\hline & & & {$[0.505]^{* *}$} & & group & group & \\
\hline & \multirow[t]{2}{*}{14} & & 0.968 & & -0.144 & -0.098 & 0.689 \\
\hline & & & {$[1.040]$} & & {$[0.155]$} & {$[0.116]$} & \\
\hline & \multirow[t]{2}{*}{15} & & & & 0.268 & -0.090 & 0.005 \\
\hline & & & & & {$[0.154]$} & {$[0.128]$} & \\
\hline & \multirow[t]{2}{*}{16} & & & & 0.100 & $-0.029^{\circ}$ & 0.368 \\
\hline & & & & & {$[0.172]$} & {$[0.144]$} & \\
\hline & \multirow[t]{2}{*}{17} & & & & 0.142 & 0.202 & 0.726 \\
\hline & & & & & {$[0.230]$} & {$[0.173]$} & \\
\hline & \multirow[t]{2}{*}{18} & & & & 0.323 & -0.422 & 0.000 \\
\hline & & & & & {$[0.216]$} & {$[0.184]^{*}$} & \\
\hline & \multirow[t]{2}{*}{19} & & & & 0.530 & -0.801 & \\
\hline & & & & & {$[0.356]$} & {$[0.322]^{*}$} & \\
\hline \multirow[t]{7}{*}{$\Delta$ Grade: } & $<0$ & $\begin{array}{c}0.153 \\
{[0.363]}\end{array}$ & $\begin{array}{l}-0.205 \\
0.1781\end{array}$ & 0.044 & $\begin{array}{l}-0.344 \\
1.011]\end{array}$ & $\begin{array}{c}0.707 \\
{[0.354]^{*}}\end{array}$ & 0.003 \\
\hline & +1 & -0.424 & -0.148 & 0.000 & -0.449 & -0.089 & 0.000 \\
\hline & & {$[0.064]^{* * *}$} & {$[0.041]^{1 / * *}$} & & {$[0.154]^{2 * * *}$} & {$[0.086]$} & \\
\hline & +2 & -0.645 & -0.240 & 0.000 & 0.194 & -0.179 & 0.0000 \\
\hline & & {$[0.128]^{* * *}$} & {$[0.051]^{* * *}$} & & {$[0.203]$} & {$[0.107]$} & \\
\hline & $\geq 3$ & -0.867 & -0.296 & 0.000 & 0.012 & -0.092 & 0.395 \\
\hline & & {$[0.323]^{* *}$} & {$[0.063]^{* *}$} & & {$[0.249]$} & {$[0.122]$} & \\
\hline Observatio & & 189988 & 135195 & & 60706 & 63192 & \\
\hline
\end{tabular}

Notes: Standard errors are in parentheses. An asterisk denotes that the coefficient is significant at the 5 percent level, two asterisks denote significance at the 1 percent level. 
Table 4.8: Performance Evaluation and Other Variables

\begin{tabular}{|c|c|c|c|c|c|c|}
\hline \multirow{2}{*}{$\begin{array}{l}\text { 1st observed } \\
\text { Evaluation Score }\end{array}$} & \multicolumn{3}{|c|}{ Blue-Collar Workers } & \multicolumn{3}{|c|}{ White-Collar Workers } \\
\hline & $1987 \cdot 1991$ & $1991-1996$ & $\mathrm{p}$-values & $1987-1991$ & $1991-1996$ & $\mathrm{p}$-values \\
\hline missing & $\begin{array}{c}0.870 \\
{[0.154]^{* *}}\end{array}$ & & & $\begin{array}{l}-0.023 \\
{[0.464]}\end{array}$ & & \\
\hline 1 & $\begin{array}{c}0.574 \\
{[0.335]}\end{array}$ & $\begin{array}{c}1.501 \\
{[0.307]^{* *}}\end{array}$ & 0.002 & $\begin{array}{c}3.011 \\
{[0.284]^{* * *}}\end{array}$ & $\begin{array}{c}2.530 \\
{[0.290]^{* * *}}\end{array}$ & 0.097 \\
\hline 2 & $\begin{array}{c}0.832 \\
{[0.113]^{* * *}}\end{array}$ & $\begin{array}{c}0.599 \\
{[0.087]^{* *}}\end{array}$ & 0.007 & $\begin{array}{c}0.643 \\
{[0.140]^{* * *}}\end{array}$ & $\begin{array}{c}0.760 \\
{[0.118]^{* *}}\end{array}$ & 0.319 \\
\hline 4 & $\begin{array}{c}-0.179 \\
{[0.057]^{* * *}}\end{array}$ & $\begin{array}{c}-0.207 \\
{[0.033]^{* *}}\end{array}$ & 0.399 & $\begin{array}{c}-0.066 \\
{[0.123]}\end{array}$ & $\begin{array}{l}-0.086 \\
{[0.087]}\end{array}$ & 0.824 \\
\hline 5 & $\begin{array}{c}-0.169 \\
{[0.089]}\end{array}$ & $\begin{array}{c}-0.426 \\
{[0.062]^{* *}}\end{array}$ & 0.000 & $\begin{array}{c}-1.345 \\
{[0.540]^{*}}\end{array}$ & $\begin{array}{c}-1.034 \\
{[0.456]^{*}}\end{array}$ & 0.495 \\
\hline 6 & $\begin{array}{l}-0.153 \\
{[0.150]}\end{array}$ & $\begin{array}{c}-0.426 \\
{[0.128] * *}\end{array}$ & 0.033 & & & \\
\hline Other & & & & & & \\
\hline married & $\begin{array}{c}-0.5 \mathbb{1 9} \\
{[0.045]^{* *}}\end{array}$ & $\begin{array}{c}-0.223 \\
{[0.032]^{* *}}\end{array}$ & 0.000 & $\begin{array}{c}-0.443 \\
{[0.082]^{* * *}}\end{array}$ & $\begin{array}{c}-0.291 \\
{[0.065]^{* *}}\end{array}$ & 0.019 \\
\hline divorced & $\begin{array}{c}-0.908 \\
{[0.234]^{* *}}\end{array}$ & $\begin{array}{l}-0.099 \\
{[0.129]}\end{array}$ & 0.000 & $\begin{array}{l}-0.122 \\
{[0.421]}\end{array}$ & $\begin{array}{l}-0.005 \\
{[0.329]}\end{array}$ & 0.722 \\
\hline male & $\begin{array}{c}-0.386 \\
{\left[0.063^{7 * *}\right.}\end{array}$ & $\begin{array}{c}0.281 \\
{[0.050]^{* *}}\end{array}$ & 0.000 & $\begin{array}{c}-0.303 \\
{[0.155]}\end{array}$ & $\begin{array}{c}-0.444 \\
{[0.100]^{* * *}}\end{array}$ & 0.160 \\
\hline part-time & $\begin{array}{c}0.473 \\
{[0.084]^{*}}\end{array}$ & $\begin{array}{c}0.499 \\
{[0.060]^{* * *}}\end{array}$ & 0.671 & $\begin{array}{l}-0.328 \\
{[0.260]}\end{array}$ & $\begin{array}{l}-0.021 \\
{[0.115]}\end{array}$ & 0.008 \\
\hline rehired & $\begin{array}{c}0.110 \\
{[0.193]} \\
\end{array}$ & $\begin{array}{l}-0.160 \\
{[0.104]} \\
\end{array}$ & 0.009 & $\begin{array}{c}0.508 \\
{[0.441]}\end{array}$ & $\begin{array}{l}-0.361 \\
{[0.209]}\end{array}$ & 0.000 \\
\hline Observations & 189988 & 135195 & & 60706 & 63192 & \\
\hline
\end{tabular}

Notes: Standard errors are in parentheses. An asterisk denotes that the coefficient is significant at the 5 percent level, two asterisks denote significance at the 1 percent level.

Married workers face lower separation hazards than non-married workers during both periods, but this difference is significantly smaller during the period of downsizing (Table 4.8). The effects are quantitatively similar for blue-collar and white-collar workers. Men are less likely to separate during the period of expansion ( $32 \%$ lower separation for blue-collar men and $26 \%$ lower hazards for white-collar men than women), but blue-collar male workers become more likely to separate during downsizing. The change between periods is significant. Male white-collar workers are always less likely to separate than female white-collars and there is no significant difference in the point estimate of the gender effect in the two periods. Hazard rates for part-time blue-collar workers are significantly higher than for their full-time 
working colleagues, while no significant difference is found for white-collar employment. Finally, workers who are rehired during the downsizing period face a lower risk of job separation, but the effect is not significant.

\subsection{Conclusion}

This chapter has investigated the determinants of separation rates and has assessed differences in effects of worker separation characteristics between periods of workforce expansion and contraction. Many predictions from different turnover models are confirmed by our estimation results. For instance, we find that separation rates increase with tenure in the first week of the employment relation and then start to decrease thereafter. This is consistent with turnover models in which jobs are experience goods like Jovanovic (1979a). However, this model alone cannot explain other patterns, in particular the negative dependence on age. Models with human capital accumulation and search perform better on that dimension, but cannot explain an initially rising hazard. Our finding with respect to the effect of human capital accumulation supports theories of job-specific capital.

But turnover theories largely ignore the effects of changing economic conditions. Our results show that such nonstationary forces cause relative separation rates to change. White-collar and blue-collar workers are affected differently. In particular, separation rates of blue-collar workers rise earlier during downsizing. White-collar workers are less affected early during a period of contraction, but their job separation hazard rate rises as downsizing persists. We also find relative hazard rates to change within the groups of blue-collar and white-collar workers.

Performance evaluation scores gain importance for blue-collar workers in periods of downsizing. In our data, this effect is not found for white-collar workers. Less than $2 \%$ of all workers get performance evaluation score in the lower third of the scale, but they face substantially higher job separation hazards. When turnover rates are high, as in periods of downsizing, individual separation hazards are much lower for those in the upper four deciles of the performance evaluation score distribution.

Career paths within the firm exhibit a dependence relation with a worker's turnover probability. The more frequently a blue-collar worker is promoted, the less likely he becomes to separate. This effect is stronger during expansion. The first promotion is important to lower a white-collar worker's turnover hazard during prosperous periods of the firm, but promotions do not matter in bad times. However, workers who experienced a demotion become much more likely to separate when the prospects of the firm worsen. 
A final result of our study concerns the specification of empirical models. We find that fitting a quadratic age effect may produce misleading results, In fact, the effect of age on separation rates is marked by important discontimuities, which are probably driven by discontinuous changes of the value of the retirement option. Option values for retirement schemes change dramatically with the prospects of the firm. Workers kill the option to retire early more frequently in periods of downsizing. However, if early retirement is offered only beyond a certain age, the option to retire early at a given age has important spill-over effects for slightly younger workers, who, as a result, become less likely to separate. A downsizing firm should take this crowding out effect into account when designing early retirement plans. The role of retirement and its relation to worker turnover rates deserves a more careful treatment in future work on corporate downsizing and worker mobility.

We have presented a case history analysis of worker mobility and compared the characteristics of turnover between prosperous and diminishing periods of a firm. We believe that many of the characteristics of turnover that we find are similar across firms so that we can learn something about other firms from our analysis. This work can be expanded upon in a variety of ways. First, the behavior of other declining firms could be studied. A second, more important route would be the development of a theoretical model to explain differences in turnover behavior between blue-collar and white-collar workers in good and bad times. The generally important point we have made - that smooth functional forms of the age effect in mobility studies produce misleading results - seems applicable to better understand and design early retirement plans and incentive schemes for corporate reorganization. 
Chapter 5

Monkey Bars and Ladders: The Importance of Lateral and Vertical Movements in Internal Labor Market Careers 


\subsection{Introduction}

An important impulse for the development of an "internal labor market" (ILM) literature within the labor economics literature was Doeringer and Piore's (1971) seminal work. They emphasized the institutionall character of employment relations arguing that administrative rules and procedures, i.e. personnel policies, govern employment relationships, which result in outcomes concerning the pricing and allocation of labor that contrast sharply with the predictions of traditional labor economics. Part of this ILM literature has been devoted to study the design and effects of such persomel policies (e.g. Prendergast, 1993; Prendergast and Topel, 1996; Millgrom and Roberts, 1988), while a substantial body of the theoretical literature focuses on job ladders, career movements, promotions, and their relationship to compensation (e.g. Lazear and Rosen, 1981; Waldman, 1984; Gibbons and Waldman, 1999a). ${ }^{1}$

Despite a growing empirical literature that studies firm personnel records; theories of the internal workings of firms are still based on little empirical evidence derived from personnel data that record job positions and compensation in firms. Early exceptions include Osterman (1979), Medoff and Abraham (1980), Lazear (1992) and Baker, Gibbs and Holmstrom (1994a and 1994b). The most detailed empirical study of wage and career dynamics in internal labor markets so far is Baker, Gibbs and Holmstrom (1994a, b), who analyze a yearly panel of personnel data of management employees from a large U.S. company, which expands over the observation period. Many of their findings - including that career paths are important for the allocation of workers to jobs, that there is a substantial amount of wage variation within job levels in spite of the strong relation between hierarchical levels and compensation, and that there is no evidence of distinct ports of entry and exit as predicted by Doeringer and Piore (1971) - are confirmed by contemporary studies (e.g. Ariga et al, 1999; Seltzer and Merrett, 2000; Lima, 2000; Gibbs and Hendricks, 2001; Treble et al., 2001).

We complement this literature by analyzing ten years of personnel records from the Dutch aircraft manufacturer Fokker to assess whether these empirical "facts" are valid for a different firm, in a different industry, over a different period, and in a different economy. While doing so, we provide answers to a number of questions that were advocated by Gibbons (1997) to facilitate the composition of a broader picture of internal labor markets for which individual studies provide pieces of a puzzle based on firm-level data which are often collected in different ways and measure different variables.

\footnotetext{
'See Gibbons and Waldman (1999b) for a recent survey of this literature.
} 
We shed light on issues that have not been addressed in this literature so far: The exceptional feature that the data set covers an episode of corporate growth as well as an episode of corporate decline allows us to explore how personnel decisions of the firm differ between periods of growth and decline. We investigate the consequences of a changing corporate environment for promotion dynamics and organizational stability. We can distinguish between production workers and managers, so that we can examine whether the internal workings of the firm differ with respect to worker type. In addition, we can study whether such differences exist across different fields of activity within the firm, as for instance Production, R\&D, Sales \& Customer Relations or Administration. Finally, in contrast to existing studies, which commonly rely on year-end panel data, we analyze event history data which record the exact timing of all events related to wage or position changes. The knowledge of the exact timing of all events not only allows us to explore whether wage and position changes occur simultaneously, but it allows us also to look at all events that happen, also those that would remain hidden between two cross-sections of personnel records. Information that would be lost in yearly cross-sections turns out to be substantial, in particular with respect to temporary worker re-allocation and downward mobility.

Our main findings are as follows. Job mobility is substantial in our firm and an important determinant of wages. Although we find somewhat lower upward transition rates than related studies, we do observe a substantial number of lateral transitions. Job transitions are the major source for sustained wage growth as wages are strongly related to job levels, although wage changes do not always occur simultaneously with upward job transitions. However, wages are not tied to jobs in a strict sense. Considerable wage spread is found in all job levels, and wage distributions of adjacent job levels overlap. We also find that downward mobility almost never results in nominal wage cuts, yet it frequently coincides with degradation in wage scales and hence a reduced prospect of future wage growth. Real wage decreases, on the other hand, are common, especially during downsizing when nominal wages are not changed for most workers for more than two years.

The chapter is organized as follows. Section 5.2 describes the firm and its personnel data. Section 5.3 depicts the hierarchical structure of the firm and the procedure used to identify those hierarchical levels. Section 5.4 analyzes the job mobility pattern. It portrays entry and exit as well as job transitions within the firm. Section 5.5 examines the relationship between wages and hierarchical job positions. Section 5.6 takes a closer look at wage growth and its relation to job transitions. Section 5.7 investigates career paths within the firm and shows that both careers across hierarchies as well as within hierarchical positions exits. Section 5.8 concludes. 


\subsection{The Firm and its Personnel Data}

\subsubsection{The Firm}

We have personnel data from the Dutch national aircraft builder N.V. Fokker over the period from January 1, 1987, when the firm introduced its electronic personnel system, until March 15, 1996, when the firm was officially declared bankrupt. ${ }^{2}$ N.V. Koninklijke Nederlandse Vliegtuigenfabriek Fokker was structured in an administration unit (Fokker Administration B.V.), an aircraft production unit (Fokker Aircraft B.V.) with plants in three different locations as well as four other subsidiaries at different locations (see Table A.1 in Appendix A.1). The majority of the workforce was affected by the bankruptcy of the holding company, the production unit, and the administration unit, which formed the core business of aircraft manufacturing. The other viable parts of the firm did not enter the bankruptcy procedure and were eventually sold. Most of the organizational structure remained unchanged until the day of the bankruptcy, except for one division, Fokker Space, that was spun off in December $1995^{3}$

We analyze the data until the bankruptcy date. This might prompt the criticism that the firm is not a representative example of a downsizing firm as it fails eventually. This could be problematic if the demise was expected and if behavior was brought into line with the anticipation of the failure. However, there is reason to believe that the bankruptcy came suddenly and unexpectedly for most of the employees. ${ }^{4}$

\subsubsection{The Data}

We use information on each employee's job, compensation, and demographics. The job position file records every worker's job code, job title, organization code, organization name, the activity his job belongs to, the plant name, as well as the starting and end date of all his job positions within the company during the observation period. The wage files contain information on the salary grade, the nominal wage rate, the start and ending date of the wage contract, the reason for a change in the wage contract, and a performance measure that refers to performance in the previous year. In addition, we know the schooling and the vocational degree of most employees. The file

\footnotetext{
The data were made available to us for acaclemic purposes by the company's bankruptcy trustees. The report of the bankruptcy trustees is publicly available (see
Deterink et al., 1997).

"Workers employed at this division leave our data files on that date.

${ }^{4}$ See the argument and citation on page 53.
} 
of demographic characteristics has the date of birth, gender, marital status, and the hiring date for every employee. We merged these raw data files into one event history data file. Since we know the exact timing of job changes and wage changes, we can detect whether job changes and wage changes occur simultaneously. Another advantage of our data structure is that we do not loose information about events that happen in the time-span between two cross-sections of panel data.

\subsubsection{Development of the Workforce}

The time period spanned by the data can be divided into a period of workforce expansion and one of workforce reduction. The number of employed workers with permanent contracts rises from 10275 in January 1987 to 12852 at the peak in February 1991. During the subsequent period, which is marked by a series of reorganizations with employment reductions and mass layoffs, the number of employed workers falls to 7141 on the day before the bankruptcy.

Figure 5.1 plots the number of workers employed at the beginning of each month from January 1987 until March 1996 stacked by ten broad activities into which jobs are categorized. Most workers are employed in one of the five production activities (Assembly (F), Support \& Supplies (G), Production Preparation (D), Planning \& Coordination (E), and Quality (M)). Employment changes in production activities increasing steadily from 6684 workers in January 1987 to a peak of 8838 workers in June 1991, and then falling to 4651 workers on the day before the bankruptcy account for the largest part of the workforce expansion and the subsequent contraction. Employment in the three administrative activities (Finances and Administration (K), Human Resources \& Support (H), and Management \& Information Processing (S)) rises from 1966 workers in January 1987 to 2252 workers in February 1991 and falls subsequently to 1113 workers in March 1996. Employment in R\&D (C) and in Sales \& Customer Relations, on the other hand, grows for a prolonged period (peaking not until the second quarter 1993), and declines only moderately until the end of 1995 . As a result, the employment share of production related activities falls during the episode of downsizing from a peak of $68.8 \%$ in mid 1991 to $62.3 \%$ in December 1995 and that of administrative activities falls from $17.1 \%$ in mid 1991 to $15.9 \%$ by the end of 1995 . 
Figure 5.1: Development and Composition of the Workforoe BY Actrvitries

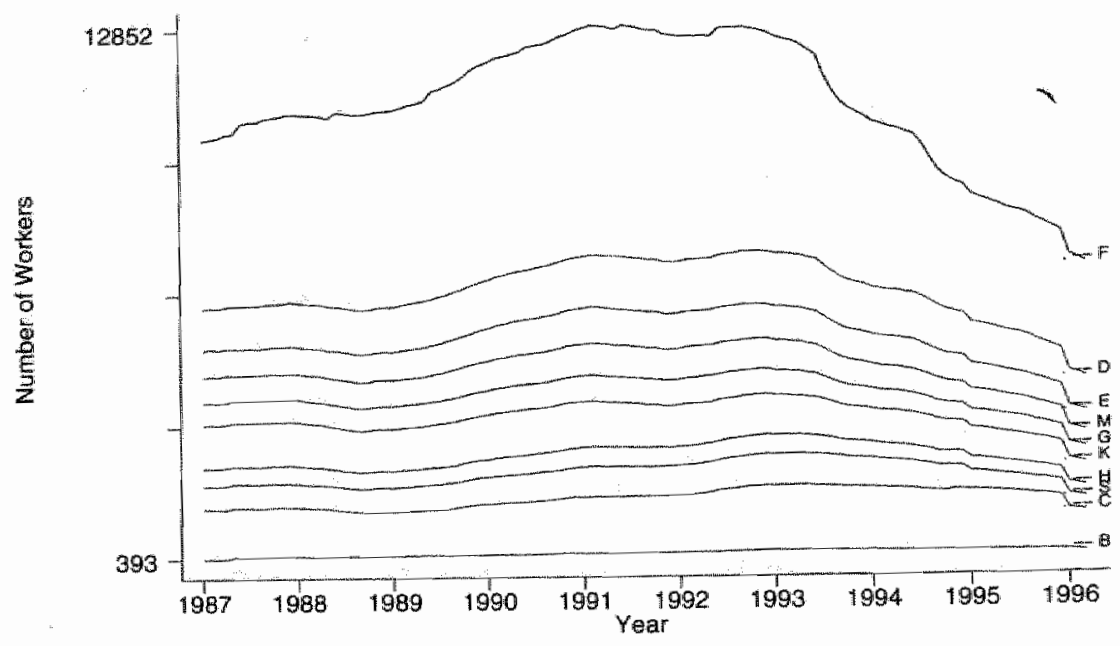

Notes: The figure plots the number of workers with a permanent contract employed att the beginning of each month from January 1987 until March 1996 stacked by the different job: activities defined in the data. Job activities comprise: Sales \& Customer Relations (B), R\&D (C), Management \& Information Processing (S), Human Resources \& Support (H), Finances and Administration (K), Support \& Supplies (G), Quality (M), Planning \& Coordination (E), Production Preparation (D), and Assembly (F). Labels are in parentheses. The distance to the next lower line represents the number of workers in a particular job activity. Total employment at the firm is, therefore, characterized by the top line, labelied as " ${ }^{3 "}$.

\subsection{The Corporate Hierarchy}

\subsubsection{Identification of Levels}

We relied on job transitions, job titles, reporting relations and team composition - but we did not use information from the wage files - in order to identify the hierarchical job structure of the firm. There are 6085 different job codes and 6318 different job names in the data. ${ }^{5}$ Fortunately, the number of levels could be inferred easily from transitions between a few important job titles

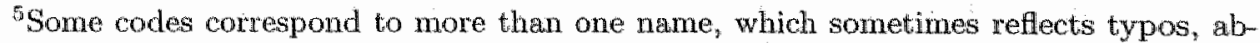
breviations in nomes, or a change from a Dutch to an English name. On the other hand, some job names are not unique to a single job code which often reflects the fact that codes have changed over time, while the job itself remained unchanged.
} 
which account for a large portion of the workforce. ${ }^{6}$ We identified 10 hierarchical levels. Production workers, supporting workers (e.g. cleaning, catering or tramsportation staff), and lower-level clerical workers are organized in the bottom three levels. We refer to this group of workers as blue-collar workers. Higher level clerical workers form level 4 of the hierarchy. Management and the remaining white-collar workforce are organized in six management levels (levels 5-10). ${ }^{7}$ The 'Executive Board', which consisted of a group of 3 managers most of the time, forms the top of the hierarchy (level 10). Directors of subdivisions and plants are in level 9. For confidentiality reasons, we lack salary information for those employees in levels 9 and $10 .{ }^{8}$ Consequently, analyses involving compensation are only for the bottom 8 levels of the corporate hierarchy. Moreover, due to the small number of employees in the top 3 levels, we group these levels together in our job transition analyses. Level 8 comprises heads of departments. Levels 5,6 , and 7 comprise managers who report to those in level 8 and head or work in lower level departments of the firm. Besides, a large fraction of employees in levels 4 to 6 are engineers or specialists.

Suggestive job titles confirmed the hierarchical structure inferred from job transitions. For example, "Assemblers" or "Lathe Operators" are organized in level 1 in production, whereas team leaders (e.g. an "Team Leader Assembly" or "Team Leader Lathe Operation") are in level 2, and group chiefs (e.g. "Group Chief Assembly" or "Group Chief Lathe Operation") in level 3. Similarly, job titles confirmed our assignment of job codes to higher hierarchical levels. For example, we observe transitions from "Specialist" to "Senior Specialist", or from "Engineer" to "Senior Engineer". These suggestive job titles also facilitated the assignment of minor job codes comprising only one or very few persons, who sometimes had no transition to or from another job code during the observation period. Finally, we exploited information about the composition of teams or subdivisions to assert that the hierarchical structure inferred from job transitions is consistent with the organization of teams in the sense that a team leader is assigned to a higher hierarchical level than the team members reporting to him.

\footnotetext{
The largest 30 job codes comprise $35 \%$ of the workforce, and 130 job codes encompass $50 \%$ of the workforce.

That we inferred the correct number of levels for white-collar amployees from job transitions is confirmed by additional information on the firm"s organizational structure of management which is provided by Deterink at al. (1997).

Wages for level 8 employees that exced 200,000 guilders annually are also not recorded.
} 


\subsubsection{Structural Stability and the Size of Levels}

Table 5.1 reveals the pyramid structure of the hierarchy with "sub-pyramids" for blue-collar and white-collar job levels. We find that many features of this hierarchical job structure are remarkably stable over the entire period. The number of levels in the hierarchy is unchanged and the main job titles in each level in 1987 remain in the respective levels until the bankruptcy. ${ }^{9}$ Corresponding with Baker et al. (1994a), who report stable relative sizes of hierarchical levels for an expanding firm, we also find that the relative size of levels is largely unaffected by the workforce expansion from 1987 until 1991 (see Table 5.1). However, relative level sizes change markedly during the period of employment reduction from 1991 until 1996, when the blue-collar share of total employment (levels 1-3) declines from $75.9 \%$ in 1991 to $67.7 \%$ in 1995 .

Table 5.1: Hierarchical Composition, 1987-1996

\begin{tabular}{l|rrrrrrrrrr}
\hline & \multicolumn{10}{|c}{ Year } \\
Level & 1987 & 1988 & 1989 & 1.990 & 1991 & 1992 & 1993 & 1994 & 1995 & 1996 \\
\hline 1 & 51.3 & 52.9 & 53.7 & 54.1 & 53.0 & 52.3 & 50.4 & 45.2 & 42.3 & 43.9 \\
2 & 16.2 & 15.6 & 15.4 & 14.8 & 14.6 & 14.4 & 14.4 & 15.6 & 15.7 & 16.0 \\
3 & 9.0 & 8.6 & 8.6 & 7.9 & 8.3 & 8.5 & 8.7 & 9.2 & 9.7 & 9.8 \\
4 & 11.1 & 10.9 & 10.6 & 11.4 & 11.9 & 11.8 & 12.6 & 13.4 & 13.4 & 12.9 \\
5 & 6.2 & 6.0 & 5.8 & 5.9 & 6.2 & 6.6 & 7.2 & 8.3 & 9.1 & 8.2 \\
6 & 3.4 & 3.4 & 3.3 & 3.3 & 3.5 & 3.7 & 4.0 & 5.2 & 6.2 & 5.6 \\
7 & 1.3 & 1.2 & 1.2 & 1.3 & 1.2 & 1.4 & 1.4 & 1.5 & 1.9 & 1.7 \\
8 & 1.0 & 1.0 & 1.0 & 1.0 & 1.0 & 1.0 & 1.1 & 1.3 & 1.4 & 1.6 \\
$9-10$ & 0.4 & 0.4 & 0.4 & 0.3 & 0.3 & 0.3 & 0.2 & 0.3 & 0.3 & 0.3 \\
\hline Total & 100.0 & 100.0 & 100.0 & 100.0 & 100.0 & 100.0 & 100.0 & 100.0 & 100.0 & 100.0 \\
\hline
\end{tabular}

Notes: The table shows for each year the percentage of employees in each of the 10 hierarchical job levels on March 14 of every year. Levels 9 and 10 are combined for
confidentiality reasons.

\footnotetext{
${ }^{9}$ It is noteworthy, however, that the firm apparently reorganized certain division during downsizing. For example, different engineering jobs are summarized in one job code in
1992.
} 


\subsection{Mobility}

\subsubsection{Entry and Exit}

Turnover is comparatively low during the first five years of our observation period so that we can confidently speak of an internal labor market: The average annual exit rate equals $7.1 \%$ from January 1987 until March 1991 , whereas Baker et al. (1994a) find exit rates of $10 \%$ and more when their firm grows at a similar rate as ours.

Table 5.2: EnTry Into Hierarchical Levels, 1987-1996

\begin{tabular}{l|rrrrrrrrrr}
\hline & \multicolumn{10}{|c}{ Year } \\
Level & 1987 & 1988 & 1989 & 1990 & 1991 & 1992 & 1993 & 1994 & 1995 & 1996 \\
\hline 1 & 76.8 & 76.6 & 70.9 & 70.3 & 72.0 & 55.5 & 24.3 & 45.2 & 44.1 & 45.8 \\
2 & 6.1 & 8.5 & 7.8 & 6.9 & 7.1 & 5.8 & 15.9 & 5.5 & 13.6 & 12.5 \\
3 & 2.9 & 2.9 & 3.6 & 5.1 & 4.1 & 7.3 & 11.2 & 11.0 & 5.9 & 8.3 \\
4 & 10.1 & 7.3 & 12.1 & 12.2 & 10.8 & 20.6 & 19.6 & 11.0 & 8.5 & 8.3 \\
5 & 2.4 & 2.6 & 3.7 & 4.2 & 3.8 & 8.2 & 15.9 & 9.6 & 16.1 & 0.0 \\
6 & 0.9 & 1.1 & 0.7 & 0.9 & 0.8 & 1.1 & 5.6 & 6.8 & 6.8 & 16.7 \\
7 & 0.5 & 0.2 & 0.8 & 0.2 & 0.8 & 0.6 & 4.7 & 4.1 & 2.5 & 4.2 \\
8 & 0.3 & 0.6 & 0.3 & 0.1 & 0.4 & 0.8 & 0.9 & 4.1 & 1.7 & 4.2 \\
$9-10$ & 0.1 & 0.1 & 0.1 & 0.0 & 0.2 & 0.1 & 1.9 & 2.7 & 0.8 & 0.0 \\
\hline Total & 100.0 & 100.0 & 100.0 & 100.0 & 100.0 & 100.0 & 100.0 & 100.0 & 100.0 & 100.0 \\
\hline
\end{tabular}

Notes: The table shows for each year the percentage of just hired employees that entered into the respective level. Levels 9 and 10 are combined for confidentiality reasons.

We do not find evidence of a completely closed internal labor market. There is entry into all levels in all years as Table 5.2 shows. Yet, entry is concentrated in the bottom levels of blue-collar employment (level 1) and of white-collar employment (level 4) - especially during the episode of corporate expansion when $70.3 \%-76.8 \%$ of all beginners, or $85.5 \%-89.5 \%$ of all newly hired blue-collar workers enter level 1 and when $60.1 \%-71.1 \%$ of all newly hired white-collar workers enter level 4 (see Table 5.2). Relative entry rates into blue-collar ranks are markedly lower during downsizing and entry measured relative to level size is generally less concentrated in bottom ranks from 1992 onwards, possibly because hiring then takes place to staff vacancies in existing slots that cannot be filled from within rather than to hire into slots newly created during expansion.

Hiring and firing takes place at all times. Monthly inflow rates are higher and more erratic (with peaks occurring commonly in May) than outflow rates during corporate expansion, while the opposite holds for the episode of corpo- 
Figure 5.2: INFLOW- OUTFLOW AND EMPLOYMENT GROWTH RATES

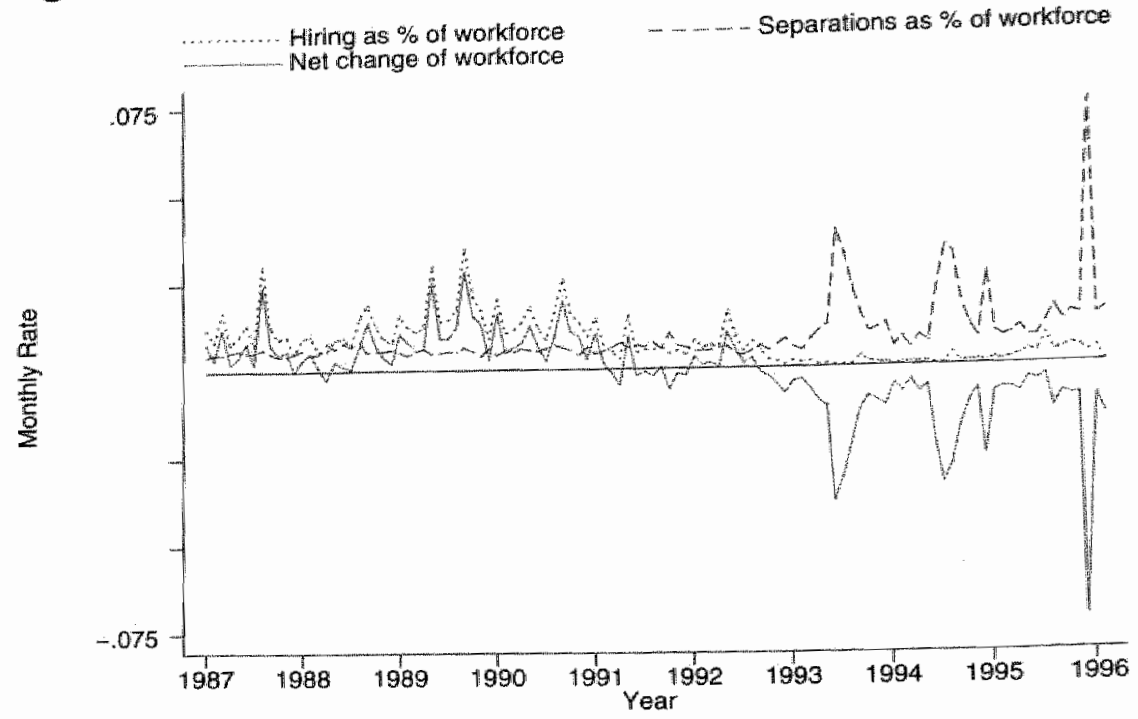

Notes: The fighre plots the monthly hiring rate, the separation rate, and the net employment growth rates.

rate downsizing (see Figure 5.2). Early during downsizing, in 1991 and 1992, the workforce reduction is mainly accomplished by a fall in the inflow rate, while the outflow rate rises only slightly. The dramatic decline in employment during 1993-1996, however, is brought about by a substantial increase in the outflow rate and a further drop of the inflow rate. ${ }^{10}$ Remarkable are the enormous jumps in outflow in June 1993, June - August 1994, December 1994, and December 1995, which follow downsizing announcements in April 1993, April 1994, and January 1995.

Exit rates are highest out of level 1 in the period of downsizing (see Table 5.3). Blue-collar workers, particularly those in level 1, separate first during downsizing. Exit rates from level 1 jump most during the 1993 downsizing episode, the first with mainly involuntary dismissals (see Table 5.3). Higher exit rates out of the bottom level of blue-collar employment can partly be ascribed to higher turnover rates among workers with short tenure who predominately entered in level 1 and separate before having made an upward transition. But even controlling for tenure and other characteristics, Dohmen and Pfann (2000) find that corporate downsizing affects exit rates of blue-

\footnotetext{
10 The total number of hirings in the period of dowmsizing is less than a third of the inflow during expansion. Hiring rates into white-collar ranks fall by less than hiring rates into blue-collax employment (cf. lower part of Table 5.3).
} 
Table 5.3: Exit from HIerarchical LEvels, 1987-1996

\begin{tabular}{|c|c|c|c|c|c|c|c|c|c|c|}
\hline \multirow[b]{2}{*}{ Lewel } & \multicolumn{10}{|c|}{ Year } \\
\hline & 1987 & 1988 & 1989 & 1990 & 1991 & 1992 & 1993 & 1994 & 1995 & 1996 \\
\hline 1 & 54.0 & 49.2 & 64.0 & 66.1 & 63.7 & 63.6 & 73.4 & 60.5 & 42.2 & 43.0 \\
\hline 2 & 10.9 & 14.8 & 11.5 & 11.9 & 11.3 & 10.8 & 9.7 & 13.2 & 18.1 & 13.8 \\
\hline 3 & 8.8 & 7.7 & 4.4 & 4.4 & 6.3 & 6.6 & 5.0 & 5.9 & 7.4 & 9.5 \\
\hline 4 & 16.1 & 13.4 & 10.0 & 9.3 & 10.7 & 8.4 & 7.3 & 12.1 & 15.9 & 14.7 \\
\hline 5 & 6.4 & 6.6 & 3.2 & 3.7 & 4.9 & 5.0 & 2.1 & 4.5 & 7.4 & 9.0 \\
\hline 6 & 1.7 & 4.6 & 3.7 & 1.5 & 1.8 & 2.5 & 1.6 & 2.0 & 5.8 & 6.3 \\
\hline 7 & 1.2 & 1.5 & 1.5 & 1.3 & 0.6 & 1.7 & 0.4 & 0.7 & 1.3 & 1.8 \\
\hline 8 & 0.6 & 1.7 & 1.1 & 1.0 & 0.3 & 1.0 & 0.4 & 0.7 & 1.5 & 1.7 \\
\hline $9-10$ & 0.3 & 0.5 & 0.6 & 0.9 & 0.3 & 0.4 & 0.2 & 0.4 & 0.4 & 0.3 \\
\hline Total & 100.0 & 100.0 & 100.0 & 100.0 & 100.0 & 100.0 & 100.0 & 100.0 & 100.0 & 100.0 \\
\hline
\end{tabular}

Notes: The table shows for each year the percentage of separating workers that exit the firm from a given level. Levels 9 and 10 are combined for confidentiality reasons.

collar and white-collar workers differently. While job separations are, if anything, more frequent for white-collar employees than for blue-collar workers during the period of corporate expansion, workers in the lower ranks become more likely to separate during downsizing, which is also revealed by Table 5.3. It is not until late 1995 that exit rates from the top 5 levels of the hierarchy increase markedly, which seems to indicate a shift in layoff policy.

\subsubsection{Vertical Job Mobility}

Since the relative sizes of hierarchical levels remain stable during the episode of workforce expansion in spite of entry concentrated in the bottom levels of blue-collar and white-collar employment but similar exit rates across levels, there must be transitions from lower to higher ranks in the hierarchy. We record 5704 upward moves and 1627 downward moves over the entire period which amounts to an average upward (downward) annual mobility rate of $5.6 \%$ (1.6\%) over the entire period. ${ }^{11}$ Of all the 17610 workers employed at some time during the observation period, 4543 enjoy at least one upward hierarchical transition, 1536 workers are demoted at least once, but a large fraction of them (1121) is also promoted at some time during the observation period. We observe no vertical transition in the hierarchy for 12652 workers, and 7584 of them - who are mostly in level $1(70.4 \%)$ and rarely in levels $7-1.0$

${ }^{11}$ Summing up the length of all employment spells at the firm from January 1, 1987, until the bankruptcy yields a total of 102,147 employment years. 
$(1.7 \%)$ - have the same job code throughout while they are in the sample.

Upward mobility in our firm is lower than in organizations analyzed in related studies, despite the fact that these studies are commonly based on year-end data and, therefore, miss offsetting vertical moves of stayers as well as all job changes of separating workers that take place during the year. Using year-end data (and including the cross-section the day before the bankruptcy as 1996 year-end data), we would miss $18.7 \%$ of promotions and $27.0 \%$ of demotions. Offsetting vertical movements that occur within 365 days (but not necessarily in the same calendar year) account for $21.6 \%$ of all demotions. Such temporary reassignments across job levels might either result from correcting previous mis-assignments or might be due to interim assignments to fill vacant positions temporarily. It should be noted that $12.9 \%$ of demoted workers leave the firm within a year after the demotion. Their domotions potentially remain unobserved when panel data at yearly frequencies are examined.

The fact that related studies commonly consider only white-collar jobs partly explains why upward mobility is lower in our firm as a whole: Job transition rates for white-collar workers are also higher in our firm in both periods. The average annual promotion (demotion) rate for white-collar workers is $7.7 \%(2.7 \%)$ during expansion and $6.4 \%(2.6 \%)$ during contraction, but $6.4 \%$ $(1.0 \%)$ during expansion and $3.9 \%(1.4 \%)$ during downsizing for blue-collar workers.

Tables 5.4 and 5.5 summarize the vertical job transition pattern for different groups of workers for the episodes of workforce expansion and downsizing by comparing their hierarchical position at the beginning of the period to that at the end. ${ }^{12}$ The tables are divided into four blocks. The upper two blocks contain transition patterns of workers who were employed at the beginning of the period as shares of incumbent workers, while the lower two describe transition patterns of all workers entering aluring the period as shares of all new entrantis at given entry levels during the respective period. The rows of the blocks depict what shares of workers assigned to a given level at the beginning of the period (upper blocks) - or the beginning of the employment relation for new entrants (lower blocks) - are employed in different levels at the end of the period (left blocks) and what shares left after having reached a particular level (right blocks). For example, $65.1 \%$ of all workers who were employed at level 1 on January 1, 1987, are still employed at level 1 on March 1,$1991 ; 11.1 \%$ have advanced to level $2,2.6 \%$ to level 3 , and $0.6 \%$ to level 4 ;

\footnotetext{
${ }^{12}$ Clearly, this gives only an incomplete picture on total vertical mobility as it ignores offsetting vertical movements which occur when a worker is promoted and demoted within
the period.
} 


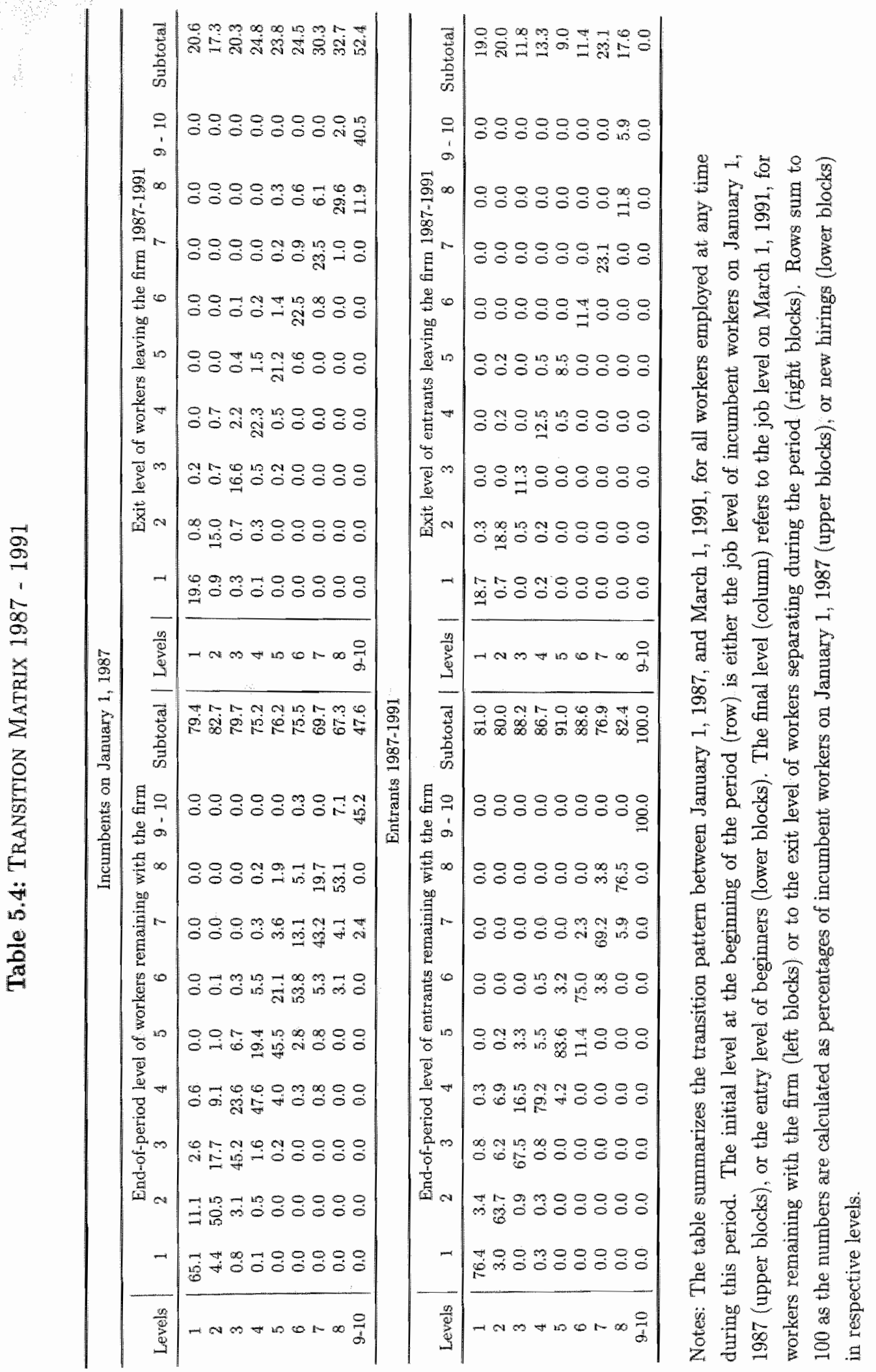




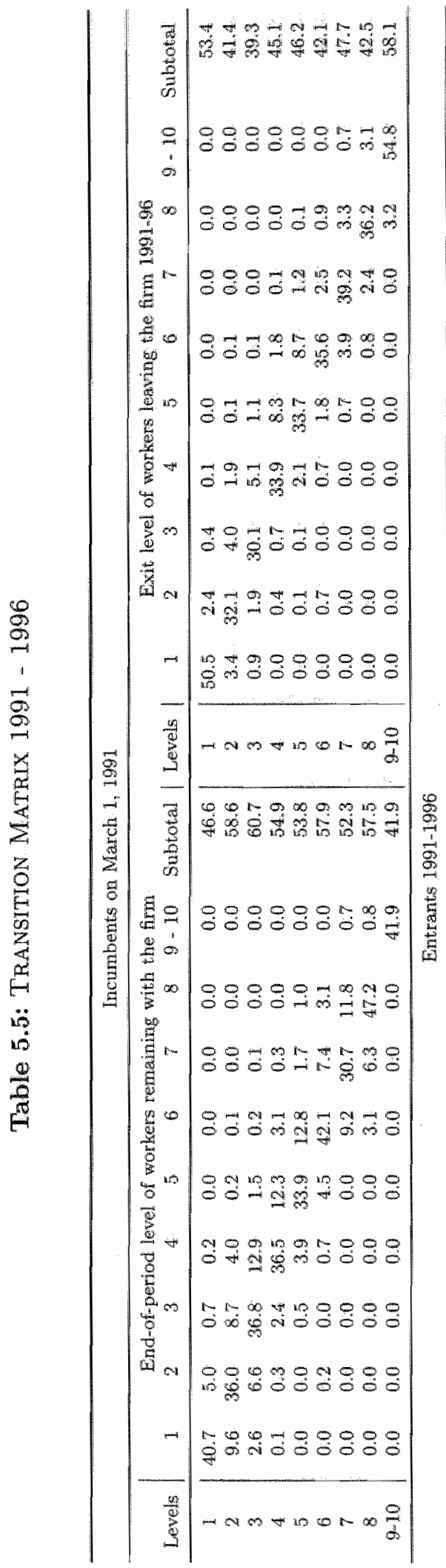

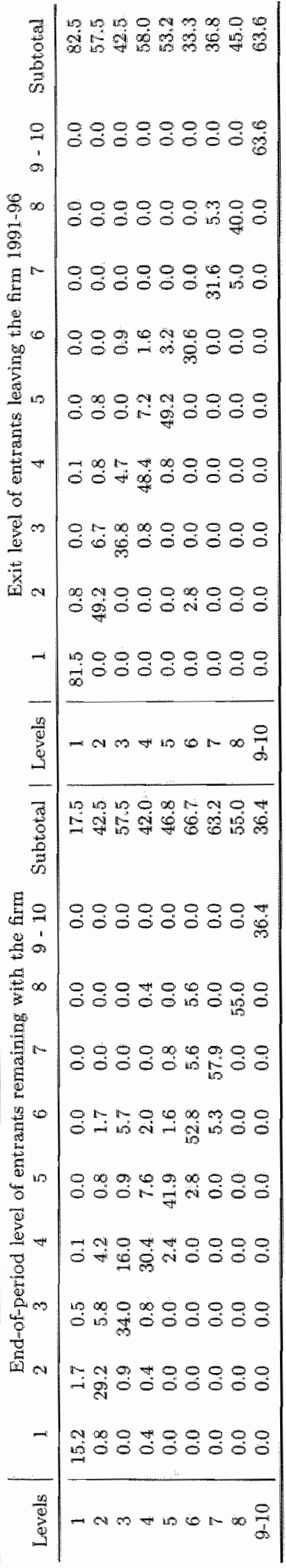

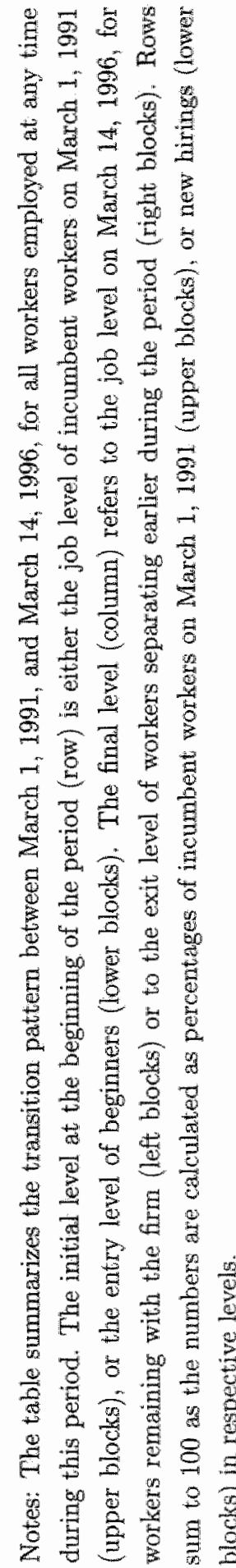


$20.6 \%$ separated during the period and the vast majority of them had not been promoted. Only $1 \%$ of all workers employed at level 1 at the beginning of the period had been promoted prior to their separation.

A comparison of Tables 5.4 and 5.5 reveals important facts: First, a larger fraction of workers who separate in the second period had progressed to higher levels before their employment relation ends. Second, upward mobility is lower in the period of downsizing so that substantially fewer workers staying with the firm are promoted to higher levels. An obvious explanation is that less slots become vacant in higher positions when the company reduces employment, especially as the employment reduction is not proportional to level size. That many workers who were promoted during downsizing sepam rate also suggests that "talented" workers leave the firm, possibly because of reduced further career prospects in a downsizing firm. More evidence that promotion rates are inversely related to exit rates comes from the fact that promotion rates fall most for blue-collar workers who also experience a more severe increase in separation rates. While $14.9 \%$ of all blue-collar workers and $20.0 \%$ of white-collar workers move upward in the hierarchy between January 1987 and March 1991, only 11.6\% blue-collar workers but 21.1\% of white-collar workers have proceeded to a higher hierarchical positions in the longer period between March 1991 and the bankruptcy or their separation date. Consequently, relative upward mobility falls for blue-collar worker during downsizing. ${ }^{13}$

Separating workers have lower upward mobility than staying workers, but similar downward mobility in both periods. ${ }^{14}$ Not correcting for the length of the employment spell, upward mobility rates are smaller for beginners than for the incumbent workforce. But workers who enter after January, 1987, and remain with the firm have higher upward mobility rates than entrants who separate before the end 1991. Tables 5.4 and 5.5 also show that more workers are demoted in the second period and that a substantial fraction of them leaves. Although the downward mobility rate remains higher in the upper segment of the hierarchy downward moves become relatively more common for blue-collar workers.

The mobility pattern indicates interrelations between vertical internal job mobility and turnover rates. Upward mobility is lower during downsizing and seems to be related to the scale of workforce reductions (upward mobility falls most in blue-collar jobs where exit is concentrated). Downward

\footnotetext{
${ }^{13}$ These percentages are calculated based on the absolute numbers of transitions underlying Tables 5.4 and 5.5 , but cannot be readily inferred from the tables as these average percentages for the fraction of all blue-collar workers and white-collar workers are weighted by the size of the levels.

14 Note that they have less time for vertical moves.
} 
mobility is higher during periods of workforce reductions and upward mobil ity is positively correlated with entry rates. Figure 5.3 plots the entry rate, exit rate, promotion rate and demotion rate. Not only are promotion rates higher when entry is high, but promotion rates follow entry rates in the sense that they rise when entry in the previous months had been unusually high as is evident from the period from the second half of 1988 until the beginning of downsizing in 1991. This implies that corporate expansion initiates reassignment of workers to jobs, consistent with the theory of internal labor markets where entry is concentrated in some jobs, while the remaining jobs are predominately filled from within.

\section{Figure 5.3: MONTHLY MoBILITY}

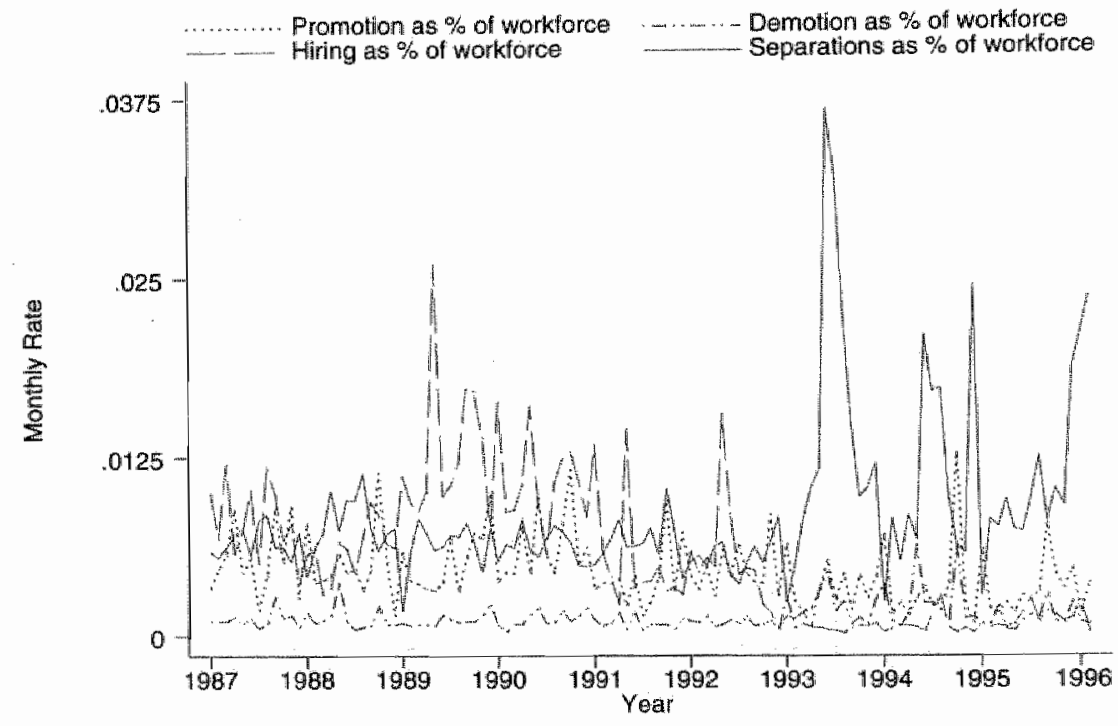

Notes: The figure plots monthly promotion and demotion rates - calculated as the number of transitions relative to the number of incumbent workers - along with the hiring rate and the separation rate from Figure 5.2.

Similarly, the demotion rate usually peaks shortly before the exit rate. Finally we notice that promotion and demotion rates are positively correlated (correlation coefficient of 0.48). The graph suggests that this result is to some degree driven by the co-movement of the promotion rate and demotion rate in periods with severe employment reductions, as is reflected in the coincidence of local peaks in both rates in May 1988, January and June 1993, January, May and October 1994, and September 1995. This suggests that such reorganizations trigger reassignments across job levels. 


\subsubsection{Lateral Job Mobility}

We observe a substantial number (13636) of lateral job transitions, which we define as changes in job codes of jobs belonging to the same hierarchical level. Admittedly, some fraction of these are spurious job transitions due to the fact that codes might be changed over time, while the content of the job remains the same. But the largest fraction of these lateral transitions relates to changes in the job description. About one fourth of all lateral job transitions involve a transition to a different field of activity within the frm. Table 5.6 reports for each job level the shares of lateral transitions that involve a job change to a different field of activity.

Table 5.6: LATERAL Job Transitions to A DIFFERENT FIELd of ACTrVity

\begin{tabular}{l|ccccccccc}
\hline & \multicolumn{1}{c}{ Job Level } & & \\
& 1 & 2 & 3 & 4 & 5 & 6 & 7 & 8 & $9-10$ \\
\hline Number & 1515 & 426 & 336 & 525 & 227 & 159 & 62 & 83 & 19 \\
Percent & 23.1 & 23.1 & 30.1 & 26.4 & 22.1 & 23.6 & 32.0 & 40.3 & 46.3 \\
\hline
\end{tabular}

Notes: This table reports for each job level the absolute number of lateral job transitions that involve a job change to a different field of activity (row 2 ) and their percentage shate (row 3) of all lateral transitions at the respective level. Levels 9 and 10 are combined for confidentiality reasons.

This suggests an interesting additional dimension in the analysis of job change, promotion dynamics, and wage dynamics. Lateral transitions might occur across different fields of activities within the firm to prepare for subsequent upward mobility thereby increasing career prospects. For instance, an assembly worker might be assigned to quality assessment or to production preparation to widen his knowledge on the entire production process which is crucial in higher level jobs. Such reassignments are usually referred to as job rotation. If the acquisition of a wider portfolio of skills that might be required in higher level jobs is the motive, the probability of an upward move increases for workers who have held different jobs at the same level. ${ }^{15}$ On the other hand, job rotation might be used to screen workers or learn about their optimal assignment (Ortega, 2001), in which case lateral transitions do not entail a priori information on career perspectives. ${ }^{16}$ Besides, a lateral tran-

\footnotetext{
${ }^{15}$ Campion et all (1994) study these aspects of job rotation empirically.

${ }^{16}$ Eriksson and Ortega (1994) find limited support for the employer learning bypothesis, but no favorable evidence for job rotation theories of employee leaning and employee motivation in data from Danish private sector firms.
} 
sition might entail a career step in itself, both in terms of wage growth and in terms of characteristics of the job. Finally, workers might be transferred lateraily because they do not qualify for upward mobility.

An inspection of the job titles gives rise to the conjecture that such "flatter" careers exist since job titles often suggest differences in qualification requirements or responsibilities. Some apparent examples include movements from "Secretary of departmental chef" to "Secretary of the Head of the Department", from "Assembly Worker" to "Aircraft Mechanic", or from "Assembler Electrical Assembly A" to "Assembler Electrical Assembly B" "These three examples all involve transitions to a job in which the median wage scale is higher. $45.0 \%$ of lateral movements are to jobs with a higher median wage scale, while $19.1 \%$ are to jobs with a lower median wage scale.

There is evidence that a fraction of lateral reassignments lasts only for a short time - $31 \%$ of all lateral movements are not observed in a year-end panels. This possibly results from temporarily staffing of crucial vacancies, from intended job rotation to learn about a worker"s performance at different jobs or to stimulate the accumulation of different skills, or from correcting 'mistakes' in assignment, when an intended lateral move turns out to have resulted in an inefficient allocation.

\subsection{Wages and the Hierarchy}

Since internal labor markets are characterized by substantial fixed costs of hiring, screening or training, which become sunk upon a separation, internal labor markets foster long-term relations between workers and the firm. Wages no longer have to equal marginal productivity at every moment during the employment relation in presence of such fixed costs, even with competitive Labor markets (see Oi, 1962). Although external labor market conditions potentially constrain the internal wage structure, for example, by affecting hiring wages, competitive forces do not restrict wage determination to a unique outcome in internal labor markets. Exploiting this indeterminacy of wages, the firm can design the wage structure to encourage long-term relations, shield workers from external conditions or accomplish other goals, as, for example, the provision of incentives to elicit optimal effort levels.

In the tournament model of Lazear and Rosen (1981), workers supply the optimal level of effort competing for a promotion which is associated with a sufficiently higher wage. This model, but also the models by Rosen (1982) and Calvo and Wellisz (1979), predicts that wage differences between 
hierarchical levels increase towards the top of the hierarchy. ${ }^{17}$ These predictions concern the vertical wage structure, i.e. differences between wage rates among workers in different job levels. Other theories make predictions about the horizontal wage structure, i.e. about wage differentials for individuals in the same job. Lazear (1979) illustrates, for example, how deferred compensation schemes can provide non-shirking incentives. In that case, wages are not solely determined by jobs, but depend on worker characteristics like age and tenure, too.

Formal rules and procedures might play an important role in wage determination. Such rules might improve efficiency, for example, by solving hold-up problems, which arise when wages are set or renegotiated after firmspecific investments (e.g. including firm-specific training or broadly defined organization-specific capital, Prescott and Visscher, 1980) have been made. A contractual arrangement which fixes wages in advance can serve as a commitment device and help resolve the hold-up problem (MacLeod and Malcomson, 1993b). Moreover, the existence of favoritism (Prendergast and Topel, 1996) would give rise to rules in the wage setting process to limit discretion. Consequently, we should expect the wage structure to be governed by contractual arrangements and administrative rules.

In the following paragraphs, we analyze the wage structure of the firm in some depth to shed light on such questions of whether wage determination is governed by administrative rules and whether theses rules are binding; whether the wage structure is stable; whether wages are attached to jobs; and what the vertical and horizontal wage structure looks like.

\subsubsection{Administrative Rules in Wage Setting}

Doeringer and Piore (1971) argue that wages in internal labor markets are determined by formal, impersonal administrative procedures. Strong evidence for such rules is the existence of a wage scales in our firm. There are 10 blue-collar scales (scales 2-11) and 8 white-collar scales (scales 12-19). A range of wages exists in each white-collar wage scale. Minimum, maximum and mean wages are increasing in subsequent $\mathrm{scales}^{18}$ but wage ranges of subsequent scales overlap.

All blue-collar workers are covered by collective bargaining agreements

\footnotetext{
${ }^{17}$ Baker, Gibbs and Holmstrom (1994a) find evidence of a strong relation between wages and hierarchical levels and a convex relationship between hierarchical levels and wages in their data set.

${ }^{18}$ An exception is scale 12 which absorbs all that have not been put into a particular scale - usually recently recruited employees - so that the maximum wage in scale 13 might be lower than the maximum wage in scale 12 .
} 
(CAO) between unions and employer federations and cover all blue-collar workers in the firm. ${ }^{19}$ The collective bargaining agreement defines, among other things, nominal wages for each of the (up to 9) wage grades within all blue-collar wage scales. ${ }^{20}$ Firms can pay above these wages, and Fokker does so. The wage grades can be interpreted as a contractual tenure-wage profile since workers commonly climb the within-scale wage ladder at distinct, mostly yearly, intervals. This structure of wage grades and wages scales is usually not changed in yearly bargaining. Instead, a percentage nominal wage increase, pertaining to all wages in blue-collar scales, is negotiated to adjust wages for aggregate conditions (e.g. inflation, technological progress, etc.). Fokker usually adjusts white-collar salaries by the same percentage, thereby shifting its entire wage frame keeping the wage structure stable.

As is common in the Netherlands (see Teulings and Hartog, 1998), wage increases can be decomposed into three components: First, a worker is usually awarded a yearly raise according to the contractual experience-wage or tenure-wage profiles defined in the collective wage agreement until the highest wage in the scale is achieved. Second, contractual initial increases adjust all wages to changes in aggregate conditions. ${ }^{21}$ Third, incidental wage increases relate to any other type of wage increase including promotions. The latter type of wage contract changes might occur throughout the year, but the bulk of wage changes, pertaining to collectively negotiated wage adjustments or contractual periodical increases take place at the turm of the year and are usually administered in our data set in the last week of December or the first week of January.

\subsubsection{Job Levels and Wages}

The existence of a formal wage system provokes the question of whether formal bureaucratic rules actually constrain individual compensation by attaching wages to jobs, or whether they leave scope for sufficient managerial Hexibility in rewarding individual worker characteristics. The correlation between job levels and salary scales (0.92 in the entire sample, or 0.68 and 0.81 in the blue-collar and white-collar scales respectively) indicates a strong relation between wages and jobs. This is confirmed by Figure 5.4 which plots

${ }^{19}$ There is a high degree of coordination between unions and employer federations in the Netherlands (see Teulings and Hartog, 1998).

${ }^{20}$ Nominal contracts are characteristic for the Dutch labor market.

2"The nature of wage determination and the existence of fixed nominal wage contracts, which can be adjusted to aggregate conditions, helps solving hold-up problems in the way described by Teulings and Hartog (1998). 
Figure 5.4: MEAN WAGE

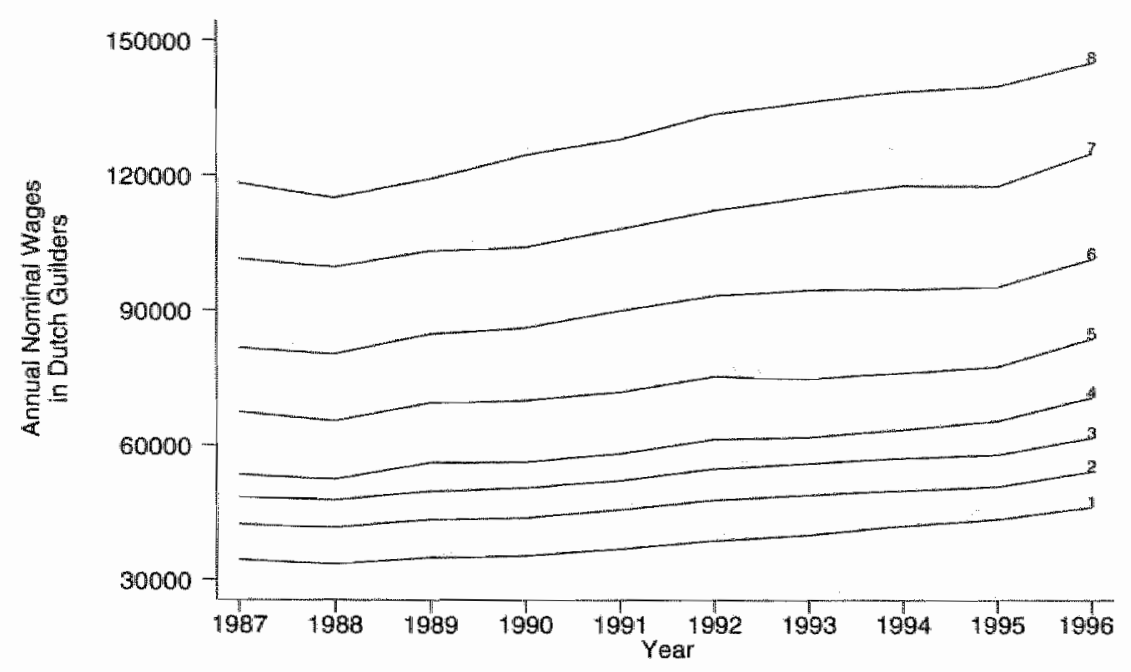

Notes: The figure plots average full-time equivalent nominal wages of incumbent workers in the hierarchical job levels 1 through 8 , which are labelled accordingly. The thick crossed line reflects average full-time equivalent nominal wages at the firm-level. Means are calculated based on cross-sections taken at the beginning of a year.

mean nominal, full-time equivalent within-job-level wages over time. ${ }^{22}$

The vertical wage structure is remarkably stable throughout in the sense that the magnitude of differences in average wages between job levels persists. Only average nominal wages in levels 1 and 4 rise somewhat faster during downsizing mainly because of the entry and exit patterns that change the within-level wage distribution. Table 5.7 illustrates, for example, that new lires predominately start off in the lowest decile of the within-level wage distribution. ${ }^{23}$ A considerable fraction of separating workers also comes from the lower deciles of the wage distribution (see Table 5.8), so that average within-level wages increase when the hiring rate falls and the separation rate rises.

Such changes in within-level wage distributions explain why average nominal job level wages - especially in levels 1 and 4 (see Figure 5.4) where exit is concentrated and hiring falls most - rise after 1993 although it was agreed in collective bargaining not to adjust wage scales at the firm for inflation be-

\footnotetext{
${ }^{22}$ A werages are taken over wage contracts active on March 14 of each year.

${ }^{23}$ Entry wages are much more variable in higher levels (levels 6 to 8), especially during downsizing.
} 
Table 5.7: Distribution of PAY FOR NEW HIRES IN WAGE DECILES

\begin{tabular}{|c|c|c|c|c|c|c|c|c|c|c|c|c|}
\hline \multirow[b]{2}{*}{ Level } & \multirow[b]{2}{*}{$N$} & \multicolumn{10}{|c|}{ Decile in Job Level Wage Distribution } & \multirow[b]{2}{*}{$\mathrm{AH}$} \\
\hline & & Ist & 2 nd & $3 \mathrm{rd}$ & 4th & $5 \mathrm{th}$ & 6th & 7 th & $8 \mathrm{th}$ & 9th & Top & \\
\hline 1 & 4270 & 33.1 & 20.0 & 16.9 & 14.2 & 7.7 & 4.2 & 2.5 & 0.7 & 0.6 & 0.2 & 100.0 \\
\hline 2 & 405 & 52.1 & 22.7 & 8.4 & 4.0 & 2.5 & 3.7 & 1.5 & 1.0 & 2.2 & 2.0 & 100.0 \\
\hline 3 & 212 & 49.5 & 9.4 & 17.9 & 10.4 & 4.2 & 3.3 & 1.4 & 0.9 & 0.9 & 1.9 & 100.0 \\
\hline 4 & 602 & 35.5 & 18.4 & 22.8 & 6.3 & 4.7 & 2.8 & 3.0 & 2.7 & 2.3 & 1.5 & 1000 \\
\hline 5 & 189 & 53.4 & 9.0 & 9.5 & 6.3 & 2.6 & 4.2 & 5.8 & 0.5 & 4.2 & 4.2 & 100.0 \\
\hline 6 & 45 & 33.3 & 13.3 & 4.4 & 20.0 & 6.7 & 4.4 & 2.2 & 2.2 & 6.7 & 6.7 & 100.0 \\
\hline 7 & 24 & 20.8 & 25.0 & 12.5 & 4.2 & 0.0 & 12.5 & 4.2 & 16.7 & 4.2 & 0.0 & 100.0 \\
\hline 8 & 12 & 25.0 & 0.0 & 16.7 & 0.0 & 8.3 & 25.0 & 0.0 & 0.0 & 0.0 & 25.0 & 100.0 \\
\hline
\end{tabular}

\begin{tabular}{|c|c|c|c|c|c|c|c|c|c|c|c|c|}
\hline \multirow[b]{2}{*}{ Level } & \multirow[b]{2}{*}{$\mathrm{N}$} & \multirow[b]{2}{*}{ lst } & \multirow[b]{2}{*}{$2 \mathrm{nd}$} & \multicolumn{6}{|c|}{ Decile in Job Level Wage Distribution } & \multirow[b]{2}{*}{$9 \mathrm{hh}$} & \multirow[b]{2}{*}{ Top } & \multirow[b]{2}{*}{ All } \\
\hline & & & & $3 r d$ & 4 th & 5 th & $6 \mathrm{th}$ & 7 th & 8 th & & & \\
\hline 1 & 926 & $=$ & 18.3 & & & & 1.4 & & & 0 . & 0.3 & 100.0 \\
\hline 2 & 111 & 35.1 & 16.2 & & 7.2 & & 5. & & & & 2.7 & 100.0 \\
\hline 3 & 102 & 58.8 & 9.8 & 10.8 & 6.9 & 2 & 2.0 & 2. & 1 & 1. & 4.9 & 100.0 \\
\hline 4 & 243 & 43.6 & 33.3 & 7.0 & 3.3 & 3 & 0.8 & 1. & 3 & 2. & 1.6 & 100.0 \\
\hline 5 & 120 & 76.7 & 8.3 & 6.7 & 3.3 & 0.0 & 0.8 & 1.7 & 0. & 0.8 & 0.8 & 100.0 \\
\hline 6 & 31 & 35.5 & 16.1 & 6.5 & 9.7 & 0.0 & 0.0 & 3.2 & 6. & 6.5 & 16.1 & 100.0 \\
\hline 7 & 14 & 21.4 & 7.1 & 14.3 & 7.1 & 0.0 & 14.3 & 7.1 & 0.0 & 0.0 & 28,6 & 100.0 \\
\hline 8 & 9 & 11.1 & 0.0 & 22.2 & 0.0 & 11.1 & 0.0 & 22.2 & 0.0 & 22.2 & 11.1 & 100.0 \\
\hline
\end{tabular}

Notes: The two blocks of the table show for the periods from January 1, 1987, unit March 1, 1991 (upper block), and from from March 1, 1991, until March 14, 1996 (lower block), the number of entrants into each level (column 2). Columns 3-12 of the blocks show the percentage shares of workers entering in a given job level whose starting wage is in a particular decile of the respective job level wage distribution. Wage distributions are based on hourly wages for all workers employed in the relevant job level and period and calculated dates following contract wage adjustments due to inflation compensation and (semi-)annual raises. For privacy reasons, there is no salary information for levels 9 and 10 in the personnel files. 
Table 5.8: Distribution of PAy For Separating Workers in Wage DECILES

$1987-1991$

\begin{tabular}{|c|c|c|c|c|c|c|c|c|c|c|c|c|}
\hline \multirow[b]{2}{*}{ Level } & & \multirow[b]{2}{*}{ 1st } & \multirow[b]{2}{*}{ 2nd } & \multicolumn{6}{|c|}{ Decile in Job Level Wage Distribution } & \multirow[b]{2}{*}{9 th } & \multirow[b]{2}{*}{ Top } & \multirow[b]{2}{*}{ All } \\
\hline & & & & $3 \mathrm{rd}$ & 4 th & 5 th & 6 th & 7 th & 8 th & & & \\
\hline 1 & 1835 & 11.0 & 15.5 & 15.9 & 11.9 & 11.1 & 10.1 & 6.7 & 6.0 & 5.4 & 6.4 & 100.0 \\
\hline 2 & 376 & 19.4 & 12.5 & 10.1 & 6. & 6. & 4.8 & 8.5 & 7.7 & 9.3 & 14.4 & 100.0 \\
\hline 3 & 202 & 17.8 & 10.9 & 6.9 & 6.9 & 4.0 & 6.9 & 5.0 & 8.9 & 13.4 & 19.3 & 1000 \\
\hline 4 & 356 & 17.1 & 10.7 & 9.8 & 7.0 & 7.9 & 5.9 & 10.7 & 8.7 & 5.6 & 16.6 & 100.0 \\
\hline 5 & 172 & 16.3 & 8.1 & 8.1 & 10.5 & 12.2 & 5.2 & 7.0 & 4.1 & 14.0 & 14.5 & 100.0 \\
\hline 6 & 92 & 15.2 & 12.0 & 12.0 & 8.7 & 7.6 & 9.8 & 6.5 & 7.6 & 5.4 & 15.2 & 100.0 \\
\hline 7 & 42 & 9.5 & 11.9 & 7.1 & 4.8 & 7.1 & 9.5 & 9.5 & 7.1 & 9.5 & 23.8 & 100.0 \\
\hline 8 & 31 & 3.2 & 3.2 & 3.2 & 12.9 & 3.2 & 6.5 & 19.4 & 6.5 & 25.8 & 16.1 & 100.0 \\
\hline
\end{tabular}

$1991-1996$

\begin{tabular}{l|r|rrrrrrrrrr|r}
\hline \multirow{2}{*}{ Level } & \multirow{2}{*}{$\mathrm{N}$} & \multicolumn{8}{|c|}{ Decile in Job Level Wage Distribution } & & & \\
\hline 1 & 4271 & 16.1 & 13.6 & 13.0 & 11.9 & 10.0 & 8.7 & 7.0 & 4.6 & 8.2 & 7.0 & 100.0 \\
2 & 865 & 13.8 & 11.4 & 10.8 & 9.7 & 7.3 & 8.6 & 9.8 & 6.0 & 9.2 & 13.4 & 100.0 \\
3 & 484 & 14.5 & 11.0 & 8.1 & 8.7 & 9.3 & 3.1 & 10.5 & 14.0 & 5.6 & 15.3 & 100.0 \\
4 & 765 & 12.9 & 13.5 & 10.6 & 8.5 & 7.2 & 6.1 & 10.7 & 8.8 & 3.8 & 17.9 & 100.0 \\
5 & 502 & 14.1 & 13.3 & 10.0 & 8.0 & 11.2 & 8.4 & 6.0 & 2.2 & 15.9 & 11.0 & 100.0 \\
6 & 287 & 11.5 & 12.2 & 8.7 & 11.5 & 7.7 & 1.0 & 10.5 & 9.8 & 10.5 & 16.7 & 100.0 \\
7 & 92 & 12.0 & 10.9 & 12.0 & 3.3 & 20.7 & 5.4 & 6.5 & 1.1 & 7.6 & 20.7 & 100.0 \\
8 & 66 & 7.6 & 10.6 & 6.1 & 6.1 & 12.1 & 6.1 & 13.6 & 3.0 & 28.8 & 6.1 & 100.0 \\
\hline
\end{tabular}

Notes: The two blocks of the table show for the periods from January 1, 1987, until March 1, 1991 (upper block), and from from March 1, 1991, until March 14, 1996 (lower block), the number of exits from exch level (column 2). Columns 3-12 of the blocks show the percentage shares of workers exiting from a given job level whose final wage is in a particular decile of the respective job level wage distribution. Wage distributions are based on hourly wages for all workers employed in the relevant job level and period and calculated dates following contract wage adjustments due to inflation compensation and (semi-) hannual raises. Only the first accession to the firm of a worker is considered, so that rehiring is neglected. For privacy reasons, there are no salary information for levels 9 and 10 in the personnel, files. 
cause of the firm"s depressed economic condition. Such inflation corrections remained eventually set out until January 1,1996 , when they were made up for ${ }^{24}$ However, the rise in average firm-level wages can be mainly attributed to the rise in the employment share in higher hierarchical levels resulting from the relative lower separation rates of high-wage workers discussed in section 5.4.1.

Separating Workers are more evenly distributed over the wage distribution than new hires (compare Tables 5.7 and 5.8). A substantial fraction of workers moves up in the job-level wage distribution before separating. This provokes the question of how big the spread in job-level wage distributions is, i.e. how much wage growth is associated with moving up a decile in the job-level wage distribution. Kernel density estimates of the within-level wage distributions in Figure 5.5 reveal substantial wage variation. The wage distributions in the figure refer to 1991, but their main features are the same in all years ${ }^{25}$ : Wages rise on average with job-levels, but wage distributions of successive hierarchical levels overlap. Wages are definitely related to job levels as the correlation between job levels and wage scales already suggested, but wages are not tied to jobs in a strict sense as substantial within-job-level wage variation remains.

Within-level wage variation generally increases in hierarchical levels, ${ }^{26}$ but wage distributions for blue-collar job levels have a markedly smaller variance. This disparity in the pay structure most likely results from more stringent formal rules in blue-collar wage setting as a consequence of collective bargaining. The higher wage variation for white-collar workers suggests that there is scope for individual negotiation in spite of the formal wage system.

Still, the existence of pay ranges for jobs indicates that such scope is limited, certainly for blue-collar workers. For example, 99\% of assembly workers' wage contracts (the largest job code) are in wage scales 4-8 (95\% are in 5-8). Within that pay range, individual wages depend on experience and tenure. The tenure-wage profile, however, is again governed by the contractual wage system. The firm seems to have some discretion to reward

24"This collective bargajning outcome underlines the importance of coordination between unions and employer federations in the Netherlands.

${ }^{25}$ Differences pertain to the remarkable fact that the 5 th percentile wage in level 3 exceeds the 5th percentile wage in level 4 in every year until 1991, but never in later years. The substantial number of new hired white-collar workers during expansion, who typically enter level 4 and earn starting wages in the bottom deciles of the within-level wage distribution, cause the left tail of the wage distribution in level 4 to stretch out in these years. A similar pattern holds for level 1 wage distribution which is also more skewed to the right during years of substantial entry.

${ }^{26}$ Note that we do not observe wages for those workers in level 8 whose anmual wages exceed a 200,000 Dutch guilders, so that the observed wage distribution is truncated. 
Figure 5.5: JoB Level Wage Digtributions IN 1991

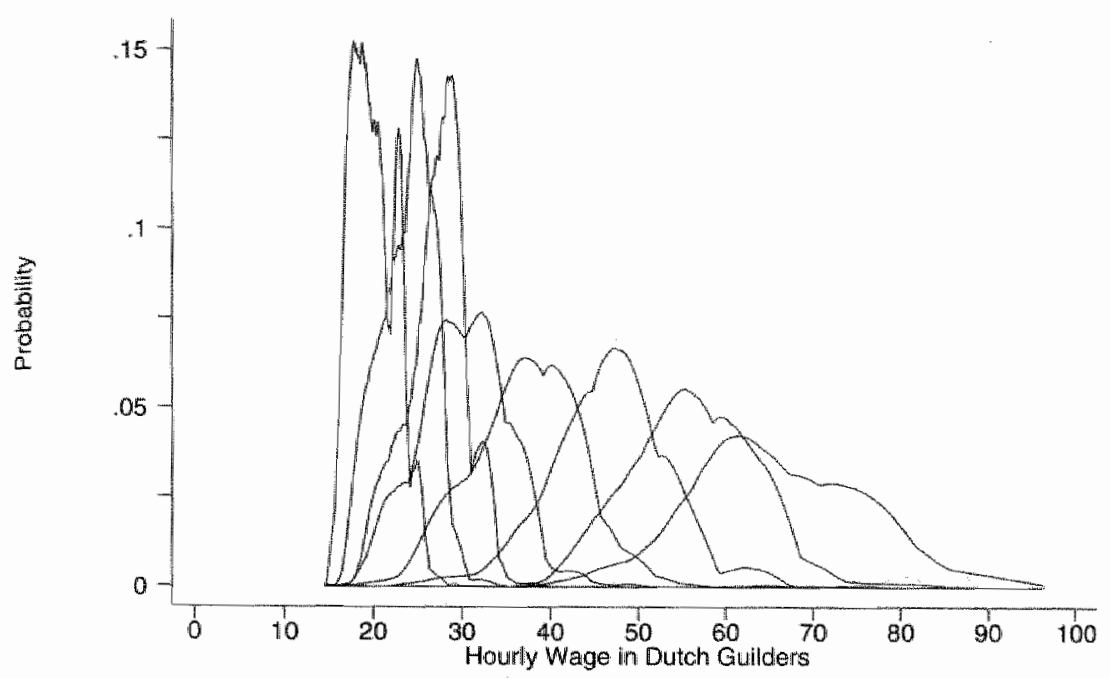

Notes: The figure plots kernel density estimates of the within job-level distribution of lourly full-time equivalent wages on March 14, 1991. Observed amnual wages are truncated at 200,000 Dutch Guilders. This truncation affects only very few workers in level 8 , but should not bias estimates of the wage distribution in level 8 significantly.

workers below the top of the within-job pay range with higher wage growth by awarding more than 1 periodical increase at a time or granting a wage in a higher wage scale. However, once the highest wage in the job has been reached, additional wage growth - exceeding wage adjustments to aggregate conditions as fixed in collective bargaining agreements - can only result from job change. ${ }^{27}$

A transition to a higher paying job need not necessarily entail an upward transition in the hierarchy, as wage ranges differ for different jobs at the same hierarchical level. For example, catering staff, assembly workers and quality controllers are all in level 1 , but the wage range is scales $3-4(97 \%)$ for catering jobs, scales 4-8 for assembly workers, and scales 5-9 (95\%) for quality controllers. This explains some of the within-level wage distribution depicted by Figure 5.5, but it also implies that lateral job mobility can be a source of wage growth. Potentially "flatter" career paths, which involve lateral job transitions associated with upward wage-mobility, exist. Before

\footnotetext{
${ }^{27}$ In fact, a letter was sent to workers informing them once they had reached the highest wage in the job. Unfortunately, we lack the information when and to whom such a lettier was sent, but we can infer such situations from the data.
} 
we consider this issue in section 5.6, we analyze the relation between wage growth and job transitions in more depth.

\subsection{Wage Growth and Job Transitions}

\subsubsection{How are Promotions and Demotions Defined?}

In the tournament model of Lazear and Rosen (1981), a promotion entaills a transition to a higher hierarchical level and is associated with substantial wage increase. But what a promotion really is, is not so clear. We have already seen that a transition to a job on the same hierarchical level with a higher median wage is another source of wage growth. Moreover; pure "wage-promotions" exist, when workers keep the same job, but progress to a higher wage scale and enjoy a steeper within-job wage profile than defined by the contractual tenure-wage profile. Information on the reason for a wage contract change reveals that contract changes are frequently coded as "promotion" when they coincide with job transitions to a higher level. Similarly, movements down the hierarchical ladder are often coded as demotions. ${ }^{28}$ Therefore, we refer to upward hierarchical transitions as promotions and to downward movements as demotions in the remainder of the chapter. Still, it is not obvious that such promotions are associated with wage growth as many theories predict, an issue to which we turn in the next section.

\subsubsection{Wages and Promotions}

Since wages are positively correlated with hierarchical levels, we expect wages to rise upon a promotion. The large difference in mean job-level wages unveiled by Figure 5.4 might suggest that promoted workers enjoy substantial wage gains. On the other hand, Figure 5.5 shows that wage distributions of successive levels overlap so that promotions might not be associated with nominal wage increases at all. We find that wage contracts are changed simultaneously with upward transitions in $51.6 \%$ of the cases. Nominal wages rise in these cases by an average of $5.2 \%$ and these upward job transition are mostly (in $72 \%$ of the cases) associated with climbing at least one wage scale. Wages change for the majority of the remaining $48.4 \%$ of upward movers occur within 3 months after the upward job transition. ${ }^{29}$ However, fewer of

\footnotetext{
${ }^{28}$ When such transitions occur on the date when contractual wage increases are awarded, a transition may not be coded as a promotion, but instead as a "yewrly increase" or "price compensation" since only one reason for wage-contract change is recorded.

${ }^{29}$ More than $80 \%$ heve their wage contract changed within half a year after the upward transition.
} 
them (29.9\%) proceed to a higher wage scale and average wages grow less $(3.1 \%)$. Table 5.9 discloses that average wage increases upon promotions are substantially lower than the gap between mean wages of successive levels in both periods and for all levels.

Table 5.9: Salary Premium of Promotion

\begin{tabular}{|c|c|c|c|c|c|c|}
\hline \multirow[b]{3}{*}{ Level } & \multicolumn{3}{|c|}{$1987-1991$} & \multicolumn{3}{|c|}{$1991-1996$} \\
\hline & \multicolumn{2}{|c|}{ Premium $(\%)$} & \multirow[t]{2}{*}{$\%$ diff. means } & \multicolumn{2}{|c|}{ Premium $(\%)$} & \multirow[t]{2}{*}{$\%$ diff. means } \\
\hline & immediate & later & & immediate & later & \\
\hline \multirow[t]{2}{*}{$1-2$} & $\begin{array}{c}4.7 \\
94\end{array}$ & 2.7 & \multirow[t]{2}{*}{24.4} & 4.4 & 2.9 & \multirow[t]{2}{*}{20.4} \\
\hline & $\begin{array}{c}(2.4) \\
4.4\end{array}$ & $(2.1)$ & & $(2.7)$ & $(1.9)$ & \\
\hline $2-3$ & $(2.2)$ & $(2.3)$ & 14.8 & $\begin{array}{c}4.4 \\
(2.4)\end{array}$ & $\begin{array}{r}2.9 \\
(1.8)\end{array}$ & 14.4 \\
\hline \multirow[t]{2}{*}{$3-4$} & 5.4 & 3.1 & \multirow[t]{2}{*}{10.7} & 4.9 & 3.7 & \multirow[t]{2}{*}{12.1} \\
\hline & $(4.3)$ & $(3.0)$ & & (3.1) & $(2.4)$ & \\
\hline \multirow[t]{2}{*}{$4-5$} & 5.7 & 3.7 & \multirow[t]{2}{*}{24.6} & 5.6 & 3.4 & \multirow[t]{2}{*}{20.6} \\
\hline & (3.1) & $(2.7)$ & & $(3.5)$ & $(1.9)$ & \\
\hline \multirow[t]{2}{*}{$5-6$} & 5.6 & 3.2 & \multirow[t]{2}{*}{23.0} & 6.3 & 3.4 & \multirow[t]{2}{*}{24.4} \\
\hline & $(2.4)$ & $(2.3)$ & & $(7,0)$ & $(2.2)$ & \\
\hline \multirow[t]{2}{*}{$6-7$} & 6.5 & 3.2 & \multirow[t]{2}{*}{22.9} & 8.4 & 2.6 & \multirow[t]{2}{*}{21.8} \\
\hline & $(4.2)$ & $(1.9)$ & & $(10.9)$ & (1.9) & \\
\hline \multirow[t]{2}{*}{$7-8$} & 8.3 & 1.8 & \multirow[t]{2}{*}{15.9} & 8.5 & 2.9 & \multirow[t]{2}{*}{18.5} \\
\hline & $(6.9)$ & $(1.8)$ & & $(11.4)$ & (1.9) & \\
\hline \multirow[t]{2}{*}{ Total } & 5.2 & 3.1 & \multirow[t]{2}{*}{19.5} & 5.2 & 3.2 & \multirow[t]{2}{*}{18.9} \\
\hline & $(3.3)$ & $(2.5)$ & & (4.9) & (2.1) & \\
\hline
\end{tabular}

Notes: The table shows salary premiums as percentage gains relative to the wage before the promotion. Workers either receive a wage increase on the day of promotion (immediate) or in the months following the promotion (later). Average premiums are calculated for both groups separately and are reported in the columns labelled "immediate" and "later". The columns labelled "\% diff. means" reports the percentage difference between the mean wage of adjacent job levels. Standard deviations are printed in parentheses below the means. For privacy reasons, there are no salary information for levels 9 and 10 in the personnel files.

This observation triggers the conjecture that workers only receive a new job title in order to grant them additional wage growth when they have reached the upper range of wages in their current job, which implies that workers are always promoted out of the top decile of their job-level wage distribution. Table 5.10 shows for each level what fraction of workers was 
(2)

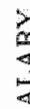

م.

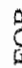

i

a

3

$\ddot{\circ}$

$\frac{1}{0}$

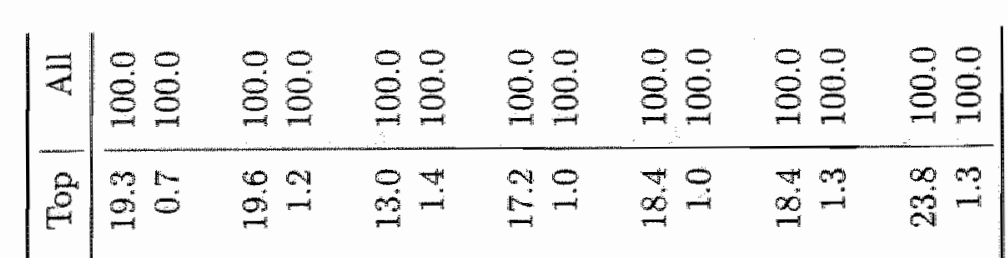

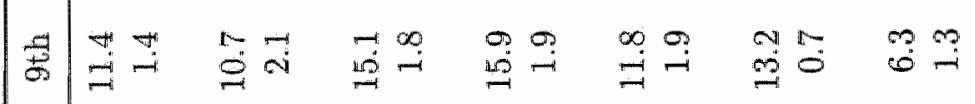

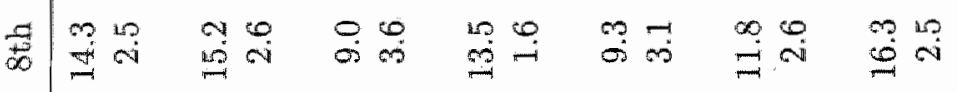

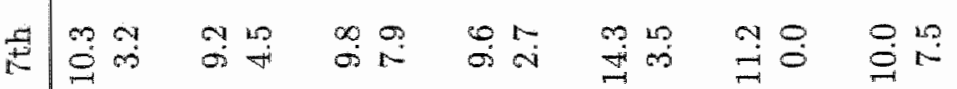

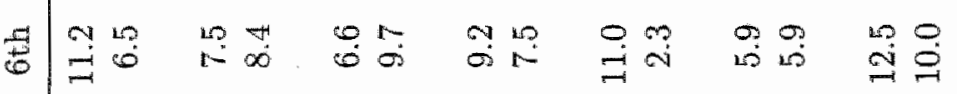

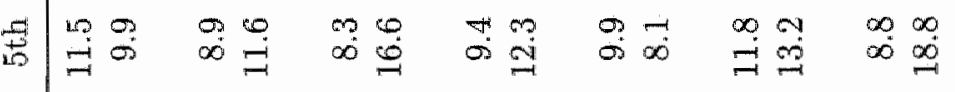

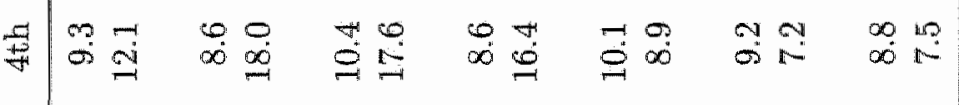

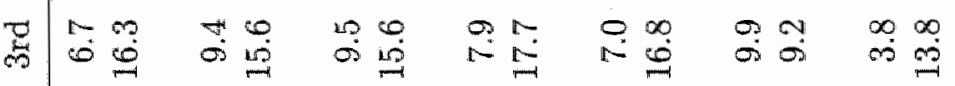

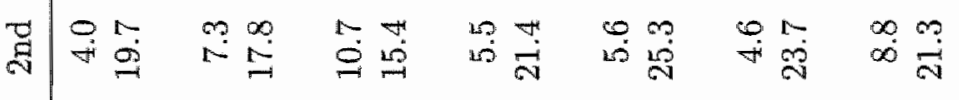

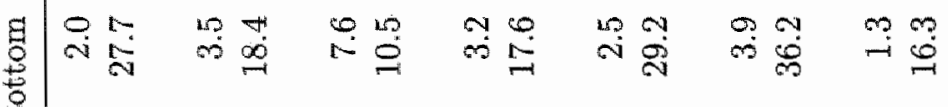
ต

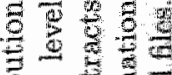

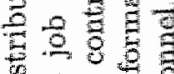

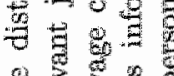

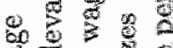

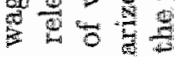

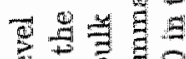

을

응

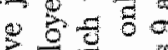

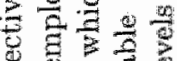

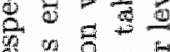

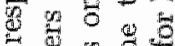

o

5 .

के ने

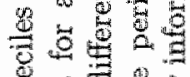

वे

诘

实

굴

政实

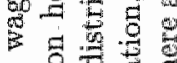

so

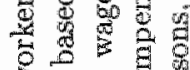

今

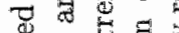

尊

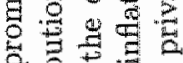

눙

of

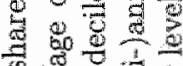

$\circ 5$

焉焉

웧

总吉

的需需

缕 का

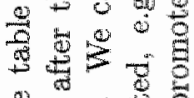

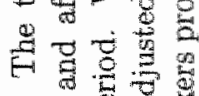
的

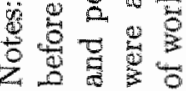


promoted out of a given decile of that level's wage distribution and how promoted workers are distributed in the new level's wage distribution.

The table illustrates that promotees were predominantly, but not exclusively, in the upper deciles of their previous level wage distribution and mostly earn below median wages in their new job-level. In a more detailed analysis than is documented in Table 5.10, we find that workers promoted out of the bottom three deciles of their job level wage distribution move predominately to the lowest decile of the wage distribution in the new job, workers from the 4th and 5th decile move predominately to the 2 nd decile, from the 6 th and 7 th decile to the $3 \mathrm{rd}$ decile, and from the 8 th, 9 th, and 10 th decile to the 4 th, 5 th, and 6th decile respectively. The transitions in the wage distributions of promoted workers are remarkably similar in both periods. We interpret this as evidence that the principal reason for a vertical job transition is not to merely grant higher wages, but to assign workers to more complex jobs with more responsibility or span of control.

In addition, our results concerning the relation between wages and upward job transitions do not suggest that tournaments as described in Lazear and Rosen (1981) explain promotions in levels 1-8 well. For one thing, Table 5.9 does not provide evidence of a convex relation between the logarithm of wages and hierarchical levels. The percentage differences between mean wages of adjacent levels are similar across levels, and if anything, slightly decreasing in job levels in both blue-collar and white-collar ranks. ${ }^{30}$ Unfortunately, we do not observe wages for workers in the two top levels where one would expect tournaments more likely to be relevant. Although immediate wage increases upon promotions are much smaller than tournament theory would predict, the discounted value of expected future wages might rise substantially upon a promotion as a promotion entails an improved perspective of future wage growth beyond the immediate wage rise enjoyed upon the promotion, because promoted workers may climb the wage ladder in their new job.

We find evidence that wage growth rates are persistent. For every year, we calculated the wage growth distribution separately. Workers with wage growth in the upper (lower) quartile of the wage growth distribution are likely to be in the upper (lower) quartile in sulssequent years. Regression results reported in Table 5.11 show a positive effect of lagged wage growth on current wage growth (column 2) even if we control for recent promotions (column 3).

\footnotetext{
${ }^{30}$ The difference in level 7 and level 8 mean wages is, of course, an underestimate of the true difference since wages of some workers in level 8 are not reported as the distribution of reported wages is truncated at 200,000 guilders.
} 
Table 5.11: SERAL Correlation IN WAGE GroWTH

\begin{tabular}{|c|c|c|c|}
\hline & Dependen & t Variable: & $\Delta \ln (W)$ \\
\hline$\Delta \ln (W)_{t-1}$ & $\begin{array}{r}0.424 \\
(0.017)^{*}\end{array}$ & $\begin{array}{r}0.416 \\
(0.017)^{*}\end{array}$ & $\begin{array}{r}-0.013 \\
(0.006)\end{array}$ \\
\hline Promotion & & $\begin{array}{r}0.033 \\
(0.001)^{*}\end{array}$ & $\begin{array}{r}0.026 \\
(0.001)^{*}\end{array}$ \\
\hline Promotion $_{t-1}$ & & $\begin{array}{r}-0.001 \\
(0.001)\end{array}$ & $\begin{array}{r}0.005 \\
(0.000)^{*}\end{array}$ \\
\hline Controls for Iridividual Characteristics & No & No & Yes \\
\hline Year Durnmies & Yes & Yes & Yes \\
\hline Observations & 75772 & 75772 & 75772 \\
\hline R-squared & 0.36 & 0.40 & 0.61 \\
\hline
\end{tabular}

Notes: The dependent variable in all estimations is the log differences of annual hourly wages $(\Delta \ln (W))$. Reported coefficients are marginal effects evaluated at the mean of the explanatory variables. Standard errors are in parentheses. An asterisk denotes that the coefficient is significant at the 1 percent level. Controls for individual characteristics include binary variables for nine education categories, yearly age dummies, tenure, dummies for hierarchical levels, and binary variables for the six performance evaluation scores.

This strong effect disappears if we control for the concavity of the tenurewage profile, individual characteristics, such as age and education, and job characteristics (column 4 ). ${ }^{3 \Perp}$ These results raise the question of whether wage increases predict promotions as workers who are candidates for higher level positions might already be rewarded for better than average performance by higher than usual wage increases in their current job. Moreover, if promotion fast-tracks (Rosenbaum 1984) exist and if promotions are associated with wage growth (see previous section), past wage increases should identify career movers and predict future promotions. In order to test the predictive power of previous wage increases for a promotion, we estimate probit models in cross-sections of the data, in which promotions are explained by past wage growth, and individual characteristics.

The results reported in Table 5.12 show that past wage growth has a positive effect on the probability to be promoted (column 2 and 3), but

\footnotetext{
${ }^{31}$ These regression results portray the pattern of serial conelation in individual wage growth well. Yet, we are aware that more sophisticated econometric techniques and estimators could improve the results along various dimensions, e.g. increase efficiency, account for learning effects (see Farber and Gibbons, 1996), etc.
} 
Table 5.12: Promotion And WAGE Growth

\begin{tabular}{l|rrr}
\hline & \multicolumn{3}{|c}{ Dependent Variable: Promotion } \\
\hline$\Delta \ln (W)_{t-1}$ & 0.413 & 0.719 & -0.101 \\
& $(0.045)^{*}$ & $(0.062)^{*}$ & $(0.06)$ \\
Promotion $t-1$ & & -0.088 & -0.08 \\
& & $(0.003)^{*}$ & $(0.003)^{*}$ \\
Controls for Individual Characteristics & & & \\
Year Dummies & No & No & Yes \\
\hline Observations & Yes & Yes & Yes \\
\hline
\end{tabular}

Notes: The dependent variable in all estimations is a binary variable indicating a promotion. $\Delta l n(W)$ denotes the $\log$ differences of annual hourly wages. Reported coefficients are marginal effects evaluated at the mean of the explanatory variables. Standard errors are in parentheses. An asterisk denotes that the coefficient is significant at the 1 percent level. Controls for individual characteristics include binary variables for nine education categories, yearly age dummies, tenure, and binary variables for the six performance evaluation scores.

that this effect works through the impact of individual characteristics on wage growth, as the direct effect of wage growth on promotion probability disappears if we include controls for tenure, age, education, and performance evaluation (column 4).

\subsubsection{Wages and Demotions}

The logic of the previous section which established that promotions are associated with nominal (and real) wage growth suggest wage cuts at demotions. However, nominal wage cuts are extremely rare. Only 197 nominal hourly wage rate cuts are recorded, which amounts to 0.1 percent of all wage contract changes ${ }^{32}$ Ninety percent of those experiencing nominal cuts remain in the same function. Moreover, most nominal wage cuts (117 out of 197) occur between January 1993 and January 1995 and are concentrated (105 out of 117) at a single plant (ELMO). ${ }^{33}$ The absolute number of observed wage cuts would obviously be smaller if we had data at yearly frequency

\footnotetext{
${ }^{32} 1309$ further contracts entail nominal wage cuts because of changes in working hours.

${ }^{35}$ Wage drops are due to fewer shifts at ELMO during downsizing, i.e. result from reduced working hours.
} 
due to attrition and within-year contract changes. ${ }^{34}$ Real wage cuts become more frequent during downsizing. In 1994 and 1995, 33.8 percent and 42.5 percent of employees, respectively, do not receive nominal wage increases. ${ }^{2}$ Nominal wages are rarely cut (only 8 out of 1957 times) when a worker is demoted. This partly results from rules in collective bargaining agreements: which prescribe that the nominal wages of workers demoted to a lower job level can only be lowered after a period of advance notice which depends on the worker's age and tenure. But we observe that demoted workers are downgraded in the salary scales, which reduces their prospect of future wage growth.

\subsection{Careers}

Careers are a crucial characteristic of internal labor markets. According to the theory of internal labor markets careers help foster long-term employment relations and shield workers from external labor market conditions. We saw already in section 5.4 that most workers do not move up in the hierarchy during five-year periods, and that only few workers move up more than 1 level. This triggers a number of questions. Are there career paths within job levels along which workers transfer to jobs on the same hierarchical level? Are such jobs more attractive jobs, both in terms of wages and the amount of shielding from external conditions? We begin, however, by investigating whether firm-specific capital is important in our firm by assessing whether workers hired from outside into a job level differ in their characteristics from workers who are promoted to the same level from within.

\subsubsection{New Hires versus Incumbents}

To shed light on the question of whether specific-capital is important in our firm, we compare age and education levels of new hires to a given level and workers promoted from inside to the same level. Table 5.13 shows that new hires into levels $2-5$ are on average 4.5 to 7 years younger than incumbent workers who have been promoted to the same hierarchical level. Age differences are smaller in higher levels and almost negligible in levels 7 and 8 . The pattern does not differ between periods. The two right-most columns show that promoted workers have on average been employed for 7 years to 12

\footnotetext{
${ }^{34}$ If we base our analysis on a yearly panel in which the cross-sections are taken on March 14 in each year, we would observe only 134 nominal wage cuts.

${ }^{35}$ Nominal wage freezes are more frequent for workers affected by collective bargaining agreements.
} 
Table 5.13: Age and Tenure: New Hres versus Promoted Incumbents

\begin{tabular}{|c|c|c|c|c|c|c|}
\hline \multirow[b]{3}{*}{ Level } & \multicolumn{4}{|c|}{ Age } & \multicolumn{2}{|c|}{ Tenure } \\
\hline & \multicolumn{2}{|c|}{$1987-1991$} & \multicolumn{2}{|c|}{ 1991-1996 } & $1987-1991$ & $1991-1996$ \\
\hline & Entree & Promotee & Entree & Promotee & Pron & notee \\
\hline 1 & $\begin{array}{r}24.5 \\
(6.8)\end{array}$ & & $\begin{array}{r}25.2 \\
(6.6)\end{array}$ & & & \\
\hline 2 & $\begin{array}{c}26.4 \\
(6.4)\end{array}$ & $\begin{array}{r}30.3 \\
(7.2)\end{array}$ & $\begin{array}{r}28.2 \\
(6.8)\end{array}$ & $\begin{array}{r}31.3 \\
(7.1)\end{array}$ & $\begin{array}{r}7.2 \\
(6.7)\end{array}$ & $\begin{array}{r}8.3 \\
(6.9)\end{array}$ \\
\hline 3 & $\begin{array}{r}27.8 \\
(6.0)\end{array}$ & $\begin{array}{r}35.0 \\
(8.2)\end{array}$ & $\begin{array}{r}28.4 \\
(7.4)\end{array}$ & $\begin{array}{r}34.9 \\
(7.2)\end{array}$ & $\begin{array}{r}11.1 \\
(9.1)\end{array}$ & $\begin{array}{r}11.8 \\
(8.4)\end{array}$ \\
\hline 4 & $\begin{array}{r}27.5 \\
(4.8)\end{array}$ & $\begin{array}{r}35.4 \\
(8.6)\end{array}$ & $\begin{array}{r}26.7 \\
(4.9)\end{array}$ & $\begin{array}{r}34.9 \\
(7.2)\end{array}$ & $\begin{array}{r}10.5 \\
(9.6)\end{array}$ & $\begin{array}{r}10.6 \\
(8.8)\end{array}$ \\
\hline 5 & $\begin{array}{r}30.6 \\
(6.7)\end{array}$ & $\begin{array}{r}34.4 \\
(7.2)\end{array}$ & $\begin{array}{r}28.1 \\
(4.4)\end{array}$ & $\begin{array}{r}34.7 \\
(6.8)\end{array}$ & $\begin{array}{r}8.5 \\
(8.0)\end{array}$ & $\begin{array}{r}8.3 \\
(7.4)\end{array}$ \\
\hline 6 & $\begin{array}{r}33.5 \\
(6.2)\end{array}$ & $\begin{array}{r}38.1 \\
(7.5)\end{array}$ & $\begin{array}{r}35.1 \\
(8.7)\end{array}$ & $\begin{array}{r}36.9 \\
(6.4)\end{array}$ & $\begin{array}{r}10.8 \\
(8.5)\end{array}$ & $\begin{array}{r}10.4 \\
(8.0)\end{array}$ \\
\hline 7 & $\begin{array}{r}39.3 \\
(6.6)\end{array}$ & $\begin{array}{r}39.1 \\
(6.1)\end{array}$ & $\begin{array}{r}39.3 \\
(6.1)\end{array}$ & $\begin{array}{l}39.8 \\
(6.1)\end{array}$ & $\begin{array}{r}11.2 \\
(6.8)\end{array}$ & $\begin{array}{r}11.8 \\
(7.6)\end{array}$ \\
\hline 8 & $\begin{array}{r}44.6 \\
(6.3)\end{array}$ & $\begin{array}{r}42.5 \\
(7.1)\end{array}$ & $\begin{array}{r}40.9 \\
(7.2)\end{array}$ & $\begin{array}{r}41.4 \\
(5.4)\end{array}$ & $\begin{array}{r}14.0 \\
(9.7)\end{array}$ & $\begin{array}{r}13.0 \\
(7.0)\end{array}$ \\
\hline
\end{tabular}

Notes: The table compares entry ages and firm tenure of promoted incumbents and workers hired into the same level for the episodes of workforce expansion (1987-1991) and workforce contraction 1991-1996). Columns 2-5 show the mean ages of workers respective levels and provide standard deviations in parentheses below the respective means. Columns 6-7 report firm tenure of promoted workers. When judging the magnitude of the standard deviations, it should be taken into account that the age and tenure distributions are very skewed.

years in the firm. ${ }^{36}$. If firm-specific capital is important in the firm, promoted workers should have accumulated sizable levels of firm-specific capital during their elapsed tenure and new hires should compensate by either having more experience - which is unlikely given that they are substantially younger on average - or higher levels of education. Table 5.14 reveals that new beginners indeed hold higher level general and vocational schooling degrees than promoted incumbent workers. So new hires seem to make up for lower levels of firm-specific capital with higher levels of general capital.

\footnotetext{
${ }^{36}$ Average tenure in the table escalates with level because the table reports average years of tenure since accession to the firm and not the average years spent in the lower hierarchical level, which is smaller for those who experience more than one promotion.
} 
Table 5.14: EduCAtion Level: New Hires versus Promoted InCUmbents $198 \% 1991$

\begin{tabular}{|c|c|c|c|c|c|c|c|c|c|c|}
\hline & Job Level & lo & lbo & mavo & $\begin{array}{l}\text { Edu } \\
\text { llw }\end{array}$ & havo & $\begin{array}{l}\text { evel } \\
\text { mbo }\end{array}$ & vwo & hbo & uni \\
\hline \multirow{2}{*}{2} & Promotees & 0.6 & 15.5 & 8.8 & 36.0 & 4.6 & 27.8 & 2.7 & 3.5 & 0.5 \\
\hline & Entrees & 0.0 & 4.1 & 8.8 & 5.0 & 9.1 & 42.0 & 6.3 & 20.8 & 3.8 \\
\hline \multirow{2}{*}{3} & Prom & 0.5 & 7.4 & 4.2 & 19.3 & 3.2 & 45.4 & 2 & 13.1 & 1.7 \\
\hline & Entre & 0.0 & 0.6 & 5. & 2.4 & 4.2 & 16.7 & 6.5 & 44.0 & 20.2 \\
\hline \multirow{2}{*}{4} & Prom & 0.0 & 4.8 & 6.3 & 7.2 & 1.5 & 31.9 & 5.4 & 34.3 & 8.7 \\
\hline & Entrees & 0.0 & 0.2 & 1.2 & 0.4 & 3.3 & 2.7 & 14.7 & 39.0 & 38.4 \\
\hline \multirow{2}{*}{5} & Pron & 0.0 & 1.2 & 5.2 & 2.5 & 3.1 & 9.3 & 5.9 & 44.8 & 28.1 \\
\hline & Entre & 0.0 & 0.0 & 0.7 & 0.0 & 1.3 & 1.3 & 17.0 & 19.0 & 60.8 \\
\hline \multirow{2}{*}{6} & Prom & 0.0 & 1.1 & 3. & 1.1 & 1.1 & 1.1 & 6.1 & 35.4 & 50.3 \\
\hline & Entre & 0.0 & 0.0 & 0. & 0.0 & 3.2 & 3.2 & 22.6 & 22.6 & 48.4 \\
\hline \multirow[t]{2}{*}{7} & Prom & 0.0 & 0.0 & r & 0.0 & 3.2 & 4.8 & 6.5 & 33.9 & 51.6 \\
\hline & Entrees & 0.0 & 0.0 & & 0.0 & 0.0 & 0.0 & 13.6 & 31.8 & 50.0 \\
\hline \multirow{2}{*}{8} & Promote & 0.0 & 3.3 & 3.3 & 3.3 & 0.0 & 0.0 & 0.0 & 30.0 & 60.0 \\
\hline & Entrees & 0.0 & 0.0 & 0.0 & 0.0 & 0.0 & 0.0 & 0.0 & 50.0 & 50.0 \\
\hline
\end{tabular}

$1991-1996$

\begin{tabular}{ll|rrrrrrrrr}
\hline & & \multicolumn{8}{c}{ Education Level } \\
\multicolumn{1}{l|}{ Job Level } & lo & lbo & mavo & llw & havo & mbo & wwo & hbo & uni \\
\hline \multirow{2}{*}{2 Promotees } & 0.4 & 10.4 & 10.9 & 33.0 & 4.9 & 35.4 & 2.1 & 2.7 & 0.2 \\
& Entrees & 0.0 & 0.0 & 8.3 & 1.7 & 5.0 & 43.3 & 13.3 & 20.0 & 8.3 \\
3 & Promotees & 0.7 & 5.8 & 5.1 & 20.7 & 5.1 & 49.5 & 0.4 & 10.5 & 2.2 \\
& Entrees & 0.0 & 1.8 & 0.0 & 0.0 & 1.8 & 8.9 & 14.3 & 55.4 & 17.9 \\
& Promotees & 0.0 & 5.0 & 3.1 & 10.0 & 4.6 & 36.4 & 2.3 & 28.7 & 10.0 \\
4 & Entrees & 0.0 & 0.6 & 0.6 & 0.0 & 2.3 & 6.3 & 13.1 & 43.8 & 33.5 \\
& Promotees & 0.0 & 1.3 & 2.5 & 2.3 & 1.5 & 12.4 & 7.9 & 44.4 & 27.7 \\
5 & Entrees & 0.0 & 0.0 & 0.0 & 0.0 & 1.2 & 1.2 & 13.1 & 14.3 & 70.2 \\
& Promotees & 0.0 & 0.9 & 3.6 & 1.4 & 2.7 & 6.3 & 10.8 & 34.2 & 40.1 \\
& Entrees & 0.0 & 0.0 & 0.0 & 6.3 & 0.0 & 0.0 & 6.3 & 31.3 & 56.3 \\
7 & Promotees & 0.0 & 1.4 & 2.9 & 0.0 & 0.0 & 2.9 & 7.1 & 34.3 & 51.4 \\
& Entrees & 0.0 & 0.0 & 0.0 & 0.0 & 0.0 & 0.0 & 0.0 & 37.5 & 62.5 \\
8 & Promotees & 0.0 & 0.0 & 3.0 & 0.0 & 3.0 & 9.1 & 9.1 & 21.2 & 54.5 \\
& Entrees & 0.0 & 0.0 & 0.0 & 0.0 & 0.0 & 0.0 & 100.0 & 0.0 & 0.0 \\
\hline
\end{tabular}

Notes: The table compares highest obtained schooling degrees of promoted and workers laired into the same level for the episodes of workforce expansion (1987-1991, upper block) and workforce contraction 1991-1996, lower block). The cells show the percentages of promotees or entrants with a given schooling degree so that rows sum to 100 . 


\subsubsection{Job Ladders Across Hierarchical Levels}

An important characteristic of our firm is the existence of different career paths, which sometimes span different hierarchical levels. The distribution of workers across levels in different fields of activities provides evidence of snch "pyramids within the hierarchical pyramid". For example, more than $80 \%$ of workers in "Production" (F) are in level 1 and $97.8 \%$ are blue-collar workers. This might be contrasted with "Sales" where $85 \%$ of the employees are in management levels. Two classes of career tracks can be identified in the white-collar ranks of " $R \& D$ ". The first type is a classical engineering career which involves concentration on technical aspects and specialization therein. These careers typically span levels $4-6 .{ }^{37}$ Workers on this career track typically start as a staff member of engineering on level 4 , then they may become a specialist or engineer on level 5, and finally be promoted to a lead engineer or senior specialist (commonly in aircraft design) on level 6. The second type of career is management career in which workers concentrate on supervision handling of the day-to-day business. Positions in the management career track include "Design Division Leader" on level 4, "Project Leader" or "Chief of Engineering Group" on level 5, and "Head of Division" on level 6. Finally, it should be mentioned that careers on lower ranks also exist in R\&D. About $16 \%$ are employed in these ranks, working predominately as designing engineers.

A typical career path in "Sales \& Customer Relations" which may lead to a position on level 8 as "Area Manager" or "Area Salles Manager" starts on level 4 as an "Aircraft Analyst" or "Account Manager" and involves transitions to "Market Development Engineer" (level 5), "Account Development Manager" (level 6), and "Sales Manager" (level 7). Career tracks in lower levels also exist and are predominately followed by higher-ranked blue-collar workers who transfer from production. In particular, "Basic Instrument Experts" (level 2 in production) proceed to become "Instructors" (level 3 ) in "Salles \& Customer Relations" and may be promoted to become a "Technical Representative" on level 4. (We also observe inflow into this job from level 3 - production workers.) Workers on this career track proceed to "Resident Technical Representative", but most careers that we observe end there. Only one person goes on to level 6 as "Customer Support Manager". Two persons make further careers by entering different jobs after having been a "Technical Representative".

A substantial fraction of the inflow into both activities described above - R\&D and Sales \& Customer Relations - has experience elsewhere in the

\footnotetext{
${ }^{37}$ Roughly $70 \%$ of the entire workforce in the activity field "P\&LD" are employed in these levels. The number varies somewhat over time.
} 
firm. Only $35.2 \%$ of workers who enter "Sales \& Customer Relations" from January 1987 until March 1991 are hired from outside. Those who enter from within the firm come predominately from "R\&D". Similarly, only $56.2 \%$ of new entrants into "R\&D" are new hires. Workers who transfer from other activities come predominately from production (73.6\%). This finding underpins the importance of firm-specific knowledge, not least knowledge of the sophisticated product of the firm. The degree to which such firm-specific knowledge is important varies between different activities as one would expect. There is substantially less inflow from within relative to inflow from outside in administrative activities (K, H, S). Between 1987 and 1991, when all non-production activities of the firm (Administrative activities ( $\mathrm{K}, \mathrm{H}$, S), R\&D (C), and Sales \& Customer Relations (B)) grew at a similar rates (see Figure 5.1 ), $64.5 \%$ of all new entrants into administrative activities were recruited from outside.

The existence of jobs that require knowledge acquired in other jobs in the firm implies that careers are important in the firm's internal labor market. This conjecture is confirmed when we examine job transitions across the five activities within production (Assembly (F), Support \& Supplies (G), Production Preparation (D), Planning \& Coordination (E), and Quality (M)). Of all 4184 workers who are hired into production during expansion, 3062 enter into "Assembly", a share that is substantially larger than the relative size of "Assembly" within production at all times. Only 309 enter "Assembly" from a job elsewhere in the firm, and only 140 of them enter into a job on level 1 , where more than $80 \%$ of workers in this activity are employed. Many more workers (818) leave "Assembly" for jobs in other activities of the firm during the same period, and most of them (578) change jobs to one of the other 4 production related activities.

In contrast, 362 workers are hired into "Production Preparation", but 651 are transferred from within (267 of whom come from Assembly). "Quality" is the activity where hiring from outside (122) relative to transfers from within (327) is lowest. Most of the workers (208) who enter "Quality" worked in "Assembly" before and remain on the same job level (189). But they usually climb a wage scale upon the transition. Hence, these lateral transitions reflect careers within a job level. Other examples of such career monkey bars are discussed in the next section.

$28.8 \%$ of all job changes - and $24.5 \%$ of lateral transitions - involve transitions to different fields of activity. Yet, we observe that the inflow from outside diminishes with further advancement in career tracks, implying that career decisions are for the large part taken early on, and career changes become rarer later in the employment relation. 


\subsubsection{Monkey Bars Within Hierarchical Levels}

Careers within hierarchical levels are important. In fact, wriggling the monkey bars of a within-level career is a more common phenomenon than climbing the career ladder by upward hierarchical job transitions. As already mentioned, examples include transitions from assembly workers to quality controllers, but also exist within more narrowly defined fields of activities. One particular, but typical, example is the transition from "Assembler Electrical Assembly A" to "Assembler Electrical Assembly B" which commonly does result in an immediate advancement in wage scales, but does so eventually as the median wage scale is higher for the latter job. Roughly two thirds of lateral movements are transitions to jobs with a higher mean wage scale. ${ }^{38}$ More interesting, we observe 251 transitions from the first to the latter job, but only one worker is hired from outside to the latter job during the entire observation period. Jobs towards the higher end of within-job career tracks are less frequently filled from outside.

Within-level careers are also typical for secretaries ${ }^{39}$ Lateral career movements frequently involve a transition from secretary of a section chief to secretary of a department head. For secretarial jobs, there is, however, substantially more entry from outside into positions further down the career path than for jobs in production or quality control. An obvious explanation is the greater importance of firm-specific knowledge in the latter jobs. But stiil, even for secretaries we find that positions for secretaries of department heads are more frequently filled by job transitions from within. Two other features that seem to be important for careers in general can be illustrated with the help of the 'secretary example': First, lateral movements are sometimes stepping stones for upward transitions: either within the secretary career or to other jobs within the firm. Secretaries can move upward to become the secretary of a division director or even of the Executive Board. But we also observe transitions to supervisory jobs (mostly in data processing) to higher-level administrative workers and eventually to lower level managers (mostly with tasks related to human resource management).

\subsection{Conclusion}

Our analysis confirms the existence of an internal labor market and the importance of lateral and vertical job mobility therein. Since wages are related

\footnotetext{
"As for vertical job mobility, lateral career paths are no one-way route and "demotions" occur.

Secretaries account for $2.2 \%$ to $2.5 \%$ of the workforce at all times and $3.7 \%$ of all abserved workers have been a secretary at some point in time.
} 
to job levels, transitions are material for workers'wage growth. Although immediate gains upon promotions are small - often job transitions and wage changes do not even coincide - compared to the average difference in wages for adjacent job levels, promoted workers can look forward to a period of sustained wage growth as they move up in their new job level's wage distribution. The spread of these job-level wage distributions is substantial so that wages in job levels overlap. Therefore, wages are not strictly tied to jobs as there remains considerable scope to reward workers individually. Wriggling the monkey bars in within-level careers is another valuable means for workers to secure wage growth. Lateral job changes are a significant phenomenon, which can be explained by firm-specific capital requirements in particular jobs, involving more workers and more job changes than vertical job transitions.

For the firm, the staffing of positions from within is essential especially in jobs which require firm-specific knowledge. Such organizational or firmspecific capital seems crucial in a number of jobs. Workers hired from outside must make up for the lack of firm-specific capital by obtaining higher completed schooling degrees than workers promoted from within. Even though entry occurs at all levels, entry rates are substantially smaller in some career tracks for jobs further down the career path. We find that the firm's hierarchy of job levels is relatively stable throughout periods of expansion and contraction. The hierarchical job pyramid is neither augmented by job levels during expansion nor diminished during contraction. However, relative sizes of job levels change during downsizing when the firm becomes top-heavy. This is most likely the result of sizeable differences in adjustment costs for different workers, particularly when firm-specific capital is substantial in jobs further down a career path and future growth is expected as was the case at our frrm. Changes in firm size in general and changes in relative entry and exit rates have considerable impact on job transition rates. Promotion rates fall and demotion rates rise the more the net employment growth rates fall. 
Chapter 6

\section{The Wage Policy of a Firm and Individual Earnings Profiles}




\subsection{Introduction}

This chapter explores the relation between experience, performance, and individual wage profiles. Examining the wage policy of a firm, the chapter gives particular attention to the process that generates individual career earnings. It thereby sheds light on an old but recurrent debate in the economics literature, which goes back at least to Mincer's (1974) question of whether life cycle earnings growth should be attributed to productivity gains or to institutional arrangements. Since each camp can throw a theory into the scale that supports its position, ${ }^{1}$ the dispute has to be settled empirically.

Unfortunately, the empirical literature has provided mixed results thus far. Brown (1989) argues that upward sloping tenure-wage profiles reflect returns to human capital accumulation. On the contrary, Medoff and Abraham $(1980,1981)$ conclude that the human-capital on-the-job training model cannot explain a large fraction of observed returns to experience, finding that experience-earnings profiles are largely independent of productivity differences. Evidence concerning the size of returns to firm-specific tenure, which has been argued to reflect the importance of accumulated productivity enhancing firm-specific skills, is also inconclusive (see e.g. Altonji and Shakotko, 1987; Abraham and Farber, 1987; Topel, 1991; and Altonji and Williams, 1997). ${ }^{2}$

By analyzing the wage policy of the Dutch aircraft manufacturer Fokker, I illuminate the dispute concerning the relation between performance, (firmspecific) experience and life cycle earnings. I illustrate how the rules of the firm's formal salary system affect individual earnings profiles and explore the determinants of individual wage mobility. Knowing how the salary system functions and identifying the determinants of wage mobility within the

\footnotetext{
${ }^{1}$ For example, the modern approach to human capital theory, which has its origin in the work of Becker (1964), Mincer (1962), Schultz (1963), and others, predicts that wages rise with labor market experience because the acquisition of general and specific human capital raises productivity. Contrasting theoretical approaches, which are often concerned with worker motivation in employment relations (e.g. Becker and Stigler, 1974; Lazear, 1979; Lazear and Rosen, 1981), build on life cycle wage increases that do not require increases in worker productivity. Furthermore, a vast literature on matching (e.g. Jovanovic, 1979a), sorting (e.g. Salop and Salop, 1976), and search (e.g. Burdett, 1978; Burdett and Mortensen, 1998) predicts upward sloping life cycle earnings profiles, which do not require changes in workers' innate productivity. As a polar case, the theory of intermal labor markets as advocated by Doeringer and Piore (1971) stresses that administrative rules and procedures govern compensation, not individual characteristics.

2Note that the approach to assess the importance of firm-specific investments and productivity gains by estimating the wage returns to fim-specific tenure is ill founded, because a tight theoretical link between accumulated specific capital and remuneration lacks. See also the discussion by farber (1999).
} 
system fosters our understanding of the role of administrative rules and the relation between experience, performance, and individual earnings profiles.

It tums out that a thorough knowledge of the process that generaties lifetime wages in a formal salary system also helps us to interpret conflicting results in the empirical literature. In addition, recognizing how firms set: wages in practice fosters our understanding of some other puzzles documented in the empirical literature including the 'Green Card Effect' (see Baker, Gibbs and Holmstrom, 1994a), cohort effects, and serial correlation in wage growth. Finally, having a handle on the wage policy of large firms is key to answering an array of questions including the following: do wages depend on firmspecific economic conditions?, to what extent does labor market pressure affect earnings of incumbent workers?, do economic conditions prevailing at the start of the employment relationship have a persistent effect on wages?

The chapter is organized as follows. The next section describes the data. Section 6.3 explains the formal salary system of the firm and investigates how it adjusts to changing economic conditions. Section 6.4 discusses implications for wage profiles that follow directly from institutional arrangements in wage setting. Section 6.5 explores how individual earnings profiles are affected by the formal salary system. Section 6.6 deals with the effects of the salary system on worker motivation. Section 6.7 estimates wage equations to analyze whether the firm's wage policy generates results that are comparable to findings in the literature. Section 6.8 concludes.

\subsection{The Data}

The data come from the personnel files of the Dutch national aircraft manufacturer Fokker N.V. and contain detailed information on the work histories of all 17610 workers with permanent work contracts at some time during the period from January 1, 1987, until March 15, 1996. These data, the economic conditions of the firm and the development of its workforce have been. described in chapter 3 . The empirical analysis in this chapter is based on an event history data set that contains information on all relevant events from the different personnel files on demographics, job positions, and compensation. Since all events are recorded, no information is lost, as would be the case when repeated cross-sections were used. If necessary, it is still possible to revert to snapshots of the data or to create panels at any frequency. This is useful when assessing how the results compare to those of related studies, which frequently rely on year-end snapshots. Another advantage of the data is its high degree of reliability and detail.

In addition to detailed information on demographics, job positions, salary 
scale and grade, nominal wages, hours worked, the reason for and the date of a wage contract change, the data contain a measure for subjective evaluation of performance in the previous year. Blue-collar workers are rated once a year by their immediate supervisor on a scale with 6 categories. The rating scale for white-collar workers has 5 categories (see Table A.3 in Appendix A.3 for a definition). Supervisors' ratings are reviewed by managers of the next higher hierarchical job level and by the human resource department. The human resource department sets guidelines concerning the distribution of scores among workers of an administrative unit and monitors the outcome. If a supervisor deviates too much from the norm, synchronization is achieved by re-appraising scores in collaboration with immediate and second line supervisors. The evaluation procedure is very similar to that of the firms described by Medoff and Abraham (1980, 1981). Figure 6.1 represents the distribution of performance scores for blue-collar and white-collar workers over time and shows that the distribution of ratings does not change much from year to year." It also reveals compression of the performance score distribution so that most workers get the median score.

Figure 6.1: Performance Ratings over Time

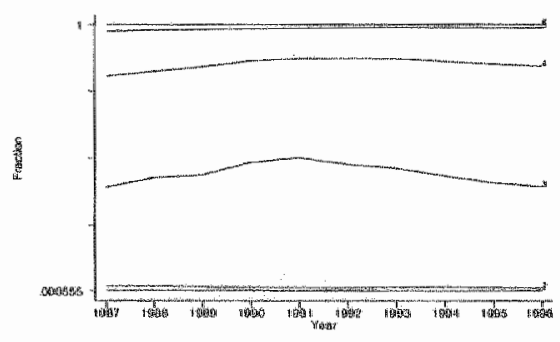

(a) Parformance of Blue-Collat Workers

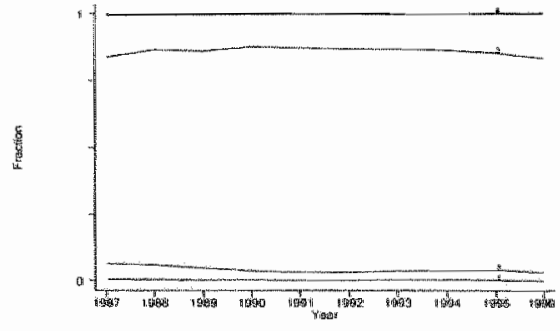

(b) Performance of White-Collar Workers

Notes: Panel (a) shows the distribution of performance ratings of blue-collar workers ower time. The distance between two lines gives the fraction of workers who obtained a score equal to the label of the upper line. Panel (b) shows the distribution of performance ratings of white-collar workers over time in an analogous manner.

\footnotetext{
${ }^{3}$ Within year Auctuation is caused by changes in the composition of workers due to hiring, firing and internal mobility.
} 


\subsection{The Wage Policy of the Firm}

Fokker's wage policy is highly centralized and bureaucratic. Formal rules govern wage setting in different salary systems for four types of workers: (1) blue-collar workers older than 23 years of age, (2) white-collar workers (including managers, salesmen, and engineers), (3) blue-collar workers younger than 23 years of age, and (4) recently hired white-collar workers who have not yet been placed into the regular white-collar salary system. The salary systems for the latter two groups map out wage profiles that channel into the respective regular salary systems for blue-collar and white-collar workers. The salary systems consist of different salary scales, in which wages contingent on performance ratings are specified by formal rules. ${ }^{4}$ Job assignment largely determines a worker's placement into a salary scale because each job typically encompasses a handful of salary scales, which fixes wage ranges for particular jobs. Wage ranges for white-collar jobs are set up according to a guide chart system, as is developed by the compensation consulting firm Hay Associates. ${ }^{5}$ Wage ranges for blue-collar jobs are established by a similar point system.

Most of the variation in wages comes from placement into different scales and hence from job assignment rather than from variation in performance ratings. This becomes evident from regressions of real hourly wages on determinants of the respective salary systems (scales, grades, and evaluation scores). In a pooled sample of yearly cross-sections taken after annual raises have been awarded, a regression of hourly real wages of workers paid according to the regular white-collar salary system on wage scale dummies alone yields an $R^{2}$ of 0.911 . Adding dummies for the five performance scores raises the $R^{2}$ to 0.918 . But a regression on evaluation dummies alone explains only 3.2 percent of the variance in real hourly wages of white-collar workers. Similarly, regressing real hourly wages of workers paid according to the regular blue-collar scale on level and grade dummies explains 97.7 percent of the wage dispersion. Including dummies for performance ratings as additional regressors increases the $R^{2}$ to 0.985 . But dummies for performance scores alone explain only 14.3 percent of the variance in real hourly blue-collar wages. Still, overly generous subjective performance evaluations would raise the total wage bill immediately, because wages depend on performance ratings. Bearing this in mind, it is not surprising that the human resource department sets guidelines that limit supervisors' discretion to award high ratings,

\footnotetext{
${ }^{4}$ These salary systems follow textbook prescriptions (e.g. Milkovich and Newman, 1999).

${ }^{5}$ See, for example, chapter 5 of Milkowich and Newman (1999) for an illustration of job evaluation systems.
} 
and that the salary system limits the amount of wage growth associated with better performance. The stability of the performance score distribution (see Figure 6.1) provides some evidence for adherence to the guidelines of the human resource department, which recommend a distribution of performance ratings.

\subsubsection{The Salary System for Blue-Collar Workers}

The salary system that regulates pay of blue-collar workers older than 23 years of age, consists of ten wage scales (numbered 2 to 11). Each scale comprises up to nine grades. ${ }^{6}$ Blue-collar workers climb one grade each year until the highest grade is reached. ${ }^{7}$ Then they might be promoted to a higher scale spanned by the job's wage range. ${ }^{8}$ Every grade within a scale defines one nominal wage rate for each of the six different performance evaluation scores. Contractual wages are higher for higher ratings. (See Table A.3 in Appendix A.3 for a definition of evaluation scores.) A wage for the lighest performance evaluation score is only defined for the highest grade of each scale. As an example, Table 6.1 summarizes contractual annual nominal wages for scale 7 that where valid in April 1992.

The absolute difference between wages in two adjacent grades of a scale is constant for a given performance rating. In the example, a worker in scale 7 whose performance rating remains unchanged receives an annual wage increase of 1050 guilders each year until he reaches the top grade of the scale. 9 If a worker's performance rating improves, he receives additional wage growth. This raise is also defined in absolute terms and independent of the grade within a scale. Table 6.1 indicates, for example, that a worker who improves his performance score from 4 to 5 receives an extra raise of 784 guilders. Contractual wage raises are higher for better performance scores, i.e. a worker workers who improves his score from 1 to 2 receives a lower absolute increase than a worker whose performance rating enhances from

\footnotetext{
${ }^{6}$ Lower wage scales have fewer grades. There are four grades in scales 2 and 3 , five grades in scales 4 and 5 , seven grades in scales 6 to 8 , eight grades in scale 9 , and nine grades in scales 10 and $\mathbb{1 1}$.

${ }^{7}$ Climbing a grade takes sometimes longer than 12 months for 190 incumbent workers. 88 of them had received their previous raise just a few weeks before contractual raises are generally awarded. In addition, 420 workers entering the firm in the last quarter of the previous year do not receive their fust increase until the end of the next year.

Blue-collar workers are typically hired into the bottom grade of the lowest scale for their job. But initial placement into a higher scale or grade is possible because the firm takes into account the education level and prior experience.

${ }^{9}$ Anmual percentage wage raises are higher the lower current wages are, i.e for workers in lower grades of a scale and workers with lower performance ratings.
} 
score 2 to 3 .

Table 6.1: Contractual Wages in a Wage Scale for Blue-Collar WORKERS

\begin{tabular}{c|ccccccc}
\hline & \multicolumn{7}{|c}{ Grade } \\
Performance Score & -6 & -5 & -4 & -3 & -2 & -1 & 0 \\
\hline 6 & & & & & & & 44527 \\
5 & 37373 & 38423 & 39475 & 40526 & 41574 & 42626 & 43676 \\
4 & 36589 & 37639 & 38690 & 39742 & 40791 & 41840 & 42891 \\
3 & 35835 & 36887 & 37936 & 38986 & 40038 & 41087 & 42137 \\
2 & 35114 & 36165 & 37214 & 38265 & 39315 & 40367 & 41415 \\
1 & 34487 & 35458 & 36507 & 37558 & 38609 & 39658 & 40709 \\
\hline
\end{tabular}

Notes: The Table reports nominal annual contractual wages in Dutch Guilders for scale 7 as walid in April 1992. For a given performance evaluation (i.e. within a row), the nom for anmual nominal wage raises is 1050 guilders. Small deviations from that norm are the result of rounding errors that have accumulated over time. Annual wages are rounded to the next integer after percentage adjustments have been made.

Table 6.2 summarizes the contractual within-salary-scale tenure-wage profiles for the modal performance evaluation score 3 ("normal - good"). Average percentage wage raises associated with a one score improvement in performance - amounting to about $2.0 \%$ in scales 7 to 11 and slightly less in lower scales - are generally lower than contractual annual wage increases associated with grade advancement. Once the highest grade in a scale is reached, a worker enjoys further real wage growth upon promotion to a higher scale.

Table 6.3 reports the percentage clifference between contractual wages in the highest grades of two adjacent wage scales. This can be interpreted as the total wage gain associated with a salary scale promotion. Most of the time, workers receive only part of this gain immediately upon promotion; for they are typically placed into a lower grade of the higher scale. The other part, i.e. wage growth until the highest grade of the new scale is reached, takes the form of deferred contractual wage growth.

Differences between top grade wages of adjacent scalles are smaller than the within-scale wage spread, so that wage ranges of adjacent scales overlap. In fact, wages overlap in a systematic way: For a given performance score, the wage in grade $Y$ (for $Y \leq-2$ ) of scale $X$ lies between the wages in grades $Y+1$ and $Y+2$ of scale $X-1$ for any scale up to scale 6 . In higher scales, the wage in grade $Y$ (for $Y \leq-3$ ) of scale $X$ lies between the wages in grades $Y+2$ and $Y+3$ of scale $X-1$. For example, the wage in scale 4, grade 0 is higher than the wage in scale 5 , grade -2 , but lower than the wage of scale 5 , 
Table 6.2: YeART CONTRACTUAL WAGE INCREASE (\%) FOR BLUE-COLIA WORKERS

\begin{tabular}{l|llllllllll}
\hline & \multicolumn{10}{c}{ Salary Scale } \\
Grade & 2 & 3 & 4 & 5 & 6 & 7 & 8 & 9 & 10 & 11 \\
\hline-1 & 2.5 & 2.6 & 2.6 & 2.9 & 2.7 & 2.6 & 2.5 & 2.4 & 2.4 & 2.4 \\
-2 & 2.6 & 2.7 & 2.6 & 3.0 & 2.8 & 2.6 & 2.6 & 2.5 & 2.4 & 2.4 \\
-3 & 2.7 & 2.7 & 2.7 & 3.1 & 2.9 & 2.7 & 2.6 & 2.5 & 2.5 & 2.5 \\
-4 & & & 2.8 & 3.2 & 3.0 & 2.8 & 2.7 & 2.6 & 2.6 & 2.6 \\
-5 & & & & & 3.1 & 2.8 & 2.8 & 2.7 & 2.6 & 2.6 \\
-6 & & & & & & 2.9 & 2.8 & 2.8 & 2.7 & 2.7 \\
-7 & & & & & & & & 2.8 & 2.8 & 2.8 \\
-8 & & & & & & & & & 2.8 & 2.8 \\
\hline
\end{tabular}

Notes: The table reports the annual contractual percentage wage growth associated with climbing to the next higher grade of the same scale. All percentage anmul wage raises are calculated under the assumption that the performance rating is 3 throughout. On top of these contractual wage raises, workers enjoy further (less) wage growth if their performance improves (worsens).

Table 6.3: Wage Differences between Adjacent Blue-Collar Scales

\begin{tabular}{l|cccccccc}
\hline & \multicolumn{8}{|c}{ Salary Scale } \\
& 3 & 4 & 5 & 6 & 7 & 8 & 9 & 10 \\
\hline$\Delta$ Highest Wage $(\%)$ & 5.0 & 4.4 & 5.2 & 6.8 & 9.7 & 9.3 & 8.3 & 7.3 \\
\hline
\end{tabular}

Notes: The table shows percentage differences between contractual wages in the highest grade of two adjacent salary scales.

grade -1 . Workers who are promoted out of scale 4 , grade 0 , to scale 5 , grade -1 , obtain an immediate wage raise and the contractual promise of another raise (from grade -1 to grade 0 ) in the next round of annual raises.

\subsubsection{The Salary System for Juvenile Blue-Collar Work- ers}

Remuneration of juwenile blue-collar workers younger than 23 years of age is standardized by youth scales 3 to 7 , which eventually feed into scales 3 to 7 of the regular blue-collar salary system. Wage grades also exist within juvenile wage scales, but they do not mark out a tenure-wage profile in a strict sense. Instead, a worker's grade depends on his age. For a juvenile 
worker is typically placed such that he reaches the top of a youth wage seale in semiannual steps at age 23 . Then he proceeds to the lowest grade of the corresponding scale of the regular blue-collar salary system. ${ }^{10}$ As semiannual raises amount to 4 to 5 percent, juvenile blue-collar workers look forward to considerable wage growth before they are placed into the blue-collar scales. Their wage profiles at the beginning of their career are steeper the younger they are at the hiring date. This is summarized in Table 6.4, which reports for different scales and ages the percentage amount by which current wages will increase - for an unchanged performance rating - until the lowest grade of the corresponding regular blue-collar scale is reached. For example, a worker who enters the firm at age 18 in scale 4 looks forward to an accumulated contractual 'real wage" growth of 61.2 percent over the next 5 years.

Table 6.4: Wage Profile of Juvenile Blue-Collar Workers

\begin{tabular}{l|lllll}
\hline & \multicolumn{5}{|c}{ Salary Scale } \\
Age & 3 & 4 & 5 & 6 & 7 \\
\hline 22.5 & 3.6 & 3.5 & 3.6 & 4.0 & 4.0 \\
22 & 7.3 & 7.3 & 7.3 & 8.4 & 8.4 \\
21.5 & 11.6 & 11.6 & 12.1 & 13.4 & 13.8 \\
21 & 16.1 & 16.1 & 17.3 & 18.7 & 18.7 \\
20.5 & 21.1 & 21.8 & 23.2 & 23.4 & 23.4 \\
20 & 26.5 & 27.5 & 29.6 & 29.4 & 29.4 \\
19.5 & 33.3 & 35.0 & 35.5 & 35.4 & 35.4 \\
19 & 40.2 & 42.8 & 42.8 & 42.8 & 42.6 \\
18.5 & 49.3 & 51.4 & 50.8 & 50.8 & \\
18 & 58.8 & 61.2 & 59.9 & & \\
17.5 & 69.7 & 70.2 & 70.1 & & \\
\hline
\end{tabular}

Notes: The table reports the percentage difference between the current contractual wage of a juvenile worker of a particular age in a given juvenile wage scale and the contractual wage of the lowest grade in the respective regular blue-collar salary system for the same performance rating. Such contractual wage increases are not calculated for age grades 17.5 and 18 in scale 6 and grades 17.5 to 18.5 in scale 7 as nobody is placed in these grades during the observation period.

Additional wage growth results from promotion to a higher scale or an improvement in performance evaluation. The difference between wages of adjacent scales, for given performance and grade (i.e. age), varies from 1.5

\footnotetext{
${ }^{10}$ For example, worker who enters scale 5 at age 18 is placed such that he reaches the highest wage in scale 5 in ten semiannual steps at age 23 . He will be paid according to the lowest grade in scale 5 of the regular blue-collar salary system in the next year.
} 
percent to 2.4 percent in scales 3 to 6 , and amounts to 4.7 percent in scales 6 and 7 . Promotions to a higher juvenile scale entail a further upgrading of wage growth perspectives, because they feed into higher regular bluecollar wage scales, which have more grades (see Table 6.2 ), and thus promise higher future contractual wage growth. Since placement into scales is related to vocational and schooling degrees, 618 (all from scale 4 to scale 5) of the 2278 promotions in juvenile wage scales occur after workers have obtained a vocational diploma.

Knowledge of the functioning of the salary system suggests that coeffcients of standard wage regressions that control for years of schooling, experience, and tenure have to be interpreted with care. Since experience is strongly correlated with the hiring age, estimated coefficients of controls for experience reflect institutional arrangements rather than returns to experience. Those who are older when they enter the firm because they have worked elsewhere receive the same wage as those who are older at the hiring date because they needed more time to obtain the same schooling degree. Using the hiring age minus the average age at completion of the obtained schooling degree as a proxy for years of experience is problematic not only for this reason, but also because it might bias the estimates for the returns to education. Workers who hold higher schooling degrees and have spent more years in school tend to be older, so that they enter higher grades within the same scale. At the same time, returns to firm-specific tenure might be underestimated.

\subsubsection{The Salary System for White-Collar Workers}

Remuneration of white-collar workers is organized in scales 12 to 18 by a system that slightly differs from that for blue-collar workers. Each scale defines a minimum and maximum wage as a percentage of a scale specific reference wage. The minimum wage is 80 percent of the reference wage in every scale. But maximum wages escalate in steps of 2 percentage points from 106 percent of the reference wage in scale 12 to 118 percent in scale 18, so that higher scales span wider wage ranges. Wage ranges of adjacent wage scales overlap because the differences between reference wages of two adjacent scales is always smaller than 20 percent, as Table 6.5 shows.

Wages and annual raises depend on 5 different performance evaluation scores (see Table A.3 in Appendix A.3). ${ }^{11}$ Each performance evaluation score is associated with a wage ceiling within the scale's salary range. The ceiling

\footnotetext{
${ }^{11}$ Workers are rated on a categorical scale: unsatisfactory, satisfactory, good, very good, outstanding.
} 
Table 6.5: Wage Differences BeTWeen Adjacent WhTte-Collar Scaleas

\begin{tabular}{l|cccccc}
\hline & \multicolumn{7}{|c}{ Salary Scale } \\
& 12 & 13 & 14 & 15 & 16 & 17 \\
\hline$\Delta$ Reference Wage $(\%)$ & 14.0 & 14.1 & 14.2 & 14.4 & 14.5 & 17.5 \\
\hline
\end{tabular}

Notes: The table shows for each salary scale the percentage difference to the reference wage in the adjacent higher wage scale.

for the lowest performance rating "unsatisfactory" is the minimum wage of the range, so that workers with this rating never receive contractual wage raises. The wage limit for workers rated "satisfactory" is 90 percent of the reference wage, and that for workers rated "good" is the reference wage itself. The highest attainable wage for workers with the second highest performance score is at the midpoint between the reference wage and the maximum wage of the salary scale, and only workers who receive the highest performance rating can realize maximum wage of the salary scale's wage range.

Wages do not jump to the respective wage ceiling upon performance evaluation. Instead, the salary system defines annual raises that mark out a particular wage path towards the wage ceiling. The magnitude of annual percentage wage raises depends on the current position in the salary range and on performance. Percentage wage increases are higher, the further a worker's current wage is below the performance-score-specific wage ceiling, and they are higher for a given position in the scale the better the performance rating is. For example, a worker in salary scale 12 who is currently paid between 80 to 85 percent of the reference wage is awarded an anmual raise of 3 percent of the reference wage if rated "satisfactory", 4 percent if rated "good", 5 percent upon very good performance, and 6 percent when his performance score was "outstanding". But when he already earns 95 to 100 percent of the reference wage, he needs at least to be rated "good", to obtain any raise, which then amounts to 2 percent. In that case, the highest possible wage increase - granted upon outstanding performance - amounts to 3 percent of the reference wage.

These rules imply that it takes seven years with unchanged performance ratings to advance from the minimum wage in a scale to the performancescore-specific wage ceiling. For example, a worker rated "good" throughout progresses from 80 percent of the reference wage in the first year to 84 percent in the second year, then to $88,91,93.5,96,98$, and finally to 100 percent of the reference wage, which represents the upper limit for his performance evaluation. Workers with higher performance ratings advance in bigger steps 
as their wage ceiling is higher: A worker in scale 13 rated "outstanding" throughout moves from 80 percent of the reference wage in the first year to 86 percent in the second year, then to $91,95,98,101,103.5$, and eventually 108 percent of the reference wage, which is the maximum wage of the range. ${ }^{12}$ The formal wage structure limits the returns to better performance and restricts the amount of within-scale wage variation that can be attributed to differences in performance. Earnings differentials for workers with different performance ratings eventually equal the difference between the respective wage ceilings and might be even lower during the transition to those ceilings.

Newly hired workers are paid according to a separate salary system until their wages are such that they can be placed into the formal white-collar compensation scheme. This system specifies different starting wages for workers with an academic degree (university or technical college) and for workers with higher vocational degrees, which amount to 72 percent of the lowest wage in scales 14 and 12 respectively. The size of annual raises depends on performance. Guidelines are such that a regularly performing worker with university degree typically reaches the lowest range of scale 14 after six years. A with the highest performance rating needs one year less.

\subsubsection{The Stability of the Salary System and Nominal Wage Rigidity}

Although the economic and financial conditions of Fokker changed dramatically during the analysis period, the firm neither altered the formal structure of its salary system nor changed relative wages within the system. To adjust for price level increases, the firm shifted all wages of the salary system by the same percentage amount. ${ }^{13}$ Such adjustments happened 9 times during the observation period (January 1, 1987 - March 14, 1996), including the change on January 1, 1987. Table 6.6 summarizes the dates when price compensations come into effect, the associated percentage wage raises, and changes in the consumer price index.

The motive for adhering strictly to the rules of its salary system is probably prevention of harm to its reputation rather than lack of economic pressure

\footnotetext{
${ }^{12}$ Since upper bounds of wage ranges are higher in higher scales, annual percentage wage raises are bigger for workers earning more than the reference wage and receiving one of the top two performance ratings.

${ }^{13}$ Lower Hoors for percentage nominal wage raises of blue-collar wonkers are determined in a collective bargaining process between national unions and employer federations of metal workers. The firm then follows the policy of changing nominal wages of all workers by the same percentage amount.
} 
Table 6.6: Nommal Wage Changes IN THE SALARY SYSTEM

\begin{tabular}{l|cc|cc}
\hline Date & $\Delta$ Wage $(\%)$ & $\Delta$ CPI $(\%)$ & Wage Index & CPI Index \\
\hline Jan 1, 1987 & & & 100.00 & 100.00 \\
Jul 1, 1987 & 0.50 & 0.11 & 100.50 & 100.11 \\
Jul 1, 1988 & 1.00 & 0.95 & 101.51 & 101.06 \\
Jan 2, 1989 & 1.00 & 0.10 & 102.52 & 101.17 \\
Apr 1, 1990 & 3.00 & 2.83 & 105.60 & 104.03 \\
Jan 1, 1991 & 0.75 & 1.83 & 106.39 & 105.93 \\
Jul 1, 1991 & 3.25 & 2.01 & 109.85 & 108.05 \\
Apr 1, 1992 & 4.00 & 2.45 & 114.23 & 110.70 \\
Jan 1, 1996 & 3.80 & 8.61 & 118.58 & 120.23 \\
\hline
\end{tabular}

Notes:

1. Column 1 reports the dates on which the firm raised all contractual wages by the percentage amount shown in column 2. These percentage nominal wrage raises are contrasted in column 3 with the inflation rate over the period since the last nominal wage increase. The inflation rate is calculated based on percentage changes of the quarterly consumer price index provided by Statistics Netherlands. Cumulative changes can be read off the nominal wage and consumer price indices in columns 4 and 5 , which are calculated based on the information in the first columns.

2. Price compensations are deferred after April 1, 1992, until January 1, 1996. Otherwise, nominal wages would have been raised in four steps by 1.25 percent on May 1, 1993, 0.5 percent in October 1993, 0.5 percent in February 1994, 0.75 percent in February 1995, and 0.75 percent in January 1996. Workers who were dismissed during the period received the accumulated deferred price compensation about four weeks prior to their dismissal. This made them eligible for higher social security benefits. The yearly inflation rate based on the consumer price inclex was steady at around 2 percent from 1992 until 1996 when Fokker did not raise nominal contractual wages.

to save on wage costs. This conjecture is supported by the fact that the only substantial interference with contractual promises of the formal salary structure was settled with the workforce: In January 1995, the firm cut all annual raises by 50 percent. Blue-collar workers who proceeded in the salary system (by advancing a grade, being promoted to a higher level, or improving performance) received half the usual contractual increase. The other half was eventually awarded as an extra raise the year after the highest grade in the scale had been reached. ${ }^{14}$ Juvenile blue-collar workers did not get a semian-

\footnotetext{
14hereby, the firm saves 0.7 percent or $1,784,650$ Dutch guilders of the entire wage bill for bluecollax workers older than 23 in a single year. Further future savings accumulate because workers reach the top of their salary scalle later.
} 
as their wage ceiling is higher: A worker in scale 13 rated "outstanding" throughout moves from 80 percent of the reference wage in the first year to 86 percent in the second year, then to $91,95,98,101,103.5$, and eventually 108 percent of the reference wage, which is the maximum wage of the range. ${ }^{12}$ The formal wage structure limits the returns to better performance and restricts the amount of within-scale wage variation that can be attributed to differences in performance. Earnings differentials for workers with different performance ratings eventually equal the difference between the respective wage ceilings and might be even lower during the transition to those ceilings.

Newly hired workers are paid according to a separate salary system until their wages are such that they can be placed into the formal white-collar compensation scheme. This system specifies different starting wages for workers with an academic degree (university or technical college) and for workers with higher vocational degrees, which amount to 72 percent of the lowest wage in scales 14 and 1.2 respectively. The size of annual raises depends on performance. Guidelines are such that a regularly performing worker with university degree typically reaches the lowest range of scale 14 after six years. A with the highest performance rating needs one year less.

\subsubsection{The Stability of the Salary System and Nominal Wage Rigidity}

Although the economic and financial conditions of Fokker changed dramatically during the analysis period, the firm neither altered the formal structure of its salary system nor changed relative wages within the system. To adjust for price level increases, the firm shifted all wages of the salary system by the same percentage amount. ${ }^{13}$ Such adjustments happened 9 times during the observation period (January 1, 1987 - March 14, 1996), including the change on January 1, 1987. Table 6.6 summarizes the dates when price compensations come into effect, the associated percentage wage raises, and changes in the consumer price index.

The motive for adhering strictly to the rules of its salary system is probably prevention of harm to its reputation rather than lack of economic pressure

${ }^{12}$ Since upper bounds of wage ranges are higher in higher scales, annual percentage wage raises are bigger for workers earning more than the reference wage and receiving one of the top two performance ratings.

${ }^{13}$ Lower foors for percentage nominal wage raises of blue-collar workers are determined in a collective bargaining process between national unions and employer federations of metal workers. The firm then follows the policy of changing nominal wages of all workers by the same percentage amount. 
Table 6.6: Nominal Wage Changes In The SALARY SYSTEM

\begin{tabular}{l|cc|cc}
\hline Date & $\Delta$ Wage $(\%)$ & $\Delta$ CPI $(\%)$ & Wage Index & CPI Index \\
\hline Jan 1, 1987 & & & 100.00 & 100.00 \\
Jul 1, 1987 & 0.50 & 0.11 & 100.50 & 100.11 \\
Jul 1, 1988 & 1.00 & 0.95 & 101.51 & 101.06 \\
Jan 2, 1989 & 1.00 & 0.10 & 102.52 & 101.17 \\
Apr 1, 1990 & 3.00 & 2.83 & 105.60 & 104.03 \\
Jan 1, 1991 & 0.75 & 1.83 & 106.39 & 105.93 \\
Jul 1, 1991 & 3.25 & 2.01 & 109.85 & 108.05 \\
Apr 1, 1992 & 4.00 & 2.45 & 114.23 & 110.70 \\
Jan 1, 1996 & 3.80 & 8.61 & 118.58 & 120.23 \\
\hline
\end{tabular}

Notes:

1. Column 1 reports the dates on which the firm raised all contractual wages by the percentage amount shown in column 2. These percentage nominal wage raises are contrasted in column 3 with the inflation rate over the period since the last nominal wage increase. The inflation rate is calculated based on percentage changes of the quarterly consumer price index provided by Statistics Netherlands. Cumalative changes can be read oft the nominal wage and consumer price indices in columms 4 and 5 , which are calculated besed on the information in the first columns.

2. Price compensations are deferred after April 1, 1992, until January 1, 1996. Otherwise, nominal wages would have been raised in four steps by 1.25 percent on May $1,1993,0.5$ percent in October $1993,0.5$ percent in February 1994, 0.75 percent in February 1995, and 0.75 percent in January 1996. Workers who were dismissed during the period received the accumulated deferred price compensation about four weeks prior to their dismissal. This made them eligible for higher social security benefits. The yearly inflation rate based on the consumer price index was steady at aronind 2 percent from 1992 until 1996 when Fokker did not raise nominal contractuall wages.

to save on wage costs. This conjecture is supported by the fact that the only substantial interference with contractual promises of the formal salary structure was settled with the workforce: In January 1995, the firm cut all annual raises by 50 percent. Blue-collar workers who proceeded in the salary system (by advancing a grade, being promoted to a higher level, or improving performance) received half the usual contractual increase. The other half was eventually awarded as an extra raise the year after the highest grade in the scale had been reached. ${ }^{14}$ Juvenile blue-collar workers did not get a semian-

\footnotetext{
14 Thereby, the firm saves 0.7 percent or $1,784,650$ Dutch guilders of the entire wage bill for blue-collar workers older than 23 in a single year. Further future savings accumulate because workers reach the top of their salary scalle later.
} 
nual raise in June 1995 as was common otherwise. Annual percentage wage raises for wite-collar workers were cut in half, thus prolonging the time until they reach the top of their respective wage range. Worsened economic conditions of the firm, therefore, depress real earnings growth for a large fraction of workers.

A comparison of the development of nominal wages and consumer prices (see the two rightmost columns of Table 6.6) reveals that contractual wages tend to grow faster than the consumer price index during expansion. But due to the nominal freeze of contractual wages from April 1992 until January 1996 real contractual wages fall during the period of contraction. This underscores that wages of all workers are affected by the firm's prosperity. Workers who do not advance sufficiently in the salary system by climbing grades and scales or by improving performance bear annual real wage declines of about 2 percent after April 1, 1992. ${ }^{15}$ Although the firm did not change its salary system, individuals might have been affected by the firm's economic conditions beyond the nominal wage freeze and the one-time postponement of 50 percent of an annual wage raise if individual job mobility and wage scale mobility rates change during downsizing. This issue will be addressed in section 6.5 .

Nominal wage cuts are extremely rare and occur only in exceptional individual circumstances, in which both parties agree to alter the employment contract, e.g. to settle on a job change or change of work conditions. Most of the 197 nominal wage declines are borne by part-time workers (156) between January 1993 and January 1995; in 105 of these cases, workers at one plant (ELMO) renounce compensation for free shifts that had been warded in the past. ${ }^{16}$

The guiding principle of not cutting nominal wages prohibits downward adjustment of actual wages to bring them into line with fallen contractual

\footnotetext{
${ }^{15}$ Despite this wage moderation, average contractual wages deflated by nominal price compensations rose during contraction due to compositional changes. First, jobs with lower pay ranges were cut predominately during downsizing (see also chapter 4 ). Second, average wages within a job escallate because workers of younger cohorts, whose wages tend to be lower than mean job-level wages, separated disproportionately, while few workers entered the firm (see chapter 5).

16 Downward adjustments of wages deflated by the firm-wide price compensations (Table 6.6) occur in 136 full-time and 164 part-time employment contracts. These reductions bring about average "real wage" declines of 2.5 percent and 2.9 percent respectively. But again, modifications of contracts reflect extraordinary situations and do not represent real wage cuts in a strict sense. For example, 118 of the 164 real wage decreases for parttimers are due to adjustments in the number of shifts worked. Often, wages of previously "overpaid" part-time workers, i.e. workers whose hourly wage exceeded the contractual hourly wage, are merely adjusted to the norm.
} 
wages that result from degradation in the salary system. Consequently; some workers' wages exceed the contractual norm or even exceed the salary scale's range, although the firm otherwise adheres to the rules of the formal salary system. ${ }^{17}$ A salary scale degradation is a very rare event to start with - only 522 out of 194,844 contract changes entail a salary scale descent - but if it accurs, workers generally keep their previons salary that applied to the higher sciale. ${ }^{18}$ Likewise, deteriorated performance ratings cause contractual wages (or the new wage ceiling for white-collar workers) to fall below the wage previously earned in 1147 cases. But workers generally keep their formerly higher nominal salary. ${ }^{19}$ When the contractual wage rises subsequently because of an advancement in the salary system (e.g. due to performance improvements or contractual grade advancement), actual wages are not increased until the contractual wage exceeds the current wage.

\subsection{Institutional Arrangements and Wage Pro- files}

\subsubsection{Serial Correlation in Wage Growth and Green Card Effects}

The formal salary system generates serial correlation in wage growth rates, as is also found in studies by Lillard and Weiss (1979) and Baker, Gibbs and Holmstrom (1994b). The correlation coefficient between past and current annual "real" growth is $0.57 .^{20}$ Several institutional arrangements contribute to this result. First, workers who have reached the top of a job's wage range enjoy no further wage growth unless they are promoted. Zero current wage growth is, therefore, more likely for workers who did not receive a raise in the

${ }^{17}$ Gibbs and Hendricks (2001) also find wages exceeding the salary range in their data. They attribute this phenomenon to "errors".

1887.5 percent of workers who are placed into a lower scale receive unchanged nominal hourly wages, 8.8 percent even experience wage growth - typically because of price compensations. Only 3.7 percent endure nominal hourly wage cuts, but these workers usually change their employment contract with the firm. A few employees (10) work lewer hours after the degrarlation and, as a consequence, suffer wage declines. Falling nominal hourly wages coincide with downward salary scale mobility only in 19 cases.

${ }^{19}$ Firm-wide price compensations as documented in Table 6.6 are fully awarded even if the actual wage exceeds the contractual wage.

${ }^{20}$ Actual wages are deflated by the firm's annual price compensation, which are reported in Table 6.6. Wage growth rates for all workers in the sample who were employed in two subsequent calendar years were then calculated based on these "real." wages, and finally the correlation coefficient was determined. 
previous period; for conditional on zero wage growth in the past, it is more likely that workers have attained a wage ceiling, so that zero wage growth in the present period is more probable. Second, the size of annual percentage wage raises depends on performance - especially for white-collar workers - so that current wage growth is strongly positively correlated with past wage growth when performance does not change. ${ }^{21}$ Third, wage growth is similar over time for workers who do not change scales because the amount of contractual wage growth is similar within a particular scale, but differs across scalles. ${ }^{22}$

The 'Green Card Effect' (Baker, Gibbs and Holmstrom, 1994a) is the phenomenon that workers in higher earnings quartiles earn lower percentage raises. This follows directly from the formal rules of the salary system. These guidelines limit individual wage increases based on performance and the position in the job wage range.

\subsubsection{Cohort Effects}

Cohort effects can also result from the formal salary system. In fact, Figure 6.2 reveals simillar results as Baker, Gibbs an Holmstrom (1994b) document for their firm. The figure plots the average real full-time equivalent wage of incumbent workers and of all cohorts entering since 1987 for the two subgroups of blue-collar and white-collar workers. Mean cohort wages develop in parallel, and wages for the 1991 and 1992 cohort of blue-collar workers are lower than those for the 1990 cohort, suggesting that cohort starting wages rise in expansion and fall during contraction. Replicating Baker, Gibbs and Holmstrom's (1994b) regression analysis with our data implies that such cohort effects are significant. ${ }^{23}$ A linear tenure model given by

$$
u_{i t}=\alpha_{o}+\gamma_{t}+\delta(t-i),
$$

where $w_{i t}$ is the wage in year $t$ of a worker entering in year $i, \alpha_{o}$ is a constant, $\gamma_{t}$ are year dummies and $\delta$ the linear effect on tenure, fits the data much worse than the following version of a cohort-year model:

$$
u_{i t}-\hat{\delta}(t-1)=\alpha_{o}+\beta_{i}+\gamma_{t}
$$

where $\hat{\delta}$ is the estimated linear tenure effect from equation $(6.1)$ and $\beta_{i}$ are cohort effects. The linear tenure effect follows immediately from the formal

\footnotetext{
21 The correlation coefficient is higher when salary scales are not changed $(0.67)$ or when performance remains unchanged $(0.66)$.

${ }^{22}$ However, declining wage growth rates in the salary system of juvenile blue-collar workers generates a negative correlation coefficient $(-0.55)$ for this sub-group.

${ }^{23}$ Results are available upon request.
} 


\subsection{INSTITUTIONAL ARRANGEMENTS AND WAGE PROFILES 149}

rules of the salary system and explains the parallel movement of average cohort wages. ${ }^{24}$ Cohort effects, i.e. differences in mean starting wages of a cohort, would be remarkable if they could not be explained by individual characteristics or by job characteristics. Cohort effects persist in a regression analysis even after controlling for cohort age, education level and job level. However, differences in average starting wages of a cohort result from nore subtle changes in the composition of jobs that newly hired workers are assigned to. Cohort effects for blue-collar workers become insignificant after controlling for the minimum (or the mode) of the wage range applying to the job into which workers are hired. Cohort effects are, therefore, rather unremarkable.

Figure 6.2: MEAN WAGES AND COHORT WAGES 1987-1996

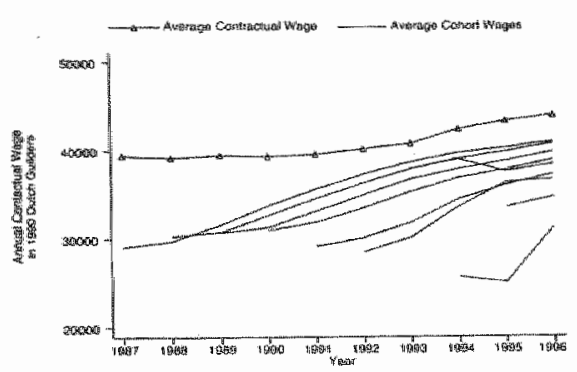

(a) Blue Gollar Wortiers

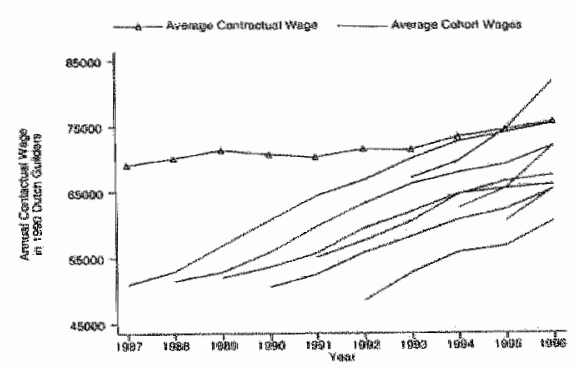

(b) Whit Collar Workers

Notes: The table shows "real" average anmual full-time equivalent contractual wages for all workers at the firm and for workers of different entry cohorts. Nominal wages are defated to 1990 Dutch guilders based on the price compensations reported in the second column of table 6.6. Note that these price compensations are not always congruent with changes in the CPI.

\footnotetext{
${ }^{24}$ Note that the linear tenure model $(6.1)$ is a special case of a general cohort-year model given by

$$
w_{i j}=\alpha_{a}+\beta_{i}+\gamma_{t}
$$
}




\subsection{Wage Mobility}

\subsubsection{Wage Mobility in Good and Bad Times}

In total, there are 20178 upward salary scale transitions (plus 1165 transitions of white-collar workers from the temporary salary system to scales in the regular white-collar salary system). Most upward scale transitions occur in the blue-collar salary systems (2510 for blue-collar workers younger than 23 years of age and 14951 for blue-collar workers in the regular salary system) as Table 6.7 shows. Upward transitions happen more frequently in the period of employment growth - when on average one of four workers moves upward during a year - than during the period of downsizing - when one out of six workers moves up on average. These changes are most marked in the regular blue-collar and white-collar salary systems.

Table 6.7: UpWard Wage Scale TransitTons

\begin{tabular}{l|cc|cc|cc}
\hline & Entire Period & Expansion & \multicolumn{2}{|c}{ Downsizing } \\
Salary System & & & & & & \\
\hline Young Blue-Collar & 2510 & $35.4 \%$ & 1715 & $36.1 \%$ & 795 & $34.0 \%$ \\
Regular Blue-Collar & 14951 & $22.1 \%$ & 8269 & $26.8 \%$ & 6682 & $18.2 \%$ \\
Preliminary White-Collar & 1165 & $19.0 \%$ & 555 & $18.2 \%$ & 610 & $19.7 \%$ \\
Regular White-Collar & 2717 & $11.8 \%$ & 1413 & $16.1 \%$ & 1304 & $9.2 \%$ \\
\hline Total & 21343 & $20.6 \%$ & 11.952 & $25.2 \%$ & 9391 & $16.7 \%$ \\
\hline
\end{tabular}

Notes: The table shows for different periods and salary system the absolute and relative numbers of upward transitions in salary scales. Relative numbers are shown as percentages of the absolute number of upward transitions relative to the number of employment years in a particular salary scale during a given period, i.e. measure the percentage of workers who move upward during one year.

The decline in upward salary scale transition rates suggest that individual earnings are affected by worsened economic conditions over and above the nominal wage freeze and the one-time cut of annual raises that were discussed in section 6.3.4. Lower upward wage scale mobility during downsizing can partly be attributed to the fact that workers have on average longer firmspecific tenure so that relatively more workers have reached the top of their job specific wage range. Anyhow, a significant factor for lower upward wage mobility is the decline in upward job mobility rates during downsizing. The overall average annual job promotion rate falls from 7.1 percent in the period 
from January 1, 1987, until March 1, 1991, to 4.2 percent in the subsequent period of downsizing. ${ }^{25}$

\subsubsection{Wage Mobility and Performance}

Since upward wage mobility - over and above the contractual tenure-wage profile within a scale - hinges on promotion to a higher salary scale, and eventually on assignment to another job with a higher wage range, it is intriguing to assess which workers proceed to higher scales and hierarchical job levels. Exploring when workers are promoted is of equal interest. The timing of a promotion to a higher wage scale or to a higher job level is an important device for motivating and retaining workers, because it affects the current size of future contractual wage growth promises. By promoting workers before they reach the top of a scale, the firm can keep remaining contractual future wage growth on a high level. This might be a useful policy to retain able workers.

Most blue-collar workers are promoted to a higher scale before they reach the highest grade in the current scale, suggesting that this motive is important for the firm. The immediate real wage increase associated with an upward transition in salary scales averages 4.6 percent. ${ }^{26}$ Promised contractual wage growth remaining to the top of the new wage scale increases on average to 6.8 percent. Early promotions are more likely for workers with higher performance ratings, as the coefficients of probit models in Table 6.8 reveal. The table displays estimated marginal effects of a recent promotion and performance on the probability of climbing to a higher salary scale among workers in the regular blue-collar salary system. ${ }^{27}$ The column labelled "Early Transition" shows estimates for the sub-group of workers who have not yet reached the top grade of their salary scale. Being rated "goodvery good" improves the promotion probability by 15.9 percent relative to

\footnotetext{
25The numbers are calculated based on the actual number of upward job level transithons and total employment years in the respective periods. It should be noted that at fraction of upward transitions $(5.3 \%)$ are of a temporal nature. They are offset by a subsequent demotion that occurs diring the duration of a wage contract, so that the concened employees hold jobs on the same level in adjacent wage contracts.

${ }^{26} \mathrm{On}$ an annual basis, this increase is on average higher $(5.4 \%)$ indicating that some workers who advance in the salary grade from one year to the other liave progressed for other reasons already during the year.

${ }^{27}$ The estimates in Table 6.8 do not distinguish between salary scale transitions with simultaneous job change and salary scale transition for workers who keep their job. The coefficient estimates are very similar, but a little smaller in absolute value, if the analysis is restricted to job stayers only. This is because better performance raises the chances of promotion to wigher job level.
} 
the modal rating "normal-good". The column labelled "Late Transition" reports the estimated effects for workers who are already in the top grade of a scale. Performance evaluations have a minor impact on their transition probabilities. But having progressed a wage scale in the previous year raises the probability of a further promotion this year considerably, implying that workers in the highest grade of a scale are either fast movers (those who moved upward last year already and are likely to be promoted this year) or are workers who have little hope for further advancement (those who are in the highest grade, but were not promoted, potentially, because they have reached the top of their current job's wage range). ${ }^{28}$

Table 6.8: Upward Wage Scale Mobility and Performance

Dependent Variable: Upward Transition ( 1 if yes, 0 if no)

\begin{tabular}{|c|c|c|}
\hline \multirow[b]{2}{*}{$\begin{array}{l}\text { Promotion Last Year } \\
\text { Performance Rating: }\end{array}$} & Early Transition & Late Transition \\
\hline & $-0.126 \quad(0.007)^{*}$ & $0.213 \quad(0.014)^{*}$ \\
\hline falls behind & $-0.090 \quad(0.172)$ & omitted \\
\hline unsatisfactory & $-0.134 \quad(0.026)^{*}$ & $-0.049 \quad(0.016)$ \\
\hline normal-good & Reference Score & Reference Score \\
\hline good-very good & $0.159 \quad(0.007)^{*}$ & $-0.027 \quad(0.005)$ \\
\hline very good - outstanding & $0.178 \quad(0.017)^{*}$ & $-0.032 \quad(0.006)$ \\
\hline excellent & & $-0.055 \quad(0.010)$ \\
\hline Observations & 22297 & 25932 \\
\hline
\end{tabular}

Notes: The Table shows marginal effects evaluated at the mean of the explanatory variables of probit regressions for the probability of a transition to a higher wage scale in the bluecollar wage system. Results are based on a pooled yearly cross-sections taken the day after annual contractual wage raises and performance evaluations are awarded. The first column shows the estimation results on the sub-sample of workers who have not yet reached the highest grade of the current salary scale. Since the highest performance score has wages defined only in the highest grade, there are no observations in this cell. The second column shows the eftect of performance on promotion for those workers who have reached the top of a salary scale. Since no worker with the lowest performance rating is ever promoted to a higher scalle, their observations are ignored in the estimation as their performance score predicts their failure to be promoted perfectly. Standard errors are in parentheses, an asterisk denotes significance at the $1 \%$ level.

\footnotetext{
${ }^{28}$ Here it is worth mentioning that 74.5 percent of workers in the regular blue-collan salary system who advance to a higher job level have not yet reached the top grade of their current salary scalle at the time of promotion.
} 
Coefficient estimates are average marginal effects, but it is possible that the effect of performance ratings differs between wage scale transitions near the bottom of a job's wage range and transitions near the top of the range. In fact, an analysis among one large group of assembly workers only - the largest job code that accounts for $8 \%$ of blue-collar jobs on average - reveals that better performance scores have a bigger impact on early promotion chances $^{29}$ and tend to be stronger for workers in the bottom grades of a given salary scale. Higher performance ratings generally have a stronger impact on promotions to the top wage scale of the job's wage range.

A higher performance rating also improves white-collar workers' outlook of advancing in salary scales. Those rated "very good" are $12.1 \%$ more likely to be promoted to a higher scale than those rated "good", and $21.9 \%$ more likely than those rated "satisfactory". Again, workers are mostly promoted before they reach the maximum wage in their current scale: 90 percent of white-collar employees who proceed to a higher salary scale are promoted before they have reached the wage ceiling in their current salary scale. Workers with higher performance scores advance earlier: workers rated "outstanding" would on average look forward to 13.5 percent contractual wage growth before reaching the wage ceiling, workers rated "very good" to 14.4 percent, workers rated "good" to 9.0 percent, while the few workers who proceed despite a worse performance rating already earn wages exceeding the performancescore-specific wage ceiling.

Because of the downward rigid nature of wages, which precludes full downward adjustment if a worker's performance deteriorates when his current wage already exceeds the new contractual wage ceiling associated with the lower performance rating, the firm might be reluctant to adjust wages immediately to the new performance score-specific wage ceiling in response to new information about a worker's ability measured by performance, as the pure learning model by Farber and Gibbons (1996) would predict. By promoting workers to a higher salary scale before they reach the wage celling in their current scale, the firm can grant a wage premium at the promotion, but at the same time ensure that a worker does not thereby reach the wage ceiling in the new scale. Such a policy motivates a worker to keep performance up, because by not awarding wage raises in the case that expected performance deteriorates in the future, the firm can adjust future wages to the contractual level for the worse performance evaluation.

\footnotetext{
${ }^{29}$ Prospects of a wage promotion to a higher scale are $35 \%$ better for workers rated "good-very good" relative to workers rated "normal-good". Moreover, no worker with a rating in the lowest two performance categories is ever promoted to a higher scale.
} 


\subsubsection{Wage Growth and Promotion to Higher Job Lev- els}

A device to motivate and retain outperforming workers is to award above contractual increases thus generating steeper profiles. The rules of the salary system do not seem to prohibit that some workers advance faster in the salary system than the contractual norm stipulates. Some blue-collar workers move up by more than one grade within a scale or even jump up two salary scales during one year. Presumably, the firm has learned that these workers are exceptionally able. If this conjecture was true, these workers should be more likely promoted to higher job levels in the future. A first casual inspection of the data reveals evidence for this supposition: 95 of the 326 (29.1\%) workers who are assigned to job level 1 and advance at least two grades in one year are promoted to a higher job level during the observation period, while only 17.2 percent of all workers who are initially assigned to job level 1 proceed to a higher job level during the observation period.

For a more rigorous test of whether steeper tenure-wage profiles predict job promotions, three-year real wage growth of new hired workers is calculated and introduced as an explanatory variable in a probit regression to estimate the probability of being promoted to a higher hierarchical job level in the fourth through sixth year of the employment relation conditional on having stayed with the firm for at least three years. Since contractual tenure-wage profiles are very different in the different salary systems, the probit models are estimated separately for the four sub-samples of (1) bluecollar workers older than 23 years of age at hiring, (2) workers hired into the regular white-collar system, (3) workers hired into the juvenile blue-collar salary system, and (4) workers initially placed into the preliminary whitecollar salary system. Table 6.9 reports the marginal effects implied by the coefficient estimates. Wage growth at the beginning of a career has strong effects on the probability of promotion to a higher job level for all workers. ${ }^{30}$ Initial placement into scales has a positive impact on promotion prospects for blue-collar workers. Moreover, chances to be promoted are generally lower for later cohorts because promotion rates fall during downsizing (see chapter 5). This is confirmed by the negative effect of later hiring years in all regressions.

${ }^{30}$ Higher educational degrees raise promotion prospects and wage growth rates, so that: the estimated coefficients of lagged wage growth are smaller when controls for education levels are included in the probit models as is done in Table 6.9. 
Table 6.9: Promotion Prospects and Wage Growth

\begin{tabular}{llllll}
\hline \multicolumn{2}{l}{ Dependent Variable: Promotion to a Higher Job Level in Years 4-6 (1 if yes) } \\
\hline & \multicolumn{2}{c}{ Blue-Collar Systems } & \multicolumn{2}{c}{ White-Collar Systems } \\
& Regular & Juvenile & & Regular & Preliminary \\
\hline 3 Year Wage Growth (\%) & 0.607 & 0.239 & 0.697 & 0.556 \\
& $(0.136)^{* *}$ & $(0.077)^{* *}$ & $(0.724)$ & $(0.235)^{*}$ \\
Promotion 1st Year & -0.038 & 0.092 & -0.045 & -0.039 \\
(1 if Yes) & $(0.010)^{* *}$ & $(0.084)$ & $(0.055)$ & $(0.036)$ \\
Promotion 2nd Year & -0.027 & -0.022 & -0.070 & -0.037 \\
(1 if Yes) & $(0.012)^{*}$ & $(0.009)^{* *}$ & $(0.076)$ & $(0.033)$ \\
Promotion 3rd Year & -0.040 & 0.015 & 0.025 & -0.091 \\
(1 if Yes) & $(0.009)^{* *}$ & $(0.023)$ & $(0.058)$ & $(0.025)^{* *}$ \\
Hiring Scale & 0.010 & 0.022 & -0.016 & \\
& $(0.003)^{* *}$ & $(0.006)^{* *}$ & $(0.017)$ & \\
Hiring Year & -0.017 & -0.019 & -0.030 & -0.059 \\
& $(0.002)^{* *}$ & $(0.003)^{* *}$ & $(0.020)$ & $(0.008)^{* *}$ \\
Education Dummies & Yes & Yes & Yes & Yes \\
\hline Observations & 2144 & 1514 & 275 & 942 \\
\hline
\end{tabular}

Notes: The table shows marginal effects on the probability of promotion to a higher hierarchical job level for workers who were hired 3 years ago into different salary systems. Job levels are defined in chapter 5. Results are presented for the sub-samples in the four different salary systems: blue-collar workers older than 23 years of age at hiring, juvenile new hired blue-collar workers, white-collar workers entering into the regular white-collar salary system, and white-collar workers placed into the preliminary system upon hiring.

\subsubsection{Downward Wage Mobility}

Although even wages deflated by the contractual price compensations generally do not fall, due to nominal rigidity paired with the policy of awarding firm-wide price compensations to all workers, degradation to a lower salary scale is not inconsequential because it reduces wage growth potential. Such degradations occur 423 (96) times among blue-collar (white-collar) workers and become more likely during the downsizing episode (228 salary scale demotions for blue-collar workers take place in 1993 and 1994, while 66 salary scale demotions of white-collar workers happen between 1993 and 1995).

The prime reason for falling contractual wages and hence lower wage growth prospects are, however, worsened performance scores. In 1147 cases the new contractual wage (or wage ceiling for white-collar workers) falls below the salary earned before the worsening in the performance rating. It should 
be noted that most deteriorations in performance ratings do not coincide with falling contractual wages. Performance ratings worsen in 10451 cases of all 194,844 wage contract changes (5.4\%). But deteriorated performance scores frequently (8030 times) coincide with promotion to a higher salary scale and do not lead to lower contractual wages for that reason. In some other cases, annual contractual wage raises, i.e. climbing a wage grade within the scale, compensate for otherwise falling contract wages. ${ }^{31}$

\subsection{Nominal Rigidity, Performance Evalua- tion and Motivation}

The formal salary system paired with nominal rigidity has adverse effects on the incentive structure of workers and supervisors. This is because wages for workers near or at the maximum wage of a scale are not determined by actual performance but by their past performance rating, when actual wages cannot be adjusted downward to a lower contractuall wage that results, for example, from deteriorated performance. ${ }^{32}$ For these workers, incentives for achieving a high performance rating stem only from an improved chances of promotion to a higher salary scale or to a higher hierarchical job level.

At the same time, it is difficult to motivate workers who have been downgraded in the past and who currently earn above contractual wages, because nominal rigidity prohibited their wages from being sufficiently adjusted downward. These workers have little incentives to recuperate to the earlier performance level, because they cannot expect immediate rewards if they work hard and improve performance. In addition, they might become demoralized when they interpret the degradation as a signal of deteriorated chances for future advancement. Such undesirable ramifications of the wage policy on worker motivation are a serious issue, because actual salaries of 3070 workers (of 17586 workers with wage information during the observation period) exceed their current wage ceiling at some time. An improvement in performance does not lead to higher wages for most of these workers, because often

${ }^{31}$ Performance falls for 8689 blue-collar workers of which 7355 coincide with transition to a higher salary scale. Some of the 1322 workers who stay in the same scale can compensate for performance deterioration by advancing to a higher grade. Real contractual wages fall only in 662 cases. Of the 1762 white-collar workers with falling performance ratings 1084 remain in the same salary scale. For 675 white-collar employees, the rating worsens after promotion to a higher salary scalle. The wage ceiling falls for 887 workers, but only 485 white collar workers already had a salary before the performance deterioration that exceeded the new wage ceiling.

${ }^{32} \mathrm{As}$ long as workets have not yet reached the wage ceiling in a scale, it is often possible to align actual remuneration to contractuall wages after a deterioration in performance. 
the contractual wage associated with better performance does not exceed the current wage. Knowing that higher effort does not raise wages, they are likely to shirk in the future. If supervisors take this response of workers into account, they might downgrade too few workers. However, because their ratings have to be consistent with the performance score distribution imposed by the human resource department, such actions have repercussion on the ratings for other employees in the group.

In order to motivate employees to keep on working hard after a promotion, the firm has an incentive to lower performance ratings upon promotion. Since wages are tied to performance scores, lower initial ratings create scope for future wage raises contingent on adequate performance. Such a motivation device is absent, if a promoted worker would immediately after the promotion already exceed the wage ceiling associated with a lower performance rating. This might explain the observation that performance ratings frequently fall upon promotion to a higher wage scale. The fact that lower performance ratings become more likely for blue-collar workers who are promoted into the highest two grades of the new scale supports the conjecture that the firm considers the incentive structure.

An alternative explanation for falling performance ratings upon promotion is that the firm uses performance ratings to simply control the total wage bill. Some support for this conjecture comes from the fact that lower performance scores upon promotion are somewhat more likely during the period of downsizing, when financial pressure is high. 52.7 percent of workers who move up a salary scale in the regular blue-collar system receive a lower performance rating immediately after the promotion during downsizing, but only 51.2 percent during expansion. Among workers who proceed in the white-collar scales, the respective percentages are 26.3 percent during downsizing and 23.7 percent during expansion.

Finally, lower performance ratings after a promotion might reflect tougher requirements in higher job levels and salary scales. This hypothesis is strongly supported by the observation that performance ratings fall in 49.7 percent of the cases, in which a promotion to a higher wage scale is associated with job change, but only in 39.5 percent of the cases, in which jobs are not changed upon transition to a higher salary scale. ${ }^{33}$ "The evidence that performance requirements are different across jobs suggests that it is likely that performance ratings are also contingent on the salary scale placement in the same

\footnotetext{
${ }^{33}$ This tendency holds true for mobility patterns in the different salary systems. For example, 60.1 percent of upward wage scale transitions in the regular blue-collar ranks coincide with lower performance ratings when jobs are changed, while only 48.8 percent do so when the job code remains the same. In the regular white-collar system, the respective numbers are 31.0 percent and 20.3 percent.
} 
job, possibly because slightly more difficult or responsible tasks are completed by workers placed in higher salary scales of a particular job.

\subsection{Performance and Earnings Profiles}

By exploring the correlations between earnings, performance and human capital, Medoff and Abraham (1980) tried to answer whether life cycle earnings growth should be attributed to productivity gains or to institutional arrangements. Assuming that performance measures reflect contemporaneous productivity, they argued that, if wages rose with experience because productivity-enhancing skills were acquired on-the-job (as the human capital model predicts), the estimated effects of skill measures - like education, seniority and pre-company experience - would be driven to zero when performance was controlled for. Since this was not borne out by their data, they concluded that "performance does not appear to be a mediating factor in the within-grade-level positive relationship between either education or labor force experience and earnings", meaning that "there does not appear to be a positive correlation between "human capital' and performance" (Medoff and Abraham, 1980, p. 714).

In this section, I scrutinize the relationship between performance, experience and earnings at Fokker and assess the role of the formal salary system in generating the observed earnings profiles. Following Medoff and Abraham (1980), I estimate a standard semi-log earnings function, which is given by

$$
\ln (y)=\mathbf{x} \beta+\epsilon_{y}
$$

where $y$ is the real annual full-time equivalent salary, $\mathrm{x}$ is a vector of individual characteristics, such as pre-company experience, company tenure, education level or performance rating, $\beta$ is a vector of coefficients to be estimated, and $\epsilon$ captures equation errors. Lacking data on pre-company experience, I construct a proxy for experience by subtracting a worker's expected age at completion of his schooling or vocational degree from his hiring age. ${ }^{34}$

Tables 6.10 and 6.11 report the estimates of the earnings function (6.3) for white-collar workers (including recently hired white-collar workers) and blue-collar workers. The results are extremely similar to those reported in Table II of Medoff and Abraham (1980). Regression model (1) shows that higher education levels and better performance raises wages. Furthermore, additional pre-company experience and firm-specific seniority cause higher

\footnotetext{
34 Medoff and Abraham $(1980,1981)$ constructed a measure of experience in the same way.
} 
earnings. This positive relation between experience and wages is, however, essentially independent of performance. A comparison of models (1) and (2) reveals that the size and statistical significance of the estimated effect of precompany experience and firm-specific tenure is not affected by the exclusion of controls for performance scores.

Based on similar evidence as provided by the estimation results of models (1) and (2), Medoff and Abraham (1980, 1981) concluded that rising individual earnings profiles do not reflect enhanced productivity of more experienced workers. However, knowing how Fokker's salary system functions and knowing that performance measures do not necessarily reflect contemporaneous productivity - even not conditional on the job leve ${ }^{35}$ - our conclusion must be different. In effect, the formal salary system causes the estimated relation between wages and experience to be independent of performance measures because its rules severely limit the amount of wage dispersion that is attributed to differences in performance scores in OLS regressions of the type reported in Tables 6.10 and 6.11. Performance ratings only affect the withinsalary scale wage dispersion directly. Direct effects of performance ratings on blue-collar workers' wages are even restricted to grades within a particular salary scale, such that a one-score improvement in the performance rating only leads to an immediate wage raise of about 2 to 3 percent. While immediate wage increases due to enhanced performance might be even lower for white-collar workers - depending on performance score and salary scale - the total wage gain, which will accumulate in future periods of persistent performance, amounts to about 10 percent. In general, within-scale wage differences are small even relative to within-job wage variation, which is caused by placement of workers' into different scales and grades. Controlling for performance can, consequently, only explain a small fraction of of job level wage dispersion, and an even smaller fraction of the overall wage variation. On the other hand, a large chunk of the variance in wages is attributed to seniority because the placement of workers to grades marks out the contractual wage profile. The estimated effect of performance on contractual wages is too small relative to that of seniority to drive the effect of experience toward zero in an OLS regression of the earnings function.

Yet, although upward mobility in the salary system is related to experience, it is not necessarily independent of productivity. In fact, the sorting of workers to higher salary scales in the same job or in higher job levels is strongly affected by performance. Previous sections provided evidence that higher performance scores raise prospects for upward salary scale mobility

\footnotetext{
${ }^{35}$ Recall that the previous section reported evidence that performance score often fall upon promotion to a higher salary scale within the same job.
} 


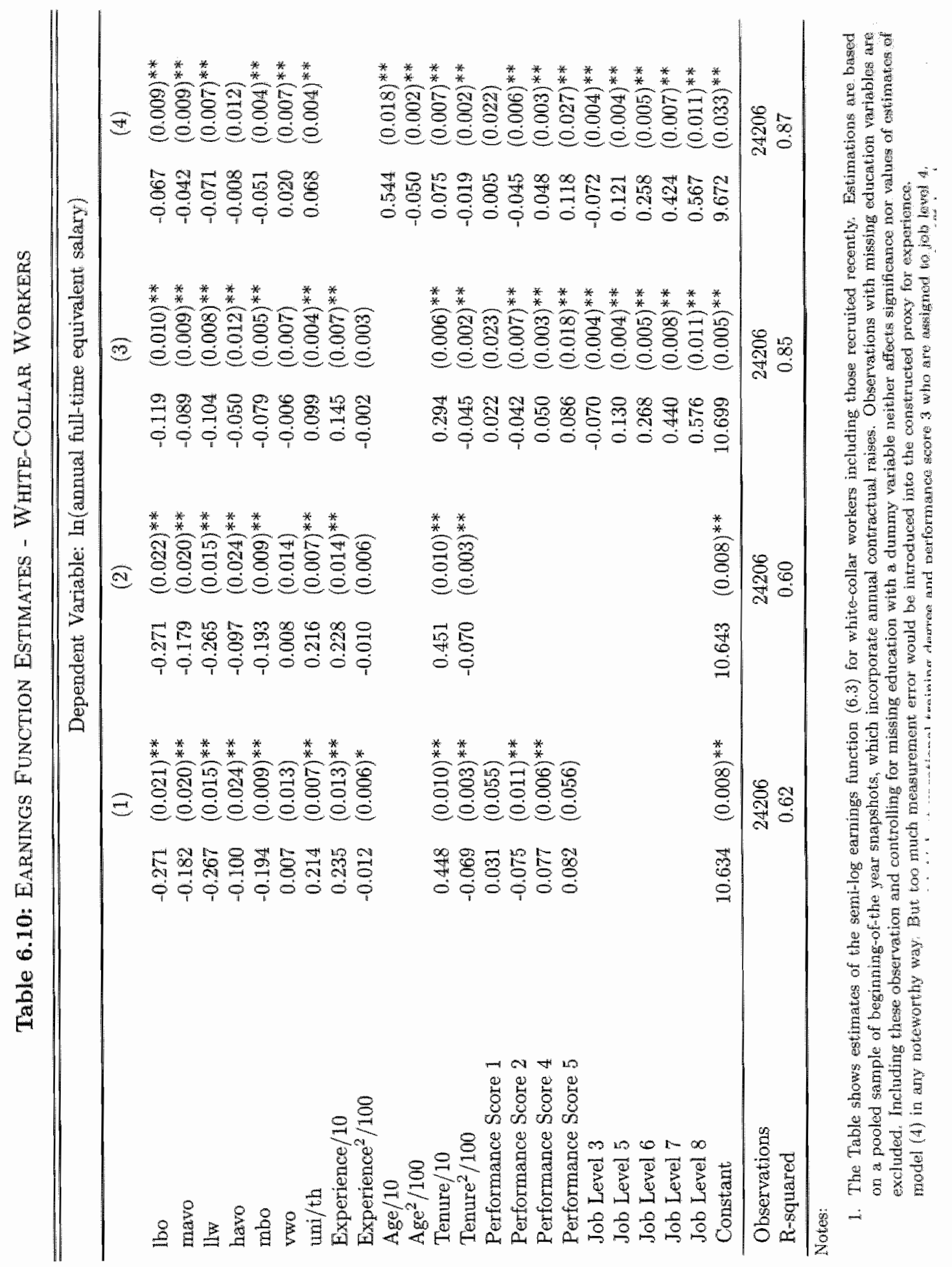




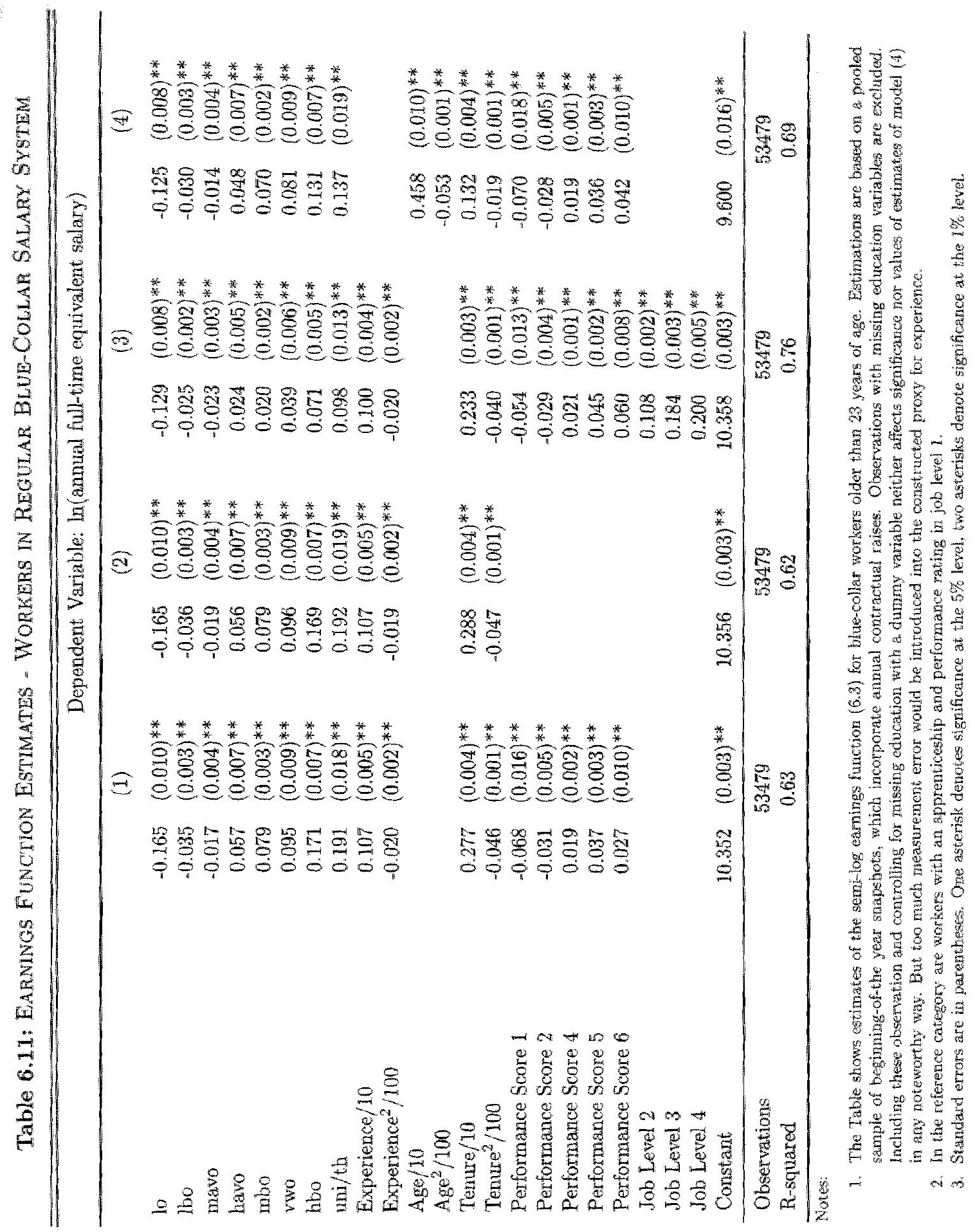


and upward job mobility. ${ }^{36}$ Thus, better performance leads to steeper expected career earnings profiles. But the performance measure in the data is not independent of job levels and salary scales (and hence of experience), i.e. it does not reflect true contemporaneous productivity adequately. This becomes obvious recalling that promotions to higher salary scales often coincide with lowered performance ratings. Since performance ratings are conditional on job level or even on salary scales within a job, OLS coefficient estimates of the earnings function (6.3) do not credit the wage growth associated with upward salary scale mobility or even job change to improved performance, although better performing workers are more likely to be promoted. This is especially problematic because most of the firm-level wage disparity stems from assignment to different job levels.

Since experience might still result in productivity growth, it is not justified to credit earnings growth entirely to institutional arrangements. In fact, the size of the estimated average effect of seniority, i.e. the average steepness of earnings profiles, is smaller (especially for white-collar workers) if the analysis is restricted to those who are never promoted to higher job levels. Coefficient estimates of model. (3), which adds controls for hierarchical job levels defined in chapter 5 , confirm this. ${ }^{37}$ They also disclose that returns to education come largely from assignment to higher job levels. These results indicate that the full returns to measures of accumulated human capital, like education or general and firm-specific experience, are only realized upon promotion to a higher job level. The estimates of model (4), in which age replaces the proxy for pre-company experience as a regressor, underscore that the returns to measures of human capital, like vocational and schooling degrees, come largely from job assignment. ${ }^{38}$ Heterogeneity of individual earnings profiles suggests that observed earnings profiles are not completely determined by institutional arrangement. If workers learn from their experience at different rates, those whose productivity grows fastest are likely to be the earliest to be promoted to higher job levels. As a resuli, they enjoy the steepest career

\footnotetext{
${ }^{30}$ Moreover, it was shown that stronger wage growth, which results from a better past performance recond, predicts promotions to higher job levels.

${ }^{3}$ In fact, when the wage regressions are rum separately for different job levels, the return to aducation becomes almost negligible, and is essentially zero when one focuses on a particular job code. This follows immediately from the institintional character of the salary system which ties wage ranges to jobs and in which wage growth past a job's wagg range is only sustained upon job change.

${ }^{38}$ Estimates for returns to education from this specification are more reliable, because it avolds introducing superfluous measurement erron into the regression - through the construction of the proxy for pre-company experience - which is potentially correlated witin the schooling variables. However, disentangling the returas to pre-company and firm-specific experience becomes a problem in this specification.
} 
earnings profiles.

Higher levels of skills, i.e. human capital acquired in school or in the labor force, map into higher wages in a different way than conventionally assumed. Wage growth in a particular job is limited by the formal salary system, no matter how high individual productivity on the job might be. Skills, acquired in the labor market or during school, that are relevant for the job, might well improve productivity and raise the probability of promotion. But returns to such human capital investments are only realized upon assignment to adequate job levels. If more able workers learn faster, i.e. accumulate skills at a higher rate, they become likely to be promoted faster, which causes heterogeneous experience-earnings profiles even if observed measures such as schooling degrees or years of experience are the same.

The interpretation that human capital acquired in the labor market does not raise productivity and wages is difficult to uphold. Evidently, earnings profiles are governed by administrative rules. But a firm is likely to design its compensation scheme not only to account for productivity improvements resulting from human capital accumulation, but also to induce investments in human capital that are often difficult to measure and verify by using promotions to higher job levels (see also Prendergast, 1993a). The strict adherence to the formal rule structure of the compensation system ensures workers to be rewarded adequately for their effort and investments. Besides that, the salary system is devised to reduce turnover by deferring compensation partly to later periods. The contractual character of the salary system helps building trust among workers that the firm keeps its promises of future earnings growth.

\subsection{Conclusion}

The wage policy of a large firm has been analyzed. Institutional arrangements in wage setting can generate many patterns that are at odds with the predictions of different human capital and learning models including cohort effects, serial correlation in wage growth and nominal rigidity. The formal salary system defines wages and annual raises conditional on job assignment, firm-specific tenure and performance. A range of wage scales is attached to a particular job. Initial job assignment and hence placement in the firm's salary system is largely determined by schooling and vocational degrees. Contractual tenure-earnings profiles determine wage growth for a given job assignment. Higher performance ratings lead to higher wages in a given job, but the wage premium associated with a better performance score is small relative to contractual wage growth within a job. Formal rules 
not only limit wage growth associated with performance scores, but also the discretion of supervisors to award lenient performance ratings. Contractual tenure-wage profiles for different performance ratings move in parallel in bluecollar jobs, whereas tenure-wage profiles are steeper for higher ratings in the salary system for white-collar jobs.

The salary system causes the observed positive relation between seniority and earnings to be largely independent of performance ratings in OLS estimations of a standard earnings equation. For the within-scale or even within-job wage variation that stems from the contractual tenure-wage profile is large relative to the variation in wages that is captured by the performance measure conditional on job assignment and seniority. While this generates observed earnings profiles that are largely independent of reported pertormance, performance has a stronger impact on life cycle wage growth as it influence how fast workers reach the top salary in a job and as it affects job assignment. Promotion to higher job levels is more likely for workers with better ratings. Performance measures do not capture this effect on wages because performance ratings are awarded conditional on task assignment so that more complex tasks require higher performance levels to result in a given performance score. Given our knowledge of the functioning of the salary system, we should not jump to the conclusion that this empirical finding implies that life cycle earnings growth is largely independent of productivity growth. Insofar, the analysis suggests a reinterpretation of the findings by Medoff and Abraham (1980, 1981).

The results of this chapter suggest that life cycle wage growth does depend on an individual's productivity growth, but not in a way predicted by standard human capital theory. Wage returns to human capital investments are only realized upon assignment to adequate jobs within the firm hierarchy. The salary system is designed to encourage workers to make productivity enhancing investments and reduce turnover by deferring wage growth to the future and attaching higher wage scales to positions in higher job levels. Adherence to the formal rule structure even during periods of adverse economic conditions creates confidence among workers that they will be rewarded for improving their productivity. 
Chapter 7
A Theory of Careers in Hierarchical Internal Labor Markets 


\subsection{Introduction}

A growing recent empirical literature that studies the internal economics of firms clocuments patterns of job mobility and earnings dynamics that are at odds with the conventional labor market model. ${ }^{1}$ The standard theory of competitive labor markets overlooks the role of firms and jobs, even though matching up workers and jobs is at the heart of employment relationships. A revival of a job-based analysis of labor market outcomes seems a promising route towards a better understanding of labor market outcomes. ${ }^{2}$ Although various alternative labor market models have stressed the importance of job mobility, career mobility inside a single hierarchically organized firm has largely been ignored. ${ }^{3}$

This chapter develops a model of careers inside organizations that is consistent with the collage of evidence about the internal workings of firms. It amalgamates different theoretical concepts - including human capital accumulation, learning, job assignment, and a hierarchical production technology with scale of operation effects - to show how the firm's demand for labor to staff different job positions and heterogeneity among workers determines career mobility and affects the evolution of life cycle labor earnings. Motivated especially by the empirical finding that promotion rates rise during corporate expansion and fall during contraction (see chapter 5), the model highlights the relation between internal mobility and changes in the size of the workforce. It thereby advances a modern theoretical literature on careers in organizations (see e.g. Bernhardt, 1995; Demougin and Siow, 1994; and Gibbons and Waldman, 1999a), which has not yet addressed this issue.

The model in this chapter considers a hierarchical organization of jobs that stems from a recursive production technology - as built on by Williamson (1967), Calvo and Wellisz (1979), and Rosen (1982) - in which the final good is produced only on the lowest level. Managerial output in higher levels augments production at lower levels. A manager's output raises marginal

${ }^{1}$ Lazear (1992) and especially Baker, Gibbs and Holmstrom (1994a, 1994b) inspired a new empirical economic literature (see e.g. Ariga et al., 1999; Seltzer and Merrett, 2000; Gibbs and Hendricks, 2001; this dissertation). Aspects of career mobility had long stimulated sociological research (see e.g. Whyte, 1956; Simon, 1957; Kanter, 1977; Spileiman, 1977; Rosenboum, 1979). Rosenbaum's (1984) study encouraged the tournament literature in economics (see e.g. Lazear and Rosen, 1981; and Rosen, 1986).

${ }^{2}$ See Lazear, 1992 and $1995 \mathrm{~b}$ for a similar argument. Doeringer and Piore (1971) provided an early account of internal labor markets which stresses the role of jobs.

${ }^{3}$ Matching and sorting models with information accumulation (e.g. Gibbons, Katz and Lemieux, 1997), for example, illustrate how wage growth is generated by job mobility. Yest, these models apply to occupational choice and labor mobility across firms more than to career mobility inside furms. 
productivity of all his subordinates multiplicatively, thereby magnifying the impact of his skills on final good production. Thus, output increases by more than the difference between two employees' productivity when the more productive manager is assigned to the higher job level. The firm's output maximizing planning problem is to staff hierarchical jobs according to the productivity ranking of its workers.

Although I focus on the sorting of workers to jobs inside a single firm, which has already optimized the number of hierarchical levels as portrayed by Williamson (1967), the model can be extended to a general equilibrium framework. ${ }^{4}$ The relative number of jobs in hierarchical levels is fixed because the command production technology necessitates time-consuming supervision. $^{5}$ Supervision cannot be separated from other managerial tasks. The implications of limited job slots in different hierarchical positions are little studied in the literature on careers in internal labor markets. An exception is the model by Demougin and Siow (1994).

Job assignment becomes a dynamic problem, which crucially impinges on individual career mobility, because information about workers' talents is only revealed over time by noisy observations of output. "I model this as a normal Bayesian learning process and assume that a worker and his current. employer share the same information regarding his productivity and learn symmetrically about his talent. But outside firms can infer talent only from observing job assignment, wages or verifiable training experiences. ${ }^{7}$ Another source of career dynamics is on-the-job human capital accumulation (see e.g. the work of Becker, 1962 and 1964); Mincer, 1962). The model illustrates how interactions between learning, ability, and human capital accumulation affect job mobility and wage dynamics. ${ }^{8}$

4The sorting of talent to jobs across different firms generates empirically observed skewed incone and firm size distributions in a general equilibrim framework. It explains why superior managers control larger firms and receive more than proportionately higher incomes, as Rosen (1982) illustrates.

Whe analysis of this chapter applies to a variety of sequential production technologies with fixed job slots, in which the marginal productivity of talent is amplified in eantier stages of the production process.

"The literature has typically treated static assignment problems. See Sattinger (d993) for a survey of the job assignment literature.

${ }^{7}$ Waldman (1984b) and Bernhardt (1995) make the same informational assumptions. Alternatiwely one could assume that all labor market participants heve the same information, as Harris and Holmstrom (1982) do. This has different implications for wage determination and strategic promotions, but generates otherwise similar results.

${ }^{8}$ Firm-specific capital gives rise to hold-up problems when it is not verifiable in court. I assume following MacLeod and Malcomson (1998), that the firm pays an efficiency wage when there is excess supply in the labor market and pays a bonus when there is excess labor demand in order to avoid hold-ups. 
In particular, the model reveals that individual prospects of career advancement improve during periods of corporate expansion and worsen during downsizing, because the firm prefers to promote incumbent workers to additional vacancies in higher hierarchical levels. Promotions are associated with sizable wage increases, because a manager's output raises the productivity of all subordinated workers, so that the marginal returns to the manager's productive skills increase at promotion to a higher job level. Hence, expected career-earnings profiles are steeper in expanding firms.

Furthermore, the model demonstrates that the hazard of promotion rises initially as workers develop skills on-the-job, but starts decreasing eventually when the most able workers of a cohort have been promoted while the productivity of job stayers is topped by more able workers of younger cohorts. The most able workers develop productive skills fastest, climb the productivity ranking quickly, and are promoted fast from one level to the next, so that promotion fast-tracks exist. The speed at which the firm learns about the abilities of its workers shapes career dynamics and promotion policies. Firm learning and the process of firm-specific skill development by workers affects turnover and the timing of promotions.

Moreover, the model predicts that training is provided throughout a career, but is concentrated around promotion dates. Postponing training investments is valuable because the firm is initially uncertain about the rate of return to the training investment, as it depends on the rate at which workers learn. By delaying the investment until more information about a worker's productivity is known, the firm limits the risk that the training investment has low returns. Further training investments become worthwhile at promotions because enhanced skills have a bigger impact on total output in higher job levels.

The chapter is organized as follows. Section 7.2 reviews key findings and stylized facts that emerge from the empirical literature on internal labor markets. Section 7.3 describes the firm's internal organization of labor, which stems from the production technology, and outlines the firm's assignment problem. Section 7.4 introduces a simple model without specific investments to concentrate on the implications for career mobility that result from the firm's planning problem under uncertainty. It works out the impact of changes in the workforce on individual careers. Section 7.5 extends the analysis to interactions between learning and on-the-job specific skill accumulation. Section 7.6 sketches the model's implications for the provision of formal firm-specific training courses. Section 7.7 describes how different forms of human capital accumulation can be incorporated into the analysis. Section 7.8 concludes. 


\subsection{Stylized Facts of the Internal Workings of Firms}

The recent empirical literature has turned anecdotal and heuristic evidence of the internal economics of firms into stylized facts. Since a model of careers should be consistent with empirically observed patterns of job and wage mobility, I briefly review some key results of this literature.

All econometric case studies based on persomel data that I am aware of report that labor is organized in jobs at different hierarchical levels (e.g. Medoff and Abraham, 1980 and 1981; Lazear, 1992; Baker, Gibbs and Holmstrom $1994 \mathrm{a}$ and 1994b; Ariga, Ohkusa and Brunello, 1999; Seltzer and Merrett, 2000; Flabbi and Ichino, 2001; Treble et al., 2001; Lima, 2000; Gibbs and Hendricks, 2001; Lin, 2002; and the analysis in chapters 5 and 6 of this dissertation). A hierarchical organization of jobs is typical for firms around the globe, both in the manufacturing sector and in the service sector. ${ }^{9}$

Stylized facts that emerge from these studies include the following: (1) promotion fast tracks exist, (2) nominal wage cuts are rare, (3) changes in wage residuals are serially correlated, (4) wage increases upon promotion are large compared to normal increases but small compared to the difference in average wage between the two levels, (5) substantial within-job-level wage spread is found, but job levels have wage ceilings so that upward job mobility is crucial for sustained wage growth, (6) wage increases forecast promotions, (7) promotions come from and go to all deciles of the wage distributions for the lower and upper levels.

In addition, the probability of being promoted to a higher hierarchical job level, conditional on the time already spent on the job, rises initially and then starts to decrease. Lazear (1992) reports evidence of a hump-shaped hazard rate of upward job mobility. Baker, Gibbs and Holmstrom (1994a) as well as van Gameren and Lindeboom (2000) find that promotion rates fall. with time spent on the previous job.

Internal job mobility is also influenced by changes in the size of the work-

\footnotetext{
9Medoff and Abraham (1980, 1981) and Lazear (1992) have personnel data from four different U.S. manufacturing firms. Baker, Gibbs and Holmstrom (1994a, 1994b) study the persomel records of a U.S. service sector firm and Gibbs and Hendricks (2001) lias further evidence for a U.S. firm. Seltzer and Merrett (2000) analyze the records of a large Australian bank. Flabbi and Ichino (2001) study data of an Italian bank and Treble at. (2001) those of a British financial institution. Ariga, Onkusa and Brunelio (1999), Lima (2000), and Dohnen, Kriechel and Pfann (2002) have data from manufacturing companies based in Japan, Portugal, and The Netherlands respectively. Lin (2002) has personnel records from a Taiwanese automobile sales and maintenance company. All studies find a hierarchy structure of jobs in the different firms.
} 
force. Chapter 5 showed that promotion rates increase during corporate expansion and fall during downsizing. This dependence relation is not explained by existing theoretical models of careers, but follows from the model that is developed in this chapter. Since the effect of employment changes on internal job mobility is a crucial part of the model, I review some empirical evidence documented in chapter 5 .

When the global slump in aircraft demand (see chapter 3) forced Fokker to trim down production capacity and reduce the number of workers, the firm announced the first of a series of downsizing operations on March 1, 1991. More severe reorganizations involving involuntary dismissals were to follow in 1993, 1994, and 1995. Figure 7.1 documents how employment dynamics at the firm level (depicted in the lower panel of the figure) responded to the falling stock of remaining orders (plotted in the upper panel of the figure). The lower panel of the figure shows total employment as well as employment. in the two sub-pyramids that can be distingtuished in Fokker's job hierarchy. The first one comprises blue-collar jobs, which are organized in the bottom three levels of the hierarchy. Assemblers and other production workers are assigned to the lowest level, while production planners, coordinators, foremen, group leaders and other supervisors work on the two higher levels of this hierarchical sub-pyramid. White-collar jobs are organized in the upper sub-pyramid, which contains 7 additional higher levels including top management. White-collar employees work, for example, as engineers in R\&D, or are involved in management and sales related activities. Total employment rose from 10275 workers in January 1987 to 12852 at the peak in February 1991. Employment falls subsequently to only 7141 workers on the day before the bankruptcy. Employment changes are much more pronounced in the lower sub-pyramid (predominately blue-collar jobs).

The average annual promotion (demotion) rate for white-collar workers is $7.7 \%(2.7 \%)$ during workforce expansion from January 1987 until February 1993 and $6.4 \%(2.6 \%)$ during the episode of contraction from March 1993 until the bankruptcy on March 15, 1996. The change in job mobility rates is more drastic in the blue-collar ranks, which account for most of the employment variation. The annual promotion rate falls from $6.4 \%$ during expansion from January 1987 until February 1991 to $3.9 \%$ during contraction from March 1991 until the bankruptcy among blue-collar workers, while the demotion rate rises from $1.0 \%$ to $1.4 \%$.

Understanding which forces drive this outcome is key to the study of labor market careers because life cycle earnings of workers are crucially affected by job mobility (see chapter 6). For example, if expanding firms offer greater chances of career advancement, workers should, ceteris paribus, prefer them to declining firms and industries. Moreover, adverse changes in career ad- 


\subsection{STYLIZED FACTS}

\section{Figure 7.1: Alrckaft Demand and Employment Dynamics}

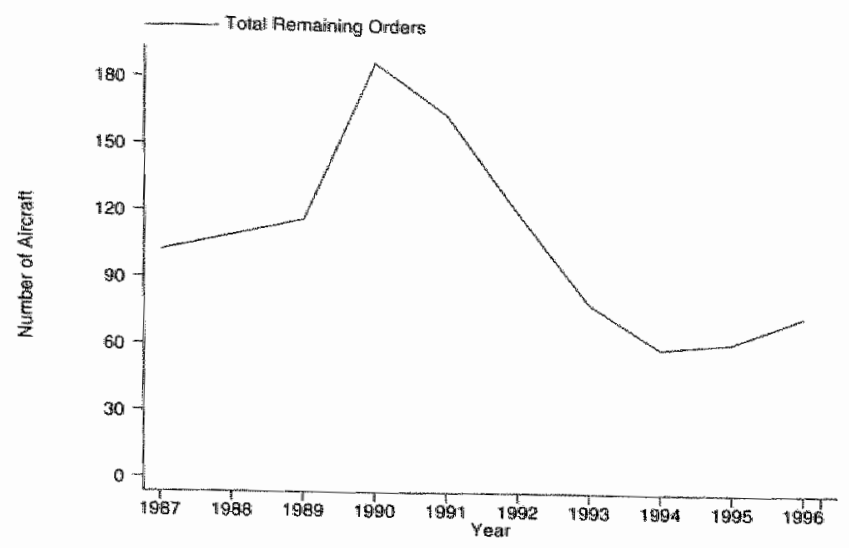

(a) Remaining Orders of Fokker Aircraft

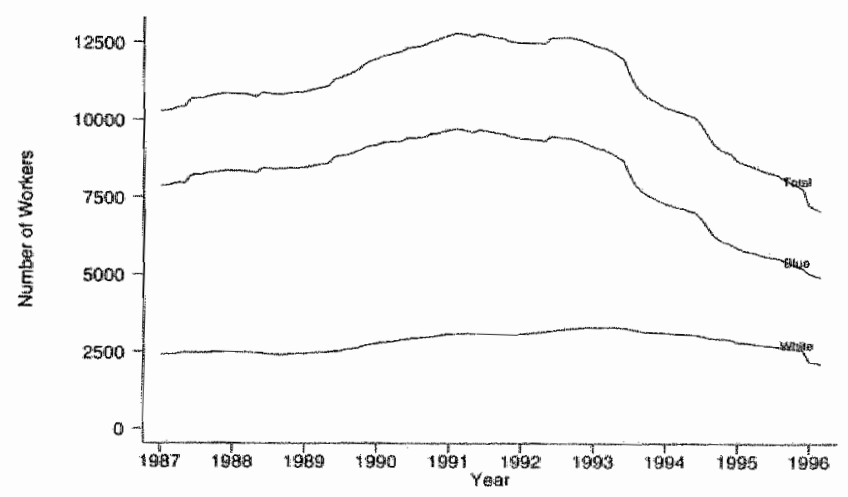

(b) Workforce

Notes: Panels (a) shows total world orders and orders of Fokker aircraft in the two market segments for 40-70 seaters and 70-1.25 seaters. Panel (b) plots the number of workers with a permanent contract empioyed at the beginning of each month from January 1987 until March 1996 (labelled "Total") and that for workers in the lower three levels of the job hierarchy ("Blue") and for workers in the upper hierarchical levels ("White"). 
vancement prospects during contraction reduce workers' welfare beyond pure wage loss or job loss. A model of careers in internall labor markets should, therefore, address implications of employment changes.

\subsection{The Internal Organization of Workers}

\section{The Production Technology, Hierarchy, and Job Slots}

I consider a firm that employs a recursive production technology, which is further defined below. Tasks have to be performed on different hierarchical job levels, but only workers on the lowest level manufacture the firm's final product. Employees in all other hierarchical levels engage in managerial activities such as supervision, research and development, forecasting, planning and administration, or selling the final product. Managers make an array of choices concerning product design, development, customer relations, product placement, the organization of production techniques, etc. The quality of these indivisible management decisions depends on the manager's competence. Managerial skills are nonadditive and noncombinable, so that it is not possible to team several to impersonate a single superior one. Only one employee can be assigned to each job slot. A manager's output is an intermediate good that serves as an input at lower levels of the production process and raises the productivity of all subordinated workers of his production line. Therefore, managerial output results in total factor improvements and has strong scale effects at the firm level. These scale effects are congested by the need for supervision; for a manager has to spend a fixed amount of time in order to communicate his ideas to his subordinated workers on the next lower hierarchical job level and in order to ensure compliance with his management decisions. Time-consuming supervision limits the span of control, i.e. the number of workers that a manager can supervise effectively, so that the number of job slots at each hierarchical level of a production line is rationed. In this chapter, I assume that the number of workers that can be supervised efficiently at each hierarchical level is fixed by the production technology.

A 3-level firm is considered here because it suffices to study the important aspects of promotion and wage dynamics including fast-tracks and serial correlation in wage growth and promotions. ${ }^{10}$ Such a firm consists of a pro-

\footnotetext{
${ }^{10}$ The analysis naturally carries over to "deeper" organizations, which have more hienarchical levels. However, their analysis is more complex but does not yield important additional insight.
} 
duction level $L_{1}$ and two higher levels $L_{2}$ and $L_{3}$. A worker $k$ who is assigned to the highest level controls a production line. His span of control is $s_{3}$, so that he manages the output of $s_{3}$ employees on level $L_{2}$. Each of these managers controls an $L_{2}$-operation. Since the span of control of a manager on level $L_{2}$ equals $s_{2}$, he supervises $s_{2}$ workers who are assigned to level $L_{1}$ in his operation. As a result, each production line has $\left(1+s_{3}+s_{3} s_{2}\right)$ job slots. The size of the firm is determined by the number of production lines and the span of control at each hierarchical job level. The total number of job slots for a firm with $K$ workers assigned to the highest level is given by

$$
N=K+s_{3} K+s_{2} s_{3} K=\left(1+s_{3}+s_{2} s_{3}\right) K .
$$

The set of all workers $S_{\text {all }}=\{n \mid n \leq N, N \in \mathbb{N}\}$ can be partitioned into three subsets $S_{L_{1}}, S_{L_{2}}$, and $S_{L_{3}}$ that contain workers assigned to levels $L_{1}$, $L_{2}$, and $L_{3}$ respectively, such that $S_{L_{l}} \subset S_{a l l}$ and $S_{L_{l}} \cap S_{L_{m}}=\varnothing$ for $l \neq m$, $l \in\{1,2,3\}$, and $m \in\{1,2,3\}$. The subset $S_{L_{3}}$ has $K$ elements that will be indexed by $k, k \in\{1, \ldots, K\}$. Likewise, subset $S_{L_{2}}$ has $s_{3} K$ elements indexed by $j, j \in\left\{K+1, \ldots, K+s_{3} K\right\}$ and subset $S_{L_{1}}$ has $s_{2} s_{3} K$ elements indexed by $i, i \in\left\{K+s_{3} K+1, \ldots, K+s_{3} K+s_{2} s_{3} K\right\}$. Let $S_{L_{2}}^{k}$ denote the $s_{3}$ workers who are subordinated to worker $k ; S_{L_{2}}^{k}$ is a subset of all workers assigned to the second level, i.e. $S_{L_{2}}^{k} \subseteq S_{L_{2}}$, such that $S_{L_{2}}^{k} \cap S_{L_{2}}^{l}=\varnothing$ for $k \neq l$, and $\bigcup_{k} S_{L_{2}}^{k}=S_{L_{2}}$. If $k>1, S_{L_{2}}^{k} \subset S_{L_{2}}$. Let $S_{L_{1}}^{j}$ denote the $s_{2}$ workers who are subordinated to worker $j$; $S_{L_{1}}^{j}$ is a subset of all workers assigned to the lowest level, i.e. $S_{L_{1}}^{j} \subset S_{L_{1}}$, such that $S_{L_{1}}^{j} \cap S_{L_{1}}^{l}=\varnothing$ for $j \neq l$, and $\bigcup_{j} S_{L_{1}}^{j}=S_{L_{1}}{ }^{11}$

Let $\omega_{n}$ denote productive skills of worker $n$. Productive skills $\omega_{n}$ are an idiosyncratic trait of worker $n$. I assume here that skills are one-dimensional, meaning that the same set of talents and competencies is used at every level of authority. In fact, this assumption implies that skills are fully transferable from one job level to the other. Consequently, job assignment is based on absolute advantage because a better production worker is also a superior manager. ${ }^{12}$ The model is straightforwardly extended to capture a more realistic world, in which not all skills are useful in every job. In such a model, the index $\omega_{n}$ would be replaced, for example, by a three-dimensional vector with possibly correlated components that reflect productive skills relevant in the three different jobs. ${ }^{13}$

\footnotetext{
${ }^{11} S_{L_{1}} \subseteq S_{L_{1}}$ iff $K=1$ and $s_{3}=1$, i.e. if only one worker is assigned to level $L_{2}$.

${ }^{12}$ This rather unrealistic assumption which simplifies the assignment rule helps us to focus on the implications of limited job slots for career mobility. The main insights of the paper still hold if a different skill mix was required at every level and a worker"s productivity across jobs was correlated, for example, because some innate trait affects his performance in all jobs.

${ }^{13}$ Such an extension has important consequences for the assignment problem, because
} 
A worker's competence or productive skills do not change when he is assigned to a different job, but the impact of his skills on production alters at different levels of authority due to the command structure of the production technology. Suppressing physical capital for simplicity, the output of an $L_{2}$ operation, in which worker $j$, assigned to level $L_{2}$, controls the set of workers $S_{L_{1}}^{j}$ on level $L_{1}$, is given by

$$
Y_{j}=g\left(\omega_{j}\right) \sum_{i \in S_{L_{\xi}^{j}}^{j}} f\left(\omega_{j} t_{w}, \omega_{i}\right) .
$$

Equation (7.2) illustrates that output produced by workers with productive skills $\omega_{i}$ on level $L_{1}$ is augmented by worker $j$ 's managerial output, $g\left(\omega_{j}\right)$, which is a function of his productive skills $\omega_{j}$, as long as $g\left(\omega_{j}\right)>1$. $^{14}$ The scale effect, which stems from enhancing the productivity of all subordinate workers, is limited because manager $j$ cannot spend all his time generating ideas to improve efficiency of his subordinates, but he has to devote a fraction of his working time $t_{w}, 0<t_{w}<1$, supervising each of his directly subordinated workers to communicate ideas and ensure compliance with his decisions. The higher his competence, $\omega_{j}$, the higher will be compliance with his aims. This is captured by the argument $\omega_{j} t_{\omega}$ in $f(\cdot)$.

Likewise, worker $k$ who is assigned to the highest level $L_{3}$ controls the output of $s_{3} L_{2}$-operations. Total output of his entire production line $Y_{k}$ is affected by his managerial skills $\omega_{k}$ :

$$
\begin{aligned}
Y_{k} & =G\left(\omega_{k}\right) \sum_{j \in S_{L_{2}}^{k}} F\left(\omega_{k} t_{w}, Y_{j}\right) \\
& =G\left(\omega_{k}\right) \sum_{j \in S_{L_{2}}^{k}} F\left(\omega_{k} t_{w},\left[g\left(\omega_{j}\right) \sum_{i \in S_{L_{1}}^{j}} f\left(\omega_{j} t_{w}, \omega_{i}\right)\right]\right) .
\end{aligned}
$$

absolute and comparative advantage do not necessarily coincide in a model with multiple skill-dimensions (see Sattinger, 1993). But, such a model offers scope to study issues concerning the impact of skill transferability on (occupational) careers. It also allows to address whether job rotation is a useful tool to foster skill accumulation or allows firms to learn faster about a worker's ability (see Ortega, 2001). An extended version of the model that has multiple (latent) skill dimensions would allow to study the trade-off between the number of signals on a single job against the variety of signals in different jobs (see also Meyer, 1994).

${ }^{14}$ Equation (7.2) is consistent with a world in which not every laborer is a good manager, even though no explicit distinction is made between managerial skills and manufacturing skills. A worker"s marginal effect on final good production might simply be insufficient in higher job levels. If a worker is endowed with so little (managerial) talent that $g\left(\omega_{j}\right)<1$, he would ruin output of his production line when assigned to level $L_{2}$. 
The firm's total production equals the sum of final good production of all its $K$ different production lines. ${ }^{15}$ It is assumed that employees can only carry out the task they are assigned to but cannot help out in other activities at the same time. The functions $f(\cdot)$ and $F(\cdot)$ exhibit diminishing returns to supervision $\left(f_{11}<0\right.$ and $\left.F_{11}<0\right)$ and complementarity $\left(f_{12}>0\right.$ and $\left.F_{12}>0\right)^{16}$

The static problem of assigning heterogeneous workers to different hierarchical job positions entails that the firm - in order to maximize output - ranks its $K\left(1+s_{3}+s_{2} * s_{3}\right)$ workers according to their productivity and then staffs the $K$ jobs on level $L_{3}$ with the highest ranked workers. ${ }^{17}$ The highest ranked $K$ workers are identified by subscript $k$ in terms of equation (7.3). The next highest ranked $s_{3} K$ workers fill the positions on $L_{2}$ and the remaining $s_{2} s_{3} K$ workers are finally assigned to $L_{1}$.

However, job assignment becomes a dynamic problem because the ranking of workers according to their productive skills changes. This does not only happen because workers with finite careers have to be replaced when they

\footnotetext{
${ }^{15}$ Rosen (1982) considers a similar production techology, in which $\omega_{n}$ is a three dimensional vector with components $s_{n i}, r_{p}$, and $q_{n}$ that capture a person's latent skills in levels 3,2 , and 1 respectively. The skills are latent because a worker only uses the skills that: are relevant for the job level he is assigned to. Output of a 3-level operation - in which worker $k$ has subordinates from the set $S_{L_{2}}^{k}$, who are indexed by $j$ and who in turn each control the output of a set of workers $S_{L, 1}^{j}$ on the production level - would be given by

$$
Y_{k}=G\left(s_{k_{i}}\right) \sum_{j \in S_{L_{2}}^{k_{2}}} F\left(s_{k} t_{j}, g\left(r_{j}\right) \sum_{i \in S_{L_{1}}^{i}} f\left(r_{j} t_{i}, q_{i}\right)\right)
$$

A manager's productive skills are time-augmenting, which is captured by $r_{j} t_{i}$ (and $s_{k} t_{j}$ ). In addition, manager $j(k)$ can choose the amount of time he spends supervising each of his subordinates $i(j)$ so as to maximize output. The span of control is endogenous and depends on the quality of managers. Multiple skill dinensions and an eudogenous span of control allow to study an array of further interesting problems for internal career mobility - including job rotation, the design of career paths, of limits to firm size.

${ }^{16}$ Rosen (1982) works out the implications of such a production technology when the functions $f(\cdot)$ and $F(\cdot)$ are in addition linearly homogeneous in their argminents and have constant returns to scale. The latter assumption implies that equilibrium production depends only on the total amount of production labor controlled, not on the number of production workers. Rosen derives the market equilibrium implied by this production diechnology.

${ }^{17}$ The assignment rule presupposes that the frrm can recruit s sufficient number of managers, whose marginal productivity in level $L_{2}$ is higher than in level $L_{1}$. This implies a sikill requirement w' defined such that the marginal productivity of a worker whose productive skills exceed $\omega^{\prime \prime}$ is always higher in level $L_{2}$ than in llevel $L_{1}$. Similarly, $\omega^{\prime \prime}$ is defined such that a worker with productive capacity $\omega$ exceeding $\omega^{\prime \prime}$ has always a higher marginal productivity in lewel $L_{3}$ compared to $L_{2}$. Assuming that $w^{\prime \prime} \geq w^{\prime}$, marginal productivity is increasing in hierarchical levels for workers satisfying $\omega \geq w^{\prime \prime}$.
} 
retire or separate, but also because workers accumulate skills at different rates. The rate of human capital accumulation is determined by a worker's innate ability $\theta$ as productive skills $\omega_{n}$ are given by

$$
\omega_{n}=\theta_{n} H
$$

where the stock of accumulated relevant human capital $H$ is -- depending on the exact specification of the model - a function of (on-the-job) experience, training or schooling. A worker's innate ability is assumed to be person-specific and constant throughout a worker's career, but not directly observable. Instead, a worker's individual ability is a draw from the known population distribution of $\theta$, which is assumed to be normal with mean $\mu_{\theta}^{0}$ and standard deviation $\sigma_{\theta}$, i.e.

$$
\theta \sim N\left(\mu_{\theta}^{0}, \sigma_{\theta}^{2}\right)
$$

At distinct intervals during the employment relationship, for example, at the end of each year, the firm obtains for each worker $n$ a noisy signal of his ability, $\hat{\theta}_{r, t, k}$, from observing individual output during the observation period $t$ at all stages of the production process. Since the signal is private to the worker and his current employer, potential employers can only infer a worker's expected ability from observed actions such as job assignments. The productivity signal is given by

$$
\hat{\theta}_{n, t}=\theta_{n}+\epsilon_{n, t} .
$$

The $N$ individual signals are obtained recursively by using inverse functions $\Psi_{\ell}^{-1}, \ell \in\{1,2,3\}$, of the production technology that map output, which is measured with error at each level $L_{t}$, into contributions of each worker's ability. It follows from the recursive structure of the production technology that such an inverse function for managers at higher levels depends on the manager's appraised augmenting managerial output and on all output signals for his subordinated workers down the production line.

The error term $\epsilon_{n, t}$ is an $i d d$ normal random variable with known variance $\sigma_{\epsilon}^{2}$, i.e. $\epsilon \sim N\left(0, \sigma_{\epsilon}^{2}\right) .{ }^{18}$ The firm uses the information of the signal to update its prior on $\theta_{n}$ in a Bayesian manner. It forms a new conditional expectation of ability according to a normal learning process as in Jovanovic (1979a)

1.5 Here, workers cannot engage in infuence activities as analyzed by Milgrom and Roberts (1988). They camnot affect the output signal by sabotage or by choosing the level of effort. This rules out incentive problems or signalling problems associated with career concerns. The model could be extended, however, to allow for effort choices by introducing a decision wariable effort provision in equation (7.5). 
or Harris and Holmstrom (1982). Learning about ability is only gradual. Since $\epsilon$ is drawn from the same distribution for all workers irrespective of job assignment and time, the rate of learning is the same across jobs. ${ }^{19}$

To simplify notation, I write the rules for updating in terms of the precision rather than the variance. The precision of the population distribution of ability is defined as

$$
h_{0}=\frac{1}{\sigma_{\theta}^{2}},
$$

and the precision of $\epsilon$ is given by

$$
\gamma=\frac{1}{\sigma_{\sigma}^{2}}
$$

The posterior beliefs about $\theta$ in period $t$, denoted by $\mu_{\theta}^{t}$, will be normal with precision $h_{t}$ (see DeGroot, 1970). The rules for updating beliefs, after having observed the output signal $\hat{\theta}_{n, t+1}$, are given by

$$
\begin{aligned}
\mu_{\theta}^{t+1} & =\frac{h_{t} \mu_{\theta}^{t}+\gamma \hat{\theta}_{r, t+1}}{h_{t}+\gamma} \\
h_{t+1} & =h_{t}+\gamma,
\end{aligned}
$$

The mean follows a random walk, while the precision increases deterministically. Defining the history of $\mu_{t}=\left(\mu_{\theta}^{1}, \ldots, \mu_{\theta}^{t}\right)$, it can be shown that $\mu_{\theta}^{t+1}$ and $\left[\mu_{\theta}^{t+1} \mid \mu_{t}\right]$ are normally distributed with means and variances given by

$$
\begin{aligned}
E\left[\mu_{\theta}^{t+1} \mid \mu_{t}\right] & =\mu_{\theta}^{t} \\
\operatorname{Var}\left[\mu_{\theta}^{t+1} \mid \mu_{t}\right] & =\left(h_{t} h_{t+1}\right)^{-1} .
\end{aligned}
$$

The arrival of new information can lead to discrete jumps in expected productivity of a worker and thereby perturb the productivity ranking triggering reassignment, which affects job mobility and individual careers. Assuming that there are no costs of reassignment ${ }^{20}$ and that the firm is risk-neutral, the simple dynamic assignment rule is to rank and relocate workers each period

\footnotetext{
${ }^{19}$ If signals were noisier in some levels than in others, the firm would take such differencest into account when making its assignment decision. For example, newcomers are more likely assigned to jobs with the least noisy output signal initially because learning is fastest when workers are assigned to such screening tasks.

${ }^{20}$ Frictions like reassignment costs reduce internal mobility. Under uncertainty, irreversible reassignment costs also affect the timing of job mobility, via the option value of postponing reassignment until more information accumulates.
} 
according to the updated belief about their productivity. ${ }^{21}$ The mean of the posterior distribution of ability converges to the true value of $\theta_{n}$, but the ranking of workers can never be based on true productivity, because there will always only be a finite number of productivity signals as workers leave the labor market, and hence the firm, at rate $\lambda$, which is assumed to be constant during a, career and across all levels.

\section{The Labor Market, Wages, and Worker Tumover}

The labor market is assumed to be segmented, for there are two types of firms. Primary sector firms employ the production technology described above. Secondary sector firms have no management levels. A worker in the secondary sector produces the same amount of output as he would produce on the production level of a primary sector firm. In absence of firm-specific skills, workers are equally productive at any primary sector firm for a given job level assignment.

Each period, young workers enter the labor market looking forward to a working life with an expected length of $\lambda^{-1}$. Workers always find employment in the secondary sector. But they prefer jobs in the primary sector because the prospect of becoming a manager raises their life cycle earnings potential there. ${ }^{22} \mathbb{I}$ assume that there is excess supply for primary sector jobs so that a firm can always satisfy its labor demand by recruiting from the pool of workers who do not have primary sector experience. The expected productivity of these workers is identical, because the firm receives no productivity signal unless the worker is employed in the primary sector. ${ }^{23}$

${ }^{21}$ The model framework allows to address a number of other issues that will not be the focus of this chapter. For example, if it is costly to make "mistakes", i.e costly to incur low output, the fim does not solely base its assigmment decision on expected productivity, but also trades off the variance and expectation of a worker's expected productivity. Senionity then gains importance, both because observable investments in human capital become relatively more important and because the precision of the prior on $\theta$ increases with temure. Likewise, senionity based promotions rules become more likely the nousier signals of individual productivity are, i.e. the slower firms learn.

${ }^{22} \mathrm{I}$ abstract from exit and entry decisions of frms here, and focus on internal job mobility. It should be noted that workers might decide to set up their own primary sector frm, i.e. become self-employed, after having learned that they are sufficiently able. Such learning might not require that workers have ever worked in the primary sector before. But the probability of becoming selfemployed depends on the work history in the two sectors if learning opportmities differ across sectors.

${ }^{23}$ Here it is implicitly assumed that pre-labor market education neither raises productive skills nor has signalling value, which existed if market ability was correlated realized schooling - possibly via a positive correlation between schooling ability, which raises returns to schooling and thus tends to increase realized schooling, and market ability. Belzil and Hansen (2002) find evidence for such a positive correlation. The model can be generalized 
The starting level of beginners depends on their expected productivity relative to that of incumbent workers. Newcomers without prior experience in the primary sector are likely to enter the lowest level, because the hiring firm believes that their talent equals the unconditional expectation of ability, i.e. the population mean of ability. This is likely to be lower than the ability of a worker who has been assigned to level $L_{2}$. Expected ability of the worst worker $j$ who is currently assigned to level $L_{2}$ depends on the span of control and on firm size, since the expectation of his ability $\theta_{j}$ conditional on the history of his output signals $\mu_{s_{j}}^{j}$, where the subscript $s_{j}$ numbers the output signal of worker $j$, is given by

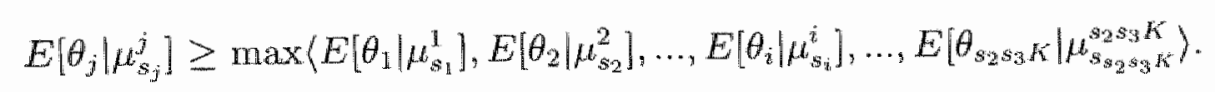

Expected ability of worker $j$ is increasing in the number of workers, $s_{2} s_{3} K$, who are assigned to the production level. ${ }^{24} \mathrm{~A}$ worker without prior experience in the primary sector is always hired into the production level $L_{1}$ if

$$
\mu_{\theta}^{0} \leq E\left[\theta_{j} \mid \mu_{s_{j}}^{j}\right], \forall j \in S_{L_{2}} .
$$

To make the analysis more tractable, I impose that condition (7.12) is always satisfied. This is justified as follows. Since jobs, even in production, are scarce, and because there are no firing costs, the firm becomes selective and fires all workers whose expected ability falls below a certain threshold value. The firm can do so because in each period there is sufficient excess supply for primary sector jobs by workers who have never worked in the primary sector. In general, expected ability of a worker retained in the lowest level exceeds $\theta^{*}$, the exact value of which is determined by the amount of excess labor supply. Normalizing the number of workers without primary sector experience to $1, \theta^{*}$ is given by

$$
\theta^{*}=\Phi^{-1}(1-d)
$$

where $\Phi$ is the cumulative distribution function of $\theta$, and $d$ denotes the amount of jobs to be filled in the primary sector as a fraction of supply of workers without prior work experience in the primary sector. The smaller $d$, i.e. the more excess supply there is, the more selective primary sector firms become and the larger is $\theta^{*}$. In the remainder of the chapter, I simply assume that $d \leq 0.5$, so that the firm dismisses all workers whose expected ability conditional on the history of output signals falls below the unconditional

to account for correlations between realized schooling and market ability.

costs that it is less likely that a new entrant is hired into higher levels of large firms. 
expectation of ability. The expected ability of the least productive retaimed worker exceeds the expected productivity of a new hire without primary sector experience. Therefore, the firm assigns workers without prior experience to the lowest level in the first period of employment.

Since all firms have the same firing strategy, dismissed production workers will never receive a primary sector job offer again, because they are believed to be less able than an average worker without primary sector experience. Consequently, they have to work in the secondary sector until their labor market career ends. It is also clear that the hazard of job separation rises initially because it takes time for sufficiently bad information to accumulate. The hazard rate then falls monotonically because low productivity workers separate early. The job separation hazard has similar properties as in Jovanovic's (1979a) matching model. While information about match quality is the driving force for separations there, it is information about worker productivity in the present model.

In order to keep the workforce constant, the firm has to hire on average $(\lambda+p) N$ workers to fill slots that become vacant because workers' labor market careers end, and because the firm dismisses production workers whose expected productivity has fallen below the threshold value; $p$ is the probability of the latter event. Instead of hiring newcomers to the primary sector, the firm could attract workers from other primary sector firms. But I assume that hiring (or poaching) costs for these workers are sufficiently large for the firm to prefer hiring inexperienced workers into the lowest level and promoting incumbent workers to vacancies at higher levels. ${ }^{25}$

Wages in the secondary sector equal the marginal product. A feasible wage schedule for primary sector firms requires wages to increase with job levels because a promotion reveals information about a worker's ability to the market when firms assign more able workers to higher levels. ${ }^{26}$ But wages of workers on the lowest level also have to rise with expected ability in order to discourage them from quitting; for they always have the option to work in the secondary labor market at an expected wage equal to their expected ability. In principle, the firm needs to pay these workers less than their expected

\footnotetext{
${ }^{25}$ Information on $\theta$ that is revealed prior to accession to the current firm, e.g. during careers with other employers, affects the hiring decision. Workers with a higher expected ability, $\mu_{\theta}^{0}$, are preferred ceteris paribus. But hiring cost are higher for more skilled labor (see Rosen, 1968 for evidence). Moreover, if workers can be fired, the firm prefers hiring risky workers whose $\sigma_{\theta}^{0}$ is larger for a given $\mu_{\theta}^{0}$ (Lazear, 1998) because of the option walue of their upside potential.

${ }^{26}$ See also Waldman (1984b) and Bernhardt (1995), who analyze the implications of asymmetric information environments for wages and promotions, for a formal derivation of this insight.
} 
marginal product to prevent turnover, because they also value the discounted value of potential career advancement in the primary sector, which is associated with higher wages. ${ }^{27}$ For simplicity, I assume here that remuneration is based on expected productivity as long as there are no rents that accrue from relationship-specific capital. ${ }^{28}$ Wages jump at promotion because the skills of a promoted worker have a bigger impact on output in the higher job level as his managerial decisions have a scale effect on production. If workers are paid according to their marginal product, wages fluctuate because the arrival of new information during the learning process can lead to discrete jumps in expected productivity. Wage determination changes, however, in the presence of relationship-specific capital. ${ }^{29}$

\subsection{A Simple Model without Human Capital Accumulation}

While the model will ultimately assume that productive skills development depends on the amount of opportunities for skill enhancement and the individual rate of skill acquisition, this section assumes that all workers have had the same fixed set of learning opportunities. This helps to disentangle the effects of employer learning about workers' innate ability from the effect of skill accumulation as different sources of career dynamics. Without productivity enhancing human capital accumulation and only one dimension of skills, productive skills of worker $n$ are given by

$$
\omega_{n}=\theta_{n}
$$

where $\theta_{n}$ measures ability of worker $n$.

\footnotetext{
${ }^{27}$ The option value declines over time as the promotion hatard declines and the time to retirement slyortens, so that wages would rise with seniority. In addition, the option value decreases with career advancement, which causes wages to jump somewhat at promotion. It also triggers differences in mean wages of adjacent job levels to increase towards the top of the hierarchy.

${ }^{28}$ If workers are paid their marginal product, they will not quit for a primary sector competitor unless they perceive their career opportunities to be better there. But as workers do not observe the ability distribution of competitors' workforces, they have no reason to quit their current employer. This might change if firms expand or contract at different rates. The analysis below suggests that upward mobility rates fall in contracting firmus, so that workers might perceive their career opportunities to be better elsewhere, aspecially at expanding firms.

${ }^{29}$ The wage policy of the firm, analyzed in the previous chapter, might, still be consistent with the model for that reason.
} 
The final good output of the $k$ th production line, in which worker $k$ has authority over workers $s_{3}$ workers $j, j \in S_{L_{2}}^{k}$ on level $L_{3}$ who in turn each control $s_{2}$ workers $i, i \in S_{L_{1}}^{j}$, on level $L_{1}$, is given by

$$
Y_{k}=G\left(\theta_{k}\right) \sum_{j \in S_{L_{2}}^{k}} F\left(\theta_{k} t_{w y},\left[g\left(\theta_{j}\right) \sum_{i \in S_{L_{1}}^{j}} f\left(\theta_{j} t_{w}, \theta_{i}\right)\right]\right) .
$$

\section{Career Mobility in a Stationary Environment}

In order to maximize output, the firm reassigns workers to job positions according to their productivity ranking in each period. Since management positions are only filled from within, the firm promotes, in each period, on average $\left[\lambda_{3}+d_{3}\right] K$ workers to level $L_{3}$ and $\lambda_{3} K+\left[\lambda_{2}+d_{2}\right] s_{3} K$ workers to level $L_{2}$, where $d_{3}$ and $d_{2}$ are the demotion rates out of $L_{3}$ and $L_{2}$ respectively. ${ }^{30}$ Since $\lambda_{3}$ and $\lambda_{2}$ are positive, the promotion rate is higher than the demotion rate. $^{31}$

A worker is demoted to a lower level if he descends sufficiently in the ranking of expected productivity. For a demotion from level $L_{3}$ to level $L_{2}$ to occur, the posterior mean of $\theta_{k}$ of the least productive worker $k$ in level $L_{3}$ must fall below the expected productivity, $E \omega_{j}$ of the $\left(\lambda_{3} K\right)+1$ 'st most productive worker $j$ in level $L_{2}{ }^{32}$ The condition for the $m$ 'th demotion from level $L_{3}$ to level $L_{2}$ entails an expected productivity comparison of the $m^{3}$ th worst ranked $L_{3}$-manager and the $\lambda_{3} K+m^{\prime}$ th ranked worker on the lower level. The conditions for demotions from level $L_{2}$ to level $L_{1}$ are analogous. Each demotion triggers another promotion, and more importantly, each additional promotion requires that workers fall behind by more and more ranks in the ranking of expected productivity.

The more volatile the productivity ranking is, the more likely are big changes in the productivity ranking to occur and the higher will promotion and demotion rates be. Hence, career mobility depends on the variability of

\footnotetext{
${ }^{30}$ In this notation, a promotion from level $L_{1}$ to level $L_{3}$ in one step accounts for two promotions: from level $L_{1}$ to level $L_{2}$ and from level $L_{2}$ to level $L_{3}$. Moreover, managers whose expected productivity falls short of expected productivity of new beginners, so that they are fired, are counted as being demoted to the production level and fired from there.

31 The promotion rate is lower in firms that hire management workers from outside. The average number of incumbent workers who are promoted to level $L_{3}$ in each period is then given by $\left[\lambda_{3}+d_{3}\right] K-N^{H_{3}}$, and only $\lambda_{3} K-N^{H H_{3}}+\left[\lambda_{2}+d_{2}\right] s_{3} K-N^{H_{2}}$ workers would be promoted to level $L_{2}$, where $N^{H_{3}}$ and $N^{H_{2}}$ count the number of workers hired from outside into $L_{3}$ and $L_{2}$ respectively.

32 Note that the highest ranked $\lambda_{3} K$ workers are promoted to level $L_{3}$ to replace the managers in the highest level who end their labor market careers.
} 
the sequence of $\mu_{\theta}^{t}$, which in turn depends on $\sigma_{\epsilon}^{2}$ and $\sigma_{\theta}^{2}$. Moreover, if firms learn fast, so that $\mu_{\theta}^{t}$ converges quickly to the true value, demotions occur less frequently. The process of information accumulation also drives changes in the promotion hazard.

Proposition 1: The hazard rate of being promoted rises initially with job tenure, but falls after having reached some maximum. The time after which this maximum is reached depends on how fast the firm learns about talent $\theta$.

Proof: Expected productivity improvements after the first year of the employment relationship for retained workers because workers are only retained if $\mu_{\theta}^{1}>\mu_{\theta}^{0}$. Since only just hired workers have lower expected ability, retained workers of a cohort that entered in year $\tau$ climb in the productivity ranking in year $\tau+1$ and become more likely to be promoted. Workers with a very positive output signal might be promoted after their first year at the firm, but typically there are still higher ranked workers in older cohorts. The most talented of them will be promoted in the next period. Workers of entry cohort $\tau$ will then climb in the productivity ranking if fewer workers overtake them in the ranking than fall behind them or leave the level because of a promotion or separation. The more able a worker of cohort $\tau$ is, the higher is the probability that his promotion chance rises. But since the most able workers of cohort $\tau$ are promoted first, fewer workers of the cohort will climb in the ranking in future years and more workers will fall behind. The promotion hazard for workers of cohort $\tau$ who have not been promoted yet starts decreasing.

As workers become more senior, changes in expected productivity shrink on average, because the conditional variance of $\mu_{\theta}^{t}$ declines with $t$ and goes to zero as $t$ approaches infinity. Job mobility rates are, therefore, smaller for workers with longer tenure. Generally, the faster workers and firms learn about the true value of $\theta$, the faster the pool of workers can be segregated into low-ability and high-ability workers and the higher are thus the chances of high-ability workers to become promoted early, while promotion perspectives of low-ability workers fall at the same time.

COROLlary 1: The faster the firm learns about a worker's talent $\theta$, the more likely are high-ability workers to be promoted early, and the less likely are low-ability workers ever promoted. 
Corollary 2: The faster the firm learns about a worker's talent $\theta$; the earlier the promotion hazard starts to decline with job tenure.

Proof: The faster the firm learns about $\theta$, the faster will expected productivity increase for workers with high true ability $\theta$ and the earlier will less talented workers fall behind in the ranking.

QED

This is consistent with empirical evidence reported by Lazear (1992) and Gibbs (1995).

\subsubsection{Corporate Expansion and Career Dynamics}

Next, I consider how internal career mobility is affected by corporate expansion that is initiated, for example, by a change in product demand, but not by a change of the production technology. ${ }^{33}$ Since the firm's technology is unaffected, the firm expands by adding new production lines.

It follows immediately from the production technology that hierarchical levels grow at the same rate, because the span of control, and thus the number of job slots at each level is fixed. The hierarchical job structure is thus stable during episodes of workforce expansion. The assumption of a fixed span of control is crucial. If the span of control of more productive workers were higher, employment in higher levels would grow relatively faster because less able managers have to be promoted on the margin during expansion.

Proposition 2: The promotion rate rises (and the demotion rate falls) in periods of employment growth. The more pronounced the expansion is, the more the promotion (demotion) rate rises (falls).

Proof: Since workers enter only in the lowest level, all vacant positions in higher levels are staffed by promoting incumbent workers. The promotion rate has to rise during an expansion because the firm has to fill additional vacancies in higher levels of new production lines. If $M$ production lines are added, the number of promotions to level $L_{3}$ rises by $M$, and the number of promotions to level $L_{2}$ by $M+s_{3} M$. Consequently, the promotion rate rises, and the increase of the promotion rate is stronger the larger $M$ is relative to K.

The demotion rate falls at the same time because a worker in a higher level needs to fall further behind in the productivity ranking, because there

33 Changes in the production function would have to be modelled explicitly. 
are now more slots in his current job level. This requires a worse output signal. The demotion rate falls because larger negative output signals are less likely due to the distributional assumptions about $\epsilon$ and $\theta$.

QED

The promotion rate would even rise if only a fixed fraction of positions that become vacant in management levels are filled by promoting incumbent workers. The rise in the promotion rate during an expansion is stronger, the larger the fraction of promoted incumbents is.

PRopostTION 3: Individual tenure-wage profiles are on average steeper in expanding firms.

Recalling that workers are paid according to their productivity which is higher on higher levels, Proposition 3 follows from the fact that workers will be promoted earlier in their careers than they otherwise would.

As the firm has to promote more workers, average ability among promotees - and hence average ability on higher job levels - tends to fall. This is because additional workers who have to be promoted to fill the extra positions in higher levels, which become vacant because of the expansion, are on average less talented than workers who would have been promoted without an expansion. The decline in average ability is stronger, the more pronounced and faster the expansion is. ${ }^{34}$ In addition, the firm has also accumulated less information about promoted workers because they tend to be promoted earlier in their careers during an expansion, so that managerial output in higher levels becomes more uncertain.

\subsubsection{Contraction}

When the firm has to lower production, e.g. because of a fall in product demand, it cuts the number of production lines. Clearly, the layoff rate will increase. Since the firm would like to retain its most productive workers, it fires workers on the production level first and then demotes managers to the lowest level. Consequently, the demotion rate rises. Wages of demoted managers lall as their marginal product falls. Note, however, that the lower wage might induce demoted workers to quit and start a new career elsewhere in the primary sector. The gain from quitting is higher, the longer the remaining

\footnotetext{
${ }^{34}$ Prescott and Visscher (1980) raise a similar point and argute that the firm growth rate is limited because the firm has to build up organization capital, which includes information accumulation of the type considered here.
} 
Led labor market career and the higher expected productivity. ${ }^{35}$ At the time, the hiring rate falls because the expected ability of workers hired 3 external labor market is lower than that of incumbent workers.

ne promotion rate decreases because fewer slots have to be filled. Exd productivity has to improve substantially for a worker to ascend the ictivity ranking. This requires a very positive output signal. Since deviations from the mean become less likely, fewer workers are prod. The hierarchical structure will be unaffected after the employment tment has been made, because the relative number of job slots in differierarchical levels is independent of the size of the organization, i.e. the yer of production lines, as the span of control at each level is fixed. ${ }^{36}$ is also noteworthy to consider what happens when the firm expects that 1 have to enlarge employment in the near future, because the kmowledge it has accumulated on the productivity of workers is lost upon separaThe implications of loss of firm-specific capital are analyzed in more it below.

\section{; Firm-Specific Capital Accumulation in the Learning Model}

his section, I show how the predictions of the simple learning model age when workers accumulate firm-specific capital on-the-job. The posity of formal firm-specific training is postponed to the next section. In section, I assume that productive skills are determined by

$$
\omega_{n}=\theta_{n} *\left[h_{f}(t)\right],
$$

sre $h_{f}$ is a non-negative function that reflects the acquisition of firmcific skills on-the-job. The specific capital accumulation function $h_{f}$ exits positive but decreasing marginal returns $\left(h_{f}^{\prime}>0\right.$ and $\left.h_{f}^{\prime \prime}<0\right)$ to firmcific tenure $t$. Workers accumulate skills faster, the more able they are.

Young workers tend to be more likely to quit in the real world because their expected laining labor market career is longer. However, this issue is not further analyzed here the simplifying assumption that remaining labor market careers last equally long fol workers independent of their age and labor market experience.

${ }^{6}$ This seems at odds with the empirical finding reported in chapter 5 at first sight. Sinc contraction considered by the model is structural and since there are no adjustment cos Cerentials across jobs, the firm jumps to the equilibrium pyramidal hierarchy structur which relative level sizes are unaffected. Asymmetric downsizing might arise when ure expansion is expected and adjustment costs, e.g. due to training investments an rning investments differ. See also section 7.5 . 
Ability determines the rate of return to a unit of firm-specific capital acquired on-the-job, and, together with the curvature properties of $h_{f}$, affects the rate at which productivity grows with each additional year of firm-specific tenure. Productivity enhancing skills acquired in one job are completely transferable to other jobs at the same firm, but are useless elsewhere in the labor market. The employment relationship, hence, generates rents, so that the wage no longer has to equal marginal product. Instead, the firm claiming a share of these rents pays a wage below the marginal product. But its wage offer must at least match that of competitors. Otherwise workers quit. Since rents can only be collected when the employment relationship is continued, the firm wants to discourage turnover in order to profit from future rents and pays a wage that is higher than the worker's expected marginal product elsewhere in the labor market, but lower than his productivity at the firm. Paying such an efficiency wage is a well-designed and credible mechanism, because of excess supply for primary sector jobs in the labor market. Paired with a monitoring system and the threat to fire workers if caught shirking, such a wage policy would also solve incentive problems if workers could choose their level of effort (see MacLeod and Malcomson, 1998).

\section{Turnover}

Under the assumption of sufficient excess labor supply for primary sector jobs, such that the firm retains only above average talented workers, inexperienced workers will always enter level $L_{1}$. But firm-specific capital reinforces this propensity to hire workers into the lowest level. If $h_{f}(0)=0$, the firm would never hire workers into level $L_{2}$ irrespective of labor supply conditions. Even if $h_{f}(0)>0$, the presence of firm-specific capital makes it less likely for a worker to be hired into level $L_{2}$; for his expected ability has to be more than $\frac{h_{f}(t)}{h_{f}(0)}$ times bigger than expected ability of the worst manager in level $L_{2}$ in order to compensate for the productivity advantage that the current. incumbent manager has after having accumulated firm-specific skills during $t$ years of tenure.

The firm tends to fire fewer production workers because firm-specific capital enhances their expected productivity relative to that of workers queuing for primary sector jobs on the labor market. Without firm-specific capital, the firm would fire worker $n$ after period 1 if

$$
E\left(\theta_{n} \mid t=1\right)=\mu_{\theta_{n}}^{1}<E(\theta)=\mu_{\theta}^{0} .
$$

With firm-specific capital, the productivity comparison of a worker employed for one year and a potential new hire alters. The potential new hire will have 
higher expected life cycle productivity if

$$
\mu_{\theta_{n}}^{1} \int_{1}^{1+\frac{1}{x}} \delta^{t-1} h_{f}(t) d t<\mu_{\theta}^{0} \int_{0}^{\frac{1}{x}} \delta^{t} h_{f}(t) d t,
$$

where $\delta$ is the discount factor.

Condition (7.17) is more likely to be satisfied, the smaller the incumbent's expected ability, $\mu_{\theta}^{\prime}$, is relative to the unconditional expectation of ability in the population, $\mu_{\theta}^{0}$. It is also more likely to be satisfied the less learning opportunities the job offers in the first period of the employment relationship because the magnitude of on-the-job skill acquisition determines an incumbent worker's productivity advantage.

Proposition 4: The more firm-specific skills can be developed early during the employment relation and the slower firms learn about ability, the lower turnover at the firm.

Proof: After having observed the output signal of a worker $n$ who has spent $s=t-\tau$ years working at the firm, the firm compares his expected ability with that of a potential new hired worker. If

$$
\mu_{\theta_{n}}^{s} \int_{s}^{s+\frac{1}{\lambda}} \delta^{t-s} h_{f}(t) d t<\mu_{\theta}^{0} \int_{0}^{\frac{1}{\lambda}} \delta^{t} h_{f}(t) d t,
$$

the firm fires worker $n$. The worker is less likely to be fired, the more learning opportunities employment at the firm offers in the first $s$ periods, because the higher the difference in potential firm-specific skill, the lower the expected ability of an incumbent has to be in order to rationalize his dismissal.

If the firm learns slowly, expected period-to-period changes in updated beliefs of worker n's ability are small. But the smaller these changes are, the longer it takes on average until the arrival of bad information has lowered the updated expectation sufficientily to trigger the worker's dismissal. Therefore, the firing rate increases with the speed of learning about ability.

The expected duration of the employment spell lengthens, and so the worker can even accumulate more firm-specific skills, which further reduces the probability of being dismissed. ${ }^{37}$

${ }^{37}$ Since slots are limited, the firm also takes into account the value of not being able to screen another worker if the incumbent worker is retained. This option value depends on the variance on the ability distribution and the variance of the conditional expectation of 


\section{Internal Mobility}

Career dynamics depend on the learning process, specific human capital accumulation, and interactions between the two.

Proposition 5: Workers are more likely to be promoted early in their careers the more talented they are. Workers who have been promoted early in their careers are likely to be promoted fast to level $L_{3}$, so that career fasttracks exist.

The productivity ranking among workers of the same cohort is solely determined by ability differences and depends on the learning process in the way described in section 7.4. The speed of learning determines how fast workers can be sorted according to their true ability, so that it affects promotion chances. Learning generates a hump-shaped promotion hazard, as has been shown above. These dynamics are reinforced by specific human capitall accumulation because on-the-job skill accumulation gives older cohorts a productivity advantage so that ability differences between workers with $t$ and $t+x$ periods of tenure have to be bigger in order for the less senior worker $n$ to become more productive than a more senior worker $m$. This is easily seen by re-arranging the condition that a less senior worker is expected to be more productive than a more senior worker:

$$
\frac{\mu_{\theta_{n}}^{t}}{\mu_{\theta_{m}}^{t+x}}>\frac{h_{f}(t+x)}{h_{f}(t)}
$$

The larger on-the-job learning opportunities for workers between period $t$ and period $t+x$ relative to past learning opportunities at time $t$, i.e. the bigger the ratio $\frac{h_{f}(t+x)}{h_{f}(t)}$, the bigger relative expected ability differences have to be in order for worker $n$ to be ranked higher than his colleague $m$ who has $x$ more years of firm-specific tenure. Since $h_{f}(t)$ reflects the marginal gain of an increase in ability, small differences in ability cause bigger differences in life cycle worker productivity the larger $h_{f}(t)$.

At the same time, more talented workers accumulate skills faster than less talented workers. A worker who is $z$ times more able than a colleague needs - because of the concavity of $h_{f}$ - less than $1 / z$ of the time to become at least as productive. Since workers with high expected productivity need

the incumbent worker, hence on the speed of learning. Furthermore, it depends on the importance of firm-specific skills in the production function, i.e. on the level of $h_{f}(t)$. Therefore, the option value of screening another worker is higher in firms with more valuable learning opportunities (i.e. with a high value of $h_{f}(t)$ ). As a result, initial screening will be more stringent there. 
e on-the-job to attain a particular productivity level, they senior, but less able, workers after a shorter period of time 1 , become more likely to be promoted early in their internal ser. Not only are promotion chances of very talented workers ining of their career, but these workers are also more likely ted a second time to level $L_{3}$ because they accumulate skills eir expected productivity rises faster. This generates serial motion and wage growth.

which firms learn about $\theta$ plays a crucial role in determining of being promoted given tenure. If firms learn slowly about. output signals are noisy, differences in seniority remain a or of expected worker productivity for a longer period. High then need on average more time until they are promoted. point, imagine that firms never learn anything about unobe. the posterior mean and variance of $\theta$ remain unchanged period. Then, talent never matters for the assignment proe ranking of workers according to expected productivity is ed by differences in seniority. Expected productivity differnembers of different cohorts decline due to the concavity of fferences remain because expected marginal productivity inaiority. As a result, promotions are only based on seniority. productivity is identical for all members of the same cohort, Idom which workers of the most senior cohort in a given level irst. In the other polar case, in which $\theta$ is revealed instantairing, the productivity ranking is always based on true ability, ility workers become more likely to be promoted early in their o Corollary 1).

i: If output of individual workers is difficult to measure, the kely to base its promotion decision on seniority.

cult to measure output, i.e. the noisier $\epsilon$ is relative to $\theta$, the d ability will converge to its true value. The distribution of starts out as a mass point on $\mu_{\theta}^{0}$ spreads out slower, so that ty differences within a cohort are smaller. This makes it less able worker of a young entry cohort overtakes an older worker ears of tenure in the productivity ranking; for condition

$$
\mu_{\theta_{n}}^{t} h_{f}(t)>\mu_{\theta_{m}}^{i+x} h_{f}(t+x)
$$

likely to be satisfied. 
For a given speed of learning, the expected time to promotion for any worker depends on the functional form of $h_{f}$. The more concave $h_{f}$, the earlier ability differences will become the dominating source of productivity differences between workers of different cohorts, as the ratio $\frac{h_{f}(t+x)}{h_{f}(t)}$ is smaller.

Internal job mobility rates are lower when productivity is partly determined by firm-specific experience, because the productivity ranking of workers is then less volatile. Acquiring skills is time consuming, so that workers of older cohorts have a productivity advantage vis a vis workers of younger cohorts, so that more positive information about the worker with the shorter employment spell has to arrive before he climbs above the more experienced worker in the productivity ranking. As a consequence, the expected time to promotion lengthens. But this means also that the prior distribution of a worker's productivity is more precise at the time of promotion, because more information about a worker's ability has arrived. Expected changes in the posterior mean from one period to the other will be smaller. Consequently, large downward adjustments of expected ability will be less likely so that demotions become rarer. ${ }^{38}$ Fewer workers have to be promoted to replace demoted workers on higher job levels. ${ }^{39}$

\section{The Impact of Employment Changes}

The results concerning the relation between promotion rates and changes in the workforce size, which were derived in the simple learning model above, remain valid: When the firm expands by adding production lines, the promotion rate rises. Workers tend to be promoted earlier during their career, so that the level of experience and ability of promoted workers - and thus managerial output in a production line - falls on average.

When the firm has to reduce employment, it bases its dismissal decision on the size of current and future expected rents accruing in individual employment relationships. The individual layoff risk is, therefore, determined by the shape of the human capital accumulation function and by individual ability; for more able workers, who accumulate skills at a faster rate, and more senior workers, who had more opportunities to acquire firm-specific skill, generate higher future rents. But the relative impact of seniority diminishes, because skills are accumulated at a decreasing rate. As a result, the firm tends to dismiss predominately workers with short tenure for two reasons. First, they have little firm-specific experience. Second, only few workers in young cohorts can compensate for that disadvantage by exceptionally high expected

\footnotetext{
38 Note also femotions occur if $\mu_{\theta}^{t}$ converges quickly to the true value of $\theta$.
}

around the time of promotion tend to decrease the probability

f a vestments in trail become clear below in section 7.6 . 
ability, because productivity beliefs that deviate much from the population mean are rare as expected ability converges only gradually to its true value.

Firing takes place in all levels. Managers with much firm-specific experience but mediocre ability are likely to be dismissed. A very able but less experienced worker, on the other hand, who is currently less productive and hence assigned to a lower level, but expected to climb the productivity ranking fast in the future, might be retained. The firing policy also depends on the firm's expectation of future firm size. If the firm expects to grow again in the future, it has to trade off the costs of hoarding labor against the costs of shedding human capital and knowledge about workers' talents. ${ }^{40}$

\subsection{Firm-Specific Training}

In this section, I consider the effect of firm-specific training on job mobility. Training is assumed to raise worker n's productive skills, which are now given by

$$
\omega_{n}=\theta_{n} * h_{f}(t, T)
$$

where $T$ is the number of units of training that casts $c_{T}$ per unit to provide. Training costs are sunk costs as the training only raises productivity at the current employer. Expected returns to training rise with the worker's ability $\theta_{n}$ and are higher in higher job levels.

The training policy of a firm involves three decisions: (1) whom to train, (2) how much training to provide, and (3) when to train. I consider two scenarios in turn. In the first, I abstract from the timing decision and assume that firms can only train workers in the first period, thus evading the complications associated with the value of the option to postpone the irreversible training investment. In the second scenario, I assume that firms can train workers during their entire careers.

\subsubsection{Training in the First Period}

Since expected ability $\mu_{\theta}^{0}$ is identical for all beginners without prior primary sector work experience, their separation rates and promotion probabilities are identical. As a result, the expected return on a training investment is the same for all members of an entry cohort, so that the firm offers the same amount of training to all workers. The firm chooses the optimal amount of

\footnotetext{
${ }^{40}$ Costs of hoarding labor include remuneration of workers who are not required to satisfy current product demand.
} 
training to balance costs and returns of the training investment. More training is provided the lower separation rates are after the first period, the more able retained workers are expected to be, the more a representative worker learns on the margin (i.e. the bigger $\frac{\delta h}{\delta T}$ ), and the higher marginal returns to productive skills $\omega$ are. ${ }^{41}$

Proposition 6: Training improves the promotion chances of more talented workers relative to those of less talented workers.

Proof: Returns to training, i.e. $\theta \frac{\delta h_{f}(t, T)}{\delta T}$, are higher - for a given level of firm-specific tenure and training - the more talented a worker is, i.e. the bigger $\theta$. Training thus raises the productivity of talented workers more, so that their productivity advantage is enlarged by training.

QED

Training reinforces the role of ability for promotion prospects. Training makes more able workers, who acquire more skills, enjoy higher returns to the initial training investment in addition to the higher returns to knowledge acquired on-the-job. Training makes them more likely to be promoted fast. The amount by which a unit of training changes relative promotion prospects depends on the specific capital accumulation function $h_{f}$ and the level of training.

\subsubsection{The Timing of Training During the Employment Relation}

Uncertainty about $\theta$ creates an option value for the firm to postpone the irreversible training investment. If training can be provided in all periods, the firm offers less training in the first period, but more in later periods. A training decision will be made based on the updated prior $\mu_{\theta}^{t}$ and its precision. The lower $\mu_{\theta}^{t}$, the smaller the optimal amount of training, so that less talented

\footnotetext{
${ }^{41}$ In this version of the model, I do not distinguish between part-time workers and fulltime workers assuming that employees work the same hours. But it is clear that the optimall amount of training for part-time workers is lower, because they spend less time working in the firm. Part-time workers will, as a consequence, have worse promotion chances at any level of ability. Moreover, since training generates more rents the longer the remaining career of a worker is, firms prefer to hire and train younger workers if their expected career is longer. Although this is typical in practice as labor market careers are censored by retirement, it is not captured by the model here due to the simplifying assumption that expected remaining career duration is identical for all workers irrespective of their age.
} 
workers will be trained less during their career. ${ }^{42}$ The smaller the precision of the updated prior, the bigger the option value of waiting. More training courses will, therefore, be postponed to later stages of a worker's career, the larger the variance of $\theta$ in the population and the slower the firm learns about workers talents, i.e. the larger the variance of $\epsilon$. As more is learned about $\theta$ over time, the option value to postpone training decreases with firm-specific tenure. The firm provides the training when this option value falls below the net return of the formal training course. ${ }^{43}$

The training decision also interacts with the assignment decision. Since ability is not observed, there is, initially, vagueness about whether and when a worker will be assigned to a higher level, so that the returns to training are uncertain. This uncertainty vanishes upon promotion. A promotion boosts returns to training and reduces the option value of postponing training. ${ }^{44}$ Therefore, training becomes more likely shortly after the promotion decision is taken.

PROPOSITION 7: Training is provided throughout a worker"s career, but it is concentrated around the time of promotion.

Proof: Training investments are spread out over a worker's career because of the option value to postpone the training investment, which stems from uncertainty about rates of return to training. Returns to training rise for promoted workers, because of the magnifying scale effect of managerial decisions. As returns to training rise, the optimal amount of training also increases, so that more training is likely to be provided upon promotion.

If training and on-the-job learning are substitutes, the firm will provide more training during an expansion for two reasons. First, more workers are promoted, so that the returns to training jump for a bigger group of workers. Second, some workers are promoted earlier than they otherwise would be. Since these workers have a lower stock of specific human capital invested in them, the marginal returns of training will be higher for given talent due to the concavity of $h_{j}$.

42If the market perceives training investments as a signal of a worker's talent, firms may deviate from such a decision rule for strategic reasons. See, for example, Prendergast (1992).

43 If the remaining expected careen duration decreases over time, returns to later training experiences fall because of the shorter anortization period of the investment. This would be taken into account.

${ }^{44}$ To the extent that returns to training amplify in higher levels, workers in higher hierarchical job positions are trained more on average. 
Firm-specific training makes demotions less likely, because it strengthens the productivity advantage of managers. A worker on lower levels, who only realizes a smaller return from an equal training investment and is on average trained less, has to excel in even higher ability to induce his promotion and the simultaneous demotion of the incumbent manager. To see this, consider two workers of the same cohort. Worker $j$ is assigned to level $L_{2}$, while worker $i$ is still on level $L_{1}$ because past output signals have been less favorable for worker $i$. Worker $j$ has received additional training so that the stock of his training investments, $T_{j}$, exceeds that of worker $i$. Suppose now that new information is revealed that pushes worker $i$ "s expected ability above that of worker $j$ 's. If there were no training, worker $i$ would be promoted to replace worker $j$, who would be demoted. But assume that worker $j$ is currently still more productive because of the additional training. The firm could provide more training to worker $i$ and promote him to replace worker $j$, but it has to take into account the lower return to the training investments in worker $j$. The firm will not train worker $i$ as long as the net returns of the investment are lower than the foregone earnings associated with the assignment of the less talented worker $j$ to the higher level. Therefore, reassignment tends to require bigger differences in ability when training is costly, and workers in higher ranks have been trained more.

\subsection{Extensions to More General Forms of Skill Accumulation}

The model can be extended by assuming more general forms of equation (7.16). As an example, assume that productive skills at the current firm $f$ are determined by

$$
\omega_{n}=\theta_{n} *\left[\beta_{f} h_{f}(t, T)+\alpha_{f} h_{g}(e)\right]+\alpha_{f} \eta_{n} h_{S}(D)
$$

where $h_{f}$ maps general skills that are accumulated with labor market experience $e$ into productive skills, $h_{S}$ measures learning opportunities associated with different schooling degrees $D$, and $\eta_{n}$ gives individual specific returns to pre-market education. Human capital accumulation technologies have decreasing marginal returns $\left(h_{f}^{\prime}>0, h_{g}^{\prime}>0, h_{S}^{\prime}>0\right.$, and $h_{g}^{\prime \prime}<0, h_{g}^{\prime \prime}<0$, $\left.h_{S}^{i t}<0\right)$. Technologies of firms might differ with respect to the importance of specific skills accumulated on the job, which is captured by $\beta_{f}$, and the extent to which general skills are relevant for the production process, captured by $\alpha_{f}$. Not all general skills raise productivity at a particular firm $f$, so that $0 \leq \alpha_{f} \leq 1$. 
New hired workers are now more likely to be assigned to higher job levels initially, because they can compensate for lower levels of firm-specific skills or lower expected ability by higher levels of general skills. This is easier, the more important general skills and the less important specific skills are at the firm. Highly educated workers and experienced workers are therefore more likely to enter management positions, especially in firms with production technologies that are intensive in general skills.

Equation (7.20) simplifies if scholastic ability $\eta$ and talent in the labor market $\theta$ are perfectly correlated. On the other hand, if $\eta$ and $\theta$ are uncorrelated, schooling is an uninformative signal of ability even if workers might have learned about their scholastic ability during school and have based their decision on additional schooling on that knowledge. The signalling value of schooling is also zero, if the schooling decision is uncorrelated with scholastic ability or if workers simply don't learn about scholastic ability even if $\eta$ and $\theta$ are correlated.

The distribution of $\alpha_{f}$ determines expected first-period output in a new match, so that it affects the wage offer distribution for a worker. Thereby, firm $f$ 's wage setting is influenced by the external labor market. Outside offers improve with experience at a given market expectation of ability because workers accumulate general skills. This requires wages to grow with experience - and hence with tenure. While outside offers to a worker represent a lower bound to the wage, the condition that the profits of the firm cannot be negative in the long run represents an upper bound. Starting wages, $W_{H}(e, D)$ are similarly set relative to the average market valuation such that the firm can attract the desired number $H$ of workers in each period.

The market price for qualities of new recruits $W_{H}(e, D, \theta)$ relative to their expected productivity at the firm determines which workers the firm hires and where they enter the firm. The relative importance of specific capital in the production technology of the firm is crucial for the hiring decision. The lower $\alpha$, i.e. the less relevant general skills are, the more likely level $L_{1}$ is to become the port of entry; for workers have to accumulate specific human capital to become sufficiently productive to be assigned to higher levels. Expected productivity differences among a cohort of just hired workers who have identical ex ante expected talent stem only from differences in schooling levels and labor market experience. But since the market values general skills, the firm has to pay a higher price for more experienced workers.

This higher price might not justify productivity differences in firms that produce with a technology that is intensive in firm-specific skills. The more important specific skills are relative to general skills in a firm's production technology, the more the firm prefers to hire young workers, who have less labor market experience. It has been argued in the literature that firms 
that invest in firm-specific skills prefer to hire younger workers because their amortization period of the investment is longer (see Hu, 2002 for an empirical assessment). Such an effect, which becomes relevant if worker's have finite careers and the future is discominted at sufficientily low rates, reinforces the result.

\subsection{Conclusion}

The chapter has developed a model of careers in organizations that is consistent with a broad pattern of evidence provided by a growing recent empirical literature. Integrating learning, human capital acquisition and job assignment have proven to be a valuable route towards a better understanding of career mobility and earnings dynamics of workers. The model emphasizes especially the scarcity of jobs on different hierarchical levels. I feel that impact of the firm's demand for different jobs has received too little attention in the theoretical literature. It is an essential element to explain promotion and turnover dynamics, especially in non-stationary corporate environments.

The main findings of the model are that internal job mobility is influenced by changes in the size of the workforce, that individual promotion hazards depend on the process according to which the firm learns about worker abilities, and that the decision to offer formal training courses as well as the timing of training provision interacts which the learning process and the need to staff vacancies in higher job levels.

In particular, the model shows that the promotion rate increases during periods of corporate expansion and falls during downsizing, while demotions occur more frequently when employment is reduced. This result is driven by the set number of relative job slots at different levels in the hierarchy and by the firm's preference to promote incumbent workers, who have developed skills and organizational knowledge by learning on-the-job. Changes in job mobility rates are stronger the more pronounced the adjustment of the workforce size is. This is important, because promotions to higher job levels are associated with sizable wage increases, so that career-earnings profiles are steeper in expanding firms. Extra promoted managers advance earlier during their career, so that they have developed fewer skills. As a consequence, the average productivity of internally promoted managers falls during corporate expansions. Output also becomes more uncertain, because the firm knows less about their innate ability as it only gradually learns about workers' talents.

Furthermore, the model demonstrates that the hazard of promotion rises initially as workers develop skills on-the-job, but starts decreasing eventually 
when the most able workers of a cohort have been promoted while the productivity of job stayers is topped by more able workers of younger cohorts. The most able workers develop productive skills fastest, climb the productivity ranking quickly, and are promoted fast from one level to the next, so that promotion fast-tracks exist. The speed at which the firm learns about the abilities of its workers shapes career dynamics and promotion policies. Firm learning and the process of firm-specific skill development by workers affects turnover and the timing of promotions.

Moreover, the model predicts that training is provided throughout a career, but is concentrated around promotion dates. Postponing training investments is valuable because the firm is initially uncertain about the rate of return to the training investment, as it depends on the rate at which workers learn. By delaying the investment untill more information about a worker's productivity is known, the firm limits the risk that the training investment has low returns. Further training investments become worthwhile at promotions because enhanced skills have a bigger impact on total output in higher job levels.

Directions in which the analysis can be extendled were mentioned. Above and beyond considering more general forms of human capital accumulation or extending the analysis to a general equilibrium framework, more progress could also be made by directing attention to other aspects of the employment relation. For example, the provision of incentives has not been considered explicitly - although paying efficiency wages should not only discourage turnover, but also encourage workers to provide adequate effort. It would be interesting to analyze, whether and how performance changes over a career when workers can choose effort levels, or how performance impacts on job mobility and earnings dynamics. The relative importance of job assignment, ability, human capital accumulation and effort provision for career advancement and wage growth should also be assessed in future work. 
Chapter 8

\section{Summary and Conclusion}


The internal organization of labor in firms differs from that in decentralized markets. Typically, an organization structure replaces the decentralized pricing system in order to coordinate the joint production of specialized workers more efficiently by avoiding various contractual problems that give rise, for example, to hold-ups or free riding and that generate transaction costs. Commonly, such an organizational structure entails that one party (the principal), that has residual control, hires the team of workers, assigns them to positions in the firm in which they are most productive, and monitors and rewards their performance. Formal rules set certain standards concerning the quantity and quality of work and define work conditions. In addition, implicit agreements, informal rules and customary law often shape employment contracts between a worker and the firm, which have to be self-enforcing, especially in the presence of specific investments.

Employment relations in internal labor markets are often long, and shape the labor market careers of many. Organizational structures and complex interactions affect careers within organizations. These complex internal workings of a firm have not been studied widely from an economic perspective in the context of a coherent framework. However, knowing what happens inside firms is essential for a better understanding of the functioning of labor markets in general, and for advancing the theory of careers in organizations in particular. This dissertation has, therefore, set out to explore the internal economics of a firm both empirically and theoretically.

The personnel data of the Dutch national aircraft manufacturer N.V. Koninklijke Vliegtuigenfabriek Fokker have been analyzed and their particularities and virtues have been taken advantage of in the empirical part of the paper (chapters $4-6$ ), both to provide new evidence on aspects of career and earnings dynamics that have been addressed using firm-level data for other firms in other contexts and to shed light on issues that have not been investigated so far. The exceptional feature that the data cover a period of workforce expansion and contraction has been exploited to augment our knowledge about differences in the functioning of an internal labor market between episodes of employment growth and downsizing. In addition, the cletailed information about the wage policy has helped us to comprehend how many patterns observed in various empirical studies - including serial correlation in wage growth, the predictive power of wage raises for job promotions, the existence of cohort effects, nominal downward wage rigidity - are generated by a formal salary system. Such knowledge is also useful to recapitulate existing empirical evidence concerning the relation between performance, promotions, and individual earnings profiles. Looking inside a single firm, evaluating personnel data econometrically, and comparing results to other studies to determine which findings are idiosyncratic and which out- 
comes apply to a broad range of internal labor market careers in different countries, industries, and periods, is necessary to crystallize a valid portrayal of the internal economics of firms.

To study the complex internal workings of a firm and their impact on individual careers inside organizations in a coherent theoretical framework, a model has been developed in chapter 7 that is consistent with the collage of evidence about the internal workings of firms emerging from the empirical findings in chapters $4-6$ as well as from related studies in the literature. This model integrates building block models of job assignment, learning, and human capital acquisition, and incorporates demand-side effects by stressing the role of scarce job slots in different hierarchical positions.

\section{Summary of the Findings}

Chapter 2 has reviewed different strands of the literature that are related to careers in organizations. The survey has shown that much theoretical progress has been made on various aspects of the organization of labor in firms, of the employment relationship, and of career dynamics. However, most models focus only on distinct features. As a consequence, they are often only consistent with a subset of empirical evidence. A single theoretical framework that is consistent with the entire pattern of evidence and stylized facts that have emerged from the empirical literature, especially from contemporary studies of personnel data sets of large firms, has not been detected. Theoretical work to develop such a comprehensive model marks one important line of research. Another challenge is to augment the still rather small set of empirical case studies based on personnel records of firms, which the literature review identifies. This is especially important to determine which results are true in general and which findings mark idiosyncrasy.

This dissertation has profited from the availability of personnel data from the Dutch national aircraft manufacturer Fokker. Chapten 3 provided some background information about the firm and about the particular economic conditions that it faced during the period from January 1987 until March 1996, for which its personnel data are available. During this period, the firm went through an expansion phase and a period of severe downsizing leading eventually to the firm's bankruptcy on March 15, 1996. The chapter showed how deteriorating global aircraft demand in the early 1990 s contributed to the economic misfortune of the firm. The data are especially valuable because they allow to investigate the impact of changes in economic conditions on various aspects of earnings dynamics and job mobility. In addition, the data are suited to study the exact timing of job change, wage change, and turnover 
because of their event history structure.

Chapter 4 took advantage of both these valuable features of the data and evaluated empirically the predictions of turnover theories. It explored differences in the pattern of separations between episodes of corporate expansion and corporate decline. The econometric technique to estimate individual hazard raties for job separation was chosen to accommodate and to take advantage of the fact that the data span a time period marked by enormous changes in economic conditions. To control for the nonstationary environment, the role of calendar time and tenure duration were reversed in a Cox proportional hazard model. The estimation results in the chapter revealed that the separation pattern changes significantly when the firm experiences a downturn.

Especially the firm's redesign of its early retirement plan had a significant and apparently nearly immediate effect on the age profile of worker separations. Workers' anticipation of the possibility to become eligible for early retirement causes strong discontinuities of separation hazards. This has at least three important implications. First, the strong impact of changes in retirement plans on separation hazards for eligible and anticipating workers has to be considered in a careful design of such personnel policies. Second, theories of worker turnover should incorporate age effects and the role of retirement adequately. Third, age effects in empirical models have to be specified with more care. The analysis showed that fitting a quadratic age effect, as is often done, may produce misleading results because of the important discontinuities.

Separation rates of blue-collar workers rise earlier during downsizing: white-collar workers are less affected early during a period of contraction, but their job separation hazard rate rises as downsizing persists. Relative hazard rates also change within the groups of blue-collar and white-collar workers. Performance evaluation scores gain importance for blue-collar workers during the downturn so that workers in the upper four deciles of the performance evaluation score distribution experience much lower separation rates. Promotions also affect worker turnover probabilities. The more frequently a blue-collar worker is promoted, the less likely he becomes to separate. This effect is stronger during expansion. The first promotion is important to lower a white-collar worker's turnover hazard during prosperous periods of the firm, but promotions do not matter in bad times. However, workers who experienced a demotion become much more likely to separate when the prospects of the firm worsen.

The empirical findings concerning the effects of firm-specific tenure, schooling, and training are largely in accordance with the implications from existing theoretical models, but no single model generates all observed patterns. For 
instance, the analysis reveals that separation rates increase with tenure in the first week of the employment relation and then start to decrease thereafter. This is consistent with turnover models in which jobs are experience goods like Jovanovic (1979a). However, this model alone cannot explain other patterns, in particular the negative dependence on age. Human capital models and search models score better in this respect, but cannot explain an initially rising hazard.

Chapter 5 focused on patterns of job mobility inside the firm, and illuminated the relationship between wages and jobs. It is important to reproduce the analyses of other studies with new data from a different firm producing in a different country and for a different product market in order wo filter out which findings about job mobility and earnings dynamics hold true in general. But beyond repetition, the unique data set allows to study how the internal organization of labor is affected during periods of expansion and contraction, and whether internal labor markets function differently for bluecollar workers and managers, or for employees in various job activities that can be distinguished.

A hierarchical organization of jobs was revealed by the analysis of job transition patterns. Workers enter the firm predominately in the lowest blue-collar and white-collar levels, but multiple ports of entry are found. New entrants are younger and have higher educational levels than incumbent. workers who are promoted to similar jobs. Promotions from within prevail and firm-specific human capital seems important. The hierarchy structure is stable when employment grows, a finding also documented by other studies of the empirical literature. While the relative size of hierarchical levels varies little during the episode of corporate expansion, job cuts are relatively stronger in lower hierarchical levels early during downsizing. Promotion rates fall and demotion rates rise when the firm enters the stage of demise. These changes in job transition rates are more severe for sub-groups of workers in jobs that are affected most by the downsizing. These latter findings are new to the empirical economic literature. The dependence relation between changes in the size of the workforce and internal job mobility has also not been addressed in theoretical models of careers in organizations.

Wage ranges within a job level allow for considerable wage growth within a job level. overlap. Yet, upward job mobility is crucial for sustained wage growth because wage ceilings in a given job level ultimately limit wage growth without job change. Only part of the average wage difference between job levels is gained immediately upon promotion as workers move predominately, but not exclusively, from the upper deciles of the lower job level's wage distribution to the lower deciles of the wage distribution in the new job level. Lateral job mobility, or job rotation, is a vital phenomenon at the firm. It 
improves promotion chances, stimulates wage growth, and reduces the lay-off risk. The chapter also finds that downward mobility almost never results in nominal wage cuts, yet it frequently coincides with degradation in wage scales and hence a reduced outlook for future wage growth. Real wage decreases: on the other hand, are common, especially during downsizing when most nominal wage contracts are not changed for more than three years.

Chapter 6 scrutinizes the wage policy of the firm in more detail and determines how it affects individual career earnings. The chapter's closer look at the formal rule structure of the firm's different salary systems helps us to better understand the sources of various empirically observed patterns and stylized facts. For example, the formal salary system generates serial correlation in wage growth because administrative rules trim down wage increases for workers in higher quartiles of a given within-job wage distribution. Moreover, the wage policy can produce cohort effects that seemingly survive controls for individual characteristics, but that result from subtle changes in the composition of jobs into which new workers are hired in different years.

The analysis shows that wage increases are more likely with higher performance evaluation for two reasons. First, improved performance always leads to a rise in the contractual wage rate. Second, better performance improves the chances to climb the wage scales and grades of the salary system faster. It also enhances the prospects of promotion to a job on a higher hierarchical level. Therefore, wage increases also forecast promotions. Wage premia at promotion are higher than typical within-job level wage raises, but they are small relative to the mean difference between wages associated with jobs on adjacent hierarchical levels. This is because workers typically move from the higher end of the previous job's wage range to the lower end of the new job's wage range.

Furthermore, the study revealed that the firm is reluctant to cut nominal wages even if a worker's contractual wage falls below his actual wage after a degradation in the salary system, which is most often initiated by a deterioration in performance. Nominal rigidity has adverse incentive effects for downgraded workers when they cannot be motivated by wage gains after an improvement in performance.

Finally, the empirical assessment of the relationship between seniority, performance, and earnings reveals that peculiarities of the formal salary system cause the effect of seniority on wages to be largely independent of controls for contemporaneous performance. The reward system defines the level of wages and annual contractual wage growth for wage scales, wage grades and performance ratings. A wage range for a given job typically covers a handful of wage scales. Workers receive an annual wage raise, the size of which depends on the performance score, until the top wage of the scale is reached. 
Thereafter, a worker only enjoys further wage growth when he is placed into a higher wage scale. Such an achievement depends on performance ratings. Wages vary with performance scores within a wage grade. But the amount of wage variation in a grade that can be attributed to differences in performance ratings is small relative to the variation caused by contractual wage experience profiles. Since it takes time to climb the firm's wage and job ladder, workers near the wage ceiling in a particular job tend to be more experienced. These experienced workers earn more than their less experienced colleagues even if their contemporaneous performance rating is worse. When controls for performance are included in standard earnings equations, the effect of seniority on wages remains largely unaffected, even if job levels are held constant. Our knowledge of the functioning of the salary system, in which job change and hence high performance is crucial for sustained life cycle earnings growth, suggests, however, that the observed relation between performance scores and earnings profiles in cross-sections merits a different interpretation than is commonly suggested in the existing literature.

Chapter 7 developed a model to advance the theory on careers in multilevel organizations. Following the modern theoretical literature on careers in organizations (e.g. Bernhardt, 1995; Demougin and Siow, 1994; and Gibbons and Waldman, 1999a), the model integrates different theoretical concepts to explain the entire collection of empirical facts about the internal workings of firms, which cannot be explained by single building block models that have been surveyed in chapter 2. Unfortunately, existing models on careers in organizations do generally not address the question of how vertical job mobility rates are affected by changes in the size of the workforce. Demougin and Siow (1994), for example, cannot study careers that involve more than one career step, while Gibbons and Waldman (1999a) do not model the internal organization of labor in firms explicitly. Their model and that of Bernhardt (1995) do not consider demand side effects but rather assume that there are abundant slots in all different jobs.

The model in chapter 7 assumes a command production technology that leads to a hierarchical organization of jobs with limited slots in different levels of the corporate hierarchy. It then explores how learning about workers' talents and the acquisition of human capital on-the-job and through formal. training courses affects individual internal job mobility, separations and earnings dynamics. The optimal allocation of workers to job positions changes during a worker's career because institutional knowledge is transferred from older generations to younger generations and skills are acquired when workers learn on the job. At the same time, the firm learns about the capabilities and talents of its workers, so that the sorting of workers to jobs becomes a dynamic process that determines job mobility and career earmings in internal 
labor markets.

The model shows that the promotion rate increases during periods of corporate expansion and falls during downsizing, while demotions occur more frequently when employment is reduced. This result is driven by the fixed number of relative job slots at different hierarchical levels and by the firm's preference to promote incumbent workers, who have developed skills and organizational knowledge by learning on-the-job. Changes in job mobility rates are stronger the more pronounced the adjustment of the workforce size. This is important, because promotions to higher job levels are associated with sizable wage increases, so that career-earnings profiles are steeper in expanding firms. Extra promoted managers advance earlier during their career, so that they have developed fewer skills. As a consequence, the average productivity of internally promoted managers falls during corporate expansions. Output also becomes more uncertain, because the firm knows less about their innate ability as it only gradually learns about workers' talents.

Furthermore, the model demonstrates that the hazard of promotion rises initially as workers develop skills on-the-job, but starts decreasing eventually when the most able workers of a cohort have been promoted and talented workers of younger cohorts top the productivity of job stayers. The most able workers develop productive skills fastest, climb the productivity ranking quickly, and are promoted fast from one level to the next, so that promotion fast-tracks exist. The speed at which the firm learns about the abilities of its workers shapes career dynamics and promotion policies. Firm learning and the process of firm-specific skill development by workers affects turnover and. the timing of promotions.

Moreover, the model predicts that training is provided throughout a career, but is concentrated around promotion dates. Postponing training investments is valuable because the firm is initially uncertain about the rate of return to the training investment, which depends on a worker's talent. By delaying the investment until more information about a worker's ability is known, the firm limits the risk that the training investment has low returns. Further training investments become worthwhile at promotions because enhanced skills have a bigger impact on total output in higher job levels.

\section{Limitations of the Study and Recommenda- tion for Further Research}

A case study analysis of worker turnover, job mobility, a firm's wage policy and its effects on individual earnings dynamics has been presented. The 
availability of a personnel data set of a firm that lives througl prosperous and diminishing periods has allowed us to assess how characteristics of worker separations change when a firm enters a downturn, how the workings of the internal labor markets differ between episodes of employment growth and decline, and how the firm adjusts its wage policy when economic conditions worsen. I believe that many of the characteristics of turnover, internal job and wage mobility, and aspects of the wage policy, all of which are documented for the special case of Fokker, are similar across large firms, so that the analysis informs us about the functioning of internal labor markets in general. In fact, many of the findings concerning the internal economics of the firm during expansion correspond to the results of different case studies. However, the work should be expanded upon by studying the issues addressed in this dissertation in other declining firms.

Apart from this, further empirical work should be done to explore issues that remain unresolved in the current study and to refine other aspects. For example, the determinants of different competing risks of worker separation including dismissal, quits, early retirement, or regular retirement should be analyzed in more depth. Particularly interesting in this context is to assess how sensitive separations for different reasons are to changes in features of retirement plans or to changes in economic conditions. In addition, further empirical work on internal job mobility, especially on the reasons for and the determinants of lateral job mobility, is warranted. A data set that would allow to pursue this goal should ideally include information about the reasons for lateral mobility as well as measures for skill requirements and skill transferability across different jobs. Another interesting aspect of internal mobility that deserves more attention is the study of vacancy chains. Here it should be assessed under what conditions internal promotions are preferred to external hiring, what determines the duration of vacancies, and when scrapping a job slot ends a vacancy chain. Further empirical and theoretical work also needs to be devoted to internal competition among different subdivisions for employees. This calls for a more thorough analysis of staffing policies in firms.

Of equal importance is the development of theoretical models of turnover and careers in organizations that are consistent with the empirical evidence including the new empirical findings of differences in turnover behavior between blue-collar and white-collar workers in good and bad times as well as the impact of employment growth and decline on internal job mobility rates. A first attempt into that direction has been made in chapter 7 . This model could be extended in numerous ways. Two extensions appear particularly interesting to me. First, the fact that different jobs require different sets of skills should be modelled. The implications of learning about latent skill 
dimensions and developing different skills for job mobility could be studied. It seems sensible to extent the model to incorporate different jobs at each hierarchical level that use and reveal different talents, in order to better understand lateral job mobility. A second main task would be to add an analysis of the provision of incentives in the model. This would not only allow to study, how the provision of effort interacts with job mobility and earnings, but would also inform us about the relative importance of different forces - learning, human capital acquisition, and motivation - on career dynamics.

Future research should be characterized by an iterative process between theory and empirical work, in which empirical findings stimulate the development of theoretical models which are then tested with new data, and so forth. Proceeding in this spirit means that the new implications of the model developed in chapter 7 concerning the relationship between the informativeness of output signals and seniority rules in promotion, or implications relating to the timing and provision of formal training should be tested using firm-level data. 
Appendix A

\section{Definition of Variables}




\section{A.1 Plant Locations}

The following table summarizes the plant locations of the six different subsidiaries. The first column defines the categories that we distinguish in the dissertation:

Table A.1: Fokrer Subsidiaries and Plant Locations

\begin{tabular}{l|l|l}
\hline Location Name & Subsidiary & Plant Locations \\
\hline FAC1 & Fokker Administration & Amsterdam \\
FAC1 & Fokker Aircraft & Schipol \\
FAC2 & Fokker Aircraft & Papendrecht/Dordrecht \\
FAC3 & Fokker Aircraft & Ypenburg \\
\hline FSS & Fokker Space and Systems & Leiden \\
ELMO & Fokker ELMO & Woensdrecht \\
FSP & Fokker Special Products & Hoogeveen \\
FAS & Fokker Aircraft Services & Woensdrecht \\
\hline
\end{tabular}

Notes: Fokker Administration is located in the city of Amsterdam. In the data, it has the same location name (FAC1) as the main assembly plant at Schipol, which is due to historical reasons. 


\section{A.2 Schooling Degrees}

Table A.2: Schooling Degreas

\begin{tabular}{l|l}
\hline Education Description & Type of Education \\
\hline lo & basic education \\
lbo & lower vocational degree \\
Ilwavo & lower general schooling degree \\
havo & apprenticeship \\
mbo & intermediate general schooling dem \\
vwo & gree \\
hbo & intermediate vocational degree \\
uni & higher general schooling degree \\
\end{tabular}

Notes: The general schooling degrees, like basic education, lower, intermediate and higher general schooling degrees are prerequisites for pursuing a given vocational or general education in the Dutch educational system. Basic education is a prerequisite for any other degree. After having completed basic education, it is possible to either follow a lower vocational schooling course or to attend any of the school forms leading to a general schooling degree. Lower general education (mavo) makes one eligible to follow intermediate vocational training or complete an apprenticeship. An intermediate general schooling degree qualifies for higher vocational schooling, a higher general schooling degree (havo) qualifies for higher vocational schooling (hbo), while the highest level general schooling degree (vwo) is a prerequisite for pursuing a college or university degree. In addition, it is possible to pursue the next higher schooling level after having obtained a given schooling degree; similarly it is possible to enter the next higher level of vocational schooling after having completed vocational schooling at the level just below, e.g. after having completed intermediate vocational schooling one is eligible to enter higher vocational schooling. 


\section{A.3 Performance Evaluations}

Table A.3: Distribution of Performance Evaluation Scores

\begin{tabular}{l|l|l}
\hline Evaluation Score & Blue-Collar Workers & White-Collar Workers \\
\hline 1 & falls behind & unsatisfactory \\
2 & unsatisfactory & satisfactory \\
3 & normal-good & good \\
4 & good-very good & very good \\
5 & very good - outstanding & outstanding \\
6 & excellent & \\
\hline
\end{tabular}

There are 6 performance evaluation categories for blue-collar workers and 5 performance evaluation categories for white-collar workers. Performance evaluation scores are given by supervisors and his supervisor and must be approved of by the human resource department. Evaluation scores are typically given once a year after evaluation talks have taken place and refer to the performance in the past year. 


\section{Bibliography}

Abraham, K. G. and Farber, H. S.: 1987, Job Duration, Seniority, and Earnings, American Economic Review 77(3), 278-297.

Akerlof, G. A.: 1970, The Market for Lemons: Quality Uncertainty and the Market Mechanism, Quarterly Journal of Economics 84(3), 488-500.

Alchian, A. A and Demsetz, H.: 1972, Production, Information Costs and Economic Organization, American Economic Review 62(5), 777-795.

Altonji, J. G. and Pierret, C. R.: 2001, Employer Learning and Statistical Discrimination, Quarterly Journal of Economics 116(1), 313-350.

Altonji, J. G. and Shakotko, R. A.: 1987, Do Wages Rise with Job Seniority?, Review of Economic Studies 54(3), 437-459.

Altonji, J. G. and Williams, N.: 1997, Do Wages Rise with Seniority? A Reassessment. NBER Working Paper no. 6010.

Ariga, K., Ohkusa, Y. and Brunello, G.: 1999, Fast Track: Is it in the Genes? The Promotion Policy of a Large Japanese Firm, Journal of Economic Behavior and Organization 38(4), 385-402.

Arrow, K. J.: 1962, The Economic Implications of Learning by Doing, Review of Economic Studies 29, 155-173.

Arrow, K. J.: 1974, The Limits of Organization, W.W. Norton, New York.

Azariadis, C.: 1975, Implicit Contracts and Unemployment Equilibria, Journal of Political Economy 83(6), 1183-1202.

Baily, M. N.: 1977, On the Theory of Layoffs and Unemployment, Econometrica 45(5), 1043-1064.

Baker, G.: 1992, Incentive Contracts and Performance Measurement, Journal of Political Economy 100(3), 598-614. 
Baker, G., Gibbs, M. and Holmstrom, B.: 1994a, The Internal Economics of the Firm: Evidence from Personnel Data Quarterly Joumal of Economics $109(4), 881-919$.

Baker, G., Gibbs, M. and Holmstrom, B.: 1994b, The Wage Policy of a Firm, Quarterly Journal of Economics 109(4), 921-955.

Becker, G. S.: 1962, Investment in Human Capital: A Theoretical Analysis, Journal of Political Ecconomy 70(5), 9-49.

Becker, G. S.: 1964, Human Capital, NBER, New York.

Becker, G. S. and Murphy, K. M.: 1992, The Division of Labor, Coordination Costs and Knowledge, Quarterly Journal of Economics 107(4), 1137 1160 .

Becker, G. S. and Stigler, G.: 1974, Law enforcement, Malfeasance and Compensation of Enforcers, Journal of Legal Studies 3(1), 1-18.

Belzil, C. and Hansen, J.: 2002, Unobserved Ability and the Return to Schooling, Econometrica 70(5), 2075-2091.

Ben-Porath, Y.: 1967, The Production of Human Capital and the Life Cycle of Earnings, Journal of Political Economy 75(4), 352-365.

Bernhardt, D.: 1995, Strategic Promotion and Compensation, Review of Economic Studies 62(2), 315-399.

Bernhardt, D. and Scoones, D.: 1993, Promotion, Turnover, and Preemptive Wage Offers, American Economic Review 83(4), 771-791.

Blanchard, O. J. and Diamond, P.: 1990, The Aggregate Matching Function, in P. Diamond (ed.), Growth/Productivity/Unemployment, MIT Press, Cambridge, MA.

Blinder, A. S. and Choi, D. H.: 1990, A Shred of Evidence on Theories of Wage Stickiness, Quarterly Journal of Economics 105(4), 1003-1015.

Bolton, P. and Dewatripont, M.: 1994, The Firm as a Communication Network, Quarterly Journal of Economics 109(4), 809-839.

Brown, J. N.: 1989, Why Do Wages Increase with Tenure? On-the-Job Training and Life-Cycle Wage Growth Observed within Firms, American Economic Revieu 79(5), 971-991. 
Brown, M., Falk, A. and Fehr, E.: 2002, Contractual Incompleteness and the Nature of Market Interactions. CEPR Working Paper No. 3272.

Bull, C.: 1987, The Existence of Self-Enforcing Implicit Contracts, Quarterly Joumal of Economics 102(1), 147-159.

Burdett, K.: 1978, A Theory of Employee Job Search and Quit Rates, American Economic Revieu 68(1), 212-220.

Burdett, K. and Mortensen, D. T.: 1998, Wage Differentials, Employer Size and Unemployment, International Economic Review 39, 257-273.

Calvo, G. A. and Wellisz, S.: 1978, Supervision, Loss of Control, and the Optimum Size of the Firm, Journal of Political Economy 86(5), 943952.

Calvo, G. A. and Wellisz, S.: 1979, Hierarchy, Ability, and Income Distribution, Journal of Political Economy 87(5), 991-1010.

Campion, Michael A., L. C. and Stevens, M. J.: 1994, Career-Related Antecedents and Outcomes of Job Rotation, Acaderry of Management Journal 37(6), 1518-1542.

Carmichael, L.: 1983, Firm Specific Human Capital and Promotion Ladders, Bell Journal of Economics 14, 251-258.

Carmichael, L.: 1989, Self-Enforcing Contracts, Shirking, and Life Cycle Incentives, Journal of Economic Perspectives 3(4),65-83.

Coase, R. H.: 1937, The Nature of the Firm, Economica 4(16), 386-405.

Davis, S. J. and Haltiwanger, J. C.: 1992, Gross Job Creation, Gross Job Destruction, and Employment Reallocation, Journal of Political Economy 107(3), 819-863.

Davis, S. J. Haitiwanger, J. C. and Schuh, S.: 1996, Job Creation and Destruction, MIT Press, Cambridge and London.

DeGroot, M. H.: 1970, Optimal Statistical Decisions, McGraw-Hill, New York.

Demougin, A. and Siow, A.: 1994, Careers in Ongoing Hierarchies, American Economic Review 84(5), 1261-1277. 
A., Knüppe, B., Leuftink, A. and Schimmelpenninck, R.: 1997, 'uptcy Trustees' Investigation of the Causes of the Bankruptcy of Koninklijke Nederlandse Vliegtuigfabriek Fokker, Fokker Aircraft and Fokker Admininstration B.V, Kluwer, Kluwer, Deventer.

P. B. and Piore, M. J.: 1971, Internal Labor Markets and Man- Analysis, Heath Lexington Books, Lexington, MA.

Г. J.: 2002, In Support of the Supporters? Do Social Forces Shape references of the Impartial? Mimeo.

T. J., Kriechel, B. and Pfann, G. A.: 2002, Monkey Bars and ers: The Importance of Job Mobility in Internal Labor Markets. $r$ prepared for the CEPR Conference on Incentives and Beyond in iholm.

M.: 1995, Aircraft Maker Fokker Faces a Bumpy Ride As Nether;, DASA Begin Bailout Talks, Wall Street Journal Europe.

I. T.: 1966, Job Vacancy Measures and Economic Analysis, in Na1. Bureau of Economic Research (ed.), The Mesurement and Interition of Job Vacancies: A Conference Report, Columbia University s, New York.

$\therefore$ Roberts, M. J. and Sarmuelson, L.: 1989, Plant Tumover and is Employment Flows in the U.S. Manufacturing Sector, Journal of or Economics $7(1), 48-71$.

n, C. and Meghir, C.: 1998, Wages, experience and seniority. IFS king Paper W99/1.

T. and Ortega, J.: December 2001, The Adoption of Job Rota: Testing the Theories. Paper presented at Universidad Publica de arra (January 25, 2002).

.J. A. and Malcomson, J. M.: 2001, Performance, Promotion, and Peter Principle, Review of Economic Studies 68, 45-66.

i. F.: 1980, Agency Problems and the Theory of the Firm, Journal olitical Economy 88, 288-307.

H. S.: 1994, The Analysis of Interfirm Worker Mobility, Journal of or Economics 12(4), 554-593. 
Farber, H. S.: 1997, Trends in Long Term Employment in the United States 1979-1996. Working Paper 384, Industrial Relations Section, Princeton University.

Farber, H. S.: 1999, Mobility and Stability: The Dynamics of Job Change in Labor Markets, in O. C. Ashenfelter and D. Card (eds), Handbook of Labor Economics, Vol. 3B, Elsevier Science, Amsterdam, The Netherlands, pp. 2439-2483.

Farber, H. S. and Gibbons, R.: 1996, Learning and Wage Dynamics, Quarterly Journal of Economics 111(4), 1007-1047.

Fehr, E., Gächter, S. and Kirchsteiger, G.: 1997, Reciprocity as a Contract Enforcement Device, Econometrica 65(4), 833-860.

Fehr, E. and Schmidt, K. M.: 1999, A Theory of Fairness, Competition and Cooperation, Quarterly Journal of Economics 114(3), 817--868.

Flabbi, L. and Ichino, A.: 2001, Productivity, Seniority and Wages: New Evidence from Personnel Data, Labour Economics 8, 359-387.

Freeman, S.: 1996, Wage Trends as Performance Displays Productive Potential: A Model and Application to Academic Early Retirement, Bell Journal of Economics 8(2), 419-443.

Garicano, L.: 2000, Hierarchies and the Organization of Knowledge in Production, Journal of Political Economy 108(5), 874-904.

Garicano, L., Palacios, I and Prendergast, C.: 2001, Favoritism Under Social Pressure. NBER Working Paper 8376.

Gautier, P. A., van den Berg, G. J., van Ours, J. C. and Ridder, G.: 1999, Separations at the Firm Level, in J. C. Haltiwanger, J. I. Lane, J. R. Spletzer, J. J. M. Theeuwes and K. R. Troske (eds), Contributions to Economic Analysis: The Creation and Analysis of Employer-Employee Matched Data, Vol. 241, Elsevier Science, Amsterdam, The Netherlands.

Gibbons, R.: 1997, Incentives and Careers in Organizations, in D. Kreps and K. Wallis (eds), Advances in Economics and Econometrics: Theory and Applications, Vol. II, Cambridge University Press, Cambridge, pp. 1-37.

Gibbons, R., Katz, L. and Lemieux, T.: 1997, Learning, Comparative Advantage, and the Inter-Industry Wage Structure. Mimeo, Université de Montreal. 
Gibbons, R and Waldman, M.: 1999, A Theory of Wage and Promotion Dynamics Inside Firms, Quarterly Joumal of Economies 114(4), 13211358.

Gibbons, R. and Waldman, M.: 1999b, Careers in Organizations: Theory and Evidence, in O. C. Ashenfelter and D. Card (eds), Handbook of Labor Economics, Vol. 3B, Elsevier Science, Amsterdam, The Netherlands, pp. 2373-2437.

Gibbs, M.: 1995, Incentive Compensation in a Corporate Hierarchy, Journal of Accounting and Economics 19(2-3), 247-277.

Gibbs, M. and Hendricks, W.: 2001, Are Formal Salary Systems a Veil? Working Paper, University of Chicago.

Grossman, S. and Hart, O.: 1986, The Cost and Benefits of Ownership: A Theory of Vertical and Lateral Integration, Journal of Political Economy 94(4), 691-719.

Grossman, S. J. and Hart, O. D.: 1983, An Analysis of the Principal-Agent Problem, Econometrica 51(1), 7-45.

Hall, R. E.: 1982, The Importance of Lifetime Jobs in the U.S. Economy, American Economic Review 72(4), 716-724.

Hall, R. E. and Lazear, E. P.: 1984, The Excess Sensitivity of Layoffs and Quits to Demand, Journal of Labor Economics 2(2), 223-257.

Hamermesh, D. S. and Pfann, G. A.: 1996, Adjustment Costs in Factor Demand, Journal of Economic Literature 34(3), 1264-1292.

Harris, M. and Holmstrom, B.: 1982, A Theory of Wage Dynamics, Review of Economic Studies 49(3), 315-333.

Hart, O, and Holmstrom, B.: 1987, The Theory of Contracts, in T. F. Bewley (ed.), Aduances in Economic Theory, Fifth World Congress, Cambridge University Press, Cambridge, UK, pp. 71-155.

Hart, O. and Moore, J.: 1990, Property Rights and the Nature of the Firm, Journal of Political Economy 98(6), 1119-1157.

Hashimoto, M.: 1981, Firm-Specific Human Capital as a Shared Investment, American Economic Review 71(3), 475-482. 
Hayek, F. A. v.: 1945, The Use of Knowledge in Society, American Economic Review 35(4), 519-530.

Holmstrom, B.: 1979, Moral Hazard and Observability, Bell Journal of Economics 10(1), 74-91.

Holmstrom, B.: 1982, Moral Hazard in Teams, Bell Journal of Economics $13(2), 324-340$.

Holmstrom, B.: 1982b, Mangerial Incentive Problems: A Dynamic Perspective, Essays in Economics and Management in Horour of Lar's Wahlbeck, Swedish School of Economics, Helsinki, Finland.

Holmstrom, B. and Milgrom, P.: 1991, Multitask Principcal Agent Analyses: Incentive Contracts, Asset Ownership and Job Design., Journal of Law, Economics and Organization 7(1), 24-52.

Holmstrom, B. and Milgrom, P.: 1994, The Firm as an Incentive System, American Economic Review 84(4), 972-991.

Holmstrom, B. and Roberts, J.: 1998, The Boundaries of the Firm Revisited, Journal of Economic Perspectives 12(1), 73-94.

Holmstrom, B. and Tirole, J.: 1989, The Theory of the Firm, in R. Schmalensee and R. Willig (eds), Handbook of Industrial Organization, Vol. 1, North-Holland, Amsterdam, pp. 60-133.

Hu, L.: 2002, The Hiring Decisions and Compensation Structures of Large Firms. Working Paper, Northwestern University, Evanston, forthcoming in: Industrial 8 Labor Relations Review.

Imbens, G. W.: 1994, Transition Models in a Non-Stationary Environment, Review of Economics and Statistics 76(4), 703-720.

Johnson, W.: 1978, A Theory of Job Shopping, Quarterly Journal of Economics 92(2), 261-278.

Jovanovic, B.: 1979a, Job Matching and the Theory of Turnover, Journal of Political Economy 87(5), 972-990.

Jovanovic, B.: 1979b, Firm-specific Capital and Turnover, Journal of Polatical Economy 87(6), 1246-1260.

Jovanovic, B. and Nyarko, Y.: 1997, Stepping-Stone Mobility, CarnegieRochester Conference Series on Public Policy 46, 289-325. 
Kahn, C. and Huberman, G.: 1988, Two-Sided Uncertainty and Up-or-Out Contracts, Joumal of Labor Economics 6(4), 423-444.

Kaldor, N.: 1934, The Equilibrium of the Firm, Economic Journal $44(173), 60-76$.

Kanter, R. M.: 1977, Men and Women of the Corporation, Basic, New York.

Keane, M. P. and Wolpin, K. I.: 1997, The Career Decisions of Young Men, Journal of Political Economy 105(3), 473-522.

Keren, M. and Levhari, D.: 1979, The Optimum Span of Control in a Pure Hierarchy, Management Science 25, 1162-1172.

Keren, M. and Levhari, D.: 1983, The Internal Organization of the Firm and the Shape of Average Costs, Bell Journal of Economics 14(2), 474-486.

Kerr, C.: 1954, The Balkanization of Labor Markets, in E. Wight Bakke, P. Hauser, G. Salwer, C. Myers, D. Yolker and C. Kerr (eds), Readings in Labor Economics, MIT Press, Cambridge MA, pp. 92-110.

Klein, B., Crawford, R. and Alchian, A. A.: 1978, Vertical Integration, Appropriable Rents, and the Competitive Contracting Process, Journal of Law and Economics 21(2), 297-326.

Kreps, D.: 1990, Corporate Culture and Economic Theory, in J. Alt and K. Shepsle (eds), Perspectives on Positive Political Economy, Cambridge University Press, Cambridge MA, pp. 90-143.

Kuhn, P. J.: 1988, A Nonuniform-Pricing Model of Union Wages and Employment, Journal of Political Economy 96(3), 473-508.

Kuhn, P. J. and Roberts, J.: 1989, Seniority and Distribution in a TwoWorker Trade Union, Quarterly Journal of Economics 104(3), 485-508.

Kwon, I.: 2001, Incentives, Wages, and Promotions: Theory and Evidence. Working Paper, Department of Economics, University of Michigan.

Lazear, E. P.: 1979, Why is There Mandatory Retirement?, Journal of Political Economy 87(6), 1261-1284.

Lazear, E. P.: 1992, The Job as a Concept, in W. Bruns (ed.), Performance Evaluation and Incentives, Harvard Business School Press, Boston, pp. 183-215. 
Lazear, E. P.: 1995a, Personnel Economics, MTT Press, Cambridge, MA.

Lazear, E. P.: 1995b, A Jobs-Based Analysis of Labor Markets, American Economic Review 85(2), 260-265.

Lazear, E. P.: 1998, Hiring Risky Workers, in I. Ohashi and T. Tachibanaki (eds), Internal Labour Markets, Incentives and Employmnet, MacMillan Press, London, U.K., pp. 143-158.

Lazear, E. P. and Rosen, S.: 1981, Rank-Order Tournaments as Optimum Labor Contracts, Journal of Political Economy 89(5), 841-864.

Levhari, D. and Weiss, Y.: 1974, The Effect of Risk on the Investment in Human Capital, American Economic Review 64(6), 950-963.

Lillard, L. and Weiss, Y.: 1979, Components of Variation in Panel Earnings Data: American Scientists 1960-70, Econometrica 47(2), 437-454.

Lima, F.: 2000, Internal Labor Markets: A Case Study from an Institutional Survey. Working Paper, Universidada Nova Lisboa.

Lin, M.-J.: 2002, Opening the Black Box - the Internal Labor Markets of Company X. Working Paper, Essay Two (Thesis Core), University of Chicago.

Lucas, R. E.: 1978, On the Size Distribution of Business Firms, Bell Journal of Economics 9(2), 508-523.

MacLeod, W. and Malcomson, J.: 1989, Implicit Contracts, Incentive Compatability, and Involuntary Unemployment, Econometrica 57(2), 447480.

MacLeod, W. and Malcomson, J.; 1993a, Investment, Holdups, and the Form of Market Contracts, American Economic Review 83(4), 811-837.

MacLeod, W. and Malcomson, J.: 1993b, Wage Premiums and Profit Maximization in Efficiency Wage Models, European Economic Review 37(6), 1223-1249.

MacLeod, W. and Malcomson, J.: 1998, Motivation and Markets, American Economic Review 88(3), 388-411.

Malcomson, J. M.: 1997, Contracts, Hold-Up, and Labor Markets, Journal of Economic Literature 35(4), 1916-1957. 
Mas-Colell, A., Whinston, M. D. and Green, J. R.: 1995, Microeconomic Theory, Oxford University Press, New York.

McCue, K.: 1996, Promotion and Wage Growth, Journal of Labor Economics 14(2), 175-209.

McLaughlin, K. J.: 1991, A Theory of Quits and Layoffs with Efficient Turnover, Journal of Political Economy 99(1), 1-29.

Medoff, J. L. and Abraham, K. G.: 1980, Experience, Performance, and Earnings, Quarterly Journal of Economics 95(4), 703-736.

Medoff, J. L. and Abraham, K. G.: 1991, Are Those Paid More Really More Productive? The Case of Experience, Journal of Human Resources 26(2), 186-216.

Meyer, M. A.: 1992, Biased Contests and Moral Hazard: Implications for Career Profiles, Annales d'Economie et de Statistique 25/26, 145-187.

Meyer, M. A.: 1994, The Dynamics of Learning with Team Production: Implicatios for Task Assignment, Quarterly Journal of Economics 109(4), 1157-1184.

Milgrom, P. and Roberts, J.: 1988, An Economic Approach to Influence Activities in Organizations, American Joumal of Sociology 94(Supplement), S154-S179.

Milkovich, G. T. and Newman, J. M.: 1999, Compensation, 6th edn, McGraw-Hill.

Miller, R.: 1984, Job Matching and Occupational Choice, Journal of Political Economy 92(6), 1086-1120.

Mincer, J.: 1958, Investment in Human Capital and the Personal Income Distribution, Journal of Political Economy 70(5), 50-79.

Mincer, J.: 1962, On-the-Job Training: Costs, Returns and Some Implications, Journal of Political Economy 66(4), 281-302.

Mincer, J.: 1974, Schooling, Experience, and Earnings, National Bureau of Economic Research, New York.

Mirrlees, J. A.: 1971, An Exploration in the Theory of Optimum Income Taxation, Review of Economic Studies 38(114), 175-208. 
Mirrlees, J. A.: 1976, The Optimal Structure of Incentives and Authority within an Organization, Bell Journal of Economics 7(1), 105-131.

Moldovanu, B. and Sela, A.: 2001, The Optimal Allocation of Prices in Contests, American Economic Revieu 91(3), 542-558.

Mortensen, D. T.: 1978, Specific Capital and Labor Turnover, Bell Joumal of Economics $9(2), 572-586$.

Mortensen, D. T.: 1988, Wages, Separation, and Job Tenure: On-the-Job Specific Training or Matching, Joumal of Labor Economics 6(4), 445471.

Mortensen, D. T. and Pissarides, C. A.: 1994, Job Creation and Job Destruction in the Theory of Unemployment, Review of Economic Studies $61(3), 397-415$.

Murnane, R., Levy, F. and Willett, J.: 1995, The Growing Importance of Cognitive Skills in Wage Determination. NBER Working Paper no. 5076.

Neal, D. A.: 1999, The Complexity of Job Mobility Among Young Men, Journal of Labor Economics 17(2), 237-261.

Oi, W. Y.: 1962, Labor as a Quasi-Fixed Factor, Journal of Political Economy $70(6), 538-555$.

Ortega, J.: 2001, Job Rotation as a Learning Mechanism, Management Science $47(10), 1361-1370$.

Osterman, P.: 1979, Sex Discrimination in Professional Employment: A Case Study, Industrial and Labor Relations Review 32(4), $451-464$.

Pencavel, J. H.: 1972, Wage, Specific Training and Labor Turnover in U.S. Manufacturing Industries, International Economic Review 13(1), 53-64.

Peter, L. and Hull, R.: 1969, The Peter Principle: Why Things Always Go Wrong, Morrow, New York.

Pfanm, G. A.: 2001, Options to Quit, Economics Letters 70(2), 259-265.

Pinfield, L. T.: 1995, The Operation of Internal Labor Markets, Plenum Press, New York.

Pissarides, C. A.: 2000, Equilibrium Unemployment Theory, 2 edn, MIT Press, Cambridge and London. 
Prendergast, C.: 1992, Career Development and Specific Human Capital Collection, Journal of the Japanese and International Economies 6(3), 207227.

Prendergast, C.: 1993a, The Role of Promotion in Inducing Specific Human Capital Acquisition, Quarterly Journal of Economics 108(2), 523-534.

Prendergast, C.: 1993b, A Theory of "Yes Men", American Economic Review $83(4), 757-770$.

Prendergast, C.: 1999, The Provision of Incentives in Firms, Journal of Economic Literature 37(1), 7-63.

Prendergast, C.: 2002, The Tenuous Trade-off Between Risk and Incentives, Journal of Political Economy 110(5), 1071-1102.

Prendergast, C. and Topel, R.: 1996, Favoritism in Organizations, Journal of Political Economy 104(5), 958-978.

Prescott, E. C. and Visscher, M.: 1980, Organization Capital, Journal of Political Economy 88(3), 446-461.

Robinson, A.: 1934, The Problem of Management and the Size of Firms, Economic Journal 44(174), 242-257.

Rosen, S.: 1968, Short-Run Employment Variation on Class-I Railroads in the U.S., Econometrica 36(3), 511-529.

Rosen, S.: 1972, Learning and Experience in the Labor Market, Journal of Human Resources 7(3), 326-342.

Rosen, S.: 1982, Authority, Control, and the Distribution of Earnings, Bell Joumal of Economics 13(2), 311-323.

Rosen, S.: 1986, Prizes and Incentives in Elimination Tournaments, American Economic Review 76(4), 701-715.

Rosen, S.: 1988, Transaction Costs and Internal Labor Markets, Journal of Law, Economics, and Organization 4(1), 49-64.

Rosenbaum, J. E.: 1979, Organizational Career Mobility, Promotion Chances in a Corporation During Periods of Growth and Contraction, American Journal of Sociology 85(1), 21-48.

Rosenbaum, J. E.: 1984, Career Mobility in a Corporate Hierarchy, Academic Press, London. 
Ross, S. A.: 1973, The Economic Theory of Agency: The Principal's Problem, American Economic Review 63(2), 134-139.

Roy, A. D.: 1951, Some Thoughts on the Distribution of Earnings, Oxford Economic Papers (New Series) 3, 135-146.

Salop, J. and Salop, S.: 1976, Self-Selection and Turnover in the Labor Market, Quarterly Journal of Economics 90(4), 619-627.

Sattinger, M.: 1975, Comparative Advantage and the Distribution of Earnings and Abilities, Econometrica 43(3), 455-468.

Sattinger, M.: 1993, Assignment Models of the Distribution of Earnings, Joumal of Economic Literature 31(2), 831-880.

Schultz, T. W.: 1960, Capital Formation by Education, Journal of Political Economy 68(6), 571-583.

Schultz, T. W.: 1961, Investment in Human Capital, American Economic Review 51(1), 1-17.

Schultz, T. W.: 1963, The Economic Value of Education, Columbia University Press, New York.

Seltzer, A. and Merrett, D.: 2000, Personnel Policies at the Union Bank of Australia: Evidence form the 1888-1900 Entry Cohorts, Journal of Labor Economics 18(4), 573-613.

Shapiro, C. and Stiglitz, J. E.: 1984, Equilibrium Unemployment as a Worker Discipline Device, American Economic Review 74(3), 433-444.

Shavell, S.: 1979, Risk Sharing and Incentives in the Principal and Agent Relationship, Bell Joumal of Economics 10(1), 55-73.

Sicherman, N. and Galor, O.: 1990, A Theory of Career Mobility, Journal of Political Economy 98(1), 145-176.

Simon, H. A.: 1951, A Formal Theory of the Employment Relationship, Econometrica 19(3), 293-305.

Simon, H. A.: 1957, The Compensation of Executives, Sociometry 20(1), 32 35 .

Smith, A.: 1976, An Inquiry into the Nature and Causes of the Wealth of Nations, Oxford University Press. 
Spence, A. M.: 1973, Job Market Signaling, Quarterly Journal of Economics $87(3), 355-374$.

Spence, A. M.: 1974, Market Signalling: Information Transfer in Hiring and Related Processes, Harvard University Press, Cambridge, MA.

Spence, M. M. and Zeckhauser, R.: 1971, Insurance, Information and Individual Action, American Economic Review 61(2), 380-387.

Spilerman, S.: 1977, Careers, Labor Market Structure, and Socioeconomic Achievement, American Journal of Sociology 83, 551-593.

Stock, J. H. and Wise, D. A.: 1990, Pensions, the Option Value of Work, and Retirement, Econometrica 58(5), 131-159.

Teulings, C. and Hartog, J.: 1998, Corporatism or Competition?, Cambridge University Press, Cambridge.

Teulings, C. N.: 1995, The Wage Distribution in a Model of the Assignment of Skills to Jobs, Journal of Political Economy 103(2), 280-315.

Tirole, J.: 1988, The Theory of Industrial Organization, The MIT Press, Cambridge, MA.

Topel, R. H.: 1991, Specific Capital, Mobility, and Wages: Wages Rise with Job Seniority, Journal of Political Economy 99(1), 145-176.

Treble, J., Barmby, T., Bridges, S. and van Gameren, E.: 2001, The Internal Economics of The Firm: Further Evidence From Personnel Data, Labour Economics 8(5), 531-552.

van Gamesen, E. and Lindeboom, M.: 2000, Promotion Probabilities vs. Exits. mimeo, Vrije Universiteit Amsterdam.

Van Veen, K. 1997, Inside an Internal Labor Market: Formal Rules, Flexibility and Career Lines in a Dutch Manufacturing Company, Thesis Publishers, Amsterdarn. Dissertation, University of Groningen.

Waldman, M.: 1984b, Job Assignments, Signalling, and Efficiency, Rand Journal of Economics 15(2), 255-267.

Wallace, T. D. and Ihnen, L. A.: 1975, Full-Time Schooling in Life-Cycle Models of Human Capital Accumulation, Journal of Political Economy $83(1), 137-155$. 
Weiss, Y.: 1972, On the Optimal Lifetime Pattern of Labor Supply, Economic Journal 82(328), 1293-1315.

Weiss, Y.: 1986, The Determinants of Life Cycle Earnings, in O. C. Ashenfelter and R. Layard (eds), Handbook of Labor Economics, Vol. 1, NorthHolland, Amsterdam, The Netherlands, pp. 603-640.

White, H.: 1970, Chains of Opportunity: System Models of Mobility in Organizations, Harvard University Press, Cambridge, MA.

Whyte, W.: 1956, The Organization Man, Simon \& Schuster, New York.

Williamson, O. E.: 1967, Hierarchal Control and Optimum Firm Size, Journal of Political Economy 75(2), 123-138.

Williamson, O. E.: 1975, Markets and Hierarchies: Analysis and Anti-Trust Implications, Free Press, New York.

Williamson, O. E.: 1979, Transaction-Cost Economics: The Governance of Contractual Relations, Journal of Law and Economics 22(2), 233-261.

Williamson, O. E.: 1985, The Economic Institutions of Capitalism: Firm, Markets, Relational Contracting, Free Press, New York.

Williamson, O. E., Wachter, M. L. and Harris, J. E.: 1975, Understanding the Employment Relation: The Analysis of Idiosyncratic Exchange, Bell Journal of Economics 6(1), 250-278. 
Summary in Dutch 


\section{Nederlandse Samenvatting}

De interne organisatie van arbeid in bedrijven is anders dan in gedecentraliseerde markten; een organisatiestructuur vervangt het gedecentraliseerde prijssysteem om de gezamenlijke productie van gespecialiseerde arbeidskrachten efficiënter te cordineren. Hierdoor kunnen verschillende contractuele problemen, zoals "hold-up" of "free-riding" die tot transactiekosten leiden, vermeden worden. Deze organisatiestructuur omvat normaalgesproken een principaal. Hij controleert, neemt werknemerteams in dienst, en plaatst deze op posities met de hoogste productiviteit binnen het bedrijf. De principaal controleert en beloont de prestaties van de werknemers, waarbij formele regels de standaard bepalen van kwantiteit en kwaliteit van het werk en de werkomstandigheden. Verder geven impliciete afspraken, informele overeenkomsten en gewoonterecht vaak vorm aan werkovereenkomsten tussen werknemers en het bedrijf. Deze overeenkomsten moeten self-enforcing zijn, zeker bij de aanwezigheid van specifieke investeringen.

Arbeidsrelaties in interne arbeidsmarkten zijn vaak langdurig en bepalen voor veel mensen hun arbeidsmarktcarrière. Organisatiestructuren en complexe interacties zijn bepalend voor carrières binnen een organisatie. Deze complexe wisselwerking binnen een bedrijf is tot op heden slechts incidenteel onderwerp geweest van intensieve studie op basis van een coherent economisch perspectief. Voor een beter begrip van de arbeidsmarkten in het algemeen en van carrières binnen organisaties in het bijzonder, is het essentieel te weten wat binnen een bedrijf gebeurt. Dit proefschrift onderzoekt daarom theoretisch en empirisch de interene arbeidsmarkten van een bedrijf.

Hiervoor werden de personeeldata van de Nederlandse vliegtuigfabrikant N.V. Koninklijke Vliegtuigenfabriek Fokker geanalyseerd. De specifieke eigenschappen en voordelen van de data werden gebruikt in het empirische gedeelte van dit proefschrift (hoofdstukken 4-6), om onderwerpen te onderzoeken die tot nu toe nog niet onderzocht zijn. Het bijzondere van de data is, dat deze zowel een periode van krimp als van uitbreiding bevatten. Dit aspect wordt gebruikt, om onze empirische kennis van interne in periodes van groei en reorganisaties te verdiepen. Verder geeft hoofdstuk 6 een uitgebreide analyse van loondeterminatie binnen een bedrijf weer. Dit helpt ons de uitkomsten van andere empirische studies te begrijpen en institutionele loonsystemen te verklaren: seriële correlatie in loongroei en het voorspellende karakter van loonstijgingen op job promoties, het bestaan van cohort effecten, nominale neerwaartse loonrigiditeit. Deze kennis is ook nuttig om bestaande empirische vindingen van de relatie tussen prestaties, promoties en individuele loonprofielen te verklaren.

Door én bedrijf te bestuderen, de personeeldata econometrisch te anal- 
yseren en de resultaten met andere studies te vergelijken - om te bepalen welke uitkomsten specifiek voor het bedrijf, en welke uitkomsten algemeen geldig zijn, over verschillende landen, industrietakken en tijdsperioden - is noodzakelijk om tot een goede beschrijving van de interne economieën van bedrijven te komen.

In hoofdstuk 7 is een model ontwikkeld om in een coherente setting de complexe werking van een bedrijf een zijn invloed op individuele carrières binnen cle organisatie te onderzoeken. Dit model is consistent met de collage van resultaten over de interne werking van bedrijven. Deze resultaten zij af te leiden uit de verschillende empirische onderzoeken, die te vinden zijn in hoofdstukken $4-6$ en in verwante studies.

In hoofdstuk 2 zijn literatuurstromingen over carrières binnen organisaties samengevat. Deze samenvatting geeft aan dat er veel theoretisch vooruitgang is geboekt met betrekking tot verschillende aspecten van de organisatie van arbeid in bedrijven, de arbeidsverhoudingen, en van carrièreloopbanen. De meeste modellen belichten slechts één deelaspect. Dit betekent dat deze modellen slechts gedeeltelijk met de empirische bevindingen overeenkomen. Een alomvattend theoretisch model dat de empirische data - vooral de recente vindingen op basis van personeeldata - kan verklaren, bestaat nog niet. Theoretisch onderzoek om een dergelijk model te ontwikkelen is daarom van belang. Een andere uitdaging is het toevoegen van empirisch resultaten gebaseerd op personeelsdata om de weinige empirische studies met bedrijvendata uit te breiden.

Hoofdstuk 3 geeft enige achtergrondinformatie over de personeelsdata van vliegtuigbouwer Fokker en de economische omstandigheden van het bedrijf in de periode januari 1987 tot maart 1996; de tijdsperiode waarvoor personeelsdata beschikbaar waren. In deze periode kende het bedrijf een periode van groei en krimp, die uiteindelijk tot het faillissement op 15 maart 1996 leiclde. In dit hoofdstuk wordt aangetoond dat wegvallende vraag in het begin van de jaren 90 aan de economische malaise van het bedrijf heeft bijgedragen. De data zijn in het bijzonder waardevol omdat zij de onderzoeker in staat stellen de invloed van economische omgevingsvariabelen op verschillende aspecten van loondynamiek en baanmobiliteit in een bedrijf te belichten. Gezien hun structuur laten de data een studie van exacte tijdstippen van baanveranderingen en loonverandering binnen het bedrijf toe.

Hoofdstuk 4 maakt gebruik van deze elementen van de data. Er wordt een empirische toetsing van de theoretische predictie van modellen van baanverloop doorgevoerd. Onderzocht worden de verschillende patronen van separatie van werknemers tussen de episodes van expansie en krimp. De econometrische techniek om de individuele hazard te schatten wan het beëjndigen van werk is gekozen om gebruik te maken van het feit dat de data een 
bepaalde tijd bestrijken waarin enorme veranderingen in de economische omstandigheden zich voordeden. Om in een niet-stationaire omgeving te kunnen schatten en te controleren werd de rol van kalendertijd en de duur van banen omgedraaid in een "Cox proportional-hazard" model. De regressieresultaten in het hoofdstuk tonen aan dat de separatiepatronen significant veranderen in tijden van economische malaise in een bedrijf.

De veranderingen in de regelingen voor vervroegd pensioen hadden significante en directe effecten op de leeftijdsprofiel van arbeidsseparatie. Werknemers anticiperen op de mogelijkheid om voor vervroegd pensioensregeling in aanmerking te komen. Dit voert tot sterke discontinuiteit van de separatiehazard. Dit heeft drie belangrijke implicaties: Ten eerste moet het sterke effect van een verandering in pensioensplamnen op separatie-hazards van werknemers in ogenschouw worden genomen bij het ontwikkelen een dergelijk personeelsbeleid. Ten tweede moeten theorieën van werknemerverloop ook leeftijdseffecten en de rol van pensionering incorporeren. Ten derde vergen leeftijdseffecten in empirische modellen bijzondere aandacht. Het gebruik van kwadratische leeftijdseffecten - zoals gebruikelijk in de literatuur - geeft misleidencle resultaten door het discontinue karakter van leeftijd.

Verloop van productiewerkers stijgt erder tijdens downsizing's; het banenverloop van hoger personeel wordt minder beinvloed in het begin van een herstructureringsfase. Wanneer deze echter langer aanhoudt, stijgen ook hun verloopcijfers. De relatieve hazard ratio's veranderen ook binnen de groep van productiemedewerkers of hoger personeel. Evaluatie scores worden in herstructureringsperiodes van groot belang voor productiemedewerkers. Werknemers in de top vier decielen van de distributie vertonen duidelijk lagere verloopkansen. Tevens zijn promoties van invloed op verloopkansen. Hoe vaker een productiemedewerker in het verleden bevorderd werd, hoe kleiner zijn de verloopkansen. Dit effect is sterker in tijden van expansie. De eerste promotie is belangrijk voor de kans op banenverloop bij hoger personee] in expansietijden van de onderneming. Zij heeft geen invloed in tijden van krimp. Werknemers die degradeert werden, hebben een grotere kans op verloop in slechte tijden.

De empirische resultaten m.b.t. de effecten van bedrijfsspecifieke kennis, scholing en training komen overeen met de theoretische implicaties van bestaande modellen. Er is echter geen bestaand theoretisch model dat alle geobserveerde resultaten voorspelt. De analyse laat bijvoorbeeld zien dat het banenverloop met senioriteit in de eerste week van een contract groeit en vervolgens weer afneemt. Dit komt overeen met modellen waarin banen ervaringsgoederen zijn (Jovanovic, 1979a). Maar dit model alleen kan de andere bevindingen, met name de negatieve invloed van leeftijd op banernverloop, niet verklaren. Menselijk kapitaal- en zoekmodellen daarentegen, 
kunnen dit element wel verklaren. Ze verklaren alleen niet de initieel hogere en vervolgens lagere kans op baanverloop van de senioriteits-variabel.

Hoofdstuk 5 concentreert zich op de baanmobiliteit binnen het bedrijf. Het onderzoekt de relatie van lonen en posities in het bedrijf en is belangrijk om ook analyses van andere, eerdere studies te reproduceren. Met deze nieuwe data van een ander bedrijf, uit een ander land en in een andere industrie, kunnen de bevindingen van baanmobiliteit gegeneraliseerd en bevestigd worden. Behalve reproductie laat het unieke karakter van de data een analyse toe van de invloed van groei en krimp op de interne arbeidsmarkten. Ook is het mogelijk de interne werkingen voor zowel productie als ook hoger personeel te vergelijken.

Het wordt een hiërarchische ordening van posities door middel van werknemertransities geidentificeerd. Werknemers beginnen meestal op het laagste niveau van de productiehiërarchie, ofwel de hiërarchie van het hoger personeel. Toch bestaan er ook werknemers die op een ander punt binnen de hiërarchie de onderneming binnentreden. Nieuwe werkmemers zijn jonger en hoger opgeleid dan werknemers die naar een soortgelijke functie binnen de onderneming gepromoveerd worden. Uit het feit dat promoties binnen interne organisaties overheersen, blijkt dat het bedrijfsspecifiek menselijk kapitaal belangrijk is. Dat de hiërarchische structuur stabiel is in tijden van groei, is een gegeven dat eerder ook door andere studies werd aangetoond. Daarentegen wordt in tijden van krimp meer dan proportioneel op lager niveau gereorganiseerd. Promotiekansen nemen af en het aantal degradaties neemt toe in tijclen van krimp. Deze veranderingen in de baanmobiliteit zijn met name te zien in posities die vooral getroffen worden door de inkrimping. Deze laatste inzichten zijn nieuw in de literatuur. De interrelatie van inkrimping en interne baanmobiliteit van werknemers zijn nog niet theoretisch gemodelleerd.

De loondistributie van een functie laat loongroei binmen een functie toe. Ook overlappen loondistributies van opeenvolgende hiërarchische posities. Toch is opwaartse mobiliteit cruciaal voor lang aanhoudende loongroei, omdat de loongroei binnen een functie beperkt is bij de bovengrens van de functiespecifieke loondistributie. Slechts een gedeelte van het gemiddelde verschil tussen de loondistributie van de initiële positie en de hogere nieuwe positie wordt bij de promotie vergoed. Werknemers promoveren van de hogere gedeeltes van een loondistributie naar een lager gedeelte in de nieuwe loondistributie. Laterale baanmobiliteit, job rotatie, is ook belangrijk binnen de onderneming. Het bevordert de promotiekansen, verhoogt de loongroei en verlaagt de kans op ontslag. Het hoofdstuk beschrijft ook dat neerwaartse mobiliteit niet tot lagere nominale lonen leidt. "Toch voert een degradatie ook tot een degradatie in de verwachte loongroei. Reële loonvermindering wordt 
wel gevonden in tijden van krimp, doordat het nominale loon over meerdere jaren niet aangepast wordt.

Hoofdstuk 6 onderzoekt in detail de loonpolitiek van de onderneming en de invloed ervan op loongroei. Door specifiek de formele loonstructuur van de onderneming te bestuderen, ontstaat er een beter begrip van empirisch gevonden loonpatronen. Bijvoorbeeld, de formele loonstructuur genereert serieel gecorreleerde loongroei, omdat administratieve regels de loongroei van werknemers in de hoogste kwartielen van een positiespecifieke loondistributie verminderen. Deze administratieve regels kunnen ook tot cohort-effecten leiden. Deze effecten lijken te blijven bestaan zelfs wanneer op individuele effecten gecorrigeerd wordt. Dit is het resultaat van compositie-effecten van banen waarvoor werknemers in de verschillende banen in dienst genomen werden. De analyse toont aan dat loonsverhogingen waarschijnlijker zij bij positieve evaluaties. Ten eerste leiden verbeterde evaluatiescores altijd tot een stijging in bet contractuele loon. Ten tweede verbetert een hogere evaluatie de kansen om in salarisschalen te stijgen en verhoogt het de kans op promotie naar een baan van hoger hiërarchisch niveau waaraan ook een hogere salarisschaal verbonden is. Hierdoor voorspelt loongroei ook promoties. Loonpremies als gevolg van een promotie zijn hoger dan een typisch loongroei binnen een positie. Maar ze zijn klein ten opzichte van de verschillen in gemiddeldes tussen de loondistributies van de voormalige en de toekomstige baan.

Verder laat dit hoofdstuk zien, dat het bedrijf terughoudend is nominale loonverminderingen toe te passen, zelfs als de werknemer door degradatie in een lager salarisschaal terecht komt. Nominale rigiditeiten leiden tot negatieve prikkels voor gedegradeerde werknemers, omdat zij, ondanks goede prestaties, geen verwachte loongroei meer hebben.

Tot slot laat de empirische evaluatie van de relatie tussen senioriteit, prestatie en lonen zien, dat lonen met senioriteit steigen. Deze verhouding blijft bestaan ook al wordt rekening gehouden met de evaluaties. Dit wordt veroozaalst door de formele salarisstructuur. Het beloningssysteem definieerti het niveau van de lonen, de jaarlijkse loongroei per periodiek en de evaluatiescore. De loondistributie van een positie omvat meestal meerdere periodieken. Werknemers krijgen een jaarlijkse verhoging, waarvan de hoogte afhanlkelijk is van de jaarlijkse beoordeling van de werknemer - totdat het einde van de salarisklasse binnen de positie bereikt is. Daarna kan slechts loongroei worden bereikt als de werknemer in een hogere salarisklasse geplaatst wordt en dit is afhankelijk van de beoordeling van een werknemer. Lonen binnen een salarisschaal variëren met evaluatiescores. De variatie in een salarisschaal is klein ten opzichte van variatie die ontstaat door senioriteit. Omdat er tijd voor nodig is om binnen een bedrijf voor promotie in aanmerk- 
ing te komen, zijn de werknemers aan het einde van hun salarisschaal vaak het meest ervaren. Deze meer ervaren werknemers hebben ondanks een lagere evaluatie een hoger salaris. Als variabelen voor evaluatie scores in standaard loonregressie meegenomen worden, blijft het effect van senioriteit bestaan, ook al is gecontroleerd voor het positieniveau. Onze kennis van het functioneren van het salarissysteem - waarin een goed functioneren tot promotie en daardoor stijgend levensinkomen leidt - geeft aan dat de relatie tussen evaluatie scores en loonprofielen uit crosssecties anders geinterpreteerd moet worden, dan wij normaal in de literatuur vinden.

Hoofdstuk 7 beschrijft een model ter bevordering van de theorie van carrières in multi-level organisaties en bevat een integratieve modelaanpak, gebaseerd op recente theoretische inzichten uit de literatuur van carrières in organisaties (bijvoorbeeld Bernhardt, 1995; Demougin and Siow, 1994; en Gibbons en Waldman, 1999a). Deze integratie van verschillende theoretische modellen is veelbelovend om de volledige verzameling van empirische feiten van interne werkingen van bedrijven te verklaren. Helaas proberen bestaande modellen niet verticale baan-mobiliteit te relateren aan veranderingen in de grote van het bedrijf. Demougin en Siow (1994), bijvoorbeeld, kunnen geen carrières onderzoeken die langer zijn dan een carrièrestap. Gibbons en Waldman (1999a) houden geen rekening met de interne organisatie van arbeid binnen bedrijven. In hun model worden, evenmin als dat van Bernhardt (1995), vraageffecten meegenomen; zij nemen aan dat er in toerijkende mate open posities aanwezig zijn.

Het model van hoofdstuk 7 gaat van een commando productietechnologie uit. Dit leidt tot een hiërarchische organisatiestructuur, met een beperkt aantal posities binnen iedere hiërarchie. Met dit model kan dan de kennisname van het bedrijf van de talenten van een werknemer als de acquisitie van menselijk kapitaal - 'on-the-job' of door trainingen - gemodelleerd worden. Ook kan de invloed hiervan op interne mobiliteit en promoties met dit model onderzocht worden. De optimale allocatie van werknemers op posities verandert tijdens de carrière van de werknemer. Dit komt door kennisoverdracht van de oudere generatie op de jongere generaties binnen de organisatie. Tegelijkertijd krijgt het bedrijf kennis van de talenten van zijn werknemers, zodat het sorteren van werknemers en posities een dynamisch proces wordt, dat zwel de baanmobiliteit als loonverandering in interne arbeidsmarkten bepaalt.

Het model toont aan dat de promotiekansen hoger zijn in periodes van groei en vallen in periodes van krimp. Degradaties komen vaker voor in tijden van inkrimpingen. Dit komt voort uit de onderlinge verhoudingen van posities binnen een hiërarchisch waarbij het bedrijf de voorkeur heeft om bestaande werknemers te promoveren. Deze werknemers hebben vaardighe- 
den en waardevolle organisatiespecifieke kennis opgebouwd. Veranderingen in grote van baanmobiliteit zijn sterker naarmate de totale aanpassing van de arbeidspopulatie veranderd wordt. Dit is belangrijk omdat promoties van groot belang zijn voor loongroei. Hierdoor zijn carrièreprofielen sterker stijgend in expanderende bedrijven. Snel gepromoveerde managers hebben minder vaardigheden geleerd in expanderende bedrijven, waardoor de productiviteit van zo een manager daalt. De productie zelf is ook onzekerder omdat het bedrijf minder tijd had om de werknemer en zijn talenten te leren kennen.

Tevens geeft het model aan op welk moment in de carrière een bedrijf moet investeren in een training voor zijn werknemers. Aangezien het bedrijf initieel onzeker is over de vaardigheden en productiviteit van een werknemer, kan het voordelig zijn om trainingen voorlopig uit te stellen. Door deze investering uit te stellen totdat er meer informatie over de productiviteit van de werknemer bekend is, kan het bedrijf het risico van onrendabel investeren t.erugbrengen. Verdere investering in werknemers die gepromoveerd worden is winstgevend omdat zij een hogere invloed op de totale productiviteit van alle werknemers krijgen. 


\section{Curriculum Vitae}

Thomas Johannes Dohmen was born in Heinsberg/Rheinland (Germany) on September 5, 1972, where we started his secondary school education at the Kreisgymnasium Heinsberg, a grammar school, in 1983. Before obtaining the Abitur at the Kreisgymnasium in 1993, he received a scholarship from the Congress-Bundestag Youth Exchange Program and spent a year at LinnMar High-School in Marion, Iowa (U.S.A.), where he obtained the high-school diploma in 1991.

After having worked at the Rurtalschule, a school for mentally handicapped children, he studied economics (International Economic Studies) at the Universiteit Maastricht from 1994 until 1998. During this period, he worked as a research assistant and as a teaching assistant. Having received a scholarship from the German Academic Exchange Service (DAAD), he studied economics in the Master's programme at the University of Warwick (England) in the academic year 1997/1998 obtaining the MSc in Economics degree. In December 1998, he graduated cum laude from the Universiteit Maastricht with an M.A. degree in economics (International Economic Studies).

In January 1999, he joined the Business Investment Research Center (BIRC) at Maastricht University as a Ph.D. researcher on a research project financed by the Netherlands Organization for Scientific Research (NWO). In his doctoral studies, he further specialized in labor economics and applied microeconometrics. He received the diploma from the Network of Economics and Quantitative Economics (NAKE) in 2000. Thomas visited the Economics Department at the University of Chicago (U.S.A) from January 2002 until June 2002. Since January 2003, he is a Research Associate at the Institute for the Study of Labor (IZA) in Bonn, Germany.

Apart from his main research, which is in personnel economics and internal labor markets, his research interest include labor market mobility, housing and unemployment, incentives and preference formation, philosophy of science, economic methodology, and the history of economic thought. 